Louisiana State University

LSU Digital Commons

1971

\title{
The Effects of Personality Traits on the Perception of Written Mass Communication.
}

Sam Joseph Bruno

Louisiana State University and Agricultural \& Mechanical College

Follow this and additional works at: https://digitalcommons.Isu.edu/gradschool_disstheses

\section{Recommended Citation}

Bruno, Sam Joseph, "The Effects of Personality Traits on the Perception of Written Mass Communication." (1971). LSU Historical Dissertations and Theses. 1965.

https://digitalcommons.Isu.edu/gradschool_disstheses/1965

This Dissertation is brought to you for free and open access by the Graduate School at LSU Digital Commons. It has been accepted for inclusion in LSU Historical Dissertations and Theses by an authorized administrator of LSU Digital Commons. For more information, please contact gradetd@lsu.edu. 


\section{$71-29,346$}

BRUNO, Sam Joseph, 1929-

THE EFFECTS OF PERSONALITY TRAITS ON THE PERCEPTION OF WRITTEN MASS COMMUNICATION.

The Louisiana State University and Agricultural and Mechanical College, Ph.D., 1971

Economics, commerce-business

University Microfilms, A XEROX Company, Ann Arbor, Michigan 


\title{
THE EFIECTS OP PERSONAIITY TRAITS ON THE PERCEPTION \\ OF WRITTEN MASS COMMUNICATION
}

\author{
A. DISSERTATION \\ Submitted to the Graduate Facuity of the \\ Iouisiana State University and \\ Agricultural ard. Nechanical College \\ in partial fulfillment of the \\ requirements for the degree of \\ Doctor of Philosophy
}

ins

The Department of Management

Sam Jos Brino

B.B.A., Lamar State College of Technology, 1962

M.S., Louisiana State University, 1965

Nay, 1971 
ACKNONLEDGEMENTS

The writer is greatly indebted to his major professor, Dr. Raymond V. Lesikar, for his guidance and helpful suggestions in the preparation of this study. Appreciation is also extended to Dr. S. Lee Ri.chard.son and $\mathrm{Dr}$. 0 . Jeff Harris for their advice and helpful recommendations which have been of great value in the completion of this manuscript.

In addition, the writer is grateful to Dr. Lloyd F. Morrison and Dr. James $W$. Reddoch for reading the manuscript and serving on the examination committee. A note of thanks to Dr. John D. Petti.t, Jr., a very dear friend, who provided the basic idea for this study. To Dr. Ralph M. Dreger and Dr. Felicia A. Pryor, professors of psychology, the writer wishes to express his grateful appreciation for their assistance in selecting the psychological test used in this investigation. Special thanks are also extended to the professors who allowed the experiment to be conducted in their classes. Without their helpful cooperation, this study could not have been completed.

To the many secretaries and student workers in the college of Business Administration at Wichita State University, especially Mrs. Pattye Dysinger and Miss Diana White, the writer is indebted for skillful typing of this manuscript in its original stages.

And finally, to my wife Joan, to whom I am indebted most of all, a very sincere expression of gratitude is offered. Her personal sacrifices and inspiration resulted in making this dissertation a reality. Her contribution to the completion of this study extended from affectionate nagging to assistance in the processing of the data. 


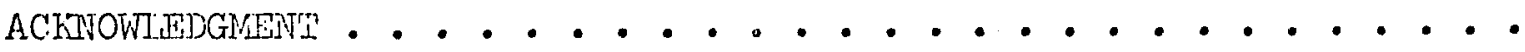

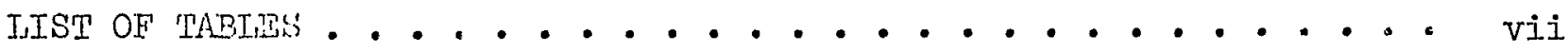

IIST OF FIGURES . . . . . . . . . . . . . . . . . . iY

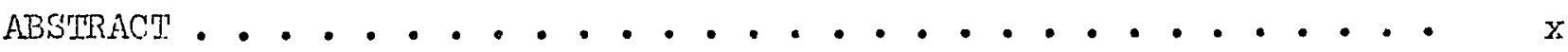

I. ORIENTAIION TO AN EXPLORATORY STUDY OF THE RELATIONSHIP

BETWEEN PEFRSNALTTY TEAITS AND RESPOINSES TO WRITTEN

MASS COMMUNICATION..$\cdot$. . . . . . . . . . . .

Introduction to the study . . . . . . . . . . . I

Purpose of the Inquiry ................ 4

Statenent of Hypotheses . . . . . . . . . . 6

Definitions of Terminology . . . . . . . . . . . "

Scope of the study ................. 8

Discernible Iimitations . . . . . . . . . . . 8

Research Methodology ................ 10

Preview of the Investigation .............. II

II. A SURVEY OF PSYCHOLOGICAL, COMMUNICATION, AND SEMANTIC

DIFFEREITIAI IITERATURE . . . . . . . . . . . 14

Personality and Personality Traits .......... 14

Synopses of Personality Studies . . . . . . . . . 17

Personality and Persuasibility . . . . . . . . . 18

Pexsonality Assessment of Iffective Oral Readers . . . 21

Fersonality Traits and Public Speaking . . . . . . 23

Fear-Arousing Communication and Personality Differences. 26

Semantic Habjts and Personality Dimension . . . . . . 29

Iiterary style and Fersonality Iraits .......... 31 
Cattell's Sixteen Personality Factor questionnaire . . •

The Nature and Validity of the Sixteen Factors . . .

Description of the Sixteen Source Traits . . . . . . 35

Test Design, Reliability, and Validity ........ 38

Administering and Scoring the 16 P.F. ........ 40

A Summary of Selected Studies Utilizing the 16 P.F. . . . 43

A Personality Profile of Student Smokers . . . . . . 43

Personality Patterns of Failing College Freshmen ... . 45

The Relationship Between Personality and Reading

Ability .................. 47

The Sernantic Differential . . . . . . . . . 48

Nature and Mechanics of the Semantic Differential . . . 48

Bipolar Adjectival Scales and Factors of Connotative

Meaning ............... 50

Determining the Relationship Between Concepts . . . . 53

The Advantages of the Semantic Differential ..... 54

A Review of Research Studies Utilizing the Semantic

Differential . . . . . . . . . . 55

Differential Perception of Certain Jobs and People . . 56

Fvaluating Communication . . . . . . . . . 57

Public Images of Business Are Stereotype. . . . . 58

A Summary of Pertinent Factors . . . . . . . . 60

III. RESEARCH METHODOLOGY . . . . . . . . . . . 66

The Nature and Procedure of the Research . . . . . 66

The Experimental Design ............ 67

The Procedure for Conducting the Experiment ..... 68

Selection of Recruitment Ads and Development of

Reader Oriented Ads . . . . . . . . 72

An Analysis of the Research Participants . . . . . 73

Selection of Study Instruments . . . . . . . . 75

The Selection of the Personality Test . . . . . . 75

The Semantic Differential Selection and Design . . . . 77

Selection of the concepts . . . . . . . . 78

Semantic Rating Scale Selection Procedure . . . . 79

Duration of the Fxperiment and Absenteeism . . . . . 83 
Data Freparation and statistical Treatment . . . . . 85

Identifying the Data... . . . . . . . 85

Statistical Treatment of the Data . . . ..... 86

Research Methodology in Capsule Form . . . . . . . 88

IV. AN ANALYSIS OF EXPERIMEINTAL DATA RETATTVI: TO MINOR

HYPOTHESES

Experimental Results Relevant to Reader and Company

Oriented Advertisements . . . . . . . . . 92

Comparison of Massey's Recäer and Company Oriented

Advertising Messages .............. 93

Comparative Analysis of Dallas Mutual Life's

Recruitment Ads ............... . 9 97

Comparative View of Reader and Company Oriented Ads . . 100

Implications of Experiments Results . . . . . . 103

Analysis of Demographic Factors . . . . . . . 105

Sex Differences in Sernantic Responses . . . . . . 106

Relevancy of Age Groups to Connotative Meaning . . . . 110

Similarity of Connotative Profiles of Age Groups . . 1724

Test of Significant Differences for Age Groups . . . 116

College Classifications Reizivive to Semantic Responses . 121

Visual. Analysis of Colleze Classification . . . . 121

D Statistic Relative to Slassification ...... 125

Statistically Significanড Relationships Relative

to Classification ........... 129

Discussion of Demographic Eactors . . . . . . . 135

Compendium of the Major Findinss . . . . . . . . 139

V. AN ANALYSIS OF PERSONALITY CHARADIERISTICS AND SEMANTIC

RESPONSES

141

Personality Traits and Responses to Recruitment

Advertisements .............. 142

Statistical Methodology ............. 142

Experimental Results Relaisive to Hypotheses one and Two. 144

Massey's Reader Orienteà Recruitrnent Ad . . . . . 145

Massey's Company Viewpoint Adveriisement . . . . . 148

Reader Viewpoint Appeal of Dallas Mutual Iife . . . 153

Dallas Mutual Life's Company Oriented Ad . . . . 158

Composite of Persorality Profiles . . . . . . . 164 
Second-Order F'actors and Experimental Results . . . . . 166

Second-Order Responses to Massey's Recruitment Ads . . I 168

Dallas Mutual Life Exvia-Invia Second-Order Responses • 172

Discussion and Implication of Findings . . . . . . . 177

Capsule Presentation of Experimental Results . . . . . 180

VI. SUMMARY AND CONCLUSIONS . . . . . . . . . . 182

Experimental Results Relative to Hypotheses IV and V . • 183

Major Findings-Fourth Hypothesis . . . . . . 183

Findings--Demographic Hypothesis . . . . . . . 184

Influence of Personality Characteristics: An Fmpirical

Analysis ............... 187

Personality Traits and Hypotheses I and II . . . . 187

Second-Order Factor and Hypothesis III . . . . . . 189

Conclusions of the Study . . . . . . . . . 190

SELECTED BJBLIOGRAPHY . . . . . . . . . . . . . . 192

APPENDTCES . . . . . . . . . . . . . . . . 202

A. Experimental Recruitment Advertisements . . . . . . . . 203

B. Sixteen Personality Factor Test Profile . . . . . . . . 210

C. Semantic Differential Questionnaires . . . . . . . . 212

D. Visual Semantic Profiles Relative to Hypotheses Four and Five. 228

E. Semantic Differential Scale Means and " $t$ " Values of the

Difference Between Personality Iraits For Each

Recruitment Advertisement .......... 242

VITA . . . . . . . . . . . . . . . . . 271 
LIST OF TABLES

TABLE

PAGE

I. Catte11's Capsule Description of the Sixteen Primary Personality Factors . . . . . . . . . . . .

I. Classes Used In Experimental Study . . . . . . . . . . 74

ITT. Factorjal Loading of the Semantic Scales . . . . . . . 82

IV. Semantic Rating Scales' Averages, Standard Deviation, and " $z$ "Values For Massey's Reader and Company Oriented Recruitment Advertisements ........... 94

V. Semantic Rating Scales Averages, Standard Deviations and. " $z$ " Values for Dallas Mutual Life's Reader and Company Oriented Recruitment Advertisements . . . . . . . .

VI. Composite View of Mean Values, and Standard Deviations For Four Experimental Ads

VII. Semantic Differential Average Scores on Reader and Company Orienter $\triangle d s$ By Sex

VIII. Significant Differences In Connotative Meanings of Reader and Company Oriented Recruitment Advertisement. . . . .

IX. Semantic Differential Scale Means For Each Recruitment Advertisement By Age Groups . . . . . . . . . . .

X. D Matrices Between Age Groups For Each Recruitment Advertisement . . . . . . . . . . . . . .

XI. " $t$ " Values of the Difference Between Age Groups Pairs For Each Concept-Scale Combination . . . . . . . . .

XII. Number of Significant Scale-Concept " $t$ " Values for Fach Age Group . . . . . . . . . . . . . . . . .

XIII. Semantic Differential Scale Means For Each Recruitment Advertisement By College Classification . . . . . . I?2

XIV. D Matrices Between College Classification for Recruitment Advertisement . . . . . . . . . . . . . . . .

XV. " $t$ "Values of the Differences Between College Classification For Each Concept Scale Combination . . . . . . . 130 
XVI. Number of Significant "t" Values For Each Classification and Each Recrujtment Advertisement . . . . . . . 134

XVII. D Matrix. For Massey's Reader Oriented Advertisement . . . . 146

XVIII. D Matrix For Massey's Company Oriented Advertisement . . . . 149

XIX. D Matrix For Dallas Mutual Life's Reader Oriented Advertisement . . . . . . . . . . . . 155

XX. D Matrix For Dallas Mutual Life's Company Oriented Acvertisement ................. I60

XXI. Semantic Differential Mean Values For Nassey's Recruitment, Advertisements By Second-Order Introversion-Extraversion Factor ....................

XXII. "t"Values of the Differences Between Second-order Factor Pairs For Each of Massey Recruitment Ads and Each Semantic Rating Scale . . . . . . . . . . 171

XXII.T. Semantic Differential Mean Values For Dallas Mutual Iife's Recruitment Advertisements By Second-Order IntroversionExtraversion Fector .............. 173

XXIV. "trvalues of the Differences Between Second-Order Factor Pairs For Each of Dallas Mutual Life Ads and Each Semantic Rating Scale .. . . . . . . . . . . 


\section{LIST OF FIGURES}

FIGURE

PAGE

2.1. Profile For Hypothetical Judgment of the Concept FATHER • • 53

3.1. Seniantic Scales Used in Pretest . . . . . . . . . . 80

3.2. Form and Order of the Final Semantic Scales . . . . . . 8I

5.1. Mean Personality Profile of 394 L.S.U. Students on the 16 P.F. 143.

5.2. Personality Iraits Demonstrating the Most Favorable Responses to Massey's Reader Oriented Advertisement . . . . . . 148

5.3. Personality Traits Demonstrating Favorable Responses to Massey's Company Oriented Advertisement . . . . . . 152

5.4. Combined Personality Profiles of Massey Recruitment Ads . . . I5?

5.5. Personality Iraits Demonstrating the Most Favorable

Responses to Dallas Mutual Life's Reader Oriented

Advertisement ................. 158

5.6. Personality Traits Which Demonstrated the Most Favorable

Responses to Dallas Mutual Iife's Company Oriented

Advertisement ............................. 163

5.7. Combined Personality Profiles of Dallas Mutual Recruitment Ad.s 163

5.8. Composite Personality Profiles for the Four Experimental

Advertisements . . . . . . . . . . . . I65 


\section{ABSTRACT}

Very little attention has been directed toward the influence of personality traits upon responses to written mass communication. In view of this apparent lack of research, the objective of this investigation was to supply some worthwhile facts relative to response behavior of individual's personality traits to recruitment advertisements. Therefore, the specific purposes of this study were: (I) to ascertain the relationship between personality traits and responses to written mass communication; (2) to demonstrate how extraverted and introverted individuals respond differently to advertising messages; (3) to determine whether or not reader oriented advertising writing style elicited more praiseworthy responses than company oriented writing; (4) to ascertain which personalicy traits were related to reader viewpoint writing and which were associated with company oriented messages; and (5) to determine the relationship of demographic factors to the perception of written mass communication.

A two-part experimental design was used to secure all data relative to the analysis of personality traits and their effects upon responses to written mass communication. Personality data were acquired by administering Cattell's Sixteen Personality Factor Questionnaire. The semantic differential was utilized to objectively and quantitatively measure responses to reader and company oriented recruitment advertisements. Three hundred ninety-four students from Iouisiana State University participated in the experiment. Iruring the first phase of the experiment, subjects received and responded to reader oriented advertisenents and completed the Cattell 
test. Subjects, during the second phase, received and responded to company viewpoint advertisements. Then comparisons were made between responses to reader viewpoint advertisements and company oriented recruiting messages. Each student read two reader viewpoint ads and two company oriented ads. Quantitative analysis indicated that students were inconsistent relative to their perception of recruitment advertisements. In one instance, they favored a company oriented ad and in another instance, they preferred a reader directed ad. Responses by sex, however, revealed that men generally viewed each of the four recruitment advertisements more favorably than women. Men also thought that reader oriented advertisements were more desirable than company directed advertisements. Women, on the other hand, were rather indifferent to either reader or company oriented advertisements.

It was further determined that the perception of written mass communcation was a function of age. The various age groups, when considered collectively, viewed a company oriented recruitment message significantly better in one instance and in another, a reader viewpoint advertising copy was considered more favorable. It was also ascertained that the perception of recruitment advertisements was a function of college classification. College Freshmen and Sophomores appeared to be more inpressionable in their judgment of recruiting messages. In contrast, Special Undergraduate students had the least positive connotation of the experimental stimuli. When grouped collectively according to college classification, students perceived one reader viewpoint ad and one company oriented ad as being most praiseworthy. These findings suggested that students' immediacy to the job market uney have had some influence upon their response behavior. 
Further analysis revealed that there were personality differences between individuils that favored reader oxiented advertisement and those that preferred company oriented advertisement. Individuals that consistently favored reader oriented-advertising copy were described as humble, trusting, self-assured, and relaxed. Individuals characterized as shy, practical, forthright, and conservative preferred company oriented advertising copy. These findings provide some indication that responses to recruitment advertisements are a function of personality.

Experimental results also demonstrated that personality types (extraverts and introverts) were definitely an influencing factor in the perception of written mass communication. Introverts, for instance, were more sensitive to recruiting nessages than extraverts.

In view of these findings, personality traits and personality types may well be meaningful variables in the communication and persuasion process. 


\section{CEIAPTER I}

\section{ORIENTATION TO AN EXPLORATORY STUDY OF THE RELATIONSHIP BEIWEEN PERSONALITY TRAITS AND RESPONSES TO WRITIEN MASS COMMUNICATION}

\section{Introduction to the study}

The relationship of personality and response to written mass communications presents a complex, but fascinating, subject for students of communication theory. To what extent should advertisements be adapted to the underlying personality traits of the reader? Should the copy writer of written mass communication attempt to segment audience on the basis of personality traits? To what extent do personaljty traits influence the perception of written mass communication? Is the perception of advertisement related to personality trajts as measured and defined by objective--type personality scales? What personality traits appear to be maximally related to advertisements which make readers the object of the message or to advertisements which emphasize the company's name and pronouns such as "we" and "our"? And what is the strength and direction of these relationships?

One would expect to find in the literature on written mass communication, as in the case with public speaking, some concern for personality traits and their relation to the perception of advertisement. However, this is not the case. Consequently, it is necessary to turn to somewhat unrelated areas to find anything pertinent to this problem. Golden, for example, investigated the personality traits of drama school students and reported that drama students scored high on the personality variable 
"aesthetic" and Iow on such personality traits as "theoretical" and "economic." 1 Based on these scores, it was concluded that personalities of drama students, as a group, differ from the personalities of other students with whom the study was compared.

A review of recent studies of written mass communication further indicated that very little has been published with regard to the influence of personality upon response to advertisements. Some research in oral communications has supported the theory of selective perception--that a person usually hears what he wants to hear and that he usually wants to hear messages which reinfurce his existing attitudes and produce a feeling of agreement. It further appears, however, that there has not been any attempt on the part of researchers to determine the relationship between readers' response to written mass communication and personalities. In fact, very little empirical evidence has been published to indicate that quantitative analysis of written mass communication can discover individuality or that personality factors might be related to response from this type of cormunication.

In this connection it seems that when a subject is exposed to written mass communication, it is possible to do more than present the frequencies with which certain writing styles of such communications are responded to. It can be noted, for example, whether the subject has a tendency to respond more favorably to certain writing styles such as reader or company oriented writing. Depending upon the responses to these contrasting writing styles, it may be possible to infer from the individual's preference whether his

IAlfred L. Golden, "Personality Traits of Drama School Students," Quarterly Journal of Speech, XXVI No. 4 (December, 1940), pp. 564-575. 
choice is indicative of personality characteristics or irrelevant to individuality. Information about an individual's personality differentiation may also be gleaned from responses to reader and company oriented advertisements. In the case of writing style it is possible to construct messages either by attending exclusively to the personal pronoun ("you" and "your") aspect of the stimuli or by using the structural aspects of company oriented messages. It may be possible to determine from responses to these messages whether respondents are introverted or extraverted. Respondents that favor one writing style over another may possess specific personality differences. Finally, it may be possible to conclude that the personalities of respondents ravoring reader oriented messages, as a group, differ from the personalities of respondents who perceive company oriented advertisement more favorably.

The implication that responses to written communication could reflect personality difference can prove to be very important to the development of communication theory and application. In lact, personalities may be a means for audience segmentation, and thereby, written mass communications could be directed toward certain personality characteristics in order to achieve maximum success from advertising messages. Moreover, considerable advances in written mass communication may be achieved when one begins to understand the relationship between personality and responses to certain sensory input from advertisements.

For a number of years colleges and universities have been faced with the problem of educating a sufficient number of students to meet the challenges of business, the conquest of space, and a number of other scientific and non scientific f'rontiers. There are problems both in recruiting appropriate talent to meet these needs and in effective utilization of 
individuals once they have become qualified to enter the business and scientific world. Psychology may make an initial contribution in recruiting talent by pointing ur personality correlates of responses to various recruitment advertisements. The increased importance assigned to the role of personality traits and interest in the neglected area of relationships between responses to written mass communication and personality traits has prompted the writer to develop a research design to investigate this area. Specifically, the investigation focuses upon the relationship between personality traits and responses to reader and company oriented recruitment advertisements.

\section{Purpose of the Inquiry}

In view of the apparent lack of interest with the issues mentioned above, the present investigation was undertaken to supply some worthwhile facts bearing on response behavior of personality traits to recruitment advertisements. Based on the general purpose of this study, five specific objectives are stated. They are as follows:

1. To relate responses to written communication to personality traits in order to determine how the various traits revealed by the personality tests appear to be responsible for the differences in responses.

2. To identify extravert and introvert characteristics from the personality inventory and show significantly different responses to written communications based on these personality types.

3. To determine whether or not reader oriented writing elicits more favorable responses than company oriented writing contained in recruitment advertisements.

4. To ascertain which personality traits are significantly related to reader oriented advertisement and those that are significantly related to company oriented messages.

5. Finally, to take advantage of the opportunity afforded by these data to explore the relationship between semantic responses and demographic factors. 
To the writer's knowledge, there has not been any previous research directly associated with personality traits as factors affecting the perception of written mass communication. Hence, the primary contribution of this investigation bears directly upon the question posed in the intro-. ductory paragraph of this chapter. The determination of response behavior to written mass communication through an analysis of personality traits is the chief desideratum to answer the questions presented in the introductory paragraph, if it can be determined that certain personality traits are related to the perception of advertisements. Therefore, the results of the present study should benefit present and future communicators in improving the effectiveness of their recruiting advertisement. Since an individual acts in terms of what he perceives, his acts lead to new perception; these lead to new acts, and so on in the incredibly complex process that constitutes life. Therefore, it car be clearly seen that an understanding of how personality traits affect the perception of written communication will hel.p to provide new insights into the comprehension of human behavior. Furthermore, if it can be proven that certain personalities respond differently to written communication, this study will appreciably broaden the framework of communication theory. It will also add significantly to the application of communication skills.

Finally, it is hoped that the present investigation would be valuable to students of communication theory and to others interested in personality by helping them to better understand the role of personality in perception. With this orientation in mind five testable hypotheses were built upon the relationship between personality traits and responses to written mass communication. 
The belief that personality characteristics can be related to differences in responses to written mass communication led to the derelopment of three major hypotheses. They sre:

1. There are certain personality traits inherent in individuals which will cause them to reaci differently to written mass communication.

2. There are personality differences, as measured by the Cattell Sixteen Personality Factor Gusstionnaire, between favorable perception of reader orientec advertisements and favorable responses to advertisements risich are company oriented.

3. Individuals with extraverted zersonality. characteristics will respond more favorably to resder oriented advertisements. Individuals with introverted sersonalivy traits, on the other hand, will respond less favorably to reader oriented messages.

Two secondary hypotheses were formulated from the major hypotheses

and from demographic data. The secondery hypotheses are:

4. Written recruitment advertiserents presented as reader oriented messages will induce more fav rable responses than company oriented messages regardless of personality characteristics.

5. Demographic factors such as sex, age, and college classificition are influential in genersting more favorable responses for reader oriented recruitment advertisements than for company oriented recruitment advertisements.

The primary hypotheses pertain to the differential reaction to messages contained in recruitment adveriisements. The first hypothesis was formulated to test the validity of the assumption that personality factors influence the perception of written mass communication. Furthermore, if hypothesis one verifies the above assumption, then it is possible to prove or disprove hypotheses two and three. If, on the other hand, hypothesis one is disproven then hypotheses two and three are likely to be invalid. Moreover, if results of the present investigation reject the major hypotheses, then importance assigned to the role of personality traits as a factor affecting responses to written communication may need re-evaluation. 
The secondary hypotheses, four and five, are not dependent upon the validity of the primary hpotheses. Hypothesis four was formulated to substantiate the general belief that reader oriented writing, clearly presented, will elicit more favorable responses than company oriented messages. Finally, hypothesis five seeks to determine whether or not demographic factors such as age, sex, college classification, and major field of study are positively related to semantic responses.

\section{Definitions of Terminology}

In order to facilitate the reader's comprehension of the study, the following definitions are presented to remove any semantic difficulties which may arise from differences of interpretation.

1. Personality Traits. There are hundreds of personality tests available; however, there does not seem to be any standardized way of simply describing personality traits. Therefore, in the present investigation personality traits are operationally defined as dimensions of personality as measured by the Cattell Sixteen Personality Factor Questionnaire. (The 16 P.F. Test).

2. Reader Oriented Writing. Reader oriented writing or reader orienter messages makes the reader the object of the written mass communication by presenting information in terms of the reader's interest. Specifically, reader oriented witing emphasizes the pronouns "you" and "your," while subordinating the personar pronouns "I," "we" and "our."

3. Company Oriented Writing. In contrast company oriented writing or company oriented messages do not make psychological use of the pronouns "you" and "your." Instead company oriented writing empluasizes the company name and the pronouns "we" and "our." Furthermore, company oriented writing directs each statement toward the viewpoint of the company. For example, "At the Travelers there's a lot more to insurance than selling. We're leaders in a fast-changing industry and we need people. . . ."

4. Advertising Copy. The words copy and message are used interchangeably throughout the investigation, and they are here defined as the written material that appears in the body of the advertisement.

5. Perception. For the purpose of this study perception refers to the individual's responses to sensory input from advertisements. 
The information pertaining to the nature of personality traits, research in the field of personality, and the semantic differential was obtained by an investigation of the current literature relevant to these areas. The remainder of the study is based upon an analysis of personality characteristics, demographic factors, and responses to recruitment advertisements. The study sought to determine whether or not certain personality characteristics affected the perception of written mass communication. In addition, the investigation endeavored to ascertain whether age, sex, and college classification were pertinent to favorable responses to reader viewpoint recruitment advertisements. The specific aspects of the inquiry included an analysis of:

1. The connotative meaning of responses given to recruitment advertisements.

2. Personality traits associated with responses to both reader and company oriented recruiting information.

3. The relationship between personality types (extraversionintrovérsion) and. responses to written mass communication.

4. Demographic factors (age, sex, and college classification) related to responses to recruitment advertisements structured with reader and company oriented messages.

5. The data to identify personality traits and responses that would contribute to more effective reader adaptation.

In addition to the above analysis the present investigation contrasted reactions between messages which were reader oriented and those which were company oriented.

Discernible Iimitations

In evaluating the results of the present irvestigation, certain limitations must be recognized. The first is the limitation inherent in the method of selecting the sample, in the personality inventory, 
and in the nature of the semantic differential questionnaire. Although the undergraduate subjects that participated in the study represented a good cross section of the student body at Louisiana State University, it is recognized that the selection of the sample was completed by a nonprobability method. That is, every student at Louisiana State University did not have an equaJ. and independent charce of being chosen for the sample. Instead a convenience sample was used because of the accessibility of the respondents. Therefore, an unknown bias might have been introduced. However, it is not possible to estimate statistically the chance that other samples would bring different results. 2

A second limitation is that the samples chosen for this exploratory study was Iimited to one Iocale (Iouisiana State University at Baton Rouge, Louisiana) and to only 14 classes of the more than 940 classes scheduled for the 1969 Summer Term.

The third discernible limitation is that undergraduate student responses are not the same as a non student population. In spite of this Iimitation, these students represented a large collection of respondents in an atmosphere conducive to experimental research. The fact that a large group of subjects were available in an environment which permits empirical research to take place seems to offset any disadvantage associated with student participation.

Clearly, no one study could include the entire area of personality. Such an investigation would require years to complete. Therefore, the fourth limitation is tjat the experimental design was restricted to the

${ }^{2}$ Harry I. Hansen, Marketing: Text, Cases, and Readings (Homewood, I11. : Richard D. Irwin, Inc., 1961), p. 284. 
relationship of responses to written mass communication and to 16 personjlity dimensions as measured by the Cattel.1 16 Personality Factor Questionnaire.

A fifth limitation is the possibility that the meaning of the semantic rating scales may change with the stimulus. There are no universal definitions for the bipolar adjectives. For example, the bipolar adjective Hot-Cold have different meaning when used in reference to the word water and when used with a stur pass receiver. This difficulty, however, is overcome when a sufficient number of semantic rating scales are used with each factor, so that the individual bipolar adjective contribution to the total variance becomes quite insignificant.

The final limitation recognizes that the experiment was of a static nature; that is, responses to written mass communication were studied at a particular point in time. These limitations seem unavoidable in an empirical study such as this where both time and resources were restricted. However, it provides a methodology and preliminary findings that can be utilized in future studies.

\section{$\underline{\text { Research Methodology }}$}

The survey materials of psychology, communication, and semantic differential contained in Chapter II were obtained by a study of current Iiterature in each of the three fields. This information was used to acquaint the reader with research associated with personality traits, experimental studies that employed the Cattell Sixteen Personality Factor Questionnaire, and semantic differential research.

A two-part experimental design was used to secure all data relating to the analysis of personality traj.ts and their effects upon responses to 
written mass communication. Data for the personality profile were acquired by administering a comprehensive and widely used personality inventory--Cattell's Sixteen Personality Factor Questionnaire. The semantic differential. was employed to measure responses to recruitment advertisements. Three hundred ninety-four students enrolled in the 1969 Summer Term at Louisiana State University participated in this empirical study. A comprehensive coverage of the research methodology is presented in Chapter III.

\section{Freview of the Investigation}

Some readers might find it helpful to have an overall view of what is to be found in the following chapters. The purpose of the second chapter, "A Survey of́ Psychological, Communication, and Semantic Differential Literature," is to provide some insight into research dealing with personality, the communication process as related to personality, and the semantic differential. In addition, Chapter II discusses the cattell Sixteen Personality Factor Questionnaire and the logic of the semantic differential. Specifically, it reviews and discusses Cattell's definition of personality. This is followed by a brief, but important, discussion of personality traits. Synopses of personality studies related to human behavior are presented in the second chapter. In addition, a complete section is devoted to describing and discussing the psychological test used in the present investigation--16 P.F. Next in order of presentation is the reported findings of several studies which utilized the 16 P.F. The final sections of Chapter II present a rather complete coverage of the nature and logic of Osgood, Suci, and Tannenbaum's semantic differential and examine the results of several empirical studies which have employed the semantic differential. 
Chapter III deals with a detailed and comprehensive presentation of the research methodology. In this chapter the writer discusses the experimental design, procedure for conductings the experiment, selection of the recruitment ads and developing the resder oriented copy. In addition, it includes an analysis of the 394 subjects that participated in the experiment. After this analysis the chapter continues with a discussion of the selection of the study instruments, duration of the experiment and absenteeism. The chapter concludes vith comments about data preparation and statistical treatment of the data.

Responses to the four experimental stimuli are compared and contrasted in Chapter IV. An analysis of the relationship between demographic factors (age, sex, and college classificcation) and semantic responses to written mass communication is also the subject of this chapter. The bases for this analysis were responses to the semantic differential questionnaire. The statistical data generated by the semantic differential are examined to test hypotheses four and five. In tinis chapter, the writer compares and contrasts responses associated with reader and company oriented. recruitment advertisements. Males' and females' responses are analyzed to ascertain which recruitment ads are preferred by the sexes. Then the analysis proceeds to establish a relationship between age and responses to recruiting messages. Afterward, the chapter continues with its analysis to determine which form of advertising iriting style (reader or company oriented) was most favorably perceived by college classification.

In Chapter V, attention is directed toward a comprehensive analysis of personality characteristics. Here, personality traits which caused favorable responses to both reader and company oriented recruitment advertisements are identified. In addition, Chapter $V$ investigates the 
relationship between personality types (extraverts, "average"--bolance mixture of extraversion and introversion characteristic, and introverts) and responses to written mass communication. Further analysis is made to ascertain whether or not extraverted. individuals responded more favorably toward reader viewpoint advertising copy. In this chapter, three major hypotheses (one, two, and three) are tested. The final chapter, Chapter VI, summarizes and highlights major findings reported in this investigation. 


\section{CHAPITER II}

\section{A SURVEY OF PSYCHOLOGICAL, COMMUNICATION, AND SEMANTIC DIFFERENTIAI LITERATURE}

The principal objective of this chapter is to acquaint and familiarize the reader with research in the field of personality traits, with experimental measurements of individual differences in the primary personality factors as measured by Cattel]'s Sixteen Personality Factor questionnaire and with semantic differential research. More specifically, its purpose is to review some diverse studies, to assay the fruitfulness of the areas of investigation, and point out the reliability of both the sixteen Personality Factor Questionnaire and Osgood's semantic differential as research tools.

Ihis material should provide the reader with a better understanding of personality traits and how they may affect the perception of written mass communications. The relationship between readers' responses to written communication and personality traits is presented in the subsequent chapters.

Before launching into a review of the literature, a brief discussion of personality and personality traits is an appropriate beginning.

Personality and Personality Traits

This brief discussion of personality and personality traits is designed to assist the reader in reviewing personality studies relative to the communication process. It should also serve as a frame of reference to orient the reader to the remainder of the present investigation. 
Unfortunately, there are as many definitions of personality as there are authors on the subject. The populer view, however, holds that personality is a wonderful quality everyone vants to have. The ambition of most people is to possess a "winning" or "charming" or "dynamic" personality. Obviously, not everyone has those magical qualities. Therefore, the reader should not assume that personality is merely an impression made by one individual upon another. Moreover, personality does not refer to any particular activity such as talking, remembering, thinking, or loving; but, an individual can reveal his personality in the way he does any one of these things. 1 with this as a frame of reference, the following definition, by Raymond B. Cattell, is offered as a guide for the reader of this study: "Personality is that which tells what a man will do when placed in a given situation."2 Thus, what an individual says, thinks, or does is some function of the stimulus situation in which he is placed. More specifically, personality is what determines behavior in a given situation.

Personality, according to Cattell, consists of several traits. These traits are used in measuring personality. Traits, on the other hand, are defined as reaction tendencies, which may be broad and relatively permanent.3 Behavioral responses can be predicted from traits. For example, if one trait of an individual's personality is known, such as aggressiveness, one could reasonably predict the degree of aggressive behavior demonstrated by the individual when confronted by armed robbers. Traits

IGordon W. Allport, Personality: A Psychological Interpretation, (New York: Henry Holt and Company, 1937), p. 47.

2Raymond B. Cattell, The Scientific Analysis of Personality (Baltimore: Penquin Books, Iric., I965), p. 25.

3 Ibid., p. 28. 
are broadly categorized into three modalities: abilities, temperament traits, and dynamic traits.

An ability is demonstrated by response to the complexity of a situation, when the individual defines the goal he wishes to achieve in that situation. 4 A temperament trait, on the other hand, covers a broad range of specific responses, and it is usually characterized as stylistic behavior. For example, an individual may be easy-going, or irritable, or bold or shy. ${ }^{5}$ Motivation and interest characterize a dynamic trait. When a person, for example, is described as being amorous, or ambitious or interested in football reference is made to dynamic traits. 6

Among personality traits certain ones are common and others are unique. Common txaits are those which everyone possesses to some extent.7 Examples of common traits include intelligence, gregariousness, and introversion. Unique traits, on the other hand, are traits so specific to an individual no one else has them. 8 For example, no two individuals have the same degree of friendship for college professors.

With the above definitions and interpretation established in the reader's mind it is now appropriate to proceed with a review of research in the fields of personality and personality traits. 9

${ }^{4}$ Ioc. cit.
5Loc. cit.
${ }^{6 \text { Ioc. cit. }}$
${ }^{7 \text { Ioc. cit. }}$
${ }^{8 \text { Ioc. cit. }}$

9The details of personality theory are beyond the scope of this dissertation. However, for more detailed treatment, see: Gordon W. Allport, Personality: A Psychological Interpretation (New York: Henry Holt and Co., 1937); Raymond B. Catteli, Personality: A Systematic Theoretical and Factual Study (New York: McGraw-Hill Book Co., Inc., 1950); and Raymond B. Cattell, Scientific Analysis of Personality (Baltimore: Penquin Books, Inc., 1965). 


\section{Synopses of Perscnality Studies}

In recent years, with the increasea availability and popularity of psychological tests, many researchers kave been using these tests as instruments for determining the relationship of personality to human behavior. There are vast amounts of literature dealing with personality studies. Most of this Iiterature, horever, is beyond the scope of the present investigation. But there are sone studies, within the larger area, which serve as a background for the study of personality and its effect on the perception of written mass communication. Therefore, a review of several related studies will provide some insight into the problem of communications and personality. The review will be confined to relatively brief summaries of the opinions and research findings offered in personality research associated with the communication process. Some readers might find it helpful to have a preview of what is to be found in the following section. Here the emphasis will be on major findings and tested hypotheses, and in a general way, the methods that have been employed in the study of individual differences. The specifics of research design and methodology are left to the reader's intellectual. curiosity.

This review of personality studies bears upon the above definitions of personality and personality traits and will be treated under the following main rubrics; no strict logic of progression is implied: Personality and Persuasibility, Personality Assessment of Effective Oral Readers, Personality Traits and Public Speaking, Fear-Arousing Communications and Personality Differences, Sernantic Habits and Personality Dimensions, and Iiterary Style and Personality Traits. 
Harriet Linton and Elaine Graham, in their study of persuasibility, were concerned with identifying variables that were related to change of opinion in response to persuasive communications. 10 They were also interested in determining the fundamental pattern of personality characteristics that seem to predispose an individual to accept or resist persuasion, influence, suggestion, and conformity in many kinds of situations. A large number of psychological tests were used to measure personality organization such as perceptual behavior, attitudes toward the self and the world, response to personality test material, and response to different kinds of social influence. Iinton and Graham used a total of eight different psychological tests to examine the phenomenon of persuasibility. ${ }^{11}$

Persuasibility by written communications was measured by an opinionchange test. Subjects were asked to read the same three articles on the topics--movie theaters, atomic powered submarines, and antihistamines. The subjects were all pre-science students. After each subject read the articles the researchers evaluated the degree of opinion change for each article and based upon these changes the subjects were divided into three categories. They were: (1) changers, (2) non changers, and (3) negative changers.

10 Harriet Linton and Elaine Graham, "Personality Correlates of Persuasibility," in Car.I S. Hovland and Irving I. Janis, (ed.), Personality and Persuasibility (New Haven: Yale University Press, 1959), pp. 69-101.

11The following tests were used in Iinton and Graham's study: an opinion-change test, a test of response in an autokinetic situation, the tilting-room--tilting-chair test, the Witkin version of the embeddedfigure test, an inner-directed versus other-directed questionnaire, items from the authoritarian personality questionnaire, a personality questionnaire, a human-figure-drawing test and the Rorschach test. For a brief description of these tests see Hovland and Janis, op. cit., p. 70 . 
Opinion changers, those individuals who were easily persuaded, appeared to be guided by external standards, had values that favored conformity, had an immature and weak concept of themselves, had a limited range of interests, and appeared to be unimaginative. other notable impressions were that changers preferred to avoid thinking about their problems, and were likely to use repression as a defense mechanism. The use of defense mechanisms seem to indicate there was an apparent lack of strong sources of direction within changers, and they coped with life situations by relying on external sources of direction. External sources of direction are strongly influenced by visual stimuli, and by comments from another person. The results of the autokinetic situation test depicts changers as individuals who did very little to form their own judgments and readily accepted the statements of confederates.

Conversely, nonchangers were least likely to be affected by external standards. Nonchangers were characterized as individuals who were comparatively uraffected by persuasive communication. These individuals appeared to have a mature and strong self image, to value subjective feeling, and to have a relatively rich inner life. In addition, they were critical of themselves and their role in life and they seemed to be independent without being rebellious. They also demonstrated self assurance, a desire for independence, and a dislike of opposition combined with some evidence of tact in social relations.

other test results indicated that nonchangers valued subjective feeling, ideas, intellectual activity, self expression and creative achievements, and they desired to live by these values in spite of pressures from social restrictions and conformity. 
The autokinetic situation revealed that nonchangers were selfassured and formed their own basis for making judgments. And when a confederate's statements were made they did not lose confidence and their judgments were little affected.

Negative changers are characterized as not being affected by externa] situations. They are, however, engaged in a struggle to win over perceived hostilities. It was interesting to note that negative changers perceived the world as a hostile, destructive place in which they were threatened by amnihilation. Furthermore, they consiaered themselves at odds with society and strongly rejected authority. This may be a suitable description for a present day Hippie.

Phobic tendencies were also evident in the negative changers. They perceived themselves as strong people; however, they were deficient in the warmer aspects of human relations and emotions.

Evidence indicated that negative changers were affected by sources of influence but actively tried to cope with the situation and fought against being influenced, rather than being relatively unaffected, as the nonchangers. Negative changers resisted the influence of confederate's statementis, and none of them changed their judgments to conform with the confederate.

The opinion-change test showed that they changed their opinions and that they were affected by communications, but they reacted negatively.

It is the quality of active resistance to an influence that affects them which differentiates them from the changers, who do not resist the influence, and from the non changers, who are relatively unaffected. by it. 12

The study confirmed the notion that there exists an underlying tendency in an individual which affects his perception, cognitive processes, attitudes 
and values, and social behavior. This investigation pointed up that persuasibility is not an isolated phenomenon, but rather it is the product of certain underlying attributes of personality. In fact, personality patterns make a person more or less susceptible to influence in a wide range of situations, regardless of whether the influence arises from another person or from written communication. 13

Personality Assessment of Effective Oral Resiers

In an effort to determine certain relationships between personality and communicative effectiveness of oral readers Shepherd and Scheidel tested three null hypotheses. 14 They were:

1. There are no personality differences between effective and ineffective oral readers.

2. There are no personality differences between effective oral readers and the normative college populations.

3. There are no personality differences between ineffective oral readers and the normative college populations.15

The participants in this study were 72 undergraduate students from four sections of a beginning oral reading course. Both students and instructors from each section rated the subjects along a continuum of oral reading effectiveness. In addition, each subject completed three measurement devices which included a 15-step Oral Reading Rating scale and two objective personality inventories. 16

13 Ibid., p. 101.

$14 \mathrm{John}$ R. Shepherd and Thomas M. Scheidel, "A Study of the Personality Configurations of Effective Oral Readers," Speech Monograph, XXIII No. 4 (November, 1956), pp. 298-304.

15 Ibid., p. 298.

16 Ihe personality inventories used in this study were cordon $W$. Allport, Philip E. Vernon, and Gardner Lindzey, Study of Values, A Scale for Measuring the Dominant Jnterests in Personality, and A. L. Edwards' Edwards Personal Preference Schedule. 
The tern efoetive reader was derined by Snepherd and scheidel as: "rihat reader who communicatos to an aujence from the printed page: works of literary art in their intellectual, emotional, and aesthetic entirety."1.7

Positicns on the continuum os oral reading effectiveness were used to c]assify subjectis as effective or ineffective oral readers. Subjects who were on the upper end of the continum vere desigrated as effective oral. readers. jhe ineffective oral readers vere subjects who ranked at the Iower end of the continuum.

A statistical ara?ysis of the dete rejected the first null hypothesis. When effective and ineflective oral realers wene compared, the former seemed inore inclined to be the aesthetie type. The aesthetic type was characterizea as one who "sees his nichest values in rom and harmony. "18 Bearing on this definition it wes not necessary that an individual be a creative artist or be efrete to be classified as an aesthetic type. Hormever, subjects who were chiefly interested in the artistic episodes of Iife were classified as aesthetic types. Scores on the personality inventories revealed that effective oral readers, as a group, had tendencies of individualism and self sufficiency.

The second null hypothesis was rejected, 2lso. The data suggested that effective oral readers, as a group, placed a high premium on aesthetic values. Also, the effective oral reader tended to be self centered, independent, and self sufficient. The data further revealed that thoy had very itthe feeling of inferiority or self deprecation, and showed I.titie concern or sympathy for the welfare of others.

\footnotetext{
17 Shepherd ard scheidel, op. cit., p. 299. 18 mia.: p. 300 .
} 
In spite of their lack of concern for others, they were not regarded as antisocial. In fact, the effective oral readers' social relationship tended toward eccentricity and self importance. The findings concluded that this group conformed to the qualities of an aesthetic type of man. The third hypothesis, which stated that there are no personality differences between the ineffective oral readers and the normative college populations, was not rejected due to a lack of consistent personality pattern for this group.

The following tenable conclusions were drawn from this investigation. ${ }^{19}$

1. That effective oral readers differ significantly on certain personality characteristics from both the ineffective oral readers and the normal college population.

2. The effective oral readers had a more individualistic attitude toward the aesthetic, social and practical aspects of life than either of the ineffective readers or the normal college populations.

3. The ineffective oral reader, on the other hand, did not differ significantly from the normal college population. There were no consistent and deviant personality patterns manifested by the ineffective oral readers.

It seems that this study provided a better understanding of the personality of the oral reader, and therefore has some implication for teaching oral reading.

Personality Traits and Public Speaking

A careful review of the literature on written mass communication failed to reveal any studies that were concerned with personality traits and its relationship to the perception of such communications. This being the case, it was necessary to turn to a somewhat unrelated area, although not immediately pertinent to the present investigation, to

$$
\text { 19 Ibid., p. 303-304. }
$$


demonstrate the effects of personality differences on the communication process.

The literature in speech and psychology, however, is replete with studies that are concerned with the relationship between personality and speech. 20

Along the same line, Clyde $W$. Dow studied personality traits of good speakers and tried to determine whether or not these speakers possessed a greater degree of such traits as introversion, extraversion, ascendance, submissiveness, emotional reaction, hyperkinesis, and hypokinesis than the average or poor speakers. 2.1

In this study Dow found there was significant proof of a relationship between personality traits and ability in public speaking. This proof, however, was not conclusive enough to place very much reliability on this relationship.

The investigator used 153 subjects to ascertain the personality traits of good speakers. These subjects were beginning and advanced students in public speaking courses. The author used four types of personalj.ty inventories to measure the following personality traits: 22

20 For a comprehensive review of the more important studies on speech and personality see Fil]more H. Sanford, "Speech and Personality," Psychological Bulletin, XXXIX No. 1 (December, 19l42), pp. 811-845.

2lClyde W. Dow, "The Personality Traits of Effective Public Speakers," Speech Monographs, XXVII No. 4 (December, 1941), pp. 525-532.

22 The measuring instruments used to determine the trend and degree of personality were: C. A. Neyman and K. D. Kohlstedtj, A Diagnostic Test for Introversion-Extraversion; G. W. Allport and F. H. Allport, Weasuring Ascendance-submission in Personality; S. I. Pressey, X-O Tests for Investigation of the Fnotions; and C.W. Dow, A Scale for Determining Hyperkinetic.Hypokinetic Reactions. 
1. Introversion--Extraversion

2. Ascendance--Submission

3. Greater and lesser degrees of emotional reaction

4. Hyperkinesis-Hypokinesis 23

Semester grades were used as student's ability in public speaking. only grades for extemporaneous public speaking were considered; grades for written or for literary, and dramatic interpretation were not included as a measure of subject's public speaking ability.

An analysis of the data revealed the following:

1. The above personality traits were positively related to ability in public speaking. As stated earlier, this relationship was not sufficiently high enough for the author to speak with certainty about the value of that connection to public speaking.

2. There was a positive, $(.17 \pm .049)$, but not completely a reliable relationship between extraversion and public speaking. Dow pointed out that introverts, too, may be good speakers, but there were more favorable indications that extraverts were better speakers.

3. Ascendancy, individuals with a strong desire to dominate, was sufficiently related $(.43 \pm .040)$ to ability in speaking. From this positive relationship one may conclude that good speakers tended to be very domineering.

4. The relationship between emotional reactions and public speaking skills was low and negative $(-.18 \pm .053)$. This finding indicated that, generally, superior speakers experienced less bodily changes in feeling, surprise or upsets than inferior speakers. 24

$$
\begin{aligned}
& \text { 23Dow, op. eit., p. } 525 \text {. } \\
& 24 \text { Ibid., p. } 530 .
\end{aligned}
$$


5. The hyperkinetic personality, which is characterized as being tremendously active, appeared to be a definite asset to good public speaking, but it was not completely statistically reliable $(.18 \pm .049)$

In spite of the small correlation coefficient discovered in this study, a very important trend was noted. This trend revealed that the best speakers tended to be extraverted, dominant, self sufficient, and more stable emotionally. Since the ascendance trait had such a significant relationship to good public speaking, the author suggested that speech teachers in their attempt to train students to become effective should try to develop in them that personality dimension.

The investigator further suggested that there would be no harm in trying to develop the traits of extraversion and hyperkinetic, and at the same time try to decrease emotional reactions. There were, however, no significant indications that improvement in these personality dimensions would necessarily result in better public speakers.

Fear-Arousing Communication and Personality Differences

Janis and Feshbach investigated anxiety predispositions associated with personality differences in responsiveness to fear-arousing communications. 25

The study of responsiveness to fear-arousing communications was carried out with the aid of 193 high school students. These students were exposed to an iJlustrated lecture on dental hygiene. The researchers gave two lectures, but the content of the presentation was not identical.

25Irving I. Janis and Seymour Feshbach, "Personality Differences Associated with Responsiveness to Fear-Arousing Communications, "Journal of Personality, XXIII No. 2 (December, 1954), pp. 154-166. 
One of the lectures contained strong fear appeals which illustrated and emphasized the threat of pain, disease, and body damage, while the other included very little fear-arousing material. Most of the material on the dangerous consequences of poor dental hygiene was omitted from the second lecture. The subjects were randomly assigned to one or the other lectures. A personality inventory and teachers' rating were used to divide the subjects into high and low anxiety predisposed groups. The degree to which each subject was influenced by the communication was ascertained by two attitude change tests, one of which measured the resistance to counter statements such as, it did not matter what kind of toothbrush a person used. These statements contradicted the previous weel's lecture which emphasized the use of a certain type of toothbrush. The other attitude change test noted the changes in the direction of conformity with dental hygiene recommendations by comparing the tooth brushing practices reported one week after exposure to the lecture with those reported one week before exposure.

The investigators compared high-anxiety subjects with low-anxiety on basis of their responsiveness to persuasive communication on dental hygiene. High and low anxiety subjects within each of the experimental groups were compared. For instance, the high and low anxiety students that were exposed to strong fear-arousing communication were compared among themselves. Iike comparisons were made between high and low anxiety subjects that received the "watered down" presentation on dental hygiene. The results of these comparisons indicated that high anxiety subjects were less influenced by strong fear-arousing communications than the low anxiety subjects. 26 The authors concluded that the higher the 26 Ibid., p. 162. 
level of fear or anxiety elicited by a communication the greater the chances are that it will reduce the effectiveness of a persuasive communication. 27

In contrast, the Iow anxiety subjects that were exposed to the "watered down" lecture were less influenced than the anxiety subjects. 28 However, both groups were equally resistant to the contradictory statement that it did not matter what type of toothbrush a person used.

The data which was concerned with attitude changes showed that more changes in attitude occurred among the high anxiety than the low anxiety subjects when exposed to strong appeal communication. On the other hand, the difference between high and low anxiety students with respect to minimal appeal was not as great as the strong appeal. Evidence seemed to suggest that mild fear-arousing communication has the same or even a greater effect on high-anxiety as on low anxiety individuals. 29

The results of this investigation tends to support the following general hypothesis:

When a relatively high degree of fear or anxiety is aroused by a persuasive communication, the recipient will become stimulated to develop defensive reactions which interfere with acceptance of the communicator's message. 30

27 Loc. cit.

28 Ibid., p. 163.

29 Ibid., p. 164.

30 I I bid., p. 166. 
Semantic Habits and Personality Dimensions

Nunnally and Flaugher investigated the relationship of semantic habits to personality variables. 31 The authors defined semantic habits in the following manner:

Essentially, semantic habits concern individual differences in the tendency to use one rather than another mode of ascribing meaning to objects in the human and material environment. 32

More specifically, semantic habits are a means of assigning meaning to objects through the use of words, and defining, describing, categorizing or depicting personal reactions to these objects. For example, some individua.ls have a tendency to use pleasant words such as good, pretty, sweet, and so on, while others are inclined to unpleasant words like bad, ugly, sour, and so on. These tendencies reflect individual differences.

The researchers used 3,000 subjects to carry out their investigation of semantic habits and their relationship to personality traits. The subjects included nursery school children, high school students, college freshmen, and military personnel. Various types of personality inventories were lised to measure individual differences.

Among 822 college freshmen, Nunnally and Flaugher found some correlation between the use of pleasant words and extraversion as scored by the Maudsley Personality Inventory. The investigators also found that college freshmen that ascribed unpleasant words to objects were inclined to be slightly neurotic as determined by the same personality inventory. Working with 294 military personnel, the researchers discovered that there was a negative correlation between categorized responses and morale loss scale which was derived Irom the Minnesota Multiphasic Personality

3l Jim C. Nunnally and Ronald L. Flaugher, "Correlates of Semantic Habits," Journal of Fersonality, XXI No. 2 (June, 1963), pp. 192-201. $32_{\text {Ibid. , p. } 201 .}$ 
Inventory (MMPI). The moxale loss scale characterizes individual.s as being depressed. Generally, depressed individuals suffer from constricted thinking and are expected to give few categorized responses. 33 There was a positive correlation between disturbed soldiers and categorized responses.

In still another study of 720 college freshrnen Nunnally and Flaugher found many statistically significant correlations with scores from the Edwards Personal Preference Schedule (EPPS). Male students, for example, who were inclined to categorize things and ascribe meaning to objects in denotative terms scored high on the following personality variables; Dominance, Order, and Endurance. They also tended to score low on the Succorance Scale of the EPPS. Similar findings showed that male students who tended to use pleasant words rated high in Affiliation, Succorance, Nurturance, and Iow in Achievement, Deference, and Order. On the other hand, male students who were inclined to assign unpleasant words to objects scored high in Affiliation, Succorance, Abasement, and Nurturance, and low in Intraception, Dominance, and Endurance.

In contrast, female college freshmen who tended to categorize things and responded in denotative terms scored high on the order scale of the EPPS; whereas, those female freshmen who were prone to assign pleasant or unpleasant meanings to objects tended to be low in achievement.

The data seems to support the notion that there is a relationship between performance and inventory measures of personality, although none of the correlations were very high. In spite of this, the individual differences as related to semantic habits may offer new insights into the study of interests, values, needs, and characterize modes of social interaction.

33 Ibid., p. 197 . 
Literary Style and Personality Traits

The work of Allport, Walker, and Iathers denonstrated that there are individual differences in written composition. $3^{4}$ The authors were primarily interested in the most highly generalized traits of individuals which seem to be expressed in their writing.

Working with nine themes from each of 70 students, the researchers found that anonymous themes of college students could be successfully matched with other themes from the same student. The themes were collected over a period of eight months and afterward the investigators attempted to group together all of the themes writien by each subject. The success of these matchings were computed in terms of a contingency coefficient of $.60 \pm .062$. The magnitude of this coefficient indicated that anonymous thenes written by students can be identified as to authorship on the basis of individuality.

Allport and his associates successfully matched the themes by making judgments concerning personality characteristics of the writers. The investigators found that a certain common quality or trait characteristic would transcend the particular topic and revealed students' identities. 35 one student was tolerant and had a sense of humor, while another subject indicated that he was never at a loss for new ideas and had a pervasive self-consciousness. ${ }^{36}$ These are but two examples of 20 case studies which illustrated what seemed to be the relation of characteristics of personality to written composition.

34Floyd H. Allport, Lynnette E. Walker, and Eleanor Lathers, "Written Composition and Characteristics of Personality," Archives of Psychology, XXVI No. 173 (December, 1.934), pp. 1-82.

35I Ibid., p. 39-40.

36 Ibid., p. 65. 
The authors, however, acknowledged that the identifying characteristics of the themes were too elusive to be stated adequately in language. The themes were evaluated for their form-quality of the individual. However, good "English" was used occasionally as a basis of identification in certain cases, as well as such cues as simple, complex, involved or loose sentences, details of organization, and students orientation toward their topics. Thus in some instances the researchers evaluated the themes based upon grammatical and lexical cues. Uncomplicated sentence structure, for example, occurred in the themes of the person judged to be direct and uncomplicated.

For the most part the authors judged the writing style through intuitive perception of form-quality and concluded that style could be more successfully identified on the basis of generalized personality traits of the writers as they are revealed in the writing rather than on the basis of objective and mechanical cues.

Allport and his associates suggested that the evidence of personality traits as shown in composition could be combined with that of personality tests, and interviews in order to produce results of value not only for the science of personality and the teaching of English, but for the guidance of students as individuals. 37

The above summaries demonstrate that personality characteristics, do, in fact, influence the communication process. However, these studies of individual differences should serve as a framework for the remaining chapters which deal with personality traits as measured by Cattell's Sixteen Personality Factor questionnaire and its relationship to written mass communication.

37 Ibid. p. 71. 
In this connection, the subsequent sections discuss the specifics of Cattell's Sixteen Personality Factor Questionnaire and review some experimental studies of personality traits as measured by this personality inventory.

\section{Catteli's Sixteen Personality Factor Questionnaire}

This section will be devoted to describing and discussing the psychological test used in this study--Cattell's Sixteen Personality Factor Questionnaire.

The 16 P.F. is an instrument designed to measure 16 dimensions of personality which have been derived empirically by Cattell and his associates. These dimensions, based on exhaustive factor analytic research, correspond to personality factors in objective tests and behavior rating. The test is not designed solely to measure neurotic or psychotic conditions but attempts to cover the whole personality.

The Nature and Validity of the Sixteen Factors

The comprehensive nature of this test is best described by Cattell and Eber:

The 16 P.F. is the psychologist's answer, in the questionnaire realm, to the demand for a test giving fullest information in the shortest time about most personality traits. It is not merely concerned with some narrow concept of neuroticism or "adjustment, "or special kind of ability, but sets out to cover planfully and precisely all the main dimensions along which people can differ, according to basic factor analytic research. 38

Since the factor structure of the 16 P.F. has been used in crosscultural surveys and translated into French, Italian, and Japanese there is little doubt that the personality traits measured by this test are in

38Raymond B. Cattell and Herbert W. Eber. Handbook for the Sixteen Personality Factor questionnaire (Champaign, Ill.: Institute for Personality and Ability Testing, 1957), p. I. 
essence universal in nature. Therefore, any research findings based upon these traits will have scientific generalizability and extensive value in clinical psychology and other applied fields. 39

The 16 dimensions of personality determinable by this test are based on a considerable amount of research directed toward unitary, independent, and real-Iife situations where imporiant source traits are discernible. Source traits affect overt personality such as intelligence, emotional stability, super-ego strength, surgency, and dominance. 40 The vocabulary of the test is comparable to the ones found in daily newspapers and there is no writing required other than placing checks in the proper boxes on a separate answer sheet. Since the test requires no writing it can be administered to groups or to an individual.

Many of the personality tests that are administered to determine personality traits are generally not well founded upon factor analytic research and consequently these tests have failed to bring out the separate aspects of the individual's personality. 41 In contrast, the 16 P.F. has been properly validated. with respect to the primary personality factors that are inveterate in general psychological research.

It is also interesting to note that the 16 P.F. is unique in:

1. having every item possessed of a demonstrated saturation with the respect to each of the factors which it sets out to measure.

39Raymond B. Cattell and John H. Morony, "The Use of the 16 PF in Distinguishing Homosexuals, Normals, and General Criminals," Journal of Consulting Psychology, XXVI No. 6 (December, 1962), pp. 531-540.

${ }^{40}$ Cattell and Eber, Ioc. cit.

${ }^{41}$ Ibid., p. 2. 
2. having proof that each of the questionnaire factors corresponds to a primary personality factor found elsewhere, i.e., beyond the questionnaire realm, notably in rating in real-life behavior situation in the Objective Analytic Factor Battery, in social response patterns and in abnormal, pathological behavior. 42

Description of the Sixteen Source Traits

Two levels of nomenclature are used to describe source traits. The names used for the source traits include both professional and popular titles. 'The bipolar description of the 16 personality factors are shown in Table $T$.

The laymen descriptions are also included in Table I for each technical title to further acquaint the reader with Cattell's personality irventory. The four factors that are labelled $Q$ indicate that they have been established only in the questionnaire realm of tests. However, these four factors do predict those personality traits indicated in Table I. The technical titles in Table I are followed by the standard symbol-alphabet index, with plus and minus notations to indicate that a low score (-) corresponds to the description at the left and a high score $(+)$ represents the behavior at the right.

A fuller description of the psychological meaning of each of these factors is beyond the scope of this section. A complete analysis of the source traits is, however, given in the Handbook for the Sixteen Personality Factor Questionnaire.

It is important to note that the main dimensions of each personality factor have been found necessary and adequate to cover all kinds of individual differcnces that are common in speech and psychological

\footnotetext{
${ }^{42}$ Ioc. cit.
} 
TABLE I

CAT'TELL'S CAPSULE DESCRIPTION OF THE SIXTEEN PRIMARY PERSONALITY FACTORS*

\begin{tabular}{|c|c|c|}
\hline Low score Description & Alphabet Index & High Score Description \\
\hline $\begin{array}{l}\text { Sizothymia, A- } \\
\text { (Reserved, Detached, Critical, Aloof) }\end{array}$ & Factor A & $\begin{array}{l}\text { Affectothymia, At } \\
\text { (Warmhearted, Easy-Going, Participating) }\end{array}$ \\
\hline $\begin{array}{l}\text { Lower Scholastic Mental Capacity, B- } \\
\text { (Iess Intelligent, Concrete Thinking) }\end{array}$ & Factor $B$ & $\begin{array}{l}\text { Higher Scholastic Mental Capacity, B+ } \\
\text { (More Intelligent, Abstract Thinking, Bright) }\end{array}$ \\
\hline $\begin{array}{l}\text { Lower Ego Strength, C- } \\
\text { (Affected by Feeling, Emotionally Less } \\
\text { Stable, Easily Upset) }\end{array}$ & Factor C & $\begin{array}{l}\text { High Ego Strength, C+ } \\
\text { (Emotionally Stable, Faces Reality, Calm, } \\
\text { Mature) }\end{array}$ \\
\hline $\begin{array}{l}\text { Submissiveness, E- } \\
\text { (Tumble, Mild, Accommodating, Conforming) }\end{array}$ & Factor $E$ & $\begin{array}{l}\text { Dominance, Et } \\
\text { (Assertive, Aggressive, Stubborn, Competitive) }\end{array}$ \\
\hline $\begin{array}{l}\text { Desurgency, F- } \\
\text { (Sober, Prudent, Serious, Taciturn) }\end{array}$ & Factor $\mathrm{F}$ & $\begin{array}{l}\text { Surgency, F十 } \\
\text { (Happy-Go-Iucky, ImpuIsive, Iifely, Gay) }\end{array}$ \\
\hline $\begin{array}{l}\text { Weaker Superego Strength, G- } \\
\text { (Expedient, Disregard Rules, Feels few } \\
\text { Obligations) }\end{array}$ & Factor G & $\begin{array}{l}\text { Stronger Superego Strength, Gi } \\
\text { (Conscientious, Persevering, Staid, Moralistic) }\end{array}$ \\
\hline $\begin{array}{l}\text { Threctia, H- } \\
\text { (Shy, Restrained, Timid, Threat-Sensitive) }\end{array}$ & Factor $\mathrm{H}$ & $\begin{array}{l}\text { Parmia, Ht } \\
\text { (Venturesome, Socially Bold, Unhibited) }\end{array}$ \\
\hline $\begin{array}{l}\text { Harria, I- } \\
\text { (Tough-Iinded, Self-Reliant, Realistic, } \\
\text { Non-nonsense) }\end{array}$ & Factor I & $\begin{array}{l}\text { Premia, It } \\
\text { (Tender-Minded, Clinging, Over-Protected, } \\
\text { Sensitive) }\end{array}$ \\
\hline $\begin{array}{l}\text { Alaxia, L- } \\
\text { (Trusting, Adaptable, Free of Jealousy) }\end{array}$ & Factor I & $\begin{array}{l}\text { Protension, It } \\
\text { (Suspicious, Self-Opinionated, Hard to Fool) }\end{array}$ \\
\hline
\end{tabular}


TABLE I (Continued)

Praxernia, M-

(Practical, Careful, Conventional, Proper)

Artlessness, N-

(Forthright, ivatural, Artless,

Unpretentious)

Untroubled Adequacy, $0-$

(Self-Assured, Confident, Serene)

Conservatism, Q ${ }_{1}^{-}$

(Conservative, Respecting Established Iceas )

Group Adherence, Q?-

(Group-Dependent, A "Joiner" and Sound Follower)

Low Integration, $Q_{3}-$

(Undisciplined Self-Conflict, Follows Ow Urges

Low Ergic Tension, Q4-

(Relaxed, Tranquil, Unfrustrated
Factor M

Factor N

Factor 0

Factor QI

Factor Q?

Factor $Q_{3}$

Factor $Q_{4}$
Autia, Nit

(Imaginative, Wrapped Up In Inner Urgencies, Careless of Practical Matters)

Shrewdness, N+

(Shrewd, Calculating, Worldly, Penetrating)

Guilt Proneness, Ot

(Self-Reproaching, Worrying, Troubled)

Radicalism, $\mathrm{Q}^{+}$

(Experimenting, Liberal Analytical, FreeThinking)

Self-Sufficiency, Q2+ (Self-Sufficient, Prefers Own Decisions, Resourceful)

High Self-Concept Control, Q ${ }_{3}+$ (Controlled, Socially Precise, Following Self-Image)

High Ergic Tension, $Q_{4}+$

(Tense, Frustrated, Driven, Overwrought)

Source: Answer Sheet: The 16 P.F. TEST, FORM $C$ and 16 P.F. TEST PROFIIT Sheet.

*Parentheses indicates laymen description of the 16 Frimary Personality Factors. 
literature. 43 In fact, the 16 P.F. leaves out no important dimension of the total personality. 44

In addition, each of the personality factors presented in Table I is independent of one another, which signifies clear functional unity. Therefore, it is possible to combine the score of one factor with the score of any other factor. Moreover, these factors are known to be important from the standpoint that each has a sufficient influence on behavior. These factors are reflected in psychological processes of maturation, learning, and interaction with psychological state. 45

Test Design, Reliability, and Validity

Even though the 16 P.F. has been properly validated 46 it would be erroneous to assume that it is a universally valid instrument. Test results are known to differ between cooperative and uncooperative, welleducated and poorly educated subjects. Differences also have been noted between honest respondents and those who deliberately distort responses. The most valid application of the $16 \mathrm{P} . \mathrm{F}$. has been, under conditions of research, with students, and with cooperative anonymous subjects. 47

The 16 P.F. Questionnaire is so constructed that the majority of the questions are indirect and subjects would not perceive them to be related to specific personality traits. Since the questions are presented in an indirect manner, this gxeatly reduces deliberately distorted responses.

\footnotetext{
$43_{\text {Loc. cit. }}$

44 Loc. cit.

45 Ibid., p. 3.

46 Ibid., p. 2.

$47_{\text {Ioc. cit. }}$
} 
Moreover, "the question responses are interpreted as behavior, not as va].id self-rating." 48

Each item in the 16 P.F. has three response alternatives or categories. The test jnstruction cautions respondents not to utilize the middle category unless absolutely necessary. The end categories measure either extreme of a personality dimension, while the middle category is an "uncertain" or "in between" category. Questions pertaining to intelligence, however, have two categories which are incorrect; and the third is correct.

Another interesting facet of the 16 P.F. is that three possible test lengths are available. The variations in lengths permit the researcher to administer tests according to the available time and desired measure of reliability. Each of the three possible tests measures the same 16 personality ractors, and the results are equivalent when expressed in standard scores. These tests are referred to as Form A, B, and C. Forms $A$ and $B$ contain 187 questions and require a minimum of 35 to 40 minutes to administer, whereas Form C, the shortest of the three, contains 105 items and a minimum of 20 minutes is needed to administer the test.

In spite of the varying lengths of the 16 P.F., this test has the highest possible reliability for the number of items contained in the questionnaire. 49

The 16 P.F. coefficient of reliability takes three major forms:

Consistency, Equivalence, and Stability coefficients. No data is given on the last, because stability varies too much with undefinable conditions and is a characteristic of the trait rather than the test. For example schizothymia . . and intelligence . . . vary

48 Ioc. cit.

${ }^{49}$ Loc. cit. 
little from day to day, but ego strength . . and still more, surgency . . , fluctuate in level a good deal. This matter belongs, therefore, to the psychology of personality. 50

In addition, the consistency coefficients are extremely high in the 16 P.F. 5.1

In arriving at the validity of the 16 P.F. Cattell and his associates retained only those items in the questionnaire which survived three successive factor analyses. The authors state:

These analyses both verified the existence and structure of 16 factors, and cross validated the items against the factors on different adult population samples. 52

A high correlation of validity also exists in the 16 P.F. In fact, the validity is high for the entire profile and not just a few selected items.

In terms of reliability and validity it is desirable to administer all three forms of the 16 Personality Factor Questionnaire to achieve the highest possible reliability and validity of measurement for the primary personality factors.

Administering and Scoring the 16 P.F.

As previously stated, the 16 P.F. may be administered to individuals or to groups. Individual tests are administered for clinical use, while group tests are given in an educational or industrial situation. 53

${ }^{50}$ Ibid., p. 4.

5I The consistency of coefficient for each of the 16 personality factors are:

$\begin{array}{llll}A=0.90 & F=0.84 & I=0.77 & Q_{1}=0.71 \\ B=0.86 & G=0.85 & M=0.88 & Q_{2}=0.79 \\ C=0.93 & H=0.83 & N=0.79 & Q_{3}=0.76 \\ E=0.91 & I=0.76 & O=0.85 & Q_{4}=0.88\end{array}$

${ }^{52}$ Loc. cit.

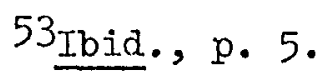


The 16 P.F. Questionnaire is relatively simple to administer. In fact, complete instructions are given on the first page of the test booklet. As with most tests of this type, when administered to a group, there tends to be a skewed distribution in the time it takes to complete the test. The average time for completing Form $\mathrm{A}$ and $\mathrm{B}$ is about 40 minutes, whereas most examinees can complete form $\mathrm{C}$ in 20 minutes. However, there is not a definite time Iimit for completing this personality survey .

Scoring the test presents no formidable task. The responses to the 16 P.F. are scored in this manner: all right answers receive a score of two points, the in-between answers one point, and all wrong answers zero. This procedure is used to ascertain the raw score for personality factors. However, once the raw scores are determined they are then converted to standard personality scores. Standard personality scores may be intelpreted in point scales of sten or stanines. The sten point scale contains ten equal interval standard score points, whereas the stanines has nine points.

The sten is irequently preferred by most 16 P.F. users. This is understandable since most people think better in terms of a ten-point scale. The sten scale for the population average is fixed at 5.5; however, the "normal" scores for the examinee may be five or six. Individuals with a sten score of 4 or 7 are considered to be a definite departure from the average. 54

The architects of the 16 P.F., in their effort to ascertain precise measures of personality dimensions, have incorporated a motivation

$$
{ }^{54} \text { Ibid., p. } 7 .
$$


distortion allowance, which attempts to reduce errors that generally occur in questionnaire types of personality surveys. Errors in personality inventories of this type are due to the following:

1. the subject's false ideas about himself;

2. his dishonesty in trying to present a false picture of himself;

3. the changing intensity, in various situations, of the subject's motivation to present a distorted picture, consciously or unconscious Iy. 55

The motivation distortion or lie detecting scale is only found in Form $\mathrm{C}$ of 16 P.F. The need for motivation distortion scale in Form $\mathrm{C}$ resulted from its extensive use in mass testing where there is a strong attempt to "fake" answers in order to create a desirable image. 56 However, distortion is greatly eliminated by the test construction. 57 The questions are not questions where the answers to them are accepted at face value in determining behavior. 58 In fact, the questions are quite indirect in their meaning and correlate with the personality factors. 59

Norms for the 16 P.F. Questionnaire have been developed for both college students and the general public. Norms for college students are based on a larger sample than those for the general public. 60 Evidence shows that personality profile and distribution for college students differ significantly from that of the general population. 61

$55_{\text {Ibid., p. }} 6$.

${ }^{56}$ Loc. cit.

$57_{\text {Loc. cit. }}$

58 Ibid., p. 7.

${ }^{59}$ Loc. cit.

${ }^{60}$ Ibid., p. 9.

${ }^{61_{\text {Loc }} \text { : cit. }}$ 
The researcher musi carefully select the norm tables which best suit his perticular needs. The authors of the 16 P.F. have developed some 13 norm tables. This writer used the stens norm table for American College Students: Men and Women Together. This table was selected for converting raw scores into standard scores because the researcher's subjects were all. college students. Second-order factors of extraversion-introversion were also utilized in this investigator's research.

\section{A Summary of Selected Studies Utilizing the 16 P.F.}

The present section will attempt to report the findings of studies which utilized the 16 P.F. A survey of the psychological Iiterature revealed that the $16 \mathrm{P} . \mathrm{F}$. had been used as the basis for a variety of research studies. These studies were concerned with whether or not certain psychological characteristics descriptive of personality were related to behavioral differences which characterizes nan's behavior. Examples of such differences include behavioral differences in successful and unsuccessful students, social mobility, voting, union activity, and many other types of behavior. It is, however, beyond the scope of this study to report the findings of all studies pertaining to the 16 P.F. A summary of certain selected studies may serve to acquaint the reader with the significance of the 16 P.F., and demonstrate and perhaps justify the use of personality inventories in behavioral research. The following studies will attempt to show in detail how personality dimensions are related to human behavior.

Personality Profile of Student Smokers

Cattell. and Krug administered the 16 P.F. to a group of male and female college students to determine the personality characteristics of 
smokers. 62 All forms of the $16 \mathrm{P} . \mathrm{F}$. were administered to 256 undergraduate students to measure all of the 16 personality f'actors. The personality frctors of smokers and non-smokers were compared.

The researchers used a questionnaire to obtain information about smoking practices. Additional information on certain demographic variables was also secured during the investigation. The demographic variables included religious interest, regional and social status, whether or not the father and mother were smokers, and so on.

An analysis of the 16 factors revealed that the most significant personality factors of the smokers were surgency, affectothymia, and premsia. Surgency is characterized as cheerful, talkative, serene, happygo-Iucky, frank, expressive, quick and alert. 63 Affectothymia, on the other hand, characterizes a person as being good natured, outgoing, easygoing, ready to cooperate, attentive to people, soft hearted, kindly, trustful, adaptable, and warm hearted. 64 The permsic person tends to be venturesome, tender-minded, imaginative, introspective, artistic, fastidious, excitable. Other indications of a premsic person are: demanding, impatient, dependent, impractical, and showing a dislike for crude people. 65 The test results also showed that smokers were more extraverted.

Since affectothymia and surgency were significantly associated with

62 Raymond B. Cattell and Samuel Krug;, "Personality Factor Profile Peculiar to the Student Smoker," Journal of Counseling Psychology, XIV No. 4 (March, 1967), p. 117.

$63_{\text {Ibid., }} \mathrm{pp}$. 116-.121.

${ }^{64}$ Cattel1 and Eber, op. cit., p. 13.

65 Ibid., p. 11 . 
smokers the authors concluded that smoking commonly begins in a social setting.

There were significant negative correlations between smoking and certain demographic variables. For example, smoking was negatively related to religious interest and attendance at religious services.

It is interesting to note that Cattell and Krug found that smoking was related to those individuals who were: more well-to-do; more protected from the world; more interested in arts than sciences; from smaller families, and so on. 66

The associations in this study were significant enough to characterize smokers as outgoing, happy-go-lucky, and venturesome.

Personality Patterns of Failing College Freshmen

The 16 P.P. has also been employed to determine personality differences between successfu]. and unsuccessful college freshmen. In an effort to determine personality patterns of unsuccessful college freshmen, Osman studied 201 students who withdrew failing from Indiana state College after their first year of academic study. 67

In the test of significant differences the researcher noted that of the 16 personality factors measured by the 16 P.F., ten were significantIy different from the norm groups. The norm groups consisted of 364 male students and 302 female students. Of the 201 students that withdrew failing 137 were male and 64 were female.

${ }^{66}$ Cattell and Krug, op. cit., p. 120.

67 William L. Osmon, "The Personality Patterns of Failing Freshmen," Indiana State College, 1961-62, The Teachers College Journal, XXV No. 2 (November, 1963), pp. 61-65. 
The factors shown to be significantly different among failing male students were:

Factor B--Mental Defect (Dull, Low General Ability)

Factor F--Surgency (Fnthusiastic, Talkative)

Factor L--Protension (Suspicious, Self-Opinionated)

Factor N--Shrewdness (Calculating, Worldly)

Factor 0--Guilt Proneness (Apprehensive, Insecure)

Factor Q1--Conservatism (Conservative, Respecting Established Ideas)

Factor $Q_{2}$-Group Dependency (A "Joiner" and Sound Follower)

Factor $\mathrm{Q}_{3}$--Poor Self-Sentiment Formation (Uncontrolled, Lax)

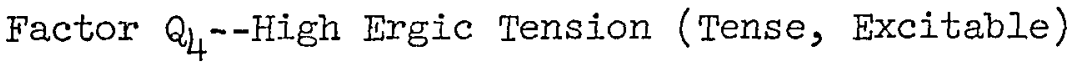

Factor B coincided for both men and women, and as one would expect the level of intelligence contributed to the attrition rate of those college freshmen. Turther findings indicated that men were more extraverted, but at the same time they were suspicious and self-opinionated. The personality traits of extraversion and suspicion are indicative of Factors $F$ and I respectively.

Another factor which coincided for both men and women was 0 . Factor 0 characterizes individuals as being insecure, depressed, moody and as having childlike tendency to anxiety in difficulties. Both males and females that withdrew were also characterized as being tense and excitable. This characterization is indicative of Factor $Q_{4}$. Further analysis indicated that men were overly cautious, moderate, and opposed to any change. This personality dimension is descriptive of Factor $Q_{1}$. Men were also found to be disinclined to make decisions for themselves and were dependent upon others for social approval and administration--Factor $Q_{2}$.

The author concluded that men and women who withdrew from college failing were not "abnormal" in the clinical sense. The findings did indicate 
however, that there were definite personality differences between successful und unsuccessful college freshmen.

The Relationship Between Personality and Reading Ability

In an effort to determine the relationship between reading ability and personality factors, Anderson administered two tests--the Cooperative Reading Test (Higher Level Form Y) and the Cattell 16 P.F. (Form A).68 These tests were administered to 415 entering freshmen at the University of Western Australia. Of the 415 students, 290 were male and 125 were female.

The personality factors which showed a consistent relationship between reading scores were $B, G, I, M, Q_{1}$, and $Q_{2}$. As indicated by Factor $B$, students who scored high on the reading test were generally more intelligent than those who scored low on the reading test. Factor $G$ denotes that the better readers were less conscientious and less persevering, but they were generally more sensitive as noted by Factor I. Those students who scored high on the reading test further indicated that they were: (I) more introverted (Factor M), (2) more radical (Factor $Q_{l}$ ), and (3) more self-sufficient (Factor $Q_{2}$ ) than those who were poor readers. In summary, the general personality description of the better readers may be characterized as being introverted, emotionally sensitive, self-sufficient, radical, and weak in superego strength.

In review of the research findings presented above it may be concluded that the 16 P.F. can be successfully utilized in behavioral research to denote individuality. Moreover, since the 16 P.F. clearly

${ }^{68}$ A. W. Anderson, "Personality Traits in Reading Ability of Western Australian University Freshmen," Journal of Educational Research, I No. 6 (February, 1961), pp. 234-237. 
identified personality characteristics of smokers, failing college freshmen, and better readers it may be further concluded that it can be effectively employed in obtaining the stated objectives of the present experiment.

Some other noteworthy studies which have employed the 16 P.F., to mention a few, are: 69 "The Use of the 16 P.F. in Distinguishing Homosexuals, Normal.s, and General Criminals," "Personality Orientations of Farm, Village, and Urban Boys," and "The Relation of the Vocational Preference Inventory to the Sixteen Personality Factor Questionnaire." The Semantic Differential

The previous section focused upon the nature of the 16 P.F. and various studies which utilized this personality inventory. In an effort to further acquaint the reader with the research tools used in this study, the subject of this section is devoted to the semantic differential. Attention is directed first to the nature and mechanics of the semantic differential. Then consideration is given to various studies which attempt to show the versatility and the diversity of application of the semantic differential in behavioral research.

Nature and Mechanics of the Semantic Differential

The description and rationale for the semantic differential is extensively described by Charles E. Osgood and his associates in one

69Raymond B. Cattell and John H. Morony, "The Use of the 16 PF in Distinguishing Honosexuals, Normals, and General Criminals," Journal of Consulting Psychology, Vol. XXVI, No. 6 (December, 1962), pp. $\overline{531-540 ;}$ "The Relation of the Vocational Preference Inventory to the Sixteen Personality Factor questionnaire," Journal of Applied Psychology, XI, No. 3 (August, 1960), pp. 291-296; A. 0. HaIlen and Carole Ellis Wolff, "Personality Orientations of Farm, Village, and Urban Boys," Rural Sociology, XXVII No. 3 (September, 1962), pp. 275-293; for complete bibliography listing of research studies utilizing the 16 P.F. consult The Handbook for the Sixteen Personality Factor Questionnaire. 
volume entit]ed The Measurement of Meaning. 70

Basically, however, the semantic differential is a combination of word associations and scaling techniques designed to give an objective measure of the connotative meanine of concepts. 71 More specifically, this technique measures meaning defined as a representation mediation process, learned state, that is elicited by siens. Responses to the semantic differential serve as an operational index of the representational mediation process or meaning.

The underlying logic assumes the existence of a semantic space; "a region of some unknown dimensionality and Euclidian in character."72 Thus, the meaning of a concept has a place in this multidimensjonal semantic space. The semantic space generated by the semantic differential is arrived at by having individuals rate concepts along graded scales, each having polar adjectives as end points. Therefore, the connotative meaning of a concept is measured as a point in the semantic space. A concept without any meaning would rest at the point of origin for all dimensions. The meanings of concepts are represented by their position in the semantic space and they are distinguishable from individual to individual and from group to group. 73 The semantic differential technique is considered to be relatively free from response biases. 74

${ }^{70}$ Charles E. Osgood, George J. Suci, and Percy H. Tannenbaum, The Measurement of Meaning, University of Illinois Press, Urbana, Ill., 1957 .

71 I Ibid., p. 20 .

72 Ibid., p. 25 .

$73_{\text {Ibid. }}$ pp. 25-30.

74 Norman S. Endler, "Changes in Meaning During Psychotherapy as Measured by the Semantic Differential, "Journal of Counseling Psychology, VIII No. 2 (Summer, 196I), p. 205. 
osgood, in hjs basic hypothesis, defined meaning operationally as the point of intersection of the component dimensions upon which meaningful cbjects have been judged. Thus the meaning of a concept is located by finding its dimensions and then ascertaining the distance along each dimension which indexes its position. Each dimension is measured by a seven point, equal-interval ordinal scale. Specifically, the scales are sevenstep, bipolar, adjectival scales representing linear functions and passing through a common origin. Adverb modifiers qualify each step on the scale; the greater the intensity of the association, the more extreme the displacement towards one or the other polar terms. With a sufficient number of bipolar scales to embrace various dimensions, it is then assumed that meaning can be definitely and accurately located. 75

Bipolar Adjectival Scales and Factors of Connotative Meaning

The adjectival scales were selected from 50 pairs of empirically defined and factor analyzed polar adjectives, with heavy factor loading labeled "evaluative," "potency," and "activity." The manner in which these scales were developed, the various experiments designed to refine and evaluate them, and the ways in which the measuring instrument has been utilized in various disciplines are well reported in The Measurement of Meaning. The scope of this section does not permit reviewing the numerous approaches that were used in finding and testing these scales. The "evaluative" factor is the attitudinal component of meaning and signifies whether or not a concept is "good" or "bad." Potency is concerned with the intensity of "goodness" or "badness." The "activity" factor is independent of both "evaluative" and "potency" factors. The "evaluative"

75Raymond G. Smith, "Development of a Semantic Differential for Use with Speech Related Concepts," Speech Monographs, XXVI No. 4 (November, 1959), p. 263. 
dimension is represented by such scales as good-bad, timely-untimely, kind-cruel, beautiful-ugly, successful-unsuccessful, important-unimportant, true-false, and wise-foolish; and the "potency" dimension is represented by hard-soft, masculine-feminine, Iarge-small, and strong-weak. 76 The "activity" dimension is characterized as active-passive, fast-slow, hotcold, sharp-dull, and angular-round. 77

The "evaluative," "potency," and "activity" factors are regarded by Osgood as being the three principal dimensions of connotative meaning. In addition, there are five other dimensions of connotative meanings. These additional factors include: ${ }^{78}$

1. "Stability"--sober-drunk, stable-unstable

2. "Tautness"--straight-curved, angular-round

3. "Novelty"--new-old, usual-unusual

4. "Receptivity"--savory-tasteless, colorful-colorless

5. "Aggressiveness"--aggressive-defensive

Indexes are established for each of these factors by using the seven-step, adjectival, bipolar scale. With this seven-point scale it is possible to make quantitative comparison of the meaning of concepts for each respondent or groups of respondents. To illustrate, the concept Father may be judged on such scales as these:

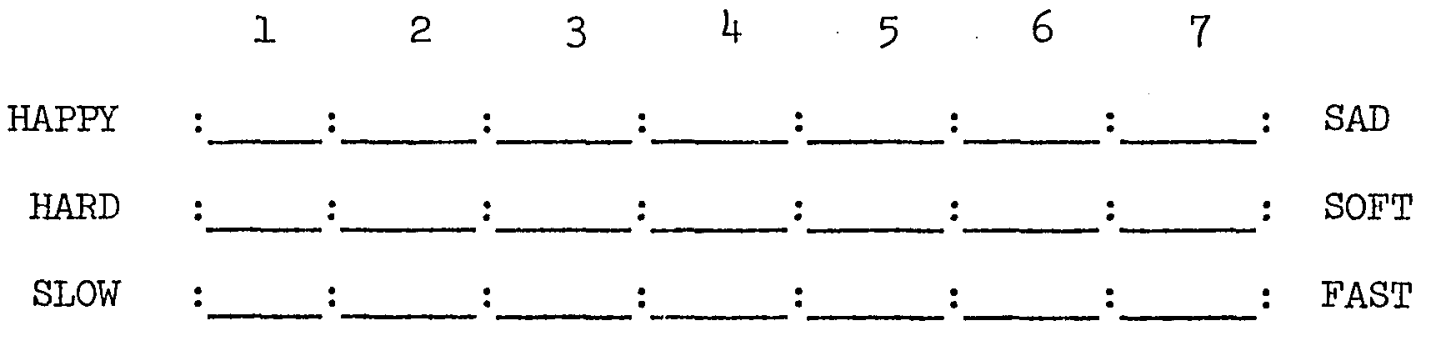

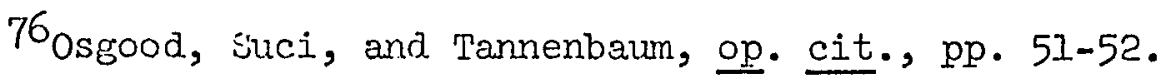

$77_{\text {Loc. cit. }}$

78 Ibia., pp. 63-64. 
The respondent places a check in the space most descriptive of the concept being juaged. The respondents are encouraged to use the scales as qui.ckly and honestly as possible: and not to puzzle over any particular concepts. A 150-item form such as the one illustrated above usually takes less than 10 minutes to complete. 79 Each scale has three degrees of polarity which describe the appropriate placenent of the concept along the scale. The middle position indicates a lack of applicability of the concept to either polar adjective. The positions from left to right are described, for example, as extremely happy, very happy, slightly happy, neutral, slightly sad, very sad, and extremely sad. The average for all respondents can be developed by numbering the spaces one through seven. Since each concept is rated on several scales the semartic profile of concepts can be plotted as show in Figure 1 . It may be noted in Figure 1 the concept FATHER was favorably rated. That is, the hypothetical respondents had a relatively "good" comnotation of the concept FA.IHER. Such a conclusion may be drawn by observing the deep penetration of the Iine toward the left (positive) side of the bipolar adjectives. The first four bipolar adjectives represent the "evaluative" factor; potency is repre-. sented by hard-soft, masculine-feminine, and strong-weak; and "activity" is characterized by the remaining three bipolar adjectives.

79 Charles E. Osgood and Zella Luria, "A Blind Analysj.s of a Case of Multiple Personality Using the Semantic Differential," Journal of Abnormal Social Psychology, XIIX (October, 1954), p. 580. 


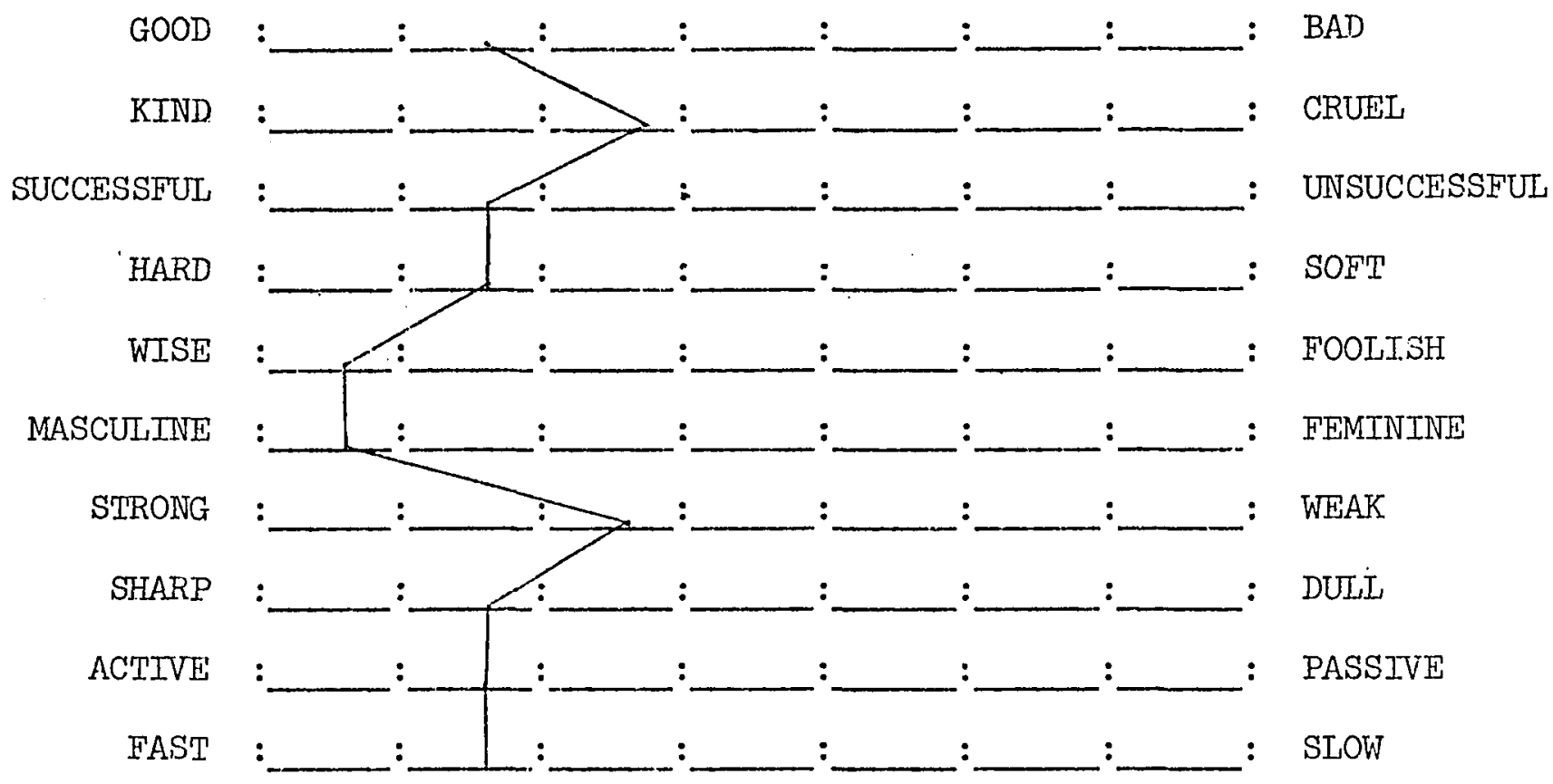

Figure 2.1.Profile for Hypotheticel Judgment of the Concept FATHER

Source: Primary; scales selectsd from Osgood, Suci, and Tannenbaum, The Measur Ement of Heaning, pp. 52-57.

Determining the Relationship Between Concepts

As previously stated the meaning ceveloped for concepts has two major components :

1. direction from the origin of the space--the place where the respondent checks the space rost descriptive of the concept being judged.

2. distance from the origin--the extreme displacement of the check mark toward one or the other polar terms.

More specifically, the meaning of the concept FATHER, as defined by the operation of measurement indicated in Figure 1 , is the profile numbers in the columns. That is to say, "the position of the $n$-dimensional space defined by the projection of these numbers onto factors. "80 By computing D statistics (the generalized distance function in n-dimensional space) 
the relationship between meaning may be determined. Specifically, "the difference in meaning for two concepts is defined by the distance between their position in this space, as computed by the generalized distance formula-D $=\sqrt{\Sigma \Omega^{2}}$. . "8I $D$ is defined as the square root of the sum of the square differences between scores on each of the scales for the profile rating of any two concepts. 82 The greater the similarity between the connotative for any two concepts the smaller the D value. 83

The Advantages of the Semantic Differential

It is generally believed by many scholars that the semantic differential is a valid and reliable instrument which can generally be applied to the measurement of connotative meaning. 84 Furthermore, the semantic differential meets other standard criteria for measuring instruments such as objectivity, sensitivity, comparability, and utility. 85 since 1960 over 100 publications have appeared dealing with the semantic differential,

${ }^{8 I_{\text {Ioc. }} \text { cit. }}$

82 Maurice Korman, "Implicit Personality Theories of Clinicans as Defined by Semantic Structures," Journal of Consulting Psychology, XX..V No. 2 (April, 1960), p. 180.

83 osgood and Luris, op. cit., p. 580 .

${ }^{84}$ See, for example, Zella Luria, "A Semantic Analysis of a Normal and a Neurotic Therapy Group," Journal of Abnormal and Social Psychology, LVIII No. 2 (March, 1959), pp. 216-220. Raymond G. Smith, "Development of a Semantic Differential for Use with Speech Related Concepts," Speech Monograph, XXVI No. 4 (November, 1959), pp. 263-272. Wallace E. Lambert and Leon A. Jakobovits, "Verbal Satiation and Changes in the Intensity of Meaning," Journal of Experimental Psychology, LX No. 6 (December, 1960), pp. 376-383. James F. Engel, Hugh G. Wales and Martin R. Warshaw, Promotionall Strategy (Homewood, Ill.: Richard D. Irwin, 1967), p. 307. William A. Mindak, "Fitting the Semantic Differential to the Marketing Problem," Journal of Marketing, XXV No. 2 (April, 1961), pp. 28-33.

${ }^{85}$ Smith, op. cit., p. 254 . 
and since that time the rate of publication in this has probably accelerated. In fact, in 1966 it was estimated that over 500 experimental studies have some form of the semantic differential as a measuring instrument. 86

A review of the advantages of the semantic differential would surely inaicate why it is one of the most promising measuring instruments to appear in recent years. Briefly, the advantages of the semantic differential, noted by both Mindak and Engel, are:

1. a Dasis is provided to isolate the dimensions of opinion

2. the technique is standardized and susceptible to comparison over time

3. it is reliable and repeatable.

4. full allowance is made for individual frames of reference

5. problems of question phrasing are eased

6. . determination of degree of intensity of feeling provide a basis for ranking alternatives and assessment of how well each perform against predetermined norms.

7. - the wording of questions reduces the danger that the
individual will play expert and distort his opinions. As such the semantic differential is among the most useful instruments in determining connotative meaning.

A Review of Research Studies Utilizing the Semantic Differential This section presents the findings of several studies dealing with the semantic differential. Specifically, the writer will examine the

86 Raymond G. Smith, "Semantic Differential Bibliography," Central States Speech Journal, XIII No. 2 (Spring, 1962, pp. 206-213.

87 James F. Engel, Hugh G. Wales, and Martin R. Warshaw, Promotional Strategy (Homewood, IIl.: Richard D. Irwin, 1967), p. 307, and William A. Mindak, "Fitting the Semantic Differential to the Marketing Problem," Journal of Marketing, XXV No. 2 (April, 1961), p. 57. 
results of some exploratory research which have employed the semantic differential technique. Studies pertaining to the semantic differential are too numerous to discuss in a paper of this limited scope. However, a brief discussion of three such studies should serve to demonstrate the applicability, versatility, and the diversity of this measuring instrument. Procedural details relating to these studies are to be largely omitted on the assumption that the interested reader can obtain details from the original sources. These studies demonstrate the value and usefulness of the semantic differential procedure in objectively measuring the connotative meaning of recruitment advertisements experimentally tested in the present investigation.

Differential Perception of Certain Jobs and People

Harry $c$. Triandis used the semantic differential to study how certain jobs and certain people are perceived by various groups of industrial workers. 88 Briefly, participants rated five specific jobs: welders, teacher, vice-president, personnel director and clerk. Subjects also rated their supervisor, the company's personnel director, the boss of their supervisor, the vice-president of their division, a fellow at work whom they like, and an effective manager they knew well but who was not the same as any of the other people rated.

It is interesting to note that in general the means of the various group on the semantic differential scales were very similar. In fact, only several distinguishable differences were noted. The job of the welder was among the more interesting findings.

88 Harry C. Triandis, "Differential Perception of Certain Jobs and People by Managers, Clerks, and Workers in Industry," Journal of Applied Psychology, XIIII No. 4 (August, 1959), pp. 222-225. 
Industrial workers rated the welcier's job as being less routine when compared to other groups. In addition, the subjects preceived the welder's job as involving more experience, and being more desirable, important, responsible, alert, difficult, professional, executive, creative, skilled and more versatile. In general industrial workers had a tendency to idealize or over evaluate the welder's job. It was suggested from this finding that management in communicating to workers about their job should carefully consider how workers perceive their jobs and not try to minimize the importance of their jobs. 89

Another finding revealed that workers perception of the job and the man were significantly interrelated. That is, "the job acquired the characteristics of the man and the man the characteristic of the job." 90

Space limitation does not permit a complete presentation of all the significant findings. However, this brief review does present the most important differences that were discernible by the semantic differential technique.

Evaluating Communication

Another interesting application of the semantic differential involves a communication incident. 91 The semantic differential was used to quantify similarity between communicators' views on certain topics (concepts) and the perception of these views by communicatees.

The communicators ivere college students who wrote short passages explaining their views on college fraternities and the University of

${ }^{89}$ Ibid., p. 223.

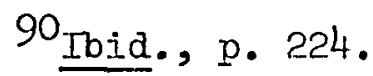

9lMelvin Manis, "Assessing Communication with the Semantic Differential," Journal of American Psychology, LXXII ('arch, 1959), pp. 111-113. 
Pittsburgh. The communicators rated these concepts on the semantic differential. The written messages were in turn distributed to the cormunicatees, another group of college students, who read the messages and recorded their prediction of how the communicators felt about the topics on the semantic differential.

From this procedure two separate sets of semantic profiles were developed from measuring the communication. One set represented the communicators' rating of the two concepts and the other represented the communicatees' predictions. Correlation analyses were used to compare the semantic profiles of the communicators and the communicatees. This comparison revealed that the evaluative dimension of connotative meanings were more highly correlated than the potency and activity dimensions. Thus, the results of the study showed that the communicators had been relatively successful in transmitting their views of the topics to the communicatees. The study also indicated that the semantic differential was a desirable technique in assessing the communication of evaluative attitudes.

Public Images of Business are Stereotypes

The following study demonstrates still another application of the semantic differential. Specifically, it sought to determine whether the public images of large companies were stereotype. 92 The specific companies involved in this study were a large bank, a major airline, a national finance company, a large food chain, a major department store, a giant public utility, and a savings and loan association. As in other

92 W. T. Tucker, "How Much of the Corporate Image is Stereotype?," Journal of Marketing, XXV No. 3 (January, 196I), pp. 61-65. 
semantic dirferential studies, respondents rated these companies on semantic scales and correlation analysis was used to compare corporate images .

The study indicated that corporate images were largely stereotype. The correlation of images for the bank, department store, public utility, food chain, finance company, saving and loan association, and airline were unusually high. In fact, the correlation coefficient between a bank image and that of each of the other companies ranged from high of .96 to low .72 . The author concluded from this study that either a true stereotype exists in public images of business or that the normal verbal stereotype thinking does not apply to judgments of major businesses.

Judging from the results of the above studies and the broad application of the semantic differential, it may be concluded that it can be successfully used as a research tool in the present investigation. This brief review also suggests the versatility and diversity of the semantic differential. In fact, the semantic differential has been applied to studies in advertising research where the investigators were concerned with the effects of color on advertised products, the effect of titles on the significance of pictures, the influence of slogans on advertised products. 93 Mindak used the semantic differential to study brand image and to compare effectiveness of certain advertising appeals for example, the scientific appeal, the romantic appeal, and so on, in advertising a new cosmetic product on radio. 94 The semantic differential has also

930sgood, Suci, and Tarnenbaum, op. cit., pp. 299, 313-37.

94 William A. Mindak, "Fitting the Semantic Differential to the Marketing Problem," Journal of Marketing, XXV No. 2 (April, 1961), pp.2833, and William Mindak, $\mathrm{A}$ New Technique for Ueasuring Advertising Effectiveness," Journal of Marketing, XX No. 2 (April, 1956), pp. 367-378. 
been used extensively in the field of psychology dealing with verbal behavior, personality, therapy, and the dynamics of social attitudes. 95 other areas in which the semantic differential has been employed include studies of symbolism, aesthetic judgment, interpretation of sonar signals, speech and theatre related concepts, and many more. 96

This chapter was designed specifically to familiarize the reader with the various research tools used in this study and the application of these tools to a variety of exploratory investigations. A summary of the pertinent information contained in this chapter is presented in the subsequent section.

\section{A Summary of Pertinert Factors}

At the center of all investigation of personality lies the complex problem of the nature of the unit which accounts for individual differences in man's behavior. The problem of describing personality traits is further complicated by the inconsistent use of the term "trait." Dr. Raymond B. Cattel1, however, defined a trait of personality as being relatively permanent and broad reaction tendency.

A discussion of personality traits would be incomplete without a definition of personality as a whole. As might be expected, there are as

95James J. Jenkins, Wallace A. Russell, and George J. Suci, "An Atlas of Semantic Profiles for 360 Words," The American Journal of Psychology, LXXI No. 4 (December, 1958), pp. 688-699; ZEIla Luria, "A Semantic Analysis of a Normal and a Neurotic Therapy Croup," Journal of Abnormal and Social Psychology, LXIII No. 2 (March, 1959), pp. 216-220; and Osgood, Suci, and Tannenbaum, op. cit., pp. 272-299.

960sgood, Suci, and Tannenbaum, 1oc. cit.; Ray G. Smith, "Development of a Semantic Differential for Use with Speech Related Concepts," Speech Monographs, XXVI No. 4 (November, 1959), pp. 263-272; and Raymond G. Smith, "A Semantic Differential for Theatre Concepts," Speech Monographs, XXVII No. 1 (March, 1.961.), pp. 1-8. 
many definitions of personaity as there are authors on the subject. With this in mind the following definition, by Cattell, is advanced: Personality is that which permits one to predict what an individual will do in a given situation.

With the definitions of personality and personality traits as a framework it is now appropriate to review briefly some research in the field of personality and personality traits. Harriet Linton and Elaine Graham in their study of persuasibility, were concerned with identifying variables that were related to change of opinion in response to persuasive communications. They were also interested in determining the fundamental pattern of personality characteristics that seem to predispose an individual to accept or resist persuasion, influence, suggestion, and conformity in many kinds of situations. A large number of psychological tests were used to measure personality organization such as perceptional behavior, attitudes toward the self and the world, response to different personality test material, and response to different kinds of social influence. The study confirmed the notion that there exists an underlying tendency in an individual which affects his perception, cognitive processes, attitudes and values, and social behavior. In addition, the investigation pointed out that persuasibility was the product of certain underlying attributes of personality. In fact, personality patterns make a person more or less susceptible to influence in a wide range of situations, regardless of whether the influence arises from another person or from written communication.

In an effort to determine certain relationships between personality and communicative effectiveness of oral readers Shepherd and scherdel tested certain hypotheses. The following tenable conclusions were drawn from this study: 
1. That effective oral readers differ significantly on certain personality characteristics from both the ineffective oral reader and the normal college population.

2. The effective oral readers had a more individualistic attitude toward the aesthetic, social, and practical aspects of life than either of the ineffective readers or the normal college population.

3. The ineffective oral readers, on the other hand, did not differ significantly from the normal college population.

There were no consistent and deviant personality patterns evident by the ineffective oral readers.

Clyde W. Dow studied the personality traits of good speakers and tried to determine whether or not these speakers possessed a greater degree of these traits than the averaze or poor speakers. This study noted that the best speakers tended to be extraverted, dominant, selfsufficient, and more stable emotionally.

In still another personality study, Janis and Feshbach investigated anxiety predispositions associated with personality differences in responsiveness to fear-arousing communications. The results of this investigation tend to support the following general hypothesis:

When a relatively high degree of fear or anxiety is aroused by persuasive communication, the recipient will become stimulated. to develop defensive reactions which interfere with acceptance of the communicator's message.

Nunnally and Flaugher investigated the relationship of semantic habits to personality variables. The data in this study seems to support the notion that there is a relationship betreen semantic habits and inventory measures of personality. Finally, the work of Allport, Walker, and Lathers demonstrated that there are personality differences in written composition.

As in the above stulies, this present investigation employed some well known objective measuring instruments. Specifically, the measuring 
instruments used in this present study included the Cattell sixteen Personality Factor Questionnaire ( 16 P.F.) and Osgood's semantic differential. The 16 P.F. is an instrument designed to measure 16 dimensions of personality which have been derived empirically by Cattell and his associates. These dimensions, based on exhaustive factor analytic research, correspond to personality factors in objective tests and behavior rating. The $16 \mathrm{P} . \mathrm{F}$. attempts to cover the whole personality and is not some special measure such as neurotic or psychotic conditions. The 16 dimensions of personality determinable by this test are based on a considerable amount of research directed toward unitary, independent, and real-life situations where important source traits are discernible.

Each of the personality factors are independent of one another, which signifies they do not overlap in their meaning. In addition, the 16 P.F. has the highest possible reliability for the number of items contained in the questionnaire and the validity is high for the entire personality profile and not just a few selected items. Norms for the 16 P.F. have been developed for both college students and the general public. Norms for college studints are based on a larger sample than those for the general public. Evidence indicates that personality profile and distribution for college students differ significantly from that of the general public.

A brief summary of selected studies which employed the 16 P.F. will demonstrate and perhaps justify the use of this particular personality inventory in the present study. Investigators employing the 16 P.F. have demonstrated a definitive relationship between personality traits and human behavior such as smoking, reading ability and academic failure. For example, Cattell and Krug found a positive correlation between smoking and 
the personality traits: affectothymia, surgency, premsia, and the extraversion factor. On the other hand, the general personaljty description of good readers included introversion, emotional sensitivity, self-sufficiency, and to some extent radicalism and weak superego strength. Failing male college freshmen in Osman's study were characterized as dull, extraverted, suspecting, insecure, accepting, dependent upon others, unsure, and frustrated. In contrast, wollen college freslmen who withdrew failing were described as being dull, insecure, tense and excitable.

In conjunction with the 16 P.F. the present study employed Osgood's semantic differential. Basically, the semantic differential is a combination of word associations and scaling techniques designed to give an objective measure of connotative meaning. The semantic space generated by the semantic differential is arrived at by having individual rate concepts along graded scales, each having polar adjectives as end points. The connotative meanings of concepts are represented by their position in the semantic space, and they are distinguishable from individual to individual and from group to group.

The "evaluative," "potency," and "activity," factors are regarded by Osgood as being the principal dimensions of connotative meaning. Each dimension is measured by a seven point bipolar adjectival scale. The seven point scale permits quantitative comparison of the meaning of concepts for each respondent or groups of respondents. The respondent places a check on the seven point scale which most nearly describes the concept being judged. The semantic differential is regarded by many scholars to be a valid and reliable instrument which can generally be applied to the measure of connotative meaning.

Exploratory investigations which have employed the semantic differential technique are many and varied; however, a brief summary of such 
studies should serve to demonstrate tine versatility and diversity of this measuring instrument. Harry C. Triandis, for example, used the semantic difierential to study how certain joos and certain people are perceived by various groups of industrial workers. In another interesting appiication of the semantic differential deait with quantifying the degree of communication profile of the communicator and the communicatee, the evaluative dimensions of connotative meanings were more highly correlated than the potency and activity dimensions. From this study it was concluded that the communicators had been relatively successful in transmitting their views to the communicatees. In still another study the semantic differential was used to determine whether the public images of large companies were stereotyped. This summary of research studies should suggest the versatility and diversity of the semantic differential. With this rather comprehensive background material attention in Chapter III is focused upon the research methodology used in this present study. 
The preceding chapter covered the important factual background necessary for an understanding of personality, personality traits, and the effects of personality on the communication process. Also, the previous chapter focused upon the design, reliability, validity, and applicability of both the $16 \mathrm{P} . \mathrm{F}$. and the semantic differential to behavioral research. In line with this background information, the purpose of this chapter is to explain in detail the research methodology used in the present investigation. Specifically, the discussion focuses upon the experimental design, experimental procedure, research participants, selection and use of study instruments, duration of the experiment, and lastly, data preparation and statistical treatment.

The Nature and Procedure of the Research

One of the several tools utilized in the study was the experimental design. An experimental design is a specific plan for research having certain quantitative qualities. There are many types of experimental designs. Each of these designs are developed for specific purposes. They also have certain advantages and disadvantages, and they even have levels of efficiency. In most studies where the experimental design is considered as a research tool, the experimenter is basically interested in a comparison of variables used in the investigation. For example, how well does company oriented writing style elicit favorable responses as compared with another writing style, such as reader oriented writing. Through the 
choice of alternatives, a measurement is taken of the responses to the alternatives tested in such a manner that nothing in experimental design favors one alternative over another. The present experiment was concerned with the relationship between perception of written mass communication and personality. The details of the experimental design are presented below.

The Experimental Design

Specifically the experinental plan was so constmucted that responses to reader oriented advertising writing style could be compared to responses to company oriented advertising writing style. Recruitment advertisements structured with reader and company oriented writing styles comprised the experimental variables.

In an effort to make this comparison, the investigator utilized an experimental design known as the after-only plan. The after-only plan is so designed that the effects of the experimental variables are measured after the subjects have been exposed to the experimental variables. Here, reader and company oriented ads represent the independent variables and the responses to these ads constituted the dependent variables. A twophase experimental study was conducted. During the first phase, subjects received and responded to reader oriented variables, whereas in the second phase they received and responded to company oriented variables. Measurements were taken to ascertain students' reaction to each of the independent variables. Then comparisons were made between responses to reader viewpoint advertisements and company oriented recruiting messages. These comparisons served to either affirm or disaffirm the stated hypotheses. Specific purposes of the experiment were to investigate: 
1. Whether reader oriented advertisements were perceived more favorably than company oriented advertisements.

2. The effects of age, sex, college classification, and personality characteristics on the perception of written mass communication.

Each student read four recruitment advertisements. Two of the ads contained reader oriented writing and the other two contained company oriented copy. The four ads represented only two advertisers. The advertisements for each of the advertisers were identical in every respect except for the writing style of the message. That is, each advertiser's message that appeared in the experiment was presented as both reader and company oriented advertisement. Recruitment advertisements used in the present experiment were obtained from the College Placement Annual 1969. ${ }^{I}$ The names of the advertisers, however, were disguised to preclude any interference with testing the experimental variables. The experimental variables were alternated in such a fashion that 50 per cent of the subjects read one advertiser's message first and the other 50 per cent read the other advertiser's message first. The procedure for conducting the experiment is presented in the following section.

The Procedure for Conducting the Experiment

To obtain measures that were related to personality and its affect upon the perception of written mass communication, it was necessary to conduct the experiment in two phases. Both phases of the experiment were completed during the first few weeks of the 1969 summer session at Louisiana State University. Prior to conducting the experiment, however, the

${ }^{I_{C o l l e g e}}$ Placement Annual 1969 (Bethlehem, Pa.: The College Placement Council, Inc., 2968$)$, pp. I-695. 
researcher contacted each professor personally and asked his permission to use one and one-half hours of class time to obtain information on personality traits and responses to written mass communication. Ten of the 11 professors contacted agreed to cooperate in this investigation. During the first phase of the experiment, the researcher explained to the students that his study was important from the standpoint of enhancing the knowledge of communication theory. The investigator then said that the study would be conducted in two parts, and he asked for their cooperation in completing both a personality inventory and a semantic differential questionnaire during the first session. It was then explained to the students that the second session would only consist of completing a semantic differential questionnaire.

The personality survey and the semantic differential were given to students in their respective classrooms during the regular class period, and one and one-half periods were required to complete both phases of the experiment. It was, again, explained to students that the test represented a personality inventory and if they wished they could be excused from the experiment.

Most of the subjects completed the personality inventory in approximately 30 minutes. Upon completion of the personality test the semantic differential questionnaires were distributed to the participants. Attached to the semantic differential test was a questionnaire especially designed for student participants, containing six questions pertinent to age, sex, college classification, major field of study, type of employment desired, whether or not they were presently enrolled in Business Communication, Management 71, and whether or not they had previously taken the course Management 71. The questions relative to Business Communication served 
to eliminate students from the investigation who were either enrolled in the course Management 71 or who had previously taken the course Business Communication. These students were not included in the study because they had been conditioned and exposed to reader oriented writing in Management 71. It is generally believed that this exposure would result in response bias, if they were included in the analysis.

The semantic differential test booklet was arranged in such a way that the classification data sheet appeared as the first page of the booklet. The sequence of the remaining pages was as follows:

1. Instructions for rating the semantic differential scales.

2. The advertising message of one advertiser.

3. The semantic differential rating scale form.

4. The advertising copy of the other advertiser.

5. The rating scale form for the semantic differential.

The instructions and arrangement of the scales were identical to those suggested by Osgood, Suci, and Tannenbaum. However, the researcher explained the importance and method of semantic differential research to the subjects and asked them not to omit any of the rating scales. The subjects were requested to read the instructions; and if they had no questions, they were told to proceed at their normal speed. The researcher at this point asked the subjects to give their honest assessment of the advertising messages. The subjects were also requested to place their names on both the personality inventory and the semantic differential questionnaire. All experimental tests, both the personality inventory and the semantic differential, were administered by this investigator. On the average it took the subjects 15 minutes to complete the semantic differenm tial questionnaire. 
During the first phase of the experiment students read and gave their responses to recruitment advertisements which contained only reader oriented copy. To eliminate any possj.ble response bias the researcher administered the second phase of the experiment approximately one week later. It is generally believed that bias introduced by the advertising message disap.pears after a week or more. ${ }^{2}$ The investigator reminded the subjects of What he was doing and of its importance. After these comments the semantic differential test booklet which contained, in that order, instructions for rating the semantic scales, company oriented advertising copy, semantic differential rating scales form, company oriented advertising copy, and the rating scale form for the semantic differential were distributed. Students were again requested to read the instructions, and if they had no questions they were to proceed through the test at their own rate of speed. They were also reminded to give honest responses to each of the company oriented advertising messages.

After all of the students completed the semantic differential questionnaire during the second session the experimenter explained to the classes that the messages for each of the advertisers were identical except the ads they read and responded to at the first session contained reader oriented writing whereas the ads in session two contained company oriented writing. The researcher explained how reader oriented writing differed from company oriented writing. The real identity of the advertiser was revealed at this time and the investigator answered frankly any questions students had. As a final gesture the experimenter thanked each of the subjects for their cooperation in this empirical study. The selection of

${ }^{2}$ James F. Engel, Hugh G. Wales, and Martin R. Warshaw, Promotional Strategy (Homewood, Ill.: Richard D. Irwin, 1967), p. 267. 
recruitment ads and the development of reader oriented ads are discussed in the subsequent section.

Selection of Recruitment Ads and Development of Reader Oriented Ads

The first step in this study was very painstakingly to puruse 300 recruitment advertisements which appeared in the College Placement Annual 1969. Afterwards, the researcher selected two company oriented recruitment advertisements as a base for this investigation. The advertisers chosen were Montgomery Ward and Connecticut Mutual Life. Names of the advertisers were changed. This precaution was taken to avoid prejudicing the students' assessment of the ads in case they were familiar with the advertisers. The Montgomery Ward company name ras changed to Massey's and Connecticut Mutual Iife was changed to Dallas Mutual Iife. To the best of the researcher's knowledge these companies' names are fictitious. After the two advertisements were selected, the researcher then reconstructed these ads so that they contained reader oriented messages. This was accomplished by rewriting sentences so that the reader part of the advertisement received the greatest emphasis rather than the company viewpoint. That is, the reader was made the object of the advertising message by emphasizing the personal pronouns "you" and "your" and at the same time subordinating the company's name and the personal pronouns "we" and "our." This was done without seriously afrecting the meaning of the ads. Appendix A contains copies of each of the advertising messages used in this experiment. The procedure described above was followed in developing the reader oriented advertising messares for both Dallas Mutual Iife and Massey's.

Each of the four advertisements appeared on plain white mimeograph paper with all of the art work removed for the experiment. The basic 
format of: the original advertisement was generally jreserved. The succeeding section presents a detailed analysis of the subjects that participated in the study.

An Analysis of the Research Participants

The omnipresent decision of what size sample to use in an investigation must be met at the outset. Usually this is a complex problem with several non-statistical facets, primarily involving availability of human resources. Thus, in an effort to assure an adequate and representative sample, the researcher chose students from 14 different classes. These classes included begirning and advanced students from sociology, psychology, management, marketing, economics, and speech. The specific classes that participated in this experiment are presented in Table. II. The original sample consisted of 4.17 undergraduate students and represented a good crosi section of students enrolled at Louisiana State University in widely divergent courses. The effective sample size, however, was 394 due to incomplete information on certain phases of the experiment and ineligibility. In total 23 subjects were eliminated from the study for reasons presented below.

Four subjects were eliminated from the investigation because they were either enrolled in Management 71 (Business Communications) or had previously taken the course Management 71. Thirteen subjects failed to particjpate in the second phase of the experiment; consequently, they vere eliminated. Five other respondents were omitted from the study because they failed to either understand the correct method of marking the semantic scales or else the adverticing messages had no fixed connotation for them. Due to non participation in the first phase of the experiment six subjects were excluded from the sample. The initial sample size was 
TABLE II

CLASSES USED IN EXPERIMENTAL STUDY

\begin{tabular}{|c|c|c|c|c|}
\hline course Title & $\begin{array}{l}\text { Course } \\
\text { Number }\end{array}$ & $\begin{array}{l}\text { Section } \\
\text { Number. }\end{array}$ & Participants & Percentage* \\
\hline Speech Fundamentals & 1 & 2 & 18 & 4.6 \\
\hline Speech Fundamentals & 1 & 3 & 18 & 4.6 \\
\hline Speech Fundamentals & 1 & 4 & 21 & 5.3 \\
\hline $\begin{array}{l}\text { Economic Principles } \\
\text { and Problems }\end{array}$ & 51 & $I$ & 19 & 4.8 \\
\hline $\begin{array}{l}\text { Economic Principles } \\
\text { and Problems }\end{array}$ & 52 & 1 & 16 & 4.1 \\
\hline $\begin{array}{l}\text { Management Principles } \\
\text { and Policies }\end{array}$ & 59 & 1 & 37 & 9.4 \\
\hline Principles of Marketing & 60 & 1 & 38 & 9.6 \\
\hline $\begin{array}{l}\text { Introduction to } \\
\text { Psychology }\end{array}$ & 51 & $I$ & 78 & 19.8 \\
\hline Introductory Sociology & 51 & 1 & 29 & 7.4 \\
\hline Introductory Sociology & 51 & 2 & 49 & 12.4 \\
\hline Current Social Problems & 62 & 1 & 22 & 5.6 \\
\hline The City & 81 & 1 & 22 & 5.6 \\
\hline The Family & 104 & 1 & 17 & 4.3 \\
\hline $\begin{array}{l}\text { Personnel Management- } \\
\text { Industrial Relations }\end{array}$ & 167 & 1 & 10 & 2.5 \\
\hline Total & & 14 & 394 & 100.0 \\
\hline
\end{tabular}

*Percentages do not add to total due to rounding. Source: Louisiara State University, Summer, 1969. 
further reduced because five participants in the first phase of the investigation completed only the personality inventory and did not complete the semantic differential questionnaire.

Two hundred and forty-seven subjects vere men and 147 were women. The age distribution was 17 to 44 years, with a mean age of 20.95 years. This is significant since Cattell's mean age for his college population was 21 years of age. It is interesting to note the majority of these subjects were sophomores, juniors and seniors. 3 Reference will be made from time to time concerning these demographic characteristics, and their significance will be discussed in detail in the analysis presented in Chapter IV. At the present, however, an explanation of the measuring devices used in this study is in order.

\section{Selection of Study Instruments}

In an attempt to study the relationship of personality to the perception of written communications it was necessary to employ two measuring devices, namely the Cattell Sixteen Personality Factor Questionnaire and. osgood's semantic differential. The selection of these study instruments are discussed in the subsequent sections.

The Selection of the Personality Test

The personality test used in the present study is the product of painstaking research, which included reviewing many studies that utilized some form of personality assessment, discussions with faculty members of the Psychology Department at Louisiana State University, and the use of the Fifth and Sixth editions of the Mental Yeasurements Yearbook. The

3 The number of students in each classification were: 63 (Freshmen); 107 (Sophomores); 116 (Juniors); 101 (Seniors); and 7 (Special undergraduates). 
Mental Measurements Yearbook presents frank, critical test reviews written by competent testing specialists representing many disciplines and viewpoints. Most test reviewers are college professors in education and psychology, and most tests are reviewed by two or more individuals in order to secure a variety of viewpoints. The critical evaluation of each test that appears in the Mental Measurements Yearbook permits test users to select tests with greater discrimination. The Yearbook lists all tests known to be in print at the time it is submitted for publication. Each Mental Measurements Yearbook supplements earlier editions rather than replaces the previous edition. Consequently it becomes necessary at times to consult all of the yearbooks to obtain wanted information. Some specific objectives of the Yearbook are:

1. To provide test users with detailed and accurate information about the construction, validation, uses, and limitations of specific tests.

2. To suggest to test users better methods of arriving at their own appraisals of both standardized and nonstandardized tests in light of their particular values and needs. 4

Dr. Felicia A. Pryor, professor of psychology at Louisiana State University, was consulted, after the researcher had become familiar with some of the tests used in personality research, in an effort to select the most appropriate personality test for the present investigation. Dr. Pryor. suggested three possible test alternatives, namely, the Guilford-Zimmerman Tempermanent Survey, Cattell's Sixteen Personality Factor Questionnaire, and The California Test of Personality. Dr. Pryor also recommended that the researcher consult the Mental Measurement Yearbook for detailed information and critical reviews of each of these personality inventories.

${ }^{4}$ Oscar Krisen Buros, The Sixth Mental Measurements Yearbook (Highiand Park, New Jersey: The Gryphon Press, 1905), pp. xxviii-xxix. 
Based on the critical reviews of each of the recommended tests and the researcher's needs, the Cattell 16 P.F.--Form $C$ was tentatively selected as the study instrument. The 16 P.F. appeared to be one of the most comprehensive, reliable and valid personality inventories. In addition, it is considered to be the most complete and best factor-based personality survey available. 5

After the tentative decision to use the 16 P.F. was made, the researcher sought the advice of Dr. Ralph M. Dreger, professor of psychol. ogy at Louisiana State University, about the desirability of this test, because he had worked extensively with the 16 P.F. both academically and clinically. Dr. Dreger, after reviewing the researcher's proposed study, agreed that the 16 P.F. was the most appropriate of the three tests to use in the investigation.

The Psychology Department at Iouisiana State University ordered the 16 P.F. for the researcher. A copy of the 16 P.F. profile sheet appears in Appendix B.

The Semantic Differential Selection and Design

Since one of the stated purposes of this study was to determine whether or not reader oriented recruitment advertisement elicited more favorable responses than company oriented recruitment advertisement, it was clear that some objective measuring device was necessary. Consequently, the semantic differential was employed to measure these responses because it is an objective, reliable, valid, and general method for measuring connotative meaning of concepts. In practical application the semantic space generated by the semantic differential is arrived at by having individuals rate concepts along graded scales. The selection of both the 
concepts and the semantic scales is discussed in the following section. Selection of the Concepts. The selection of the concepts was the initial step in developing the semantic differential. These concepts were to be rated on a series of bipolar semantic scales. The concepts selected were those thought to be germane to the purpose and the validation of hypotheses set forth in this investigation.

Four recruitment advertisements (hereafter called concepts) were chosen to ascertain the degree of responsiveness to reader and company oriented advertising messages. The choice of recruitment advertisement, therefore, was directed by the attempt to obtain those which would be most useful experimentally. The concepts selected were:

1. Company oriented recruitment advertisement for Massey's.

2. Reader oriented recruitment advertisement for Massey's.

3. Dallas Mutual Life, company oriented advertisement.

4. Dallas Mutual Lif'e, reader oriented advertisement.

These concepts were used as stimuli for responses. Moreover, they make possible an intensive study of responses to reader and company oriented recruitment advertisements. Responses to these advertisements are reported in subsequent chapters.

As previously noted, fictitious names were created for both Connecticut Mutual Life and Montgomery Wara. These two fictitious companies were created because subjects often fail to use the negative sides of the semantic rating scales or graduate a concept negatively for large wellknown companies. 6 In this way, the researcher hoped to circumvent this tendency by using names which, although fictitious, seem to be authentic

6William A. Mindak, "Fitting the Semantic Differential to the Marketing Problem," Journal of Marketing, XXV No. 2 (April, 1961), p. 30 . 
and fit more logically and naturally into an individual's frame of reference.

Additional steps were taken to guard against response bias. First of all, each concept appeared on a separate sheet and behind it was a set of semantic scales. Secondly, the arrangement of the advertisements were alternated in such a way that half of the subjects rated the Massey's ad first and then the Dallas Mutual Life. The other half read and rated the Dallas Mutual Iife ad first and then Massey's. Finally, to insure uniformity in rating, the instructions asked respondents to evaluate these advertisements on the basis of their reaction to the writing style.

After the concepts were selected, the next step in designing the semantic differential was the selection of the bipolar adjectives-semantic rating scales. The painstaking procedure in selecting the bipolar adjectives is the subject of the next section.

Semantic Rating Scale Selection Procedure. Since the subjects were to rate concepts in a classroom setting it was decided to restrict the number of scales to twelve. These scales were selected from among 21 sciles used by Osgood, Suci, and Tannenbaum. 7 The scales were selected so that 12 scales would represent the Evaluation factor; the Potency factor was represented by four scales; two scales represented the Activity factor; and the Tautness, Receptivity, and Novelty factors were each represented by one scale. In the initial choosing of these scales consideration was given to their relevancy to the concepts being tested and the factor loading. The factor loading is an index of the extent to which scales measure the same dimension of meaning. Moreover, these scales were thought to be representative of the major dimensions of meanings.

7 Charles E. Oscood, George J. Suci, and Perry H. Tannenbaum, The Management of Meaning (Urbana, Ill.: University of Illinois Press, 1957), pp. 53-61. 
A pilot study, conducted on May 26, 1969, determined which of these 21 sciles best differentiated the concepts being judged. The scales, in the form and order in which they were used in the pretest are show in F'igure 3.1.

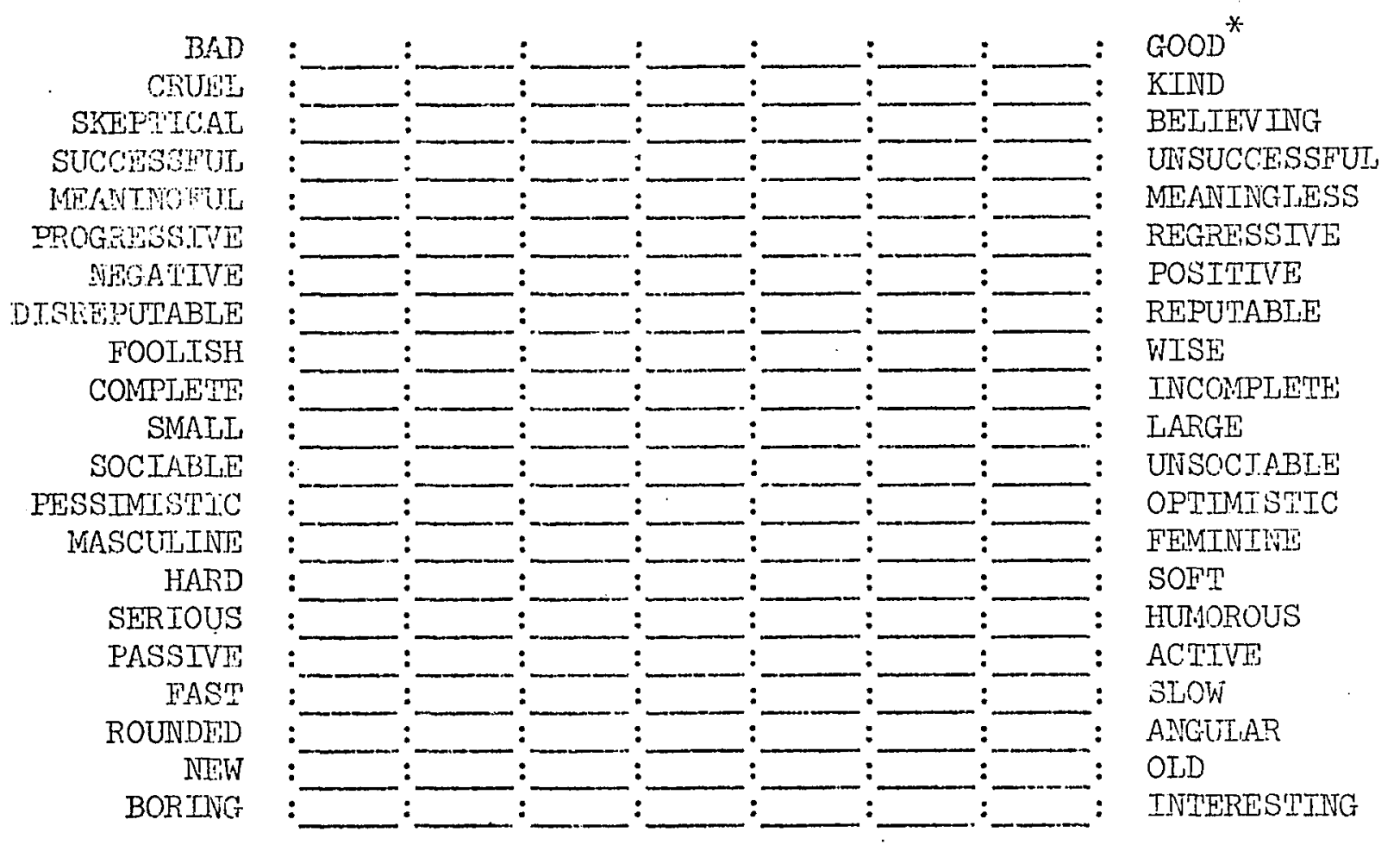

Figure 3.1: Semantic Scales Used in Pretest

*The above scales are rotated both vertically and horizontally.

Source: Osgood et. al., The Messurement of Meaning, pp. 53-61; scale arrangement primary.

The semantic rating scales were alternated in polarity direction to prevent the formation of position preference. That is, the 21 scales were presented in a fixed randomized order, with the scales representing each factor altornated so that some of the favorable (positive) adjectives ran fron I.efi to right and others from right to left. In addition to being rotated vertically the scales were also rotated horizontally. Thus, scales representing the same factors were not always together. The vertical and hoxizontal rotation was accomplished by utilizing a table of random 
numbers. Thus arrangement of the scales was identical to those suggested by osgood, Suci, and Tannenbaum. The rotation procedure, once again, was used to eliminate possible patterns and systems of responses to the concepts being rated.

Twenty undergraduate students from Louisiana State University at Baton Rouge were obtained on a volunteer basis to participate in the pilot study. Based on the results of the pretest, II semantic rating scales were eliminated. Ten scales were excluded because of high variances which indicated very little meaningful connotation between the concepts being judged and the semantic rating scales. It was later determined that one other scale was not the most representative of the concepts under investigation; consequently it was eliminated.

As a result of the pretest 12 scales were used in conducting the present experiment. The scale arrangement is presented in Figure 3.2.

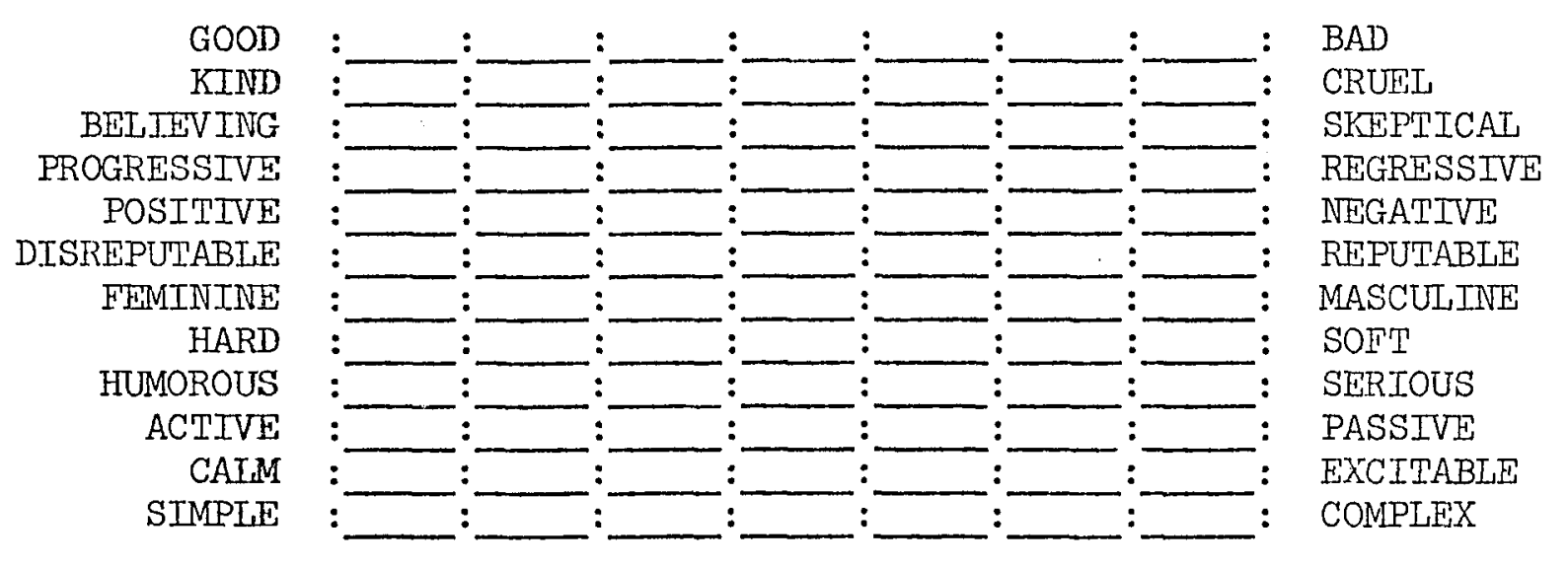

Figure 3.2: Form and Order of the Final semantic Scales

Source: Primary

The same procedures described above were used in rotating the semantic rating scales. In scoring the semantic differential the values one through seven were assigned to the respective gradients going from positive pole to negative pole. 
The factorial composition of the final scales used in this study is given in Table III. Each scale has a maximal loading on the factor it represents and minimal loading on the other two factors. The ideal scale is one which is heavily loaded on the factor it measures and minimally loaded on all other factors.

The scales which have high loadiñ on Evaluative factors, as shown in Table III, are: good-bad, kind-cmel, believing-skeptical, progressiveregressive, positive-negative, and reputable-disreputable. On the other, the scales masculine-feminine, hard-sof't, serious-humorous are weighted heavily on the Potency factor. The following scales are weighted heavily on the Activity factor: active-passive, excitable-calm, complex-simple.

TABLE III

FACTORIAI LOADING OF THE SEMAITIC SCALES

\begin{tabular}{lccc}
\hline & & Factors & \\
\cline { 2 - 4 } \multicolumn{1}{c}{ Scales } & Evaluative & Potency & Activity \\
\hline Good--Bad & 1.00 & .00 & .00 \\
Kind--Cruel & .52 & -.28 & .00 \\
Believing--Skeptical & .38 & -.06 & .02 \\
Progressive--Regressive & .43 & .08 & .24 \\
Positive--Negative & .48 & .00 & .07 \\
Reputable-Disreputable & .68 & -.02 & .05 \\
Masculine-Feminine & -.14 & .47 & .03 \\
Hard--Soft & -.24 & .97 & .00 \\
Serious--Humorous & .01 & .23 & .09 \\
Active-Passive & .17 & .12 & .98 \\
Excitable--Calm & -.15 & .03 & .26 \\
Complex--Simple & .17 & .05 & .25 \\
& & & \\
\hline
\end{tabular}

*The above scales are not rotated.

Source: Osgood et. al., The Measurement of Meaning, pp. 53-61. 
The entire final semantic differential questionnaires used in this investigation appear in Appendix C. Four identical semantic differential forms were used to conduct the experiment. However, the forms used to rate reader oriented writing were-odd numbered. For example, the reader oriented form for Massey's was numbered one and Dallas Mutual Iife reader oriented. form was numbered three. The company oriented rating form for Massey's was numbered two and Dallas Mutual Life company oriented semantic differential rating form was numbered four. Since the experiment was carried out in two sessions, two semantic differential test booklets were prepared. In the first test booklet, the classification data sheet preceded the instructions for scoring the semantic differential rating scales. The instructions for marking the semantic differential preceded the company oriented advertising messases, and the semantic rating scales in the second semantic differential test booklet. The time required to carry out the present experiment is discussed in the subsequent section.

Duration of the Experiment and Absenteeism

Two experimental conditions were created for the present experiment. The first condition was concerned with evaluating reader oriented recruitment advertisements. The second condition necessitated the judgment of recruitment advertisements which contained company oriented messages.

A total of about one and one half class periods were utilized per class in carrying out both phases of the experiment. It was believed that an approximate week's delay after each phase of the experiment would eliminate any possible response bias. During the second phase of the experiment some of the participants recalled reading similar recruitment advertisements; however, they were unable to remember how they had previously evaluated the ads on the semantic differential. Consequently response bias was eliminated or at least minimized. 
The experiment began on June 16, 1969, and was terminated on July 6, 1969. Several times throughout the experiment the researcher was fortunate, because of class scheduling to test as many as three classes in one day. This considerably shortened the duration of the experiment and permitted the experimenter to complete the present investigation before the end of the 1969 Summer Term.

Students' class attendance did not significantly interfere with the experimental procedure. Absenteeism, however, was more of an inconvenience than a problem in collecting the data for the present experiment. In fact, students that were absent from class during the first phase of the experiment were not permitted to participate in the second phase of the study. By eliminating these subjects from the investigation, administrative problems associated with the experimental procedure were held to a minimum.

on the other hand, students that did participate in the first experimental session but were absent from class during the second session were contacted to complete the latter phase of the experiment. The researcher prepared a list of absentees, contacted these students' professors and asked them to please distribute the semantic differential questionnaire to those students whose names appeared on the list. These absentees, for the most part, did not complete the semantic differential during the regular class session. They were allowed to keep the questionnaire and evaluate company oriented advertisements at their leisure. The completed semantic differential ratings were picked up the next day or as soon as they were available. Failure to get absentees to complete the second phase of the experiment accounted for most of the incomplete data noted abcre. 


\section{Data Preparation and Btatistical Treatment}

The data obtained from the personality inventory and the semantic differential were punched into IBM cards to facilitate the necessary calculations. The ratings given to one concept by one subject and the scores on the personality inventory for each subject made up one IBM punchedcard. Since each subject judged four concepts and was administered only one personality test, four IBM punched-cards were prepared for each particj.pant. These card.s were prepared on IBM 029 Key Punch and IBM 059 Verifier. The data collected during the three-week period of experimentation were processed at Louisiana State University's Computer Research center. The raw data were processed on an IBIS $360 / 60$ computer by means of a FORTRAN IV program. 8

The 394 subjects times 4 concepts times 12 semantic scales yielded a 18,912 item cube of data. The data nere sumned over subjects and concepts to give 1,576 scores for each scmantic scale. That is, each of the 12 scales elicited 1,576 responses ( $39 \div$ subjects times 4 concepts). An additional 6,304 items of information were generated from the personality inventory--394 subjects times 16 personality factors (6,304 items of data). The procedure for coding the data and the statistical techniques used to analyze the data are discussed in subsequent sections.

Identifying the Data

After each class completed both the.16 P.F. and the semantic differential, the answer sheets were coded to identify each student's responses to each of the four recruitment advertisements and the personality survey.

8 The FORTRAN IV program was written by Joan D. Bruno, the wife of the researcher. 
The semantic profile and the personality profile for each subject was numbered consecutively, from 1 to 394 , to identify the respondent.

The data comprising each response were punched in successive columns (fields) of an IBM card. For example, the classification data for each subject were punched successively into columins 1 through 6 . Specifically, the IBM punched-card format was as follows:

$$
\begin{aligned}
& \text { Columns } 1 \text {.. 6: Classification Data } \\
& 7 \text { - 8: Class Identificaition Number } \\
& 9 \text { - 10: Motivation Distortion Factor } \\
& 11 \text { - 42: Personality Proiile } \\
& 43 \text { - 54: Semantic Profile } \\
& 77 \text { - 79: Student Identification Number } \\
& \text { 80: Advertisement Iaentification Number }
\end{aligned}
$$

Students' responses to both semantic differentials and the personality inventory were quantified and transferred into IBM punched-cards. The other information, however, was merely coded and punched into the IBM card.

Statistical Treatment of the Data

The statistical comparisons of similarity and differences are based primarily upon 16 personality factors and semantic differentials. The raw scores for the 16 personality factors were converted to standard scores called sten scores. These sten scores are distributed over ten equal interval standard score points from one through ten, the average is fixed at 5.5 .9

Based on this system of scoring, respondents may score high, average (normal), or low on each of the 16 personality factors. For example, a sten score of five or six is considered as average "normal"; scores one

9 Raymond B. Cattell and Herbert W. Eber, Handbook for the Sixteen Personality Factor Questionnaire (Champaign Ili.: Institute for Personality and Ability Testing, 1957), p. 7 . 
through four are characterized as low; and scores seven through ten are considered as high. The high score (Sten 7-10) on each of the 16 personality factors corresponds to the description in Table I of Chapter II, and the low score (Sten 1-4) corresponds to the behavior at the opposite pole, listed at the right of this table. The average score (sten 5-6) indicates that neither of the bipolar personality factors is dominantly present in individual behavior. For example, an individual with a sten score of five or six for Factor A (reserved versus outgoing) would not be considered outgoing. Instead this individual is regarded as having a balanced mixture of the personality traits reserved and outgoing. Neither the reserved nor the outgoing personality trait is dominant. Thus, respondents for each of the 16 personality iactors were categorized as high, average, and low for statistical comparisons.

For purposes of analysis of semantic responses the mean values for the 12 semantic scales for each of the four concepts (advertisements) were computed for each personality group--high, average, and 1ow. This involved a comparison of 48 means and the corresponding personality factor ( 4 concepts time 12 scales).

To obtain measures of semantic similarity or differences between the mean values for each personality group within a personality factor the D statistic was computed for each semantic scale for each of the four concepts. Although the $D$ statistic provides an adequate index of relative difference, it does not, however, sufficiently represent statistical significance. Therefore, student's "t" statistic was used as the test of significant difference between the semantic mean value and each personality group. That is, the "t" statistic was computed for each semantic scale for 
comparisoni of high personality group to average personality group, average to low, and high to low.

Statisticans commonly accept a difierence as being significant if there are five or fewer chances out of a hundred of finding a difference due to chance alone. $\quad:$; being the case, a level of significance of 0.05 was used throughout this investigation to determine significant differences between semantic responses and personality factors. Specifically, if the semantic averages for each conc@pt within personality factors of high, average, or low differed at the 0.05 level of significance, the personality factor is considered as her:ing influenced the perception of the concepts.

In addition to $D$ and "t" statistical analysis, correlation coefficients were computed to measure the degree of relationship between semantic responses and age, sex, and college clessification. However, before discussing the relationship between personality characteristics and semantic responses and between demographic and semantic responses, a summary of the present chapter is given.

\section{Research Wethodolos. in Capsule Form}

All data pertaining to the analysis of personality and its effects upon responses to written communication were secured through empirical research by means of a personality survey and the semantic differential. The study, however, was accomplished with the aid of an after-only experimental design. The after-only experimental design measures the effect of experimental variables after subjects have been exposed to various alternatives.

To illustrate, each subject read four recruitment advertisements, two of which contained reader oriented messages and two contained company 
oriented advertising copy. The advertising messages served as the experimental variables, and it was necessary to carry out the experiment in two phases. During the first phase of the experiment students completed a personality survey and recorded their responses to reader oriented advertisements on the semantic differential. Approximately a week later subjects completed the second phase of the experiment, in which they responded to company oriented advertising messages.

The advertising copies used in the experiment were obtained from the College Placement Annual. 1969. The two advertisers were Montgomery Ward and Connecticut Mutual Life. Names of the advertịsers were disguised to prevent any interference with testing the experimental variables in case respondents had previous experience with these companies. In order to obtain contrasting company and reader oriented advertising messages, the researcher reconstructed the company oriented ads so that they contained reader oriented messages. This was accomplished by rewriting sentences so that the reader was made the objective of the advertising messages. The four advertisements were presented in the experiment on plain white mimeograph paper with all of the art work removed.

The research participants were students enrolled in the 1969 summer Term at Louisiana State University. To assure a representative sample, the researcher chose students from 14 different classes. These classes included beginning and advanced students from sociology, psychology, management, marketing, economics, and speech. In all there were 394 subjects who were taught by ten different instructors.

Data for the personality profile were secured by administering the Cattell Sixteen Personality F'actor Questionnaire. The semantic differential, with scaled values of one through seven, was used to measure 
responses to each of the four advertisements. Class attendance did not significantly interfere with the experimental procedure. Students that were absent from class during the first phase of the experiment were not allowed to participate in the second phase of the study. On the other hand, students that did participate in the first session but were absent during the second session were contacted to complete the latter phase of the experiment.

Students' responses to both the semantic differential and the personality survey were quantified and transferred into IBM punched-cards. The raw scores for the 16 personality factors were converted to sten scores. For purposes of analysis of semantic responses the mean values for the 12 semantic scales for each of the four advertisements were computed for each personality factor designatec as high, average, or low. The $D$ statistic was computed for the four advertisements within the personality factor rating of high, average, or low. The "t" statistic was conputed for each semantic scale for comparison of high personality factors to average personality factors, average to low, and high to low. In addition to $D$ and " $t$ " statistics, correlation coefficients were computed to measure the degree of relationship between semantic responses and the demographic data. Results of the experimental data are presented and discussed in the subsequent chapters. The data are discussed in terms of the research hypotheses. 
CHAPTER IV

AN ANALYSIS OF EXPERIMENTAL DATA RELATIVE TO MINOR HYPOTHESES

In this and the subsequent chapter experimental results are discussed. These chapters are devoted to substantiating or refuting the stated hypotheses of the present investigation. The primary hypotheses pertain to the relationship between personality traits and responses to written inass conmunication. The secondary hypotheses are designed to test: (I) the responsiveness to reader and company oriented recmuting advertisements, and (2) the relationship of demographic factors to semantic responses.

Before reporting on the primary hypotheses, however, it is believed essential to first analyze the semantic differential data as they are related to the secondary hypotheses. Therefore, the specific purpose of the present chapter is to relate experimental results to hypotheses four and five--minor hypotheses.

The minor hypotheses are tested first because the variables involved are limited and provide a maimentary framework for the analysis of the major hypotheses which contain an extremely large number of variables relative to the relationships between personality characteristics and responses to written mass communication. Since the variables of the minor hypotheses are limited they permit extensive use of visual semantic profiles in the subsequent analyses. Furthermore, testing the minor hypotheses first (especially the fourth hypothesis) provides the reader with an indication of how all respondents perceived the experimental 
advertisements ixrespective of their demographic characteristics and personality traits.

Experimental Results Relevant to Reader and Company Oriented. Advertisements

Since it is genecally believed that reader oriented writing will elicit more favorable responses than company oriented messages, hypothesis four will be examined in this section. The fourth hypothesis states:

Written recruiting advertisements presented as reader oriented message will induce more favorable response than company oriented messages regardless of personality characteristics.

To accomplish the stated purpose of this section the mean values for each of the 12 semantic rating scales are plotted for each of the four ads used in the experiment. The plotted mean averages will produce semantic profiles which will partially serve to affirm or disaffirm the above hypothesis.

Before discussing the data generated by the semantic differential a brief review of the scoring technique will prove valuable. Each subject made a check in one of seven positions on each of the 12 semantic rating scales for each concept. Scores of one to seven were assigned to the scale interval.

In original form the semantic differential generated a three dimensional matrix of scores: subjects by concepts by scales. When the individual scale scores are averaged over subjects a concept by scale matrix is obtained. This was done for each of the four concepts tested in this investigation. 
Table IV represents the means, standard deviations and " $z$ " values of such a matrix, mentioned above, for Massey's reader and company oriented recruitment advertisements. It can be seen from Table IV that the average scores for reader and company oriented advertising messages differed on the various semantic rating scales; however, virtually all of them indicated that both were favorably perceived, because none of the mean scores were 5.0 and over. The possible ranges of mean scores is 1.0 to 7.0. The smaller the score the closer the judgment is toward the favorable side of the scale. Larger scores, on the other hand, are projected toward the negative or unfavorable side of the scale. The midpoint or the neutral position of the scale is 4.0 . This neutral position signifies that respondents possessed no mental concept of the recruitment ads after receiving the message stimuli.

The ratings from Table IV demonstrate a number of things. First, it indicates that Massey's company oriented advertising message was perceived slightly more favorably than its reader oriented ad. The mean rating of the former on five of the I2 scales was cnly one, and three, decimal points smaller than the reader oriented message. In fact, four of the five were only one decimal point smaller.

In contrast, the reader oriented message had four scale ratings that were judged slightly better than the company oriented message. In examining Table IV, it will be noted that all of the standard deviations for the company oriented advertising message were smaller than the standard deviations for the message presented from the reader's viewpoint. This indicates that the company oriented message has the most representative means. The generally favorable standard deviations, mean scores and the limited 


\section{TABLE IV}

SEMANTIC RATING SCALES" AVERAGES, STANDARD DEVIATIONS, AND " $z$ " VAIUES FOR MASSEY'S READER AND COMPANY ORIENIED RECRUITIVENT ADVERTISEMENTS

\begin{tabular}{|c|c|c|c|c|c|c|c|}
\hline Factor ${ }^{1}$ & $\begin{array}{l}\text { Scale } \\
\text { Number }\end{array}$ & Semantic Scales & $\begin{array}{l}\frac{\text { Mean V }}{\text { Reader }} \\
\text { Oriented }\end{array}$ & $\begin{array}{l}\text { es } \\
\text { Company } \\
\text { Oriented }\end{array}$ & $\frac{\text { Standara }}{\text { Reader }}$ & 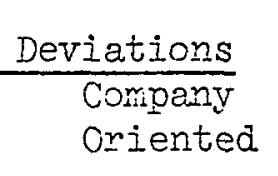 & "z" Values ${ }^{2}$ \\
\hline$E$ & 1 & Good-Bad & 2.8 & 2.7 & 1.5 & 1.4 & \\
\hline$E$ & 2 & Kinà-Cruel & 2.9 & 2.9 & 1.3 & 1.2 & \\
\hline $\mathrm{E}$ & 3 & Believing-Skeptical & 3.5 & 3.1 & 1.8 & 1.6 & 2.46 \\
\hline $\mathrm{E}$ & 4 & Progressive-Regressive & 2.3 & 2.2 & 1.3 & 1.2 & \\
\hline$E$ & 5 & Positive-Negative & 2.1 & 2.1 & 1.3 & 1.3 & \\
\hline$E$ & 6 & Reputable-Disreputable & 3.2 & 3.1 & 1.7 & 1.5 & \\
\hline $\mathrm{P}$ & 7 & Masculine-Feminine & 3.2 & 3.3 & 1.3 & 1.1 & \\
\hline$P$ & 8 & Hard-Soft & $3 \cdot 3$ & 3.4 & 1.6 & 1.4 & \\
\hline $\mathrm{P}$ & 9 & Serious-Humorous & 2.7 & 2.9 & 1.5 & 1.4 & \\
\hline $\mathrm{A}$ & 10 & Active-Passive & 2.2 & 2.2 & 1.4 & 1.3 & \\
\hline A & 11 & Excitable-Calm & 2.9 & 2.8 & 1.7 & 1.6 & \\
\hline A & 12 & Complex-Simple & 4.7 & 4.8 & 1.8 & 1.6 & \\
\hline
\end{tabular}

$I_{\text {E represents Evaluate Factor }}$

P represents Potency Factor

A represents Activity Factor

${ }^{2}$ only those values significant at the .05 level are given.

Source: Primary 
range from lowest to highest scores on each scale indicates that overall Massey's company oriented recruitment advertisement was better perceived than its reader directed ad.

However, the significance of this observation is determined in two parts. First, Osgood's generalized distance formula $\left(D=\sqrt{d_{i j}{ }^{2}}\right)$ which represents the difference between two patterns of rating was employed. That is, the reader may recall from Chapter II that the D statistic measures distance between semantic profiles. It is important to note, however, that the quantitative values generated by the $D$ statistic do not indicate: the intensity or the djrection of the connotative meaning. It merely signifies that the respondents felt distinctly different or alike about the concepts they rated. In spite of this lack of direction, the I statistic has merit for reinforcing the visual analysis. Osgood determined that for group data a shift as small as one-half of a scale unit is significant. 1

The $\mathrm{D}$ value obtained in the comparison of $\mathrm{Massey}^{\prime} \mathrm{s}$ reader and company oriented recruiting messages was .4472 . This can be interpreted as being small, and that respondents essentially perceived the advertisements alike. To test the significance of differences in the meaning between these two concepts, the standard normal distribution two-tail test was employed at the .05 level of significance. Since the .05 level of significance is used to test significant difference, this means that if at least one of the 12 semantic rating scales was significantly different, the entire concept is considered to be different. This concurs with osgood's thoughts

LCharles E. Osgood, George J. Suci, and Percy H. Tannenbaum, The Measurement: of Meaning (Urbana, Ill.: The University of Illinois Press, 1957), p. 328. See Chapter IV for evidence concerning confidence limits of the semontic differential. 
on the subject. In fact, he states: "i.f there is a significant difference on any one dimension, the overall test is significant." 2

The critical " $z$ " value was \pm 1.96 ; in other words, the critical region was between -1.96 and +1.96 . That is, statistically significant differences existed between semantic scales, if the calculated " $z$ " value is less than -1.96 or greater than +1.96 . It may be seen from Table IV, test respondents viewed the company oriented recruitment advertisement of Massey's more favorably than its reader viewpoint advertising appeal. This conclusion was dram from the fact that the company viewpoint ad had a semantic scale value that was significantly lower, which indicated that respondents viewed the ad connotatively better. This result supports a previous observation that Massey's company oriented advertising appeal was perceived more favorably than its reader oriented ad.

Figure D.I (in Appendix D) provides a visual profile of the mean responses and reveals more about the Massey's advertisements. It may be noted respondents felt that the reader directed ad was more potent than the company oriented ad. Such a conclusion was reached by noting the deeper penetration of the solid line toward the polar adjectives masculine, hard, and serious. In contrast, the subjects perceived the company directed recruiting message more positively on the evaluative scales, namely good, believing, and progressive. This pattern indicates that differences were relative to the gross masnitudes on the evaluative scales. Therefore, the connotation of the reader oriented advertising message was not completely unfavorable.

Further inspection of the semantic profile will indicate that none of the meaning ratings are on the negative side; and two are in the neutral

2. Ibid., p. 100. 
area (4). This further demonstrates that respondents had a relatively "good" connotation of both recruitment advertisements.

It is interesting to note that only one of the three active scales on the visual profile measuring both reader and company oriented messages had mean values located in the neutral position. Again, this implies that the subjects, on the average, had no mental concept of complex-simple in judging the ads.

This conclusion partially disproves hypothesis four. To fully disaffirm the hypothesis or partially affirm it, the data relative to Dallas Mutual Iiffe's recruitment advertisements must be inspected and analyzed. The experimental results of the Dallas Mutual Iife advertisements is the subject of the subsequent section.

Comparative Analysis of Dallas Mutual Iife's Recruitment Ads

As in the previous section the mean ratings for the Dallas Mutual Life recruitment advertisements were converted into semantic profiles for comparison. A glance at Figure D.2 seems to partially confirm the hypothesis that reader oriented recruitment advertisements are more favorably perceived than such advertisements presented from a company point of view. Again, looking at the vi.sual profile, it is apparent that Dallas Mutual Life's reader oriented recruiting message enjoys a slightIy more positive or favorable rating than its company directed recruitment advertisement. Even though only slight differences exist between the semantic patterns, the solid line of the reader viewpoint ad shows deeper penetrations toward the favorable side of the scale. These penetrations suggest that respondents viewed the reader oriented ad as good.

For the most part, subjects judged the Dallas Mutual Life reader oriented ad more positively on the potent and active scales and less 
positive on the evaluative scales. In contrast, the broken line of the company oriented recruiting message indicates that respondents judged it connotatively good relative to the evaluative scales. Overall both advertisements were perceived favorably, because none of the mean ratings were projected toward the right (negative) side of the visual profile. It is also interesting to note that subjects, on the arerage, did not possess a mental concept of excitable-calm and complex-simple for both ads. This observation was drawn from the neutral position of the scale ratings. The face validity of the above visual profile seems to infer that subjects perceived Dallas Mutual Life's reader criented ad with a small degree of approving connotation.

The significance of this tentative conclusion, however, needs quantitative support. Thus, an analysis of Table $V$ will serve to affirm or disaffirm the tentative conclusion.

The following table contains means, standard deviation scores, and "z" values for Dallas Mutual Iife's recruitment advertisements. It can be seen from Table $V$ that the mean ratings on six of the 12 semantic rating scales are slightly smaller for the recruitment advertisement presented in terms of the reader's interest. This result further suggests that the reader oriented ad of Dallas Mutual Life was more favorably received than its company directed ad. In contrast the scores by scales for the company oriented ad contained only four scores that were slightly smaller than the reader oriented message. By comparing the mean scores it may be seen that respondents judged both recruiting ads favorably; neither advertisement had a mean rating above five. This is significant because it reveals that students perceived both reader and company oriented recruitment advertisements for Dallas Mutual Life as being connotatively good. 
TABIE: V

SEMANTIC RATING SCALES' AVERAGES, STANDARD DEVIATIONS, AND " $z$ " VAIUES FOR DAIIAS MUTUAI LIFE'S READER AIND COMPANY ORIENTED RECRUITIENT ADVERTISEMENTS

\begin{tabular}{|c|c|c|c|c|c|c|c|}
\hline \multirow[b]{2}{*}{ Pactor ${ }^{1}$} & \multirow[b]{2}{*}{$\begin{array}{l}\text { Scale } \\
\text { Nunber }\end{array}$} & \multirow[b]{2}{*}{ Semantic Scales } & \multicolumn{2}{|c|}{ Mean Values } & \multicolumn{2}{|c|}{ Standard Deviations } & \multirow[t]{2}{*}{ "z" Valuese } \\
\hline & & & $\begin{array}{l}\text { Reader } \\
\text { Oriented }\end{array}$ & $\begin{array}{l}\text { Company } \\
\text { Oriented }\end{array}$ & $\begin{array}{l}\text { Reader } \\
\text { Oriented }\end{array}$ & $\begin{array}{l}\text { Company } \\
\text { Oriented }\end{array}$ & \\
\hline $\mathrm{E}$ & 1 & Good-Bad & 2.3 & 2.2 & 1.3 & 1.2 & \\
\hline$E$ & 2 & Kind-Cruel & 2.8 & 2.8 & 1.3 & 1.2 & \\
\hline$E$ & 3 & Believing-Skeptical & 2.7 & 2.5 & 1.6 & 1.3 & \\
\hline$E$ & 4 & Progressive-Regressive & 2.3 & 2.3 & 1.3 & 1.1 & \\
\hline $\mathrm{E}$ & 5 & Positive-Negative & 2.1 & 2.2 & 1.3 & 1.2 & ' \\
\hline $\mathrm{E}$ & 6 & Reputable-Disreputable & 2.8 & 2.7 & 1.7 & 1.6 & \\
\hline $\mathrm{P}$ & 7 & Mascuiine-Feminine & 3.2 & 3.5 & 1.2 & 1.0 & -3.84 \\
\hline $\mathrm{P}$ & 8 & Herd-Soft & 3.4 & 3.7 & 1.4 & 1.3 & -3.02 \\
\hline $\mathrm{P}$ & 9 & Serious-Humorous & 2.0 & 2.2 & 1.2 & 1.2 & -2.33 \\
\hline A & 10 & Active-Passive & 2.5 & 2.8 & 1.5 & 1.5 & -2.81 \\
\hline$\therefore$ & 11 & Excit_able-Calm & 4.1 & $4 \cdot 3$ & 1.8 & 1.6 & \\
\hline$A$ & 12 & Complex-Simple & 4.1 & 4.0 & 1.7 & 1.6 & \\
\hline
\end{tabular}

$I_{\text {E represents Evaluative Factor }}$

$P$ represents Potency Factor

A represents Activity Factor

${ }^{2}$ only those values significant at the .05 level are given.

Source: Frimary 
of special interest is the fact that the staridard deviations for both recruiting messages are consistently small. These small values of the standard deviation are significant because they demonstrate the high degree of uniformity as well as homogeneity in the respondents' judgment of the experimental variables. Moreover, the small standard deviation reinforces the confidence with which the results of the present analyses are reported. Undoubtedly, the greatest difference between the reader and company oriented advertisements of Dallas Mutual Life is relative to the mean values on the potency and the activity scales. The $D$ value for these two advertisements was .6557 . The magnitude of this $D$ value indicates that significant difference existed between the connotative meaning of reader and. company oriented recruiting messages. An inspection of Table V., however, reveals that Dallas Mutual Life's reader oriented ad was viewed more propitiously than its company viewpoint advertising message. Again, this conclusion was ascertained from the large accumulation of significant " $\mathrm{z}$ " values for the reader oriented ad. This result affirms the initial observation and partially confirms the hypothesis that reader oriented writing elicits more favorable responses than company oriented writing. The implication of this partially disproven hypothesis will be discussed after a composite view of all four recruitment advertisements is presented.

Composite View of Reader and Company Oriented Ads

The succeeding analysis will compare and contrast each of the four experimentally tested recruitment advertisements. A composite visual profile of these recruiting ads is presented in Figure D.3.

It is interesting to note that respondents, on the average, perceived all four experimental advertisements with a high degree of 
approving connotation. An additional observation may be drawn from the overall response patterms for all advertisements. These patterns indicated that the groatest differences among the recruiting messages were relative to the gross magnitude on the first three evaluative scales. Beyond that the variation in semantic patterns is not readily distinguishable. In fact, many of the patterns cluster together and occasionally disperse among the activity scales.

It is significant to note among the four advertisements iested that respondents felt slightly more favorable toward Dallas Mutual Iife's company oriented advertisement on the evaluative scales, but it is surprising that subjects judged it less connotatively strong and less active. In comparing only the response patterns for reader oriented ads, subjects considered Dallas Mutual Life somewhat better than its counterpart-Massey's. One might expect such a disparity, since Massey's ad partially disaffirmed hypothesis four. The most obvious disparity between the company oriented advertisements existed on the basis of good and. strong. Dallas Mutual Iiffe's response pattern on the evaluative scale enjoyed smaller mean values than its companion--Massey's. Conversely, Massey's was considered somewhat more potent and active and less good than Dallas Mutual Iife.

A quantitative examination of the experimental concepts revealed that only five of the $4 \dot{8}$ mean scale values recorded in Table VI were in the neutral range of four. These ratings, however, only appeared on the active scales (excitable-calm and complex-simple) which suggests a lack of connotative meaning. It is noteworthy that of the 48 mean ratings only 12 fell within the range of 3.1 to 3.7. Nearly all of the mean ratings within this range appeared on two semantic rating scales-- 
TABLE VI

COMPOSITE VIEW OF MEAN VALUES, AND STANDARD DEVIATIONS FOR FOUR EXPERIMEIVTAL ADS

\begin{tabular}{|c|c|c|c|c|c|c|c|c|c|c|}
\hline \multirow[b]{2}{*}{ Factors } & \multirow{2}{*}{$\begin{array}{l}\text { Scale } \\
\text { Number }\end{array}$} & \multirow[b]{2}{*}{ Semantic Scales } & \multicolumn{2}{|c|}{ Mean Values } & \multicolumn{2}{|c|}{ Mean VaIues } & \multicolumn{4}{|c|}{ standard Deviations } \\
\hline & & & $* A \bar{d} 1$ & Ad 3 & $A d 2$ & $\operatorname{Ad} 4$ & $\overline{\mathrm{Ad} 1}$ & $\mathrm{Ad} 3$ & Ad 2 & Ad 4 \\
\hline$E$ & 1 & Good-Bad & 2.8 & 2.3 & 2.7 & 2.2 & 1.5 & 1.3 & 1.4 & $I .2$ \\
\hline $\mathrm{E}$ & 2 & Kind-Cruel & 2.9 & 2.8 & 2.9 & 2.8 & 1.3 & 1.3 & 1.2 & 1.2 \\
\hline $\mathrm{E}$ & 3 & Believing-Skeptical & 3.4 & 2.7 & 3.1 & 2.5 & 1.8 & 1.6 & 1.6 & 1.3 \\
\hline$E$ & 4 & Progressive-Regressive & 2.3 & $2 \cdot 3$ & 2.2 & 2.3 & 1.3 & 1.3 & 1.2 & $I . I$ \\
\hline $\bar{E}$ & 5 & Positive-Negative & 2.1 & 2.1 & 2.1 & 2.2 & 1.3 & 1.3 & 1.3 & 1.2 \\
\hline$E$ & 6 & Reputable-Disreputable & 3.2 & $2 . \overline{8}$ & 3.1 & 2.7 & 1.7 & 1.7 & 1.5 & 1.6 \\
\hline $\mathrm{P}$ & 7 & Masculine-Feminine & 3.2 & 3.2 & 3.3 & 3.5 & 1.3 & 1.2 & 1.1 & 1.0 \\
\hline $\mathrm{P}$ & 8 & Hard-Soft & 3.3 & 3.4 & 3.4 & 3.7 & 1.6 & 1.4 & 1.4 & 1.3 \\
\hline $\mathrm{P}$ & 9 & Serious-Humorous & 2.7 & 2.0 & 2.9 & 2.2 & 1.5 & 1.2 & 1.4 & 1.2 \\
\hline A & 10 & Active-Passive & 2.2 & 2.5 & 2.2 & 2.8 & 1.5 & 1.5 & 1.3 & 1.5 \\
\hline A & 11 & Excitable-Calm & 2.9 & 4.1 & 2.8 & 4.3 & 1.7 & 1.8 & 1.6 & 1.6 \\
\hline A & 12 & Complex-Simple & 4.7 & 4.1 & 4.8 & 4.0 & 1.8 & 1.7 & 1.6 & 1.6 \\
\hline
\end{tabular}

*Ad 1--Massey's Reader Oriented Ad

Ad 3--Dallas Mutual Life's Reader Oriented Ad

Ad 2--Massey's Company Oriented Ad

Ad 4--Dallas Mutual Life's Company Oriented Ad

Source: Primary 
masculine-feminine and hara-soft. This consistency demonstrates the nearly indistinguishable perception between reader and company oriented. advertising messages. The mean ratings which fell in the range of three to four comprised only one fourth of the 48 computed mean scale values. This significant finding further attests to the high degree of perceived favorableness for the experimentally tested recruitment advertisements. Although both reader oriented ads were propitiously perceived by respondents, it is interesting to note that the Dallas Mutual Life's ad. enjoyed the greatest degree of popularity. Moreover, a significantIy high D value of 10.24 further demonstrated the perceived dissimilarity between the reader oriented advertisement. In contrast a comparison of company oriented ads revealed that both enjoyed an equal number of small mean scale values. However, respondents felt significantly different about them relative to the $\mathrm{D}$ value of $21.8 \mathrm{I}$, which denoted the dissimilarity.

No attempt was made to compute " $z$ " values among the mean scores in order to compare one ad against the other. It is not the purpose of this investigation to determine statistically which one of the four experimental tested advertisements was most favorably perceived, but rather it is the object of this section to ascertain whether or not reader oriented advertisements elicit more praiseworthy responses than company viewpoint advertisements.

Implications of Experimental Results

As previously stated, hypothesis four was partially affirmed and partially disaffirmed. The situation surrounding hypothesis four may be attributable to several factors. 
The f'irst of these possibilities is that even though the Massey's experimental advertising messages did adequately reflect reader and company oriented writing, the difference between these two writing styles may have been too subtle for respondents to make a sharp distinction between the styles. When the company oriented advertisement was reconstructed to conform to reader viempoint writing the meaning of the original advertising message was not altered in any manner. Since the company oriented ads, for the most part, did make effective use of the we attitude, students, in general, could not significantly distinguish between the two writing styles, because they both had favorable appeal. The reader oriented advertising message explicitly demonstrated the you attitude, whereas the company oriented message subtly implied the same orientation, thereby creating a situation that was indistinguishable. For instance, note the following passazes:

\section{Company Oriented}

This is the kind of growth that means fast-moving advancement opportunities-in virtually every professional category. opportunities that include annual performance appraisals, liberal bonuses that range up to $200 \%$ of base salary, a modern benefit program, and much more.
Reader Oriented

This is the kind of growth that can make your advancement opportunities move fast--in virtually every professional category. You'll find that Massey has a lot to offer you. Your opportunities include annual performance appraisals, liberal. bonuses that range up to $200 \%$ of your base salary, a modern benefit program designed especially for you to build on, and much more.

In contrast, the advertising copy for Dallas Mutual Life clearly presented both reader and company oriented viewpoints. Therefore, respondents were able to make a sharp aistinction in the writing style. This being the case, subjects, of course, judged the reader oriented message most favorably, thus substantiating the general belief that reader viewpoint writing elicits more laudable responses than "we" viewpoint writing. 
Another possibility is that researchers have found, in advertising context, that subjects are often reluctant to use the negative side of the semantic continuum or graduate a concept negatively. 3 This reluctancy to evaluate an advertisement negatively may have also accounted for the favorable perception of all the experinental concepts. The writer seems to think that students, in general, feel that since advertisements are prepared by a professional staff of copywriters, they must be good; and they generally are good. This feeling toward advertising may be a carryover from the belief that students usually have about published materials-if it is published, surely it must be true, and so on. This is not to say that respondents are unable to make intelligent judgments as to the level of desirability of a company's advertisement. Respondents are, however, reluctant to judge a concept undesirable, again, feeling that if it is advertised, it must be good.

\section{Analysis of DemoEraphic Factors}

In order to ascertain whether demographic factors are related to semantic responses, the information produced by the semantic differential was classified according to sex, age, and college classification. As in the previous analyses, the four concepts are compared to determine whether such demographic factors do generate more favorable responses toward reader oriented advertisements than toward company directed advertisements. In addition, hypothesis five will be examined in the following sections. The fifth hypothesis, to reiterate, states: Demographic factors such as sex, age, and college classification are influential in generating more favorable

3William A. Mindak, "Fitting the Semantic Differential To The Marketing Problem," Journal of Marketing, XXV, No.2 (April, 1969). 
responses for reader oriented recruitment advertisements than for company oriented recruitment advertisement.

Sex Differences In Semantic Responses

The semantic patterns in Figure $D .4$ are similar and move in the same general direction from scale to scale. This uniformity indicates that both males and females generally agreed on the connotative meaning of both reader and company oriented recruitment advertisement for Massey's. In general, all of the profiles are favorable; that is, they are plotted on the right side of the continuum.

A glance at Figure D.5 indicates that women consistenly judged the experjmental concepts more favorably on evaluative factors than men. However, what is particularly interesting is that no marked sex differences in the direction along the polar continuum of the scales were noted. Both males and females showed differences in the same direction. In no instance were there any apparent differences for males and females in the opposite direction. They never crossed each other on the negative end of the continuum. Senantic differential average scores on reader and company oriented ads by sex are shown in Table VII.

The D statistic was computed for males and females for each of the experimental stimuli to ascertain perceived differences between sexes. The objective D measure indicated that the sexes' connotation of Massey's reader oriented ad was significantly different $(D=2.00)$. The connotation of Massey's company directed message and Dallas Mutual Life's reader oriented advertisement was identical with a $D$ value of 1.81 . Although the $D$ values are identical it further shows that men and women felt differently about the experimental stimuli. The connotative meaning of Dallas Mutual Life's company viewpoint writing for both sexes was more 


\section{TABLE VII}

SEMAINTIC DIFFERENTIAI AVERAGE SCORES ON READER AND COMPANY ORIENTED ADS BY SEX

\begin{tabular}{|c|c|c|c|c|c|c|c|c|c|c|}
\hline \multirow[b]{3}{*}{ Factors } & \multirow{3}{*}{$\begin{array}{l}\text { Scale } \\
\text { Number }\end{array}$} & \multirow[b]{3}{*}{ Semantic Scales } & \multicolumn{4}{|c|}{ Reader Oriented } & \multicolumn{4}{|c|}{ Company Oriented } \\
\hline & & & Male & Female & Male & Female & Male & Female & Male & Femaie \\
\hline & & & $\overline{\operatorname{Ad~I}} *$ & $\overline{\mathrm{Ad} \mathrm{I}}$ & $\overline{\mathrm{Ad} 3}$ & $\overline{\mathrm{Ad} \mathrm{3}}$ & $\overline{\mathrm{Ad} 2}$ & $\overline{\mathrm{Ad} \mathrm{2}}$ & $\overline{\mathrm{Ad}} \div$ & $\overline{A d ~} 4$ \\
\hline$E$ & 1 & Good-Bad & 2.8 & 2.8 & 2.3 & 2.2 & 2.8 & 2.5 & 2.3 & 2.1 \\
\hline $\mathrm{E}$ & 2 & Kinä-Cruel & 3.0 & 2.6 & 2.9 & 2.6 & 3.0 & 2.6 & 2.9 & 2.6 \\
\hline$E$ & 3 & Believing-Skeptical & 3.3 & 3.4 & 2.8 & 2.6 & 3.3 & 2.8 & 2.6 & 2.3 \\
\hline $\mathrm{E}$ & 4 & Progressive-Regressive & 2.3 & 2.2 & 2.4 & 2.3 & 2.3 & 2.0 & 2.3 & 2.1 \\
\hline $\mathrm{E}$ & 5 & Positive-Negative & 2.1 & 2.0 & 2.2 & 2.0 & 2.2 & 1.9 & 2.2 & 2.1 \\
\hline $\bar{E}$ & 6 & Reputable-Disreputable & 3.1 & 3.4 & 2.8 & 2.9 & 3.2 & 3.1 & 2.7 & 2.6 \\
\hline $\mathrm{P}$ & 7 & Masculine-Feminine & 3.1 & 3.5 & 3.2 & 3.3 & 3.1 & 3.5 & 3.5 & 3.5 \\
\hline $\mathrm{P}$ & 8 & Hara-Soft & 3.1 & 3.6 & $3 \cdot 3$ & 3.4 & 3.2 & 3.5 & 3.7 & 3.7 \\
\hline $\mathrm{P}$ & 9 & Serious-Humorous & 2.6 & 2.9 & 2.0 & 2.1 & 2.8 & 3.0 & 2.2 & 2.2 \\
\hline A & 10 & Active-Passive & 2.2 & 2.1 & 2.5 & 2.5 & 2.2 & 2.1 & 2.7 & 2.9 \\
\hline A & 11 & Excitable-Calm & 2.9 & 3.0 & 4.2 & 3.9 & 2.8 & 2.8 & 4.3 & 4.3 \\
\hline A & 12 & Complex-Simple & 4.8 & 4.6 & 4.2 & 4.0 & 4.8 & 4.8 & 4.1 & 3.8 \\
\hline
\end{tabular}

*Ad 1--Massey's Reader Oriented

Ad 3--Dallas Mutual Life's Reader Oriented

Ad 2--Miassey's Company Oriented

Ad 4--Dallas Mutual Life's Company Oriented

Source: Primary 
similar than for any of the concepts, with a computed D measure of 1.60 . Both sexes, however, exhibited a significant difference in their judgment of the experimental stimuli.

Because of sample variations in the comparison of demographic factors to semantic responses, the " $t$ " test was employed in this phase of the investigation. However, to test the significance of differences in the meanings of the concepts between sexes for each of the scales, the one tail " $t$ " test was utilized. 4 The " $t$ " test, or critical ratio technique, automatically indicates the significance of the difference between the two groups. In comparing the male and female connotative meanings of the four experimental concepts, the critical "t" value was 1.645. That is, if the calculated " $t$ " was less than or equal to -1.645 men responded more favorably than women. If, on the other hand, the computed " $t$ " score was greater than or equal to +1.645 females responded more favorably than males:

In examining Table VIII it may be noted that a significant difference existed for every concept. A further inspection of the table reveals that, overall, men reflected more propitiously and stronger connotations relative to all recruiting messages. Although men generally viewed each of the four recruiting ads more favorably than women, it should be noted that they consistently thought that reader oriented advertisements were

${ }^{4}$ Procedurally, the following formula was used to compute the " $t$ " values:

$$
t=\frac{x_{1}-x_{2}}{s a}=\frac{x_{1}-x_{2}}{\sqrt{\frac{n_{1} s_{1}^{2}+n_{2} s_{2}^{2}}{n_{1}+n_{2}-2}} \sqrt{\frac{n_{1}+n_{2}}{n_{1} n_{2}}}}
$$

The null hypothesis that $M_{1}=M_{2}$ was tested ageinst the alternatives that $M_{1}-M_{2}<0$ and $M_{1}-M_{2}>0 . \quad M_{1}=$ males and $M_{2}=$ females. 
TABLE VIII

SIGNIFICANT DIFFERENCES IN CONNOTATIVE MEANINGS OF READER AND COMPANY ORIENTED RECRUITMENT ADVERTISEMENTS

\begin{tabular}{|c|c|c|c|c|c|c|}
\hline \multirow[b]{2}{*}{ Factors } & \multirow{2}{*}{$\begin{array}{l}\text { Scale } \\
\text { Number }\end{array}$} & \multirow[b]{2}{*}{ Semantic Scales } & \multicolumn{4}{|c|}{ Recruitment Advertisement } \\
\hline & & & Ad $1 *$ & Ad 2 & Ad 3 & Ad 4 \\
\hline$\underline{E}$ & 1 & Good-Bad & $-4.804 * *$ & $-3.746 * *$ & -1.522 & -0.587 \\
\hline$\Xi$ & 2 & Kind-Crue1 & 3.307 & 3.629 & $-4.909 * *$ & $-5.409 * *$ \\
\hline 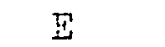 & 3 & Believing-Skeptical & $-2.330 * *$ & 1.017 & $-3.868 * *$ & $-2.675 * *$ \\
\hline $\mathbf{E}$ & 4 & Progressive-Regressive & $-1.883 * *$ & -0.318 & $-2.022 * *$ & -1.061 \\
\hline $\mathrm{E}$ & 5 & Positive-Negative & -0.386 & 1.176 & -0.406 & -0.663 \\
\hline$E$ & 6 & Reputable-Disreputable & $-2.497 * \%$ & -0.622 & $-5.527 * x$ & $-3.807 * *$ \\
\hline $\mathrm{P}$ & 7 & Masculine-Feminine & $-4 \cdot 325 * *$ & $-4.496 * *$ & $-2.339 * *$ & $-8.131 * *$ \\
\hline $\mathrm{P}$ & 8 & Hard-Soft & $-3.949 * x$ & $-4.494 * *$ & $-3.524 * *$ & $-5.511 * *$ \\
\hline$P$ & 9 & Serious-Humorous & $-6.040 * *$ & $-6.810 * *$ & $-9.145 * *$ & -1.572 \\
\hline A & 10 & Active-Passive & -1.081 & -1.069 & -3.514 & $-6.847 * *$ \\
\hline$A$ & 11 & Excitable-CaIm & $-6.315 * *$ & $-5.153 * *$ & 0.474 & $-1.889 * *$ \\
\hline A & 12 & Complex-Simple & $-3.383 \%$ & $-5.143 * *$ & 0.231 & -1.124 \\
\hline
\end{tabular}

*Ad 1--Massey's Reader Oriented.

Ad 2--Massey's Company Oriented

Ad 3--Dallas Mutual Life's Reader Oriented

Ad 4--Dallas Mutual Iife's Company Oriented.

Groups compared: 247 males--147 females

Degrees of freedom: $n_{1}+n_{2}-2=392$

Critical " $t$ " value-one tail test -1.645

**-Males responded more favorably than females.

Source: Primary 
better than the advertisements presented from a company viewpoint. In view of this, it may be concluded that male respondents find reader oriented advertisements more desirable than company viewpoint advertisements. Female respondents, on the other hand, do not indicate a significant preference for either reader or company oriented writing. Based on the data presented above, hypothesis five is partially given credence, because sex (at least, in the case of men) is influential in generating more favorable attitudes toward reader viewpoint writing than company oriented advertising copy. In order to further confirm hypothesis five, an analysis of age groups is presented in the subsequent section.

Relevancy of Age Groups to Connotative Meaning

In an attempt to further support the above hypothesis, the results of the semantic differential relative to age were divided into four groups. These four groups will be referred to simply as Groups I, II, III, and IV. Group I, the second largest group (36.0 per cent), was composed of ages 17 to 19, while Group II, the largest group (46.7 per cent), consisted of ages 20 to 22. The interval of ages 23 to 26 comprised Group III (12.2 per cent) and finally Group IV (5.3 per cent) contained the older and more mature respondents of ages 27 to 44 .

All age groups, as one might expect from the previous analyses, perceived both reader and company oriented recruiting advertisements in a very favorable manner. That is, all mean values for each advertisement appeared on the positive side of the continuum, with one exception-Massey's reader oriented ad had a calculated mean score of 5.1 for the semantic rating scale complex-simple. In fact, of the 192 mean scores 
shown in Table IX, less than 12 per cent had a value of four and above, and what is even more surprising is that these high values appeared primarily on two scales--excitable-calm and complex-simple. The reader will. notice that, for the most part, scale correspondence was very close. This is rather remarkable in view of the large number of respondents.

In an effort to explicate the semantic difference between reader and company oriented advertisements, the four age groups are analyzed by means of visual profiles, D statistics matrices, and the "t" test. Figures D.6 through D.9 (Appendix D) present a comparison of age groups' responses to each of the four experimental stimuli.

By comparing age groups I through IV's responses to the reader viewpoint recruiting message for Massey's (Figure D.6), it may be seen that all profile patterns are pointed in a positive direction. It is interesting to note, however, that Group II (ages 20 to 22) held the recruj.ting message of Massey's more in esteem than any of the other groups. Profile differences existed on eight of the 12 scales, all of which had deeper penetration toward the left side of the continuum reflecting the most favorable impression of the ad among age groups. Group III's (ages 23 to 26) judgment of the ad was slightly less positive. However, on the potency and activity scales Group III had the most positive connotation. Conversely, Group II had the greatest connotation of evaluative scales for the reader oriented writing style of Massey's recruiting message.

In contrast, the Massey's company oriented advertising copy (Figure D.7) revealed that on the evaluative scales Group I (ages 17 to 19) had the most positive connotation, whereas Group III had the best connotation of potency and activity for the recruitment advertisement. 
TABLE IX

SEMANTIC DIFEERENTIAI SCALE MEANS FOR EACH RECRUITMENT ADVERTISEMENT BY AGE GROUPS

\begin{tabular}{|c|c|c|c|c|c|c|c|c|c|c|c|c|}
\hline \multirow[b]{2}{*}{ Concepts--Advertisements } & \multicolumn{12}{|c|}{ Semantic Rating Scales } \\
\hline & 1 & 2 & 3 & L & 5 & 6 & 7 & 8 & 9 & 10 & 11 & $12 *$ \\
\hline \multicolumn{13}{|l|}{ Massey's Reader Oriented } \\
\hline Group 1 & 2.8 & 2.9 & 3.4 & 2.2 & 2.2 & 3.4 & 3.3 & 3.5 & 2.7 & 2.3 & 3.1 & 4.8 \\
\hline Group 2 & 2.7 & 2.7 & 3.3 & 2.2 & 1.9 & 3.1 & 3.3 & 3.3 & 2.9 & 2.1 & 2.8 & 4.8 \\
\hline Grcup 3 & 3.1 & 3.2 & 3.5 & 2.5 & 2.1 & 3.1 & 3.0 & 3.0 & 2.6 & 2.0 & 2.7 & 4.3 \\
\hline Group 4 & 2.8 & 3.4 & 3.5 & 2.2 & 2.3 & 3.4 & 3.1 & 3.4 & 2.8 & 2.0 & 3.2 & 4.9 \\
\hline \multicolumn{13}{|l|}{ Massey's Company Oriented } \\
\hline Group I & 2.5 & 2.7 & 3.0 & 2.0 & 2.0 & 3.3 & 3.5 & 3.4 & 2.9 & 2.1 & 2.7 & 4.9 \\
\hline Group 2 & 2.7 & 2.8 & 3.1 & 2.2 & 2.0 & 2.9 & 3.2 & 3.3 & 2.8 & 2.1 & 2.8 & 4.7 \\
\hline Group 3 & 3.2 & 3.3 & 3.6 & 2.8 & 2.5 & 3.4 & 3.0 & 3.1 & 3.4 & 2.2 & 2.6 & 4.6 \\
\hline Group 4 & $3 \cdot 3$ & 2.9 & 3.2 & 2.3 & 2.5 & 3.1 & 3.1 & 2.6 & 2.7 & 2.6 & $3 \cdot 3$ & 5.1 \\
\hline \multicolumn{13}{|l|}{ Dallas Mutual Life Reader Oriented } \\
\hline Group 1 & 2.1 & 2.8 & 2.5 & 2.2 & 2.1 & 3.0 & 3.2 & 3.1 & 2.0 & 2.5 & 4.0 & 3.8 \\
\hline Group 2 & 2.3 & 2.7 & 2.8 & 2.3 & 2.0 & 2.8 & 3.3 & 3.4 & 2.0 & 2.4 & 4.0 & 4.3 \\
\hline Group 3 & 2.6 & 2.9 & 3.2 & 3.0 & 2.9 & 2.7 & 3.1 & 3.9 & 1.9 & 3.0 & 4.3 & 4.3 \\
\hline Group 4 & 2.7 & 2.7 & 2.9 & 2.2 & 1.9 & 2.7 & 3.2 & 3.8 & 2.3 & 2.0 & 4.5 & 4.1 \\
\hline \multicolumn{13}{|l|}{ Dallas Mutual Iife Company Oriented } \\
\hline Group 1 & 2.1 & 2.8 & 2.5 & 2.2 & 2.1 & 2.8 & 3.6 & 3.6 & 2.2 & 3.0 & 4.4 & 4.0 \\
\hline Group 2 & 2.2 & 2.8 & 2.4 & 2.2 & 2.1 & 2.6 & 3.4 & 3.7 & 2.2 & 2.6 & 4.2 & 4.0 \\
\hline Group 3 & 2.6 & 3.0 & 2.7 & 2.7 & 2.6 & 2.8 & 3.4 & 3.9 & 2.3 & 2.9 & 4.5 & 4.0 \\
\hline Group 4 & 2.2 & 2.9 & 2.5 & 2.3 & 2.2 & 2.5 & 3.5 & 4.0 & 2.6 & 2.6 & 4.0 & 3.8 \\
\hline
\end{tabular}

*The semantic rating scale numbers correspond to the scale description in Table VIII.

Source: Primary 
In spite of this, respondents in Group III viewed the company viewpoint writing of Massey's less favorably than any of the other groups. 'The greatest profile differences occurred on the evaluative scales which extend toward the polar adjectives on the right side of the continuum. This negative direction indicates the least positive connotation for the company oriented recruiting message noticed among age groups. Group IV (ages 27 to 44 ), on the other hand, considered the stimulus to have the least connotation of activity.

Group III, in Figure D.8, almost unequivocally judged the reader oriented writing of Dal.las Mutual Iife less desirable than other age groups. Group I, as seen in previous analyses, perceived this reader vi.ewpoint writing most favorably. This conclusion was drawn from the profile symmetry in which Group I rated the ad somewhat better on a number of semantic rating scales. The two remaining groups' perception of the ad is nebulous without the aid of statistical techniques.

The profile symmetry in Figure D.9 shows that Group III again expresses the least positive connotation of Dallas Mutual Life's company oriented advertisement. That is, respondents in Group III felt less praiseworthy about this recruiting message than any of the other age groups. Group III viewed three of the four recruitment advertisements with substantially less positive connotation. It seems that respondents in Group III are somewhat skeptical of recruiting advertisement regardless of the witing style. It is almost indeterminable from the profile patterns which of the three remaining groups viewed the company oriented recruiting message of Dallas Mutual Ijife most propitiously. It appears, however, that subjects in Group IV visualized the ad slightly better than respondents in Group III. This is evident on the evaluative scales where 
the greatest disparity exists between Groups III and IV. Group II, on the other hand, seems to have a slightly better connotation of the ad than any other group.

Similarity of Connotative Profiles of Age Groups. Although profile analyses and comparisons are helpful in visualizing group profile patterns, another useful analytical tool. for determining the degree to which groups "think alike" with respect to concepts is Osgood's generalized distance formula, commonly known as the D statistic. The reader may recall that the $D$ statistic measures distance between semantic profiles, or it can be applied in the comparison of two groups on how similarly they perceive the same concept. As previously mentioned, Osgood established that a scale unit shift of .5 for groups is probably significant relative to differences in connotative meaning; the smaller the $D$, the greater the similarity between concepts or between groups.

Table $X$ presents the $D$ values between age groups for each of the experimentally tested recruitment advertisements. The D scores which appear in the matrix are taken over all scales' scores given in Table IX. It is interesting to note that in no instance did the $D$ values in Table $X$ exceed 1.99. Although such magnitude is sufficient to indicate possible dif'ferences between group perception of the experimental advertisements, this lack of very large $D$ values is an indication of why it was impossible, in some instances, to determine from the visual profile analysis how each group felt toward the four experimental stimuli. The reader may further note that 23 of the $24 \mathrm{D}$ values sufficiently differentiated the four age groups from one another. It may be concluded from this observation that age does influence the perception of writing style in recruiting messages. 
TABLE $X$

D MATRICES BETWEEN AGE GROUPS FOR EACH RECRUI'TMENT ADVERTISEMENT

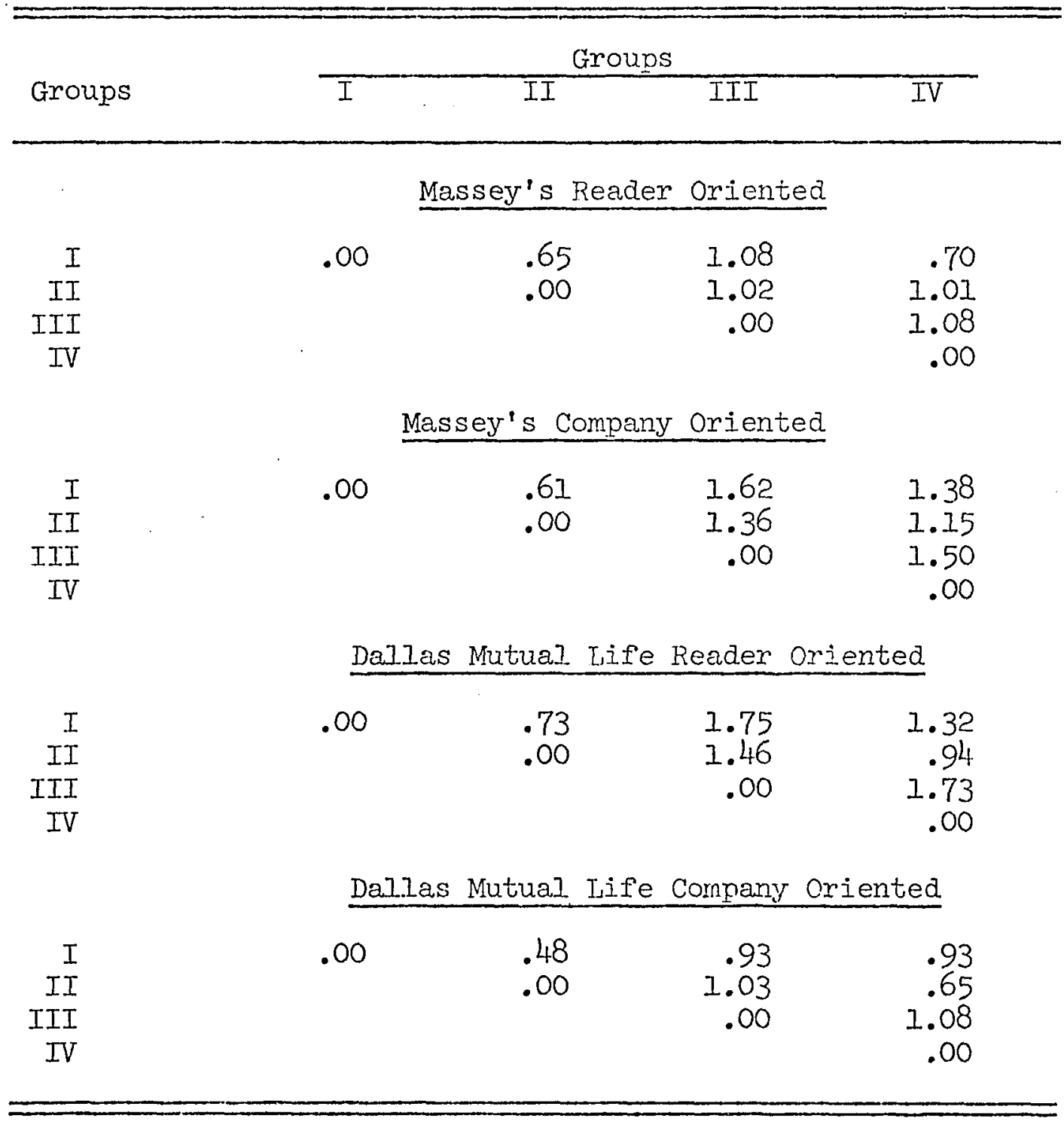

Source: Table IX 
It may be seen from an inspection of Table $\mathrm{X}$ that the largest Iinear separation in the semantic space with respect to Massey's reader oriented message existed between Group I and III $(D=1.08)$ and between Groups III ard IV $(D=1.08)$. The greatest disparity for Massey's company viewpoint. advertising message was between Groups I and III $(D=1.62)$ and the second largest difference relative to age was Groups III and IV $(D=I .50)$.

Comparing age groups' responses to Dallas Mutual Ijife's recruiting advertisements, it may be noted that the largest $D$ value for reader oriented writing occurred between Groups I and III $(D=1.75)$ and between Groups III and IV $(D=1.73)$. In contrast, company oriented messages showed the greatest disparity between Groups II and III $(D=1.23)$. In each of these cases although the D values were not unusually large, they did exceed the limit established by osgood for possible differences in connotative meaning. It may be inferred from this analysis that respondents in all age groups were sensitive to advertising writing styles. Test of Significant Differences for Age Groups. Although the D statistic provides an adequate index of profile similarity, a tesi of significant difference is needed to ascertain the direction of each group's responses. Therefore, the single tail "t" test was applied to each age group for each of the experimental stimuli at the .05 level of confidence.

Table XI presents the " $t$ " values between each age group and the four concepts. By comparing the first age group with each of the remaining age groups, or by comparing the second age group with each of the remaining age groups, it may be seen that as age increases the number of significant values decreases. The perception of advertising writing style thus appears to be a function of age difference. It can be seen 
TABLE XI

"+" VAIUES ${ }^{l}$ OF THE DIFFERENCES BETWEEN AGE GROUP PAIRS FOR EACH CONCEPT-SCALE CONBINATION

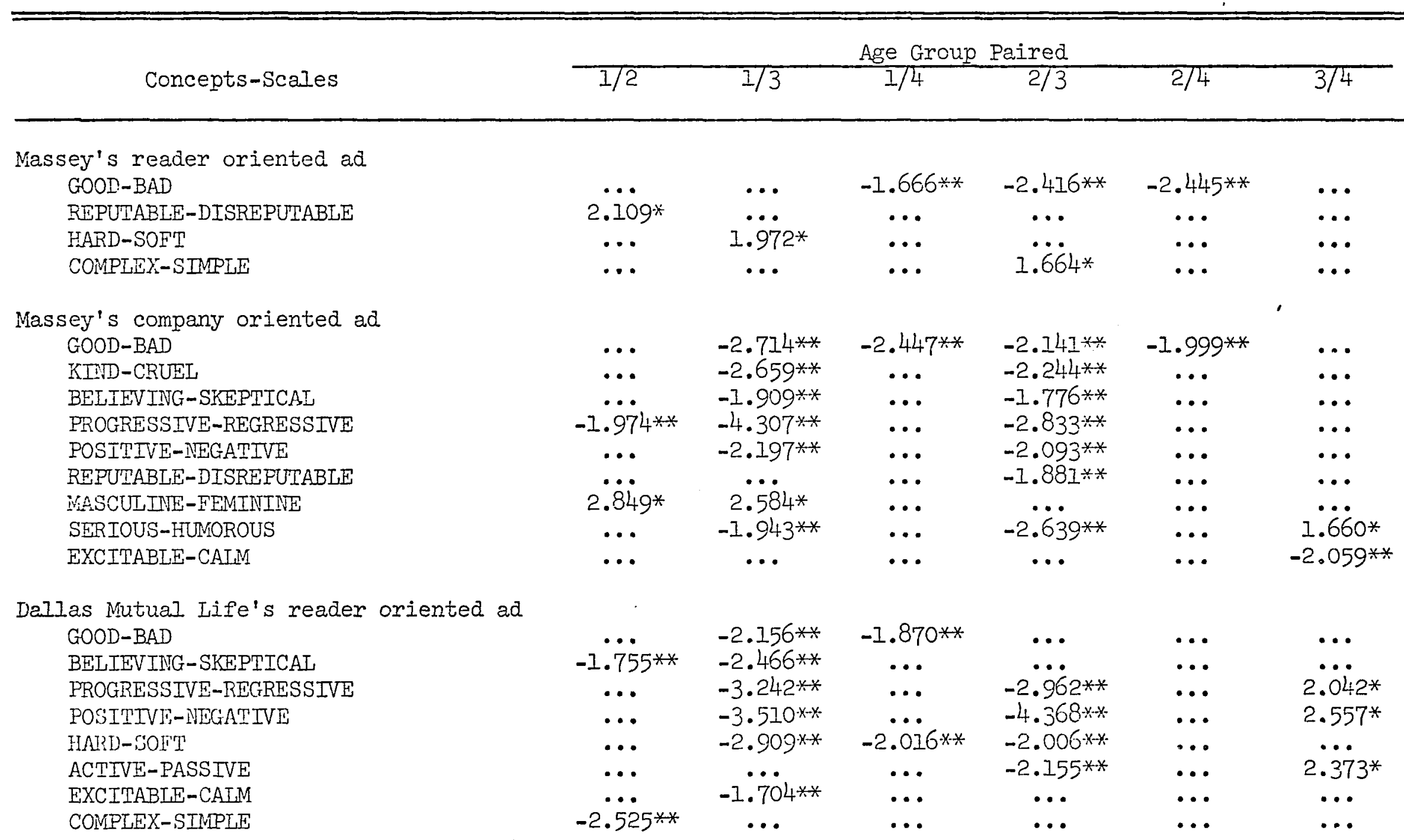


TABLE XI (Continued)

Concepts-Scales

Age Group Paired

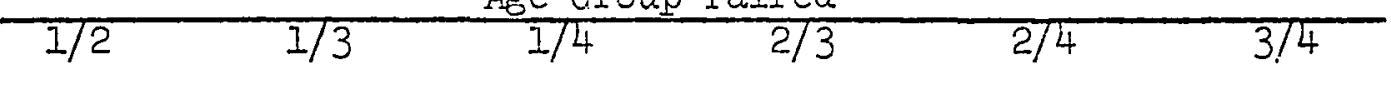

Dallas Mutual Life's company oriented ad GOOD-BAD

PROGRESSIVE-REGRESSTVE

POSITTVE-IVEGATIVE

ACTIVE-PASSIVE

$\begin{array}{ccc}\ldots & -2.276 * * & \\ \ldots & -2.645^{* *} & \\ \ldots .0 & -2.481^{* *} & \\ 1.912^{*} & \ldots & \end{array}$

$\begin{array}{cc}\ldots & -2.199 * * \\ \ldots & -2.997 * * \\ \ldots & -2.534 * * \\ \ldots & \ldots\end{array}$

$\cdots$

$\cdots$

$\ldots$

$1.912 *$

-..

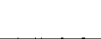

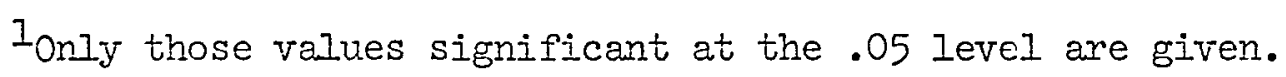 $+* 1.645--$
Group 2, 3, 4 perceived the ads more favorably than group 1
3 perceived the ads more favorabIy than 2
$* * 1.645--$
4 perceived the ads more favorably than groups 2 and 3
Group 1 perceived the ads more favorably than groups 2, 3, 4
2 perceived the ads more favorably than groups 3 and 4
3 perceived the ads more favorably than group 4

Critical "t" values single tail test: $1.645\left(\mu_{1}-\mu_{2}>0=+1.645\right.$ and $\left.\mu_{1}-\mu_{2}<0=-1.645\right)$

Solirce: Primary, Table IX 
from 'joble XI that only five of the relationships showed no statistical difference. Four out of the five appeared in the advertisenent of Dallas Mutual Life. Of these, three appeared in their company oriented advertisemert, for age group pairs I-IV, II-IV, and IIT-IV.

An inspection oI the data for Massey's reader oriented messages shous that no statj.tical differences existed for the paired age groups III-IV. A further examination of the table relative to Massey's advertiscmentis reveals that its company orianted message haa 20 statistically significantly different values, most of which were obtained for age Groups I and II. The number of significant "t" values for its reader oriented advertisement was substantially smaller--six significant "t" scores. From this comparison of significant values, it may be concluded that Massey's company oriented recruiting message was favored over its reader viewpoint message.

Examining Table XI further, it may be noted that sjgnifj.cant aitferences were not obtained between age groups I-IV, II-IV, and III-IV relative to Dallas Mutual Life's company viewpoint recruiting message. This lack of significant difference f'or these age groups probably accounts for their undeterminable profile direction discussed in the profile analysis section. The reader oriented recruiting message for Dallas Mutual. Iife, on the other hand, had 17 " $t$ " values that were of significant difference. In view of this comparatively large number of significantly different "t" values it is reasonable to assune that LeIlas Mutual Lif's's reader viewnoint recruiting advertisement was more favorably perceived than its corpany oriented message.

A summary of the number of significant differences for each of the advertisements', including a breakdow of the findings for each age group, appears in Tabje XII. 
NUMBER OF SIGNIFICANT. SCALE-CONCEPT

" $t$ " VALUES FOR EACH ACE GROUP

\begin{tabular}{cccccc}
\hline & \multicolumn{5}{c}{ Advertisements } \\
\cline { 2 - 6 } Age Groups & Ad I & Ad 2 & Ad 3 & Ad 4 & Total \\
\hline I & 1 & 8 & 10 & 3 & 22 \\
II & 3 & 9 & 4 & 4 & 20 \\
III & 2 & 3 & 0 & 0 & 5 \\
IV & 0 & $\underline{0}$ & $\underline{3}$ & $\underline{0}$ & $\underline{3}$ \\
Total & 6 & 20 & 17 & 7 & 50 \\
\hline
\end{tabular}

*Ad 1--Massey's reader oriented

Ad 2--Massey's company oriented

Ad 3--Dallas Mutual Iife's reader oriented

Ad 4--Dallas Mutual Iife's company oriented

Source: Table XI

It may be noted, in Table XII, age group I demonstrated the greatest degree of sensitivity toward advertising messages. Age group IV, on the other hand, is less sensitive to recruiting messages than any other group. The high degree of advertisement sensitivity for Groups I and II could be due to the fact that the greatest number of students comprised these two age groups.

The above finding partially validates the hypothesis that age is influential in generating more favorable responses toward reader oriented recruitment advertisements. This partial confirmation is evident when the number of statistically significant differences are summed for all age groups for each advertisement. The results of the summation indicates that respondents viewed Massey's company oriented recruiting message significantly better in one instance and in another instance they perceived Dallas Mutual Iife's reader oriented advertisement significantly 
better. Although, the hypothesis is partially validated, it is important to note that this finding substantiates a previous finding in which these ads were perceived in a like manner. This provides an additional reinforcement to the confidence with wich the experimental results are reported. A further attempt to validate hypothesis five includes an analysis of college classification which is the subject of the proceeding section.

College Classifications Relative to Sementic Responses

In order to accomplish the purpose of this section, respondents were divided, traditionally, into Freshman, Sophomores, Juniors, Seniors, and others. The others category included special undergraduate students. The number of subjects in each classif'ication respectively was $63,106,117$, 101 , and 7.

As in previous sections the mean values for each scale for the five classifications rating the four concepts were computed. These mean values, as in previous visual analysis, were plotted to form semantic profiles, which provide a visual comparison between classification for each of the experimental stimuli. Such multiple contrasts of semantic profiles for college classifications were used in testing the minor hypothesis relative to demographic Iactors. To reinforce and complement the visual analysis the $D$ statistic was computed to measure the semantic distance between each of the classification categories for each recruitment advertisement. The five categories were also contrasted by means of the student's "t" test.

Visual Analysis of College Classification. The mean values used in plotting the visual profiles are given in Table XIII. An inspection of the table indicates that a majority of the mean values ranged from 1.9 
TABLE YIII

SEMANTIC DIFFERENTIAL SCAIE MEANS FOR EACH RECRUITMENT ADVERTISEMENT BY COLLEGE CLASSIFICATION

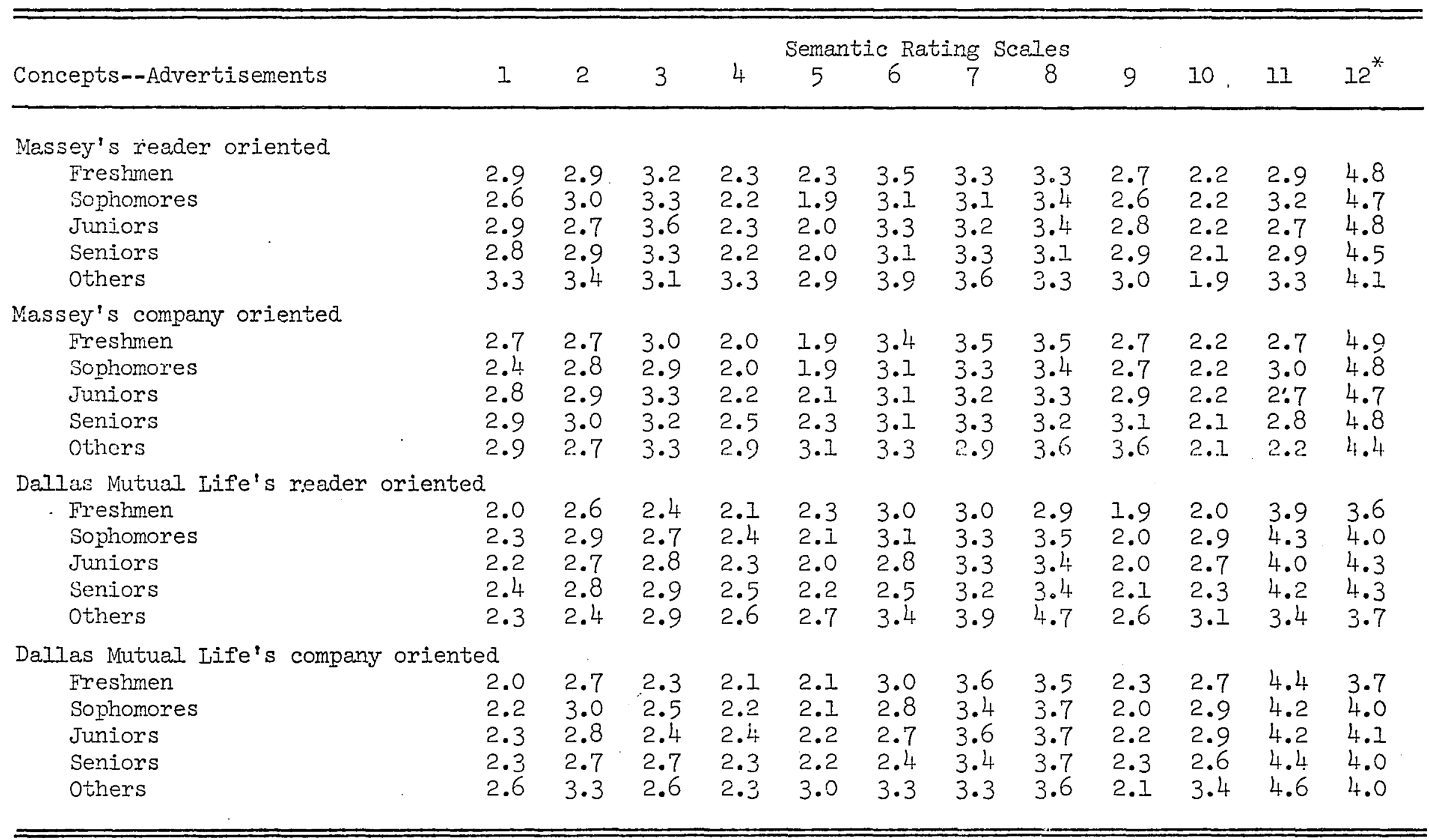

*The semantic rating scale numbers correspond to the scale description in rable VIII.

Source: Primary 
scale units to 3.6 scale units, a range of 1.7 scale units. Of the 240 mean values presented, less than 11 per cent were in the neutral position. The largest mean score among these 240 ratings was 4.9 , which further substantiates previous findings that both recruiting writing styles were perceived connotatively "good." The narrow range of mean values is best seen from an inspection of Figure D.10 through D.13 (Appendix D), which compares Freshmen, Sophomores, Juniors, Seniors, and Special Undergraduate students' responses to each of the experimentally tested recruitment advertisements.

Figure D.10 gives the semantic profile symmetry for the reader viewpoint recruiting message for Massey's. It may be seen from this illustration that respondents in each of the five classification categories virtually perceived the reader oriented recruiting ad as being connotatively "good." There appears to be little difference between the group on the potency and activity scales. However, in the subsequent section an analysis is given which combines scale magnitude and profile shape to ascertain whether or not meaningful differences exist between each classification group.

For the moment, however, the visual profile of Figure D.10 seems to indicate that sophomores perceived this reader viewpoint ad connotatively better than any of the other groups. With the exception of the Special Undergraduate group, Freshmen's impression of the recruiting message is Iess connotatively "good" than Sophomores, Juniors, and Seniors. Surprisingly, Seniors do not seem to perceive the reader oriented appeal of Massey's substantially different from Sophomores and Juniors. One might expect Seniors to be more discriminating in their perception of recruiting advertisements, because many will probably be in the job 
market in the very near future. It is quite possjble, on the other hand, that the ad's appeal was such that Sophomores, Juniors and Seniors were equally impressed by the reader viewpoint advertising copy.

The profile patterns of the Special Undergraduate group have an interesting shape. It seems as though the company oriented appeal of Massey's for the Special Undergxaduate group has the effect of giving lower (positive) activity and substantially higher (negative) potency and evaluative connotation to this experimental stimulus. A further inspection of Figure D.II suggests the possibility that all classification groups, with the exception of the Special Undergraduate group, viewed Massey's company oriented recruiting message in a somewhat similar fashion. The greatest noticeable difference between Freshmen, Juniors, and Seniors appeared on the evaluative and potency scales. Sophomores and Seniors, conversely, appeared to have the greatest degree of disagreement on how connotatively "good" the advertising appeal of Massey's company viewpoint recruitment advertisement.

Differences in the meaning of Dallas Mutual Life's reader viewpoint recruiting message for the various classification groups are noted in Figure D.12. It is quite clear from the profile symmetry that pronounced differences existed in the connotative meaning of this experimental stimulus, for each group of respondents. It is also obvious that Special Undergraduate students' judgment of the reader oriented appeal of Dallas Mutual Life is substantiately higher (negative), especially on six of the 12 semantic differential rating scales, than those of the other groups. The greatest differences are on the last three evaluative scales and the potency scales, where they rated the ad further away from the desirable end of the continuum. The reader viewpoint advertising appeal 
of Dallas Mutual Life was judged most favorable by Freshmen. on the evaluative, potency and activity factors, the ad had the most positive connotation for college Freshmen. Conversely, the pendulous rating by Juniors and Seniors suggest that they may have perceived the experimental stimulus with approximately the same degree of connotative "goodness."

The sharp distinctions that characterized the profile patterns of Dallas Mutual Jife's reader oriented advertisement are not present in its company oriented recruiting message. It may be noted from Figure D.13 that scale corespondence is extremely close, with the excepition of the Special Undergraduate group. This close proximity of semantic stimulus indicates that Freshmen's, Sophomores', Juniors', and Seniors' connotations of the company viewpoint recruiting message of Dallas Mutual Life are not appreciably dissimilar. As in the previously discussed visual proriles, Special Undergraduate students have the least positive connotation of the advertising appeal. Similarity in connotative meaning is further determined with the aid of the $D$ statistic and the test of significant difference is ascertained by the "t" test. These tests are the subject of the subsequent sections.

D Statistic Relative to Classification. Now that the visual analyses are completed, the similarity of connotation between classification for each of the four experimental concepts needs to be assessed. Thus, the following section is concerned with the proximity of the connotative meaning of each recruitment advertisement between classification Jroups. For example, did Freshmen and Sophomores perceive Massey's reader oriented recruiting message alike or did Freshmen and Juniors perceive the concept similarly, and so on, for each individual recruitment advertisenent. To ascertain the similarity or dissimilarity between each group's perception of the concepts, a matrix of D statistics relating classification to 
classification was computed for each experimental stimulus. The D matrix for the data of Table XIII is given in Fable XIV.

As can be seen from Table XIV, 48 D's significantly differentiated the given groups from one another.. Since 48 of the $D$ values are considered to be large, it can be said that groups differ significantly in their perception of the recruitment advertisements. The conclusion may, therefore, be draw that college classification does, in fact, influence the perception of recruitment advertisenent.

An analysis of the reader viewpoint writing of Massey, Table XIV shows all of the relationships to be significentiy different. By suc-: cessively pairing the $D^{\prime} \mathrm{s}$ values it is apparen: that wide clusters have been formed; that is, the classification groups perceived the reader viewpoint appeal of Massey's dissimilerly. For example, look at the Freshmen row in the natrix. The $D$ scores for Freshmen/Sophomores, Freslmen/Juniors, and Freshmen/Seniors are larger than one-half scale unit. Sophomores/Juniors, Sophonores/Seniors, and Juniors/Seniors also demonstrated this dissimilarity in connotative meaning.

The largest $D$ values are associated with the Special Undergraduate Group, thus reflecting the greatest difference in judging the concept. This finding is consistent with the profile analysis which indicated that Special Undergraduate students had the least positive connotation of the ad than any of the other groups. The smallex D values, however, seem to indicate that Massey's reader oriented ad received the most positive connotation from Freshmen, Sophomores, Juniors, and Seniors.

Inspection of the $D$ matrix for the compeny viewpoint recruiting message for Massey's shows that Juniors/Seniors viewed the ad alike. Aside from this comnotative similarity all other classification comparisons 
TABIE XIV

D MATRICES BETWEEN COLLEGE CLASSIFICATION FOR RECRUITMENT ADVERTISEMENT

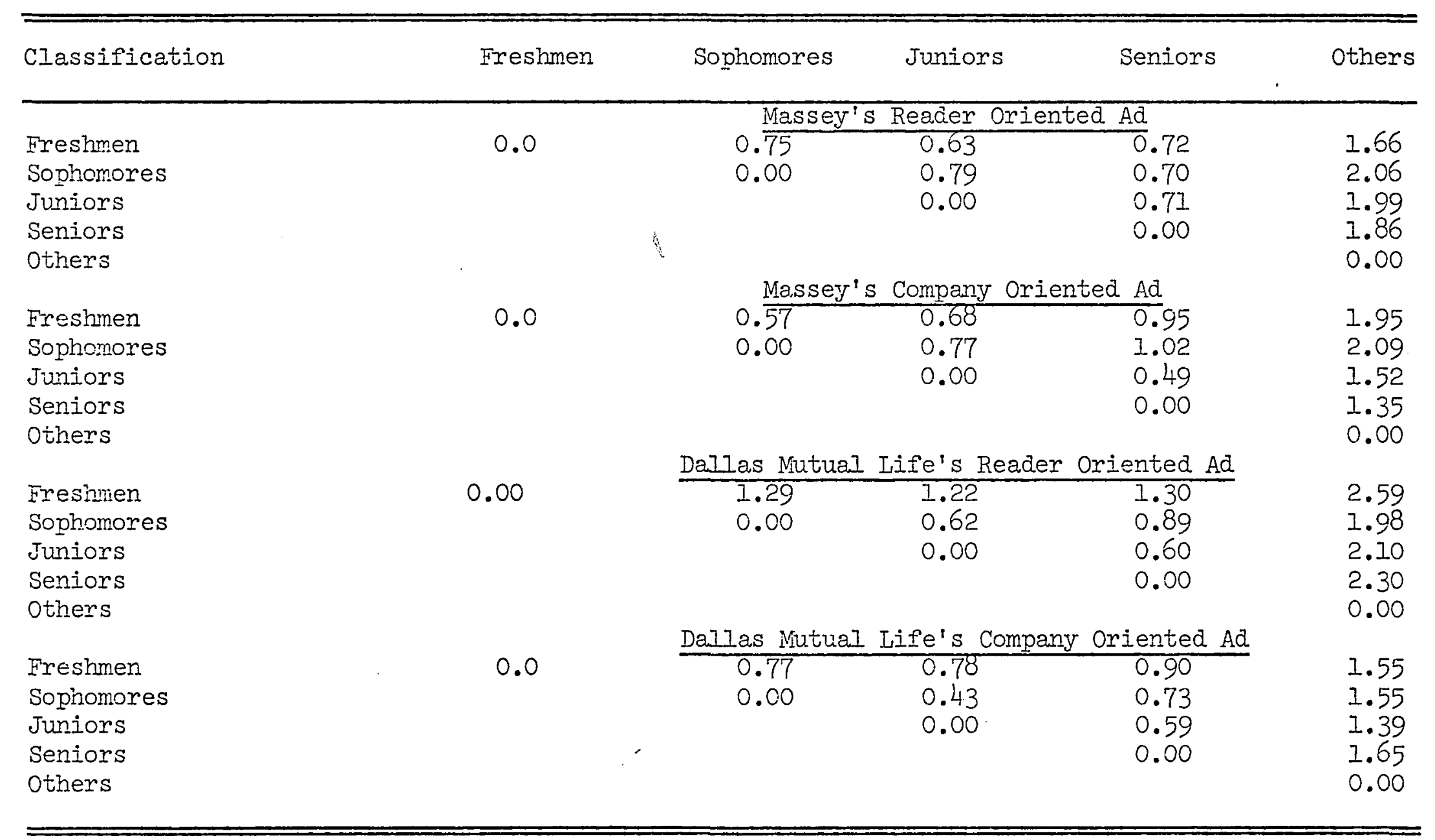

Source: Primary 
judged the ad distinctly differently. The largest $D^{\prime}$ s are, again, between the Special Undergraduate students and the other groups. ITis result also indicates that this group of students felt less positive toward the company oriented advertising appeal of Massey's.

In examining the matrix for Dallas Mutual Life's reader oriented advertisement, Table XIV, the various classification groups demonstrated they did not "think alike" in judging this particular ad. The largest Iinear separation in the semantic space was once again between the Special Undergraduate Group and the other classification groups. The second largest difference existed between Freshmen/Sophomores, Freshmen/Juniors, and Freshmen/Seniors. This distinct difference between Freshmen and the other groups seems to confirm a previous observation that Freshmen had the most favorable connotation of the reader oriented stimulus of Dallas Mutual Life. It is interesting to note there were only three $D$ values that did not exceed one scale unit. The smaller D's existed between Sophomores/Juniors, Sophomores/Seniors and Juniors/Seniors. This close proximity accounts for this alnost parallel profile symmetry.

A final inspection of Table XIV reveals that a.lI groups with the exception of the Special Undergraduate group, had D values ranging from .43 to .90 , a range of .47 scale unit, which can be interpreted as being small. This narrow range helps to explain the tendency of these groups to polarize less on the Dallas Mutual Life's company oriented ad than any of the other advertisements.

In spite of the small $D$ values, there was only one instance in which the scores did not meet the criterion for significant difference in connotative meaning. This similarity in meaning occurred between Sophomores/Juniors. The largest linear separation, as in the previous 
analysis, appeared in the comparisons with the Special Undergraduate group. The small D values, although sj.gnificant, help to explain the close scale correspondence which was shown in Table YII and Figure D.13. This analysis of linear distance between classification for each of the four recruiting advertisements suggests that neither the reader nor the company oriented writing was perceived negatively. This observation is based upon the fact that none of the significant $D$ values were excessively large. If, on the other hand, either of the witing styles was perceived negatively, the $D$ values would have been much larger than those appearing on Table XIV. A test of directional signiricant differences is the subject of the following section.

Statistically Significant Relationships Relative to Classifications. To analyze further the semantic differential data relative to classification, the "t" test was applied to 48 (12 scales for each of four concepts) semantic rating scales; however, the comparison of one classification to another yielded 120 ( 10 comparisons for each of 12 semantic rating scales) "t" values per concept. In total, 480 " $t$ " values were computed to determine whether or not statistically significant differences existed between the semantic responses of five college classification and four experimentally tested recruitment advertisements. The " $t$ " values, utilizing the .05 level of significance, for the experimental simuli are presented in Table XV.

It may be seen from Table XV that only 10 values met the criterion of the "t" test for the reader oriented advertising appeal of Massey's. When Freshmen responses to the concept are compared to Sophomores, Juniors, Seniors, and Special Undergraduate students, only one statistically significant relationship developed in each comparison. That is, Freshmen 
TABLE XV

"t" vaLUES ${ }^{l}$ OF THE DIFFERENCES BETWEEN COLIEGE CLASSIFICATION FOR EACH CONCEPT-SCALE COMBINATION

\begin{tabular}{|c|c|c|c|c|c|c|c|c|c|c|}
\hline $\begin{array}{l}\text { Concept- } \\
\text { scales }\end{array}$ & F-So & $\mathrm{F}-\mathrm{J}$ & $F-S r$ & $F-0$ & So-J & So-Sr & So-0 & $J-S r$ & $J-0$ & $S r-0$ \\
\hline \multicolumn{11}{|c|}{ Massey's reader oriented ad } \\
\hline $\begin{array}{l}\text { KIND-CRUEL } \\
\text { PROGEESSIVE- }\end{array}$ & $\ldots$ & . & $\cdots$ & $\cdots$ & $1.717^{*}$ & $\cdots$ & $\cdots$ & $\cdots$ & $\cdots$ & $\cdots$ \\
\hline $\begin{array}{l}\text { PEGRESSIVE } \\
\text { POSITIVE- }\end{array}$ & $\cdots$ & $\cdots$ & $\therefore$ & $-1.988 * *$ & $\cdots$ & $\cdots$ & $-2.194 * *$ & $\cdots$ & $-1.766 * *$ & $-2.070 * *$ \\
\hline IEGATIVE & $1.840 *$ & ... & ... & ... & $\ldots$ & ... & $-1.825 * *$ & $\ldots$ & $\cdots$ & ... \\
\hline $\begin{array}{l}\text { HARD-SOFT } \\
\text { SERIOUS- }\end{array}$ & ․ & $\cdots$ & $\cdots$ & $\cdots$ & $\cdots$ & $\cdots$ & $\cdots$ & $-1.727^{*}$ & $\cdots$ & $\cdots$ \\
\hline $\begin{array}{l}\text { HUMOROUS } \\
\text { EXCITABLE- }\end{array}$ & $\cdots$ & $\cdots$ & $\cdots$ & $\cdots$ & $\cdots$ & $-1.826 * *$ & $\cdots$ & $\cdots$ & $\cdots$ & $\cdots$ \\
\hline CALM & $\cdots$ & $\cdots$ & $\cdots$ & $\cdots$ & $2.056 *$ & $\cdots$ & $\cdots$ & $\cdots$ & $\cdots$ & $\cdots$ \\
\hline \multicolumn{11}{|c|}{ Massey's company oriented ad } \\
\hline $\begin{array}{l}\text { GOOD-BAD } \\
\text { BELIEVIYG- }\end{array}$ & $\ldots$ & $\ldots$ & $\cdots$ & $\cdots$ & $-1.915 * *$ & $-2.192 * *$ & $\cdots$ & $\cdots$ & $\cdots$ & $\cdots$ \\
\hline $\begin{array}{l}\text { SFEPIICAL } \\
\text { PROGRESSIVE- }\end{array}$ & $\cdots$ & $\cdots$ & $\cdots$ & $\cdots$ & $-1.994 * *$ & $\cdots$ & $\cdots$ & $\cdots$ & $\cdots$ & $\cdots$ \\
\hline $\begin{array}{l}\text { REGRESSIVE } \\
\text { POSTTIVE- }\end{array}$ & $\cdots$ & $\cdots$ & $-2.361 * *$ & $-1.685 * *$ & $\cdots$ & $-3.202 * *$ & $-2.102 * *$ & $-1.811 * *$ & $\cdots$ & $\cdots$ \\
\hline $\begin{array}{l}\text { NEGATIVE } \\
\text { SERIOUS- }\end{array}$ & $\cdots$ & $\cdots$ & $\cdots$ & $-2.259 * *$ & $-1.656 * *$ & $-2.361 * *$ & $-2.779 * *$ & $\cdots$ & $-2.017 * *$ & $\cdots$ \\
\hline HUMOROUS & $\cdots$ & $\cdots$ & $-1.710 * *$ & $\cdots$ & $\cdots$ & $-2 \cdot 321 * *$ & $-1.753^{* *}$ & $\cdots$ & $\cdots$ & $\cdots$ \\
\hline \multicolumn{11}{|c|}{ Dallas Mutual Iife reader oriented ad } \\
\hline$\overline{\mathrm{GOOD}-\overline{\mathrm{BAD}}}$ & ... & $\ldots$ & $-1.811 * *$ & ... & - & $\ldots$ & $\cdots$ & ... & $\cdots$ & $\cdots$ \\
\hline $\begin{array}{l}\text { KIIND-CRUEL } \\
\text { BEIIISVING- }\end{array}$ & $\cdots$ & $\cdots$ & .. & $\cdots$ & .. & $\cdots$ & $\cdots$ & $\cdots$ & $\ldots$ & $\ldots$ \\
\hline SKIPPTICAL & $\ldots$ & $-1.724 * *$ & $-1.948 * x$ & $\cdots$ & $\cdots$ & $\cdots$ & $\cdots$ & $\cdots$ & $\cdots$ & $\cdots$ \\
\hline
\end{tabular}


TABLE XV (Continued)

\begin{tabular}{|c|c|c|c|c|c|c|c|c|c|c|}
\hline $\begin{array}{l}\text { Concept- } \\
\text { Scales }\end{array}$ & F-So & $F-J$ & $\mathrm{~F}-\mathrm{Sr}$ & $\mathrm{F}-\mathrm{O}$ & So-J & So-Sr & So-0 & $J-S r$ & $T-0$ & Sr-0 \\
\hline \multicolumn{11}{|l|}{ REPUIABIE- } \\
\hline DISREPUTABLF & E $\quad \cdots$ & & $\cdots$ & $\cdots$ & $\cdots$ & $2.529 * *$ & & $\cdots$ & & \\
\hline HARD-SOFT & $-2.536 * *$ & $-2.485 * *$ & $-2.191 * *$ & $\cdots$ & $\cdots$ & $\cdots$ & $-2.184 * *$ & $\cdots$ & $-2.491 * *$ & $-2.172 * *$ \\
\hline PUSSTVE & $-3.725 * *$ & $-2.405 * *$ & . & $-2.164 * *$ & 0 & $2.438 *$ & 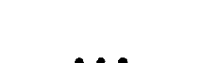 & $7806 *$ & & \\
\hline COMPIEX- & & & $\cdots$ & & $\cdots$ & & $\cdots$ & & $\cdots$ & $\cdots$ \\
\hline SIIYPLE & $\cdots$ & $-2.356 * *$ & $-2.451 * *$ & $\cdots$ & $\cdots$ & $\cdots$ & $\cdots$ & $\cdots$ & $\cdots$ & $\cdots$ \\
\hline \multicolumn{11}{|c|}{ Dallas Mutual Life company oriented ad } \\
\hline $\begin{array}{l}\text { KIND-CRUEL } \\
\text { POSITIVE- }\end{array}$ & $-1.792 * *$ & $\ldots$ & $\cdots$ & $\cdots$ & $\cdots$ & $1.840 *$ & ... & - & $\cdots$ & $\cdots$ \\
\hline $\begin{array}{l}\text { NEGATIVE } \\
\text { REPUTABLE- }\end{array}$ & $\cdots$ & $\cdots$ & . & $-1.824 * *$ & $\cdots$ & $\cdots$ & $-2.186 * *$ & $\cdots$ & $-1.875 * *$ & $\cdots$ \\
\hline DISREPUTABLI & $\ldots$ & ... & $2.526 *$ & $\cdots$ & $\ldots$ & $1.731 *$ & $\cdots$ & ... & $\ldots$ & $-1.659 * *$ \\
\hline \multicolumn{11}{|l|}{ SERIOUS- } \\
\hline HUMOROUS & $\cdots$ & ... & $\cdots$ & $\cdots$ & $\cdots$ & $-1.865 * *$ & $\ldots$ & $\cdots$ & $\cdots$ & $\cdots$ \\
\hline
\end{tabular}

$I_{0 n l y}$ those values significant at the .05 level are given.

$2_{F}=$ Freshmen; So=Sophomores; J=Juniors; Sr=Seniors; $0=0$ thers

Critical " $t$ " values single tail test 1.645 for all groups except for F-Sr; So-0; J-Sr; Sr-0. These four paired classification due to smaller sample size has a critical "t" of 1.658 . $\left(\mu_{1}-\mu_{2}>0=+1.645\right)\left(\mu_{1}-\mu_{2}<0=-1.645\right)$ and $\left(\mu_{1}-\mu_{2}>0=+1.658\right)\left(\mu_{1}-\mu_{2}<0=-1.658\right)$

* +1.645--Sophomores, Juniors, Seniors, and Others; Sophomores perceived ads more favorably than F; Juniors perceived ads more favorably than So; Seniors perceived ads more favorably than So, J; Other perceived ad more favorably than J, So, Sr.

**-1.645--Freshmen perceived ads more favorably than So, J, Sr, O; Sophomores perceived ads more favorably than $\mathrm{J}$, Sr, O; Juniors perceived ads more favorably than Sr, 0; Seniors perceived ads more favorably than 0 .

Source: Table XIII 
only perceived the Massey's reader oriented ad significantly more favorable than Special Undergraduate students. Special Undergraduates, on the other hand, had no statistically significant relationships. The results seem reasonable, because they consistently judged the concept less propitiously than any of the other groups. The reader will notice that when Special Undergraduates are compared with Freshmen, Sophomores, Juniors, and Seniors that statistically significance differences are not observed in any such comparisons.

Table XV also presents a comparable analysis of the company oriented advertising appeal of Massey's. It is apparent that perceptional differences were greater than in the preceding analysis; 16 scales possessed significant differences at the .05 level. It may be concluded from this finding that Massey's company oriented recruitment advertisement was more auspiciously viewed than its companion ad. It is interesting to note, however, the number of significant "t's" (10) between Sophomores/Juniors, Sophomores/Seniors, and Sophomores/Special Undergraduates. This is not unexpected since a similar observation was noted in the visual analysis. Another interesting finding is that no favorable significant differences were observed in the Senior comparison nor in the Special Undergraduate comparison. Of the 16 " $t$ " scores that were outside the critical value for this concept, 13 values appeared on the evaluative scales and the remaining three were concentrated on the potency scale (the bipolar adjective hard).

The Dallas Mutual Life's reader oriented recruitment advertisement had the largest number of significant relationships (17 significant "t's") of any of the recruitment advertisements. In general, subjects tended to judge this concept more favorably than its countexpart--Massey's reader oriented ad. Interesting also is that no significant patterns of perceived 
differences energed between Special. Undergraduatie students and other college students. This result is not unusual since the former consistently judged the ad less favorably than the latter groups. Freshmen, on the other hand, had a noticeable number of significant differences. Another interesting finding is that statistical differences appeared on all three factors--evaluative, potency, activity. The majority of the significant "t's," however, developed on the potency and activity scales. Only three evaluative scales possessed significant differences.

A further analysis of the data in Table XV reveals that the number of significant differences for Dallas Mutual Life's company oriented recruitment advertisement is smaller than any of the other recruiting ads. The most interesting finding in this significant pattern of responses is that eight of the nine significant " $t$ " values appeared on three evaluative scales. The potency scales had only three significant "t's," and none was observed on the activity scales. In view of the small number of statistically significant relationships it may be concluded that the concept was perceived less favorably than its twin ad. Further inspection of data revealed that no propitiously significant differences were found between the Special Undergraduate Group comparison. This result is congruous with Figure D.13, which illustrated that Special Undergraduate students had rated the ad less impressionable. The finding, however, is consistent with previous analyses which demonstrated that Special Undergraduate students rated all of the recruiting messages toward the negative end of the continuum.

Table XVI summarizes the number of significant differences for each classification and for each recruitment advertisement. 
NUMBER OF SIGNIFICANT "t" VALUES FOR EACH CLASSIFICATION AND TACH RECRUITMENT ADVERIISIMENT

\begin{tabular}{|c|c|c|c|c|c|}
\hline \multirow[b]{2}{*}{ Classiffication } & \multicolumn{4}{|c|}{ Advertisements ${ }^{*}$} & \multirow[b]{2}{*}{ Total } \\
\hline & $\overline{\mathrm{A}} \overline{\mathrm{I}}$ & $A d 2$ & Ad 3 & $\overline{A d} 4$ & \\
\hline Freshmen & 1 & 4 & 11 & 2 & 18 \\
\hline Sophomores & 4 & 10 & 1 & 2 & 17 \\
\hline Juniors & 3 & 2 & 1 & 1 & 7 \\
\hline Seniors & 2 & 0 & 4 & 4 & 10 \\
\hline \multicolumn{6}{|l|}{ Special } \\
\hline Undergraduates & 0 & 0 & 0 & 0 & 0 \\
\hline Total & 10 & 16 & 17 & 9 & 52 \\
\hline
\end{tabular}

*Ad I--Massey's reader oriented Ad 2--Massey's company oriented Ad 3-Dallas Mutual Iife's reader oriented Ad 4--Dallas Mutual Life's company oriented

Source: Table XV

It may be seen from Table XVI that, in general, the greater the classification difference the greater number of significant values. Thus it seems that the perception of recruiting messages is a function of college classifjeation.

College Freshmen and Sophomores appeared to be more impressionable in their judgment of recruiting ads. Special Undergraduates, on the other hand, had a less favorably connotative impression of the experimental concepts. Assessing the significance of this result is difficult. The Special Undergraduate group contained only seven respondents. Thus the magnitude of this group is not very large and it may account for the generally less desirable judgment of recruitment aivertisement.

The overall pattern of responses to each of the experimental stimuli revealed that the demographic hypothesis is once again only partially confirmed. In general, based upon the number of accumulative " $t$ " values 
for each äd, Dallas Mutual Life's reader oxiented advertisement and Massey's company oriented advertisement were viewed connotatively better by respondents. Since respondents judzed both a reader and company oriented ad as being most desirable, this fact partially negates a portion of the hypothesis which, in part, states: college classification is influential in generating more favorable responses for reader ads than for company oriented ads. It is important to note, this result is corlsistent with similar findings noted throughout this investigation relative to the fifth hypothesis. 5

Discussion of Demographic Factors

It is shown in the preceding sections that the semantic differential measures change in the meaning of concepts to respondents when they are analyzed according to sex, age, and college classification. The change for age demonstrated that certain age sroups are more sensitive to the perception of written mass communications than other age groups. An interesting fact to consider here is that of all the concepts tested, Massey's company oriented recruitment advertisement underwent the greatest quantitative change between levels, especially for subjects in age Group I and II. The second largest quantitative change was related to the reader oriented advertising appeal of Dallas Mutual Life; again Group I and II showed the greatest change. The least number of changes occurred in Groups III and IV. This result may be due to the maturity of the respondents in each of these age groups. That is, Group III included.

5The calculation for correlation coefficients showed no discernible relation between age, sex, classification and semantic responses. 
ages 23-26 and the age interval for Group IV was 27-44 years of age. Even though the number of respondents in Group III and IV (47 and 2.1 respectively) were relatively small, when compared with Group I (142) and Group II (184), it seems possible that students in the former groups were skeptical about these recruiting messages because they were more likely to be in the job market in the next semester or two following this investigation. This immediacy to the job market may have exerted some influence upon response behavior. Consequently, advertising messages which stressed employment opportunities in the retail and insurance industries are likely to be less appealing to older students than to younger students, because of the stereotype image of these industries. Moreover, respondents in age Groups I and II were probably more immediately concerned about successfully completing their college careers than about their employment opportunities. Therefore, they may have been more objective in judging writing styles in advertisement and less concerned about the long and irregular working hours associated with retailing and the endless pursuit of potential insurance prospects. In general, the same things may be said for college classification, because Juniors and Special Undergraduate students showed the least quantitative significance relative to connotation of recruiting messages. Special Undergraduate students' attitude toward the tested recruiting messages may have also been due to their imnediacy to the job market. It is important to note from this foregoing analysis that connotative meaning of the concepts tested changed at each level of college standing. Few changes occurred as college classification increased, thereby lending support to the finding that Special Undergraduate students were less susceptible to recruiting advertisements than Freshmen, Sophomores, Juniors, and Seniors. 
In summaxy, the perception of recruiting adrertisement appears to be a Iunction of sex, age, and classification. Furthermore, attitudes towr. these experimentally tested recruiting messages may reflect responderts' immediacy to the job-market.

One last point should be made about the subjects' responses to the experimental stimuli. First of all, the profile within each demographic category varied somewhat, but the average elevation of scores on certain semantic rating scales was significantly bettex for Massey's company oriented recruitment advertisement and for the reader viewpoint advertising appeal of Dallas Mutual Life. A review of the data relative to age groups and college classification indicates that these two groups consistently perceived the former and latter advertisements most propitiously. This phenomenon, to speculate, may be attributable to three factors, namely, the length of the advertising copy, subtle use of the "you" and "your" pronouns, and the effective use of the "we," "us," and "our" pronouns.

The Massey reader oriented advertisement said no more than its company viewpoint recruiting message. This was also true of the Dallas Mutual Iife advertisements. The reader oriented advertising appeal of Massey"s contained 225 worảs and used "we," "us," and "our" and "you" and "your" pronouns, respectively, six times and eighteen times. On the other hand, its company oriented ad contained 162 words. Of these, six were "company oriented" pronouns and four were "you" and "your" pronouns. The Dallas Mutual Iife reader viewpoint ad had 605 words, and used the "you" and "your" pronouns 39 times and employed the "we," "us," and "our" pronouns 17 times. Conversely, its company oriented message contained 501 words. Of these, four were "reader oriented" pronouns and 18 were "Company oriented" pronouns. 
Since the length of the advertising copy and the more frequent use of the "you" and "youx" pronouns were the only observable differences between each of the experimental concepts, it is difficult to understand why students in one instance perceived the company oriented advertising appeal of Massey's more favorably and in another instance they viewed the Dallas Mutual Life reader oriented ad more praiseworthy. 6

Two possible assumptions may be dram from this occurrence. First, the Massey company oriented ad made more effective use of the pronouns "we," "us," and "our" than originally anticipated. Secondly, recruitment advertisements with fewer than 300 words, which make subtle use of the "you" and "your" pronouns, seem ineffective. (The word "seem" must be used, of course, because there may be instances where 300 word ads contain what the reader wants to see most.) In short advertisements, (Iess than 300 words) as opposed to 600 word advertisements, the message may not be of significant length to adequately depict employment opportunities. Generally, short ads cannot go into enough detail about training programs, salaries, bomuses, and personal development. Therefore, it does not seem to make much difference how often the "you" and "your" pronouns are used in short advertising copy, if "we," "us," and "our" pronouns are used empathically.

6 Although the length of the advertisements varied it is believed that the variation of 63 words between Massey's reader and company oriented ads and 104 words between Dallas Mutual Iife's reader and company viewpoint ads were not significant enough to introduce any response bias. The purpose of the experiment was to determine statistically whether respondents favored the reader oriented ad over the company oriented ad for Massey's and for Dallas Mutual life. It was not the purpose of this investigation to ascertain which one of the four recruitment advertisements was most praiseworthy. However, if the investigation intended to determine which one of the four ads was most favorably perceived then it is quite possible the length of the advertising message would exert some influence on the ad's desirability. 
In contrast, the possible reason why students favored the Dallas Mutual Life reader oriented ad is that the advertising copy was of significant length adequately to develop the you attitude in depicting advancement opportunities, salaries, bonuses, and so on. This supposition seems reasonable since the analyses of demographic factors indicated that respondents consistentIy perceived the reader viewpoint advertising appeal of Dallas Mutual Life more favorsbly than its company oriented ad. Now that the data have been presented and interpretatious given, a synopsis of the results obtained is presented below.

\section{Compendium of the Niajor Eindings}

Three hundred ninety-four respondents corloleted 12 semantic differential rating scales for the four recruitment advertisements. Visual analyses were performed with the aid of semantic profiles. Statistical analyses, which included the $D$ statistic and tre " $t$ " test, were conducted to ascertain significant relationships between the demographic factors and each experimental tested concept. Comparisons were made of the connotations of the recruitment advertisements and the effects of sex, age, and college classification upon connotations. The following results were obtained:

1. In the comparison of reader and company oriented recruitment advertisements, significant differences were noted and the company oriented ad of Massey's was judged more favorably than its reader viewpoint advertising message. In contrast, the reader viewpoint recruiting message of Dallas Mutual Life was rated better than its company oriented ad. This result partially affirmed and disaffirmed the fourth hypothesis. 
2. Sex differences in connotation occurred on the reader oriented recruiting messages. Male respondents viewed both reader viewpoint writing of Massey's and Dallas Mutual Iife more favorably than female respondents. Female respondents, on the other hand, showed no significant preference for either reader or company oriented recruitment advertisements. Ihis result, in part, helped to confirm the demographic hypothesis.

3. A comparison of age groups revealed that in one instance the Massey's company oriented advertising appeal was perceived most favorably. In another instance, however, the reader oriented ad of Dallas Mutual Life was viewed most praiseworthy. This finding partially disaffirmed the fifth hypothesis. Another interesting result was that respondents between the ages of 17 and 22 demonstrated the highest degree of susceptibility toward recruitment advertisements.

4. The connotation of recruiting messages among college classification was similar to the preceding finding. That is, taken as groups, Freshmen, Sophomores, Juniors, Seniors, and Special Undergraduate students preferred the Dallas Mutual Life reader oriented ad and the company viewpoint advertising appeal of Massey's. Once again, hypothesis five was partially disaffirmed. Freshnen and sophomores appeared to be more sensitive toward recruiting ads than Juniors, Seniors, and Special Undergraduate students. 
CHAPTER V

AN ANALYSIS OF PERSONALITY CHARACIERISTICS AND SFMANTIC RESPONSES

In the previous chapter, the analyses were devoted to testing the minor hypotheses. It also established the pattern of analysis which will be employed in the present chapter. That is, the data generated by the semantic aifferential will, again, be used in reporting the results of the experiment as they are related to personality factors.

In the present chapter, however, the investigation will focus upon the possible relationship between semantic differential responses to recruitment advertisements and the personality factors of the 16 P.F. Questionnaire. Specifically, three major hypotheses will be tested. Briefly, the hypotheses formulated for this segment of the investigation are: (I) personality traits inherent in individuals will cause them to react differently to written mass communication; (2) there are personality differences between favorable responses to reader and company oriented recruiting messages; and (3) individuals possessing extraverted personality characteristics will respond more auspiciously to reader viewpo: recruitment advertisements than those individuals having introve. personalities. Thus, the emphasis of the present chapter is directed toward relating experimental results to the three major hypotheses. 
Personality Factors and Responses to Recruitment Advertisements

The reader may recall from Chapter II that the 16 P.F. Questionnaire measures 16 personality factors. The bipolar description of these personality factors appears in Table I of Chapter II. The scoring procedure for the 16 P.F. is such that a Iow sten score ( 1 through 4) on any personality factor describes a certain personality trait and a high sten score ( 7 through 10) for the same factor denotes an opposite personality trait. For example, the low score description for factor A is reserved where as the high score description is outgoing. Reserved and outgoing are general terms rather than technical psychological titles. For convenience, the general terms will be employed throughout this investigation. It is important to note that a sten score of five or six is regarded as average ("normal"); that is, neither personality trait is dominant, a "normal" blend of both traits are present in the individual. In view of the scoring procedure for the 16 P.F., respondents were grouped according to high, average, and Iow on each of the 16 factors for purposes of comparison and discussion. Before such comparisons are made, it may be helpful to the reader to briefly review the statistical methodology employed in the subsequent analysis.

Statistical Methodology

The analysis of personality variables presented in this chapter is based upon the results of a psychological test administered to a student population. The results, in standard sten scores (mean for the general population is fired at 5.5 stens) are show in Figure 5.1. It is interesting to note that less than 50 per cent of the 16 mean sten scores were average. 


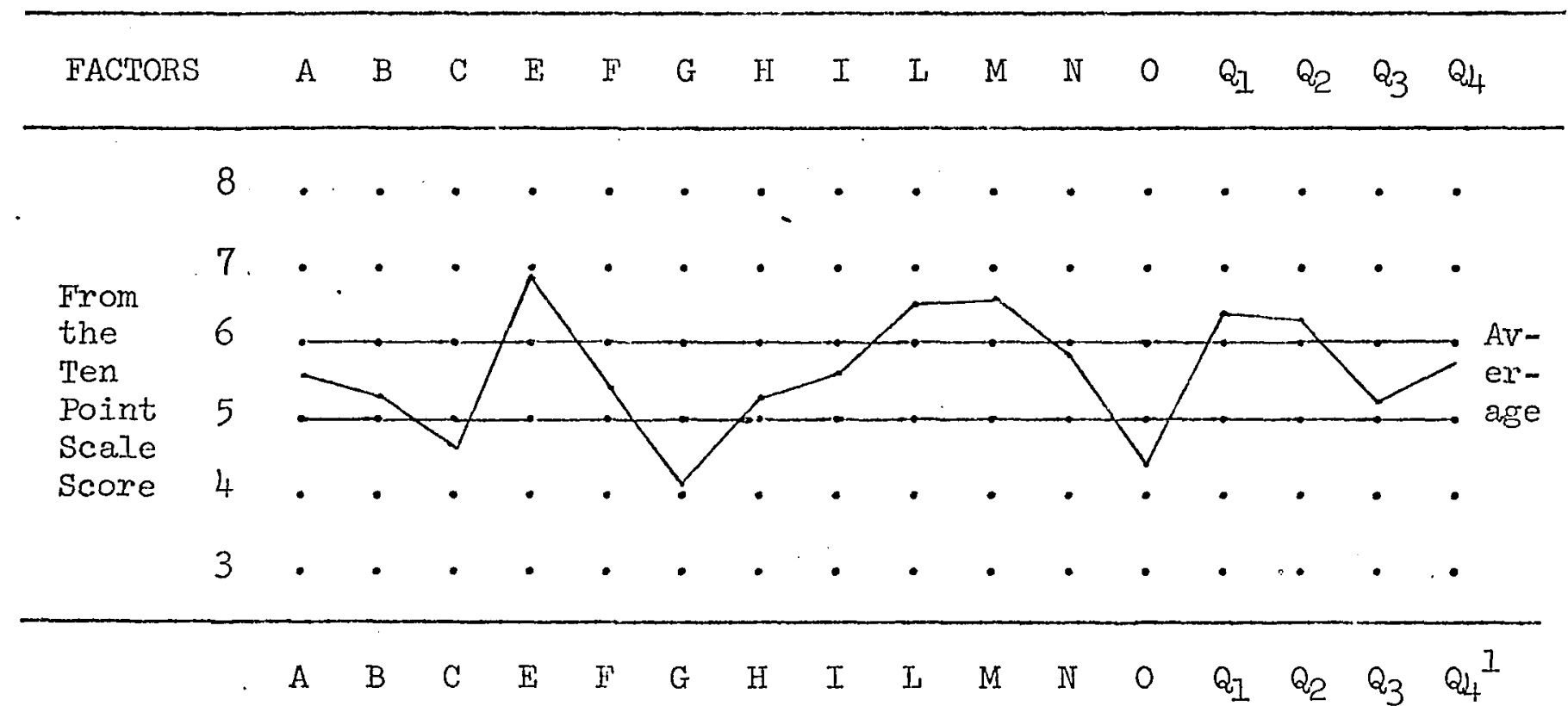

Mean Sten

Scores of

394 I.S.U. $\quad 5.65 .34 .76 .95 .54 .15 .35 .76 .56 .65 .94 .46 .46 .35 .25 .8$ Students :

Men \& Wornen

Together

Mean Sten

Scores of

American

College

Students :

7.44 .67 .14 .07 .67 .06 .56 .35 .65 .55 .15 .05 .16 .86 .95 .4

Men \& Women

Together ${ }^{2}$

${ }^{I}$ See pages 36-7 for bipolar description of the 16 personality factors.

2 Mean sten scores of American College students were taken from Cattell's Handbook Supplement for Form C.

Source: Primary

FIGURE 5.1: Mean Personality Profile of 394. L.S.U. Students on the I6 P.F.

As in the previous chapter, the responses to recruitment advertisements were measured by the semantic differential. Since each subject responded to the experimental concepts by checking one of seven positions on each of 12 semantic rating scales, the responses of all subjects on any one scale yielded a frequency distribution. From this frequency distribution, a 
measure of central tendency was made. Specifically, the computation employed in this investigation included the axithmentic mean. The means show how a group of students with the same personality trait feel, on the average, toward a given recruiting ad on a particular semantic rating scale. To investigate hypotheses one and two, the central tendencies between high, average, and low of each personality factor on each of the 12 scales for each of the four experimental concepts were compared.

The D statistic was applied between high, average, and low for each personality factor to ascertain perceived differences. To test the significance of difference in the connotative meaning of the concepts between any two personality traits for each ad, the " $t$ " test was employed. The null hypothesis in the " $t$ " test stated that two population means were equal. The .05 level of significance was utilized. The following sections present a synthesis of the findings dealing with hypotheses one and two. Specifically, the experimental results relative to personality traits for each recruiting ad are examined. Experimental Results Relative to Hypotheses One and Two The data gained from the personality tests and the semantic differential for each recruitment advertisement were put into tables. These tables (one for each advertisement) give the mean scores of each semantic rating for personality variables. To facilitate interpretation, Cattell's alternate titles and adjective descriptions for each factor are also given in the table. These simple scale synonyms are intended as an aid to the reader who is not familiar with the 16 P.F. Unlike the analysis in the previous chapter, visual semantic profiles are not utilized because of the extremely large number of variables 
involved in determining the relationships between personality traits and responses to written mass communication. For instance, in order to construct visual profiles for each personality factor, it would require that 64. (16 personality factors $\times 4$ recruitment ads) graphics or visual profiles be constructed for each ad with 48 (16 personality factors $\mathrm{x} 3$ personality variables) profile shapes appearing in the graphic presentation. Sixty-four visual profiles would be rather voluminous and uninteresting and, on the other hand, profiles with 48 semantic patterns may prove to be extremely difficult to interpret, especially since the mean values on each semantic rating scale for each personality variable hovers within a very narrow range. It is easy to recognize, however, that such multiple contrasts of semantic profiles would provide some indication of specific proof or disproof for the stated hypotheses. These same comparisons, however, can be accomplished more accurately and succinctly by quantitative techniques. Therefore, the subsequent analysis of each experimental tested advertisement relative to the 16 P.F. is void of semantic profiles.

Massey's Reader Oriented Recruitment Ad. The narrow ranges of mean values, mentioned above, may be seen in Table E.I of Appendix E. It is interesting to note that the small mean values given to this concept are consistent with the findings in the preceding chapter and suggests, as one might expect, that semantic responses are related to personality traits. The personality variables show slight differences in the same direction along the polar continuum. In no instance were there any mean scores that appeared on the negative side of the continuun. In addition to knowing that semantic responses are related traits, it is interesting and valuable to know whether or not these traits caused 
a difference in the connotative meaning of the concept. The semantic distance between responses for personality traits are shown in the D matrix of Table XVII. The reader may recall that small $D$ values show lesser degrees of connotative differences and, of course, the large D scores show greater differences in connotative meaning. The reader is also reminded that a one-half scale unit shift for group data signified that significant differences exist in connotative meaning.

As can be seen from Table XVII, 40 of the 48 D scores significantly

TABLE YIII

D MATRIX FOR MASSEY'S READEZ ORIENTED ADVERTISEMENT

\begin{tabular}{cccc}
\hline \hline $\begin{array}{c}\text { Personality } \\
\text { Factors }\end{array}$ & High/Average & $\begin{array}{c}\text { Personality Groups } \\
\text { High/Low }\end{array}$ & Average/Low \\
\hline A & .64 & .56 & .35 \\
B & .83 & 1.38 & .82 \\
C & .64 & 1.42 & 1.33 \\
E & .54 & .74 & .60 \\
F & .55 & .54 & .59 \\
G & .97 & .92 & .56 \\
H & .53 & .65 & .45 \\
I & .58 & .73 & .80 \\
L & .73 & .79 & .83 \\
M & .52 & .69 & .44 \\
N & .41 & .64 & .39 \\
O & 1.03 & 1.37 & .77 \\
$Q_{1}$ & .63 & .56 & .78 \\
$Q_{2}$ & .48 & .91 & .60 \\
$Q_{3}$ & .42 & .50 & .71 \\
$Q_{4}$ & .49 & .80 & \\
\hline \hline
\end{tabular}

Source: Table E.I

differentiated the 16 personality factors from one another. To say it differentIy, when personality traits are compared by the D statistic, nearly all perceived the reader viewpoint advertisement appeal of Massey's differently. The eight personality factor groups which perceived the 
ad alike are:

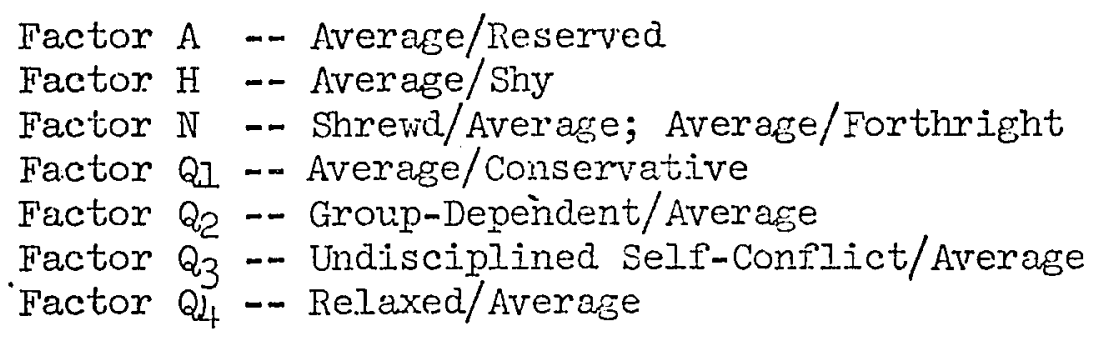

This finding strongly supports the hypothesis that there are certain personality traits inherent in individuals that will cause them to react differently to written mass communication. However, this result, at present, cannot be generalized for recruitment advertisements other than Massey's reader oriented ad.

To further validate the preceding finding, the single tailed parametric "t" test was applied to determine the significance of the difference between personality traits and the mean scores on each of the 12 semantic rating scales. High, average, and low people differed significantly in the perception of Massey's reader oriented recruiting message. This result further strengthens the preceding finding. The direction of the variation is indicated by the positive (*) and negative (**) sign of the " $t$ " values in Table E.II (Appendix E). Five hundred seventy-six "t" values (16 factors x 3 personality variables $x 12$ semantic rating scales) were computed for this test of significant difference. Of these, 127 " $t$ " values were significant at the .05 level of significance.

Personality traits show to have the most favorable connotation of this concept are presented in Figure 5.2. Factor $\mathbb{N}$ does not appear in the table because personality traits characterized as Forthright and Shrewd each had the same number of significant "t" values. It is interesting to note that people with low group descriptions showed 


$\begin{array}{lll}\text { A } & \text { High } & \text { Outgoing } \\ \text { B } & \text { High } & \text { More Intelligent } \\ \text { C } & \text { Average } & \text { Average } \\ \text { E } & \text { Iow } & \text { Humble } \\ \text { F } & \text { Low } & \text { Sober } \\ \text { G } & \text { Average } & \text { Average } \\ \text { H } & \text { High } & \text { Venturesone } \\ \text { I } & \text { Low } & \text { Tough-ninded } \\ \text { L } & \text { Low } & \text { Trusting } \\ \text { M } & \text { High } & \text { Inaginative } \\ \text { O } & \text { Low } & \text { Self-Assured } \\ Q_{1} & \text { High } & \text { Experimenting } \\ Q_{2} & \text { High } & \text { Self-Sufficient } \\ Q_{3} & \text { Low } & \text { Undiscipl.ined Self- } \\ Q_{4} & & \text { Conflict }\end{array}$

FIGURE 5.2: Personality Traits Demonstrating the Most Favorable Responses to Massey's Reader Oriented Advertisement

Source: Table E.II

more statistically significant patterns of auspicious responses than either high or average. A comparable analysis of Massey's company oriented advertising appeal is needed to further affirm or disaffirm the first hypothesis.

Massey's Company Viewpoint Advertisement. The mean values on the various scales were all favorable except for the activity scale (12) complex-simple. The complex-simple scale was the only scale in Table E.III (Appendix $\mathrm{E}$ ) to have a negative mean score of 5.0 and above. This result seems to suggest that attitudinal dimension is associated with certain personality traits. That is, personality factors A, B, G, O, and $Q_{4}$ were the only personality traits to demonstrate an unfavorable attitude toward the complex-simple scale.

Factor A indicates that respondents were easy-going but, at the same time, were intelligent (Factor B) in their judgment. These respondents 
also indicated they were conscientious and moralistic (Factor G) and tended to be worriers. They were also both tense and relaxed (Factor Q $d_{1}$-average).

Aside from the above exception, the generally favorable mean scale values and the linited range from the highest to lowest score on each scale further suggests the effects of traits on the perception of written mass cormunication.

In the comparison of two opposing personality traits, the $D$ values in Table XVIII reveal that only 11 personality variables failed to meet Osgood's standard of satisfactory perceptional dissimilarity. To say it differently, Massey's company oriented recruitment ad was perceived most similarly by individuals characterized as outgoing, reserved,

TABLE XVIII

D MATRIX FOR MASSEY'S COMPAIYY ORIENTED ADVERTISEMENT

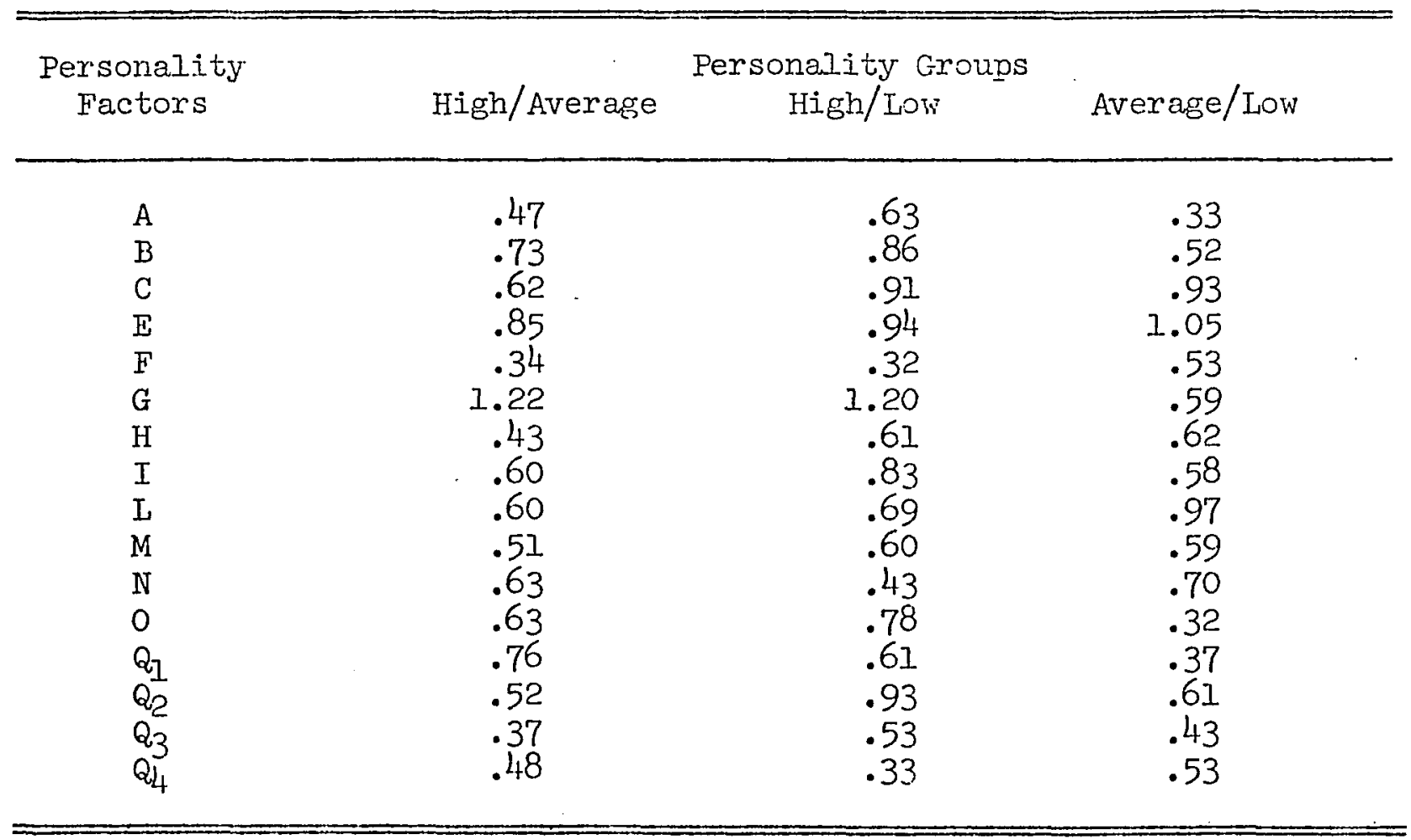

Source: Table E.III 
happy..go-Iucky, sober, venturesome, self-assured, conservative, controlled, undisciplined self-conflict, relaxed, and tense. The fact that the majority of the remaining $D$ values demonstrated satisfactory semantic distance supports the above inference that personality traits are influential in the perception of recruitment advertisement. In addition, it lends still more support to the confirmation of the first hypothesis.

As in the previous analysis student's "t" statistic was used as the test of significant difference among personality traits on each semantic rating scale. The results of this test appears in Table E.IV (See Appendix $\mathrm{E}$ ). The response patterns of personality traits within the $16 \mathrm{high}$, average and low comparisons indicated 146 statistically significant relationships.

When high and average groups of Factor A are compared, no significant differences are observed. However, a statistically significant pattern emerged between high and low and between average and low of the same personality factor.

Significantly different response patterns appeared for all possible comparisons of Factor B. Factor C's emotionally stable and average showed no statistically significant relationship in the perception of the Massey's company oriented advertising appeal.

A statistically significant pattern of response was found in the high, average, and low comparison of Factor E. However, no statistically significant difference emerged when happy-go-lucky traits of Factor $F$ was compared with the average group. This was also true with the happy-go-lucky and sober comparison of Factor $F$. This finding is consistent with the observed results in the D statistic analysis. 
Conscientious people of Factor G indicated no significant difference when compared to the average group. The other two comparisons of Factor G, however, showed significant response differences. No statistically significant relationship emerged when Factor $\mathrm{H}^{\prime} \mathrm{s}$ venturesome group was compared with its average group.

Significant differences were found between the high, average, and Low comparisons of factors $I, I, M, N, O, Q_{1}$, and $Q_{2}$. No difference was observed between high and average of Factor $Q_{3}$. This result is also in agreenent with the finding noted above in the $D$ statistic discussion. Also, no statistically significant difference was noted for the tense and relaxed groups of Factor $Q_{4}$. This finding is consistent with OsGood's generalized distance formula.

The results of the "t" test clearly reinforces the initial observation made from the analysis of $D$ scores and supports the hypothesis that personality traits inherent in individuals will cause them to react differently to written mass communication.

Based upon the number of accumulative "t" values, the personality traits of individuals favorably perceiving the company viewpoint advertising appeal of Massey's are presented in Figure 5.3 .

Factor $Q_{4}$ was omitted from Figure 5.3 because an equal number of significant "t's" were observed for the high, average, and Iow comparison. Generally those who perceived the company oriented advertisement of Massey's most favorably might be described as being reserved, humble, sober, shy, tough-minded, trusting, practical, forthright, selfassured, conservative, self-sufficient, and undisciplined self-conflict. In order to affirm or disaffirm hypothesis two relative to Massey's recruitment advertisements the personality profiles for both ads are combined and presented in Figure 5.4 . 


$\begin{array}{ll}\text { A } & \text { Low } \\ B & \text { Average } \\ \text { C } & \text { Average } \\ \text { E } & \text { Low } \\ \text { F } & \text { Low } \\ G . & \text { Average } \\ H & \text { Low } \\ \text { I } & \text { Low } \\ \text { L } & \text { Low } \\ M & \text { Low } \\ \text { N } & \text { Low } \\ \text { O } & \text { Low } \\ Q_{1} & \text { Low } \\ Q_{2} & \text { High } \\ Q_{3} & \text { Low }\end{array}$

Reserred
Average
Average
Humble
Sober
Average
Shy
Tough-Minded
Trusting
Practical
Forthright
Self-Assured
Conservative
Self-Sutficient
Undisciplined Self-
$\quad$ Conflict

FIGURE 5.3: Personality Iraits Demonstrating Favorable Responses to Massey's Company Oriented Advertisement

Source: Table E.IV

\section{FACTORS}

A

B

C

E

$\mathrm{F}$

G

$\mathrm{H}$

I

L

M

N

0

61

Q2

$Q_{3}$

Q4
RFADER ORIENIFD PROFIIT

Outgoing

More Intelligent. Average

Humble Sober

Average

Venturesome

Tough-Minded

Trusting

Imaginative

--

Self-Assured

Experimenting

Self-Sufficient

Undisciplined SelfConflict

Relaxed
COMPANY ORIENTED

PROEILE

Reserved

Average

Average

Humble

Sober

Average

Shy

Tough-Minded

Trusting

Practical

Forthright

Self-Assured

Conservative

Self-Sufficient

Undisciplined SelfConf"lict

FIGURE 5.4: Combined Personality Profiles of Massey's Recruitment Ads

Source: Figures 5.2 and 5.3 
As anticipated, the personality profiles of those who preferred the reader oriented message differed from those who preferred the company oriented ad. Differences appeared on seven of the 16 personality factors. In view of the substantial' difference in personality profiles, the second hypothesis is presently confirmed. Respondents who preferred the reader viewpoint advertising appeal might be described as being outgoing, more intelligent, socially bolder, more imaginativelycreative, more sophisticated, more radical, and more relaxed than those who preferred the company oriented recruiting message. Hypothesis one and two were strongly supported by the data in the preceding sections. However, in order to further substantiate these hypotheses, a comparable analysis of Dallas Mutual Life's recruitment advertisements is needed.

Reader Viewpoint Appeals of Dallas Mutual Iife. In comparing the responses of individual personality traits to Dallas Mutual Life's reader oriented ad, the results were positive and clearly demonstrated that personality dimensions are related to the perception of recruitment advertisements. Table $\mathrm{E} . \mathrm{V}$ of Appendix $\mathrm{E}$ presents the mean scale values for all personality variables. looking at these means it is apparent that the reader oriented appeal of Dallas Mutual Life enjoyed a positive and favorable rating from respondents.

It is interesting to note the 16 personality factors clustered on the same two semantic rating scales. The two semantic rating scales where the cluster occurred included excitable-caln and complex-simple. Personality groups were neutral in rating the concept on these two scales. This observation is based upon the fact that in nearly every instance, the mean scale ratings for excitable-caln and complex-simple were in the neutral position of the continuum. Despite the consistency of the mean 
values in these two scales, the 16 personality factors exhibited a somewhat erratic set of responses on the remaining semantic rating scales. This result is meaningful since it suggests that individuality is present in the perception of writter mass communication.

Even though the responses for the 16 personality factors were a bit erratic, they were, however, all favorable. In no instance were there any mean values toward the opposite (unfavorable) end of the polar continuum. This tends to underline further the auspicious reaction to the reader viewpoint advertising copy of Dallas Mutual Life. of particular interest is the humble scale of Factor $\Sigma$, which seems to represent the most positive response to the concept. The finding for Factor $Q_{1}$, the conservative scale, corresponds very closely to the responses given for the humble scale. This result is supported by the mean scale ratings of the semantic differential.

In spite of the seemingly close scale correspondence show in Table E.V, the D scores in Table XIX indicate marked individual differences with respect to similarity in connotative meaning. However, approximately 10 per cent of the personality variables showed fusion in the connotative meaning of the concept. That is to say, five of the 48 calculated $D$ values indicated that personality groups perceived the ad alike. The general description of the personality traits that viewed the concept alike includes assertive, shy, tough and tender minded, trusting, and relaxed.

The largest Iinear separation (1.25) between any of the personality dimensions occurred between conscientious and expedient (Factor $G$ ). The E scale of the 16 P.F. test, which is the assertive-humble scale, has the second largest (1.24) linear separation between personality variables. 
On the other hand, the most convergent view, attested to by the smallest $D$ value of .35 , pertained to Factor $I$, the tender and tough minded dimension.

TABIT XIX

D MATRIX FOR DALLAS MUIUAT LIFE'S READER ORIENTIED ADVERTISEMENT

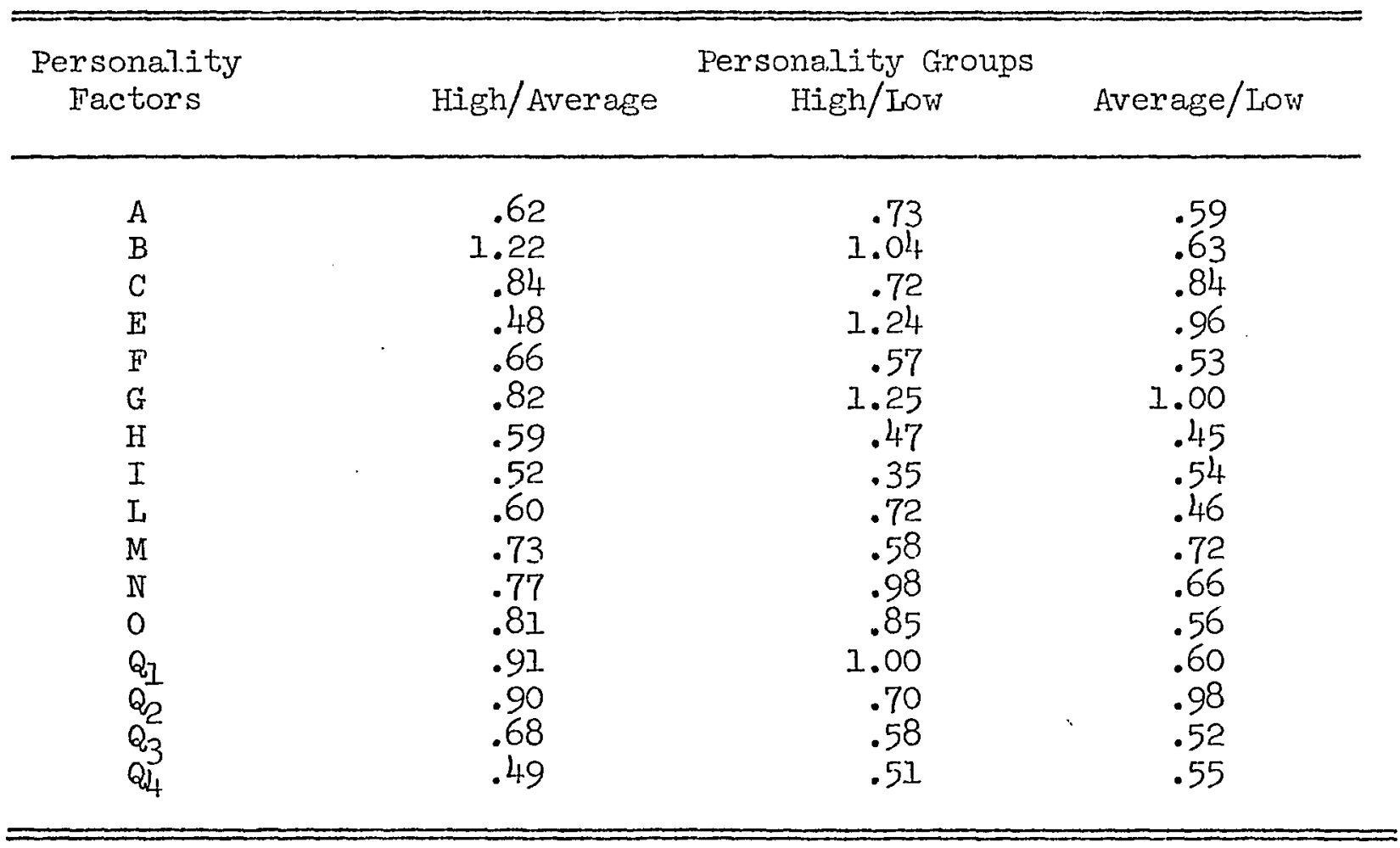

Source: Table E.V

Since Table XIX indicated specific differences between 90 per cent of the personality dimensions, it may be concluded that some relationship exists between personality traits and response to recruitment advertisement. This finding further suggests that responses to recruiting ads are a function of personality traits. In view of the obtained D values, not surprisingly, the first hypothesis is once again supported by the data.

Further confirmation of the hypothesis is revealed by the test of 
significant difference between the semantic rating scales for each of the personality variables. It should be noted that 134 items in Table E.VI (Appendix E) were statistically significant at the .05 level of significance.

Significant differences were found between the high, average, and low comparisons of factors $A, B, C, E, F, G, M, N, O, Q_{1}, Q_{2}$, and $Q_{3}$. The $Q_{2}$ scale of the 16 P.F., which is group-dependent--self-sufficient, had the largest number of scales accepted as a result of the " $t$ " test; and Factor $Q_{1}$ contained the second largest number (15) of statistically significant relationships. The personality factor on which the smallest number (3) of significant differences occurred was the self-assured..aprehensive scale of Factor 0 .

It is interesting to note that assertive people (Factor E--assertivehumble) did not judge the Dallas Mutual Iife reader oriented ad significantly different from humble individuals. Assertive individuals may not be influenced by advertising writing style as they are generally described as being hostile, authoritarian, and having a disregard for authority. Cattell indicates that among occupations the assertive scale is most associated with those individuals requiring boldness and courage, such as firemen. $^{1}$ This may have accounted for the generally higher mean values (Iess favorable rating) which appeared in Table E.V (Appendix E) for Factor $\mathrm{E}$.

Venturesome and shy people (Factor $H$ ) showed no significant difference in their response to the recruitment ad. Shy individuals and

$I_{\text {Raymond B. CattelI and Herbert W. Hber, Handbook for the Sixteen }}$ Personality Factor Questionnaire (Champaign, Ill.: Institute for Personality and Ability Testing, 1957), p. 13 . 
venturesome people, on the other hand, perceived the concept statistically differently from the average group (those individuals having a balanced blend of timidness and boldness) of Factor H. The findings are consistent with similar results noted in the analysis of the D statistic.

No significant pattern of responses were observed for the tenderminded and average group of Factor $I$. This apparent incongruity between the " $t$ " values and the $D$ values is the result of the more powerful parametric "t" test.

Suspicious people (Factor I) indicated no significant difference in their judgment of the concept when compared with the average group of the same personality factor. Suspicious individuals as well as average and trusting may prefer the security of well known employers even though recruitment advertisements carry significant reader viewpoint overtones. The other comparjson of Factor I, however, showed significant difference in response to the ad. The pattern of responses between tense and average students of Factor $Q_{4}$ was not significantly different beyond the .05 level of significance. This is not unexpected, since the D statistic indicated a similar finding. The pattern of responses, however, between tense and relaxed (Factor $Q_{4}$ ) was found to be significantly different. Significant difference was also observed between the relaxed and the average group. This result is also congruent with the $D$ statistic. Since response patterns were significantly different between all personality variables, with the exception of certain variables of Factors $H, I, L$, and $Q_{4}$, the first hypothesis is further reaffirmed with the aid of the " $t$ " test. The personality traits possessea by individuals which seem to respond most propitiously to Dallas Mutual Iiffe's reader oriented recruitment advertisement are shown in Figure 5.5 . 


$\begin{array}{lll}\text { A } & \text { Low } & \text { Reserved } \\ \text { B } & \text { Low } & \text { Less Intelligent } \\ \text { C } & \text { Average } & \text { Average } \\ \text { E } & \text { Low } & \text { Humble } \\ \text { F } & \text { Average } & \text { Average } \\ G & \text { Average } & \text { Average } \\ \text { L } & \text { Low } & \text { Trusting } \\ \text { M } & \text { Average } & \text { Average } \\ N & \text { Low } & \text { Forthright } \\ \text { O } & \text { Low } & \text { Self-Assured } \\ \text { Q1 } & \text { Low } & \text { Conservative } \\ Q_{2} & \text { Low } & \text { Group-Dependent } \\ \text { Q4 } & \text { Low } & \text { Relaxed }\end{array}$

FIGURE 5.5: Personality Traits Demonstrating the Most Favorable Responses to Dallas Mutual Life's Reader Oriented Ad

Source: Table. E.VI

From the personality traits shown in Figure $5.5 \mathrm{it}$ is now possible to give a brief description of those individuals who preferred the reader oriented appeal of Dallas Mutul Life. Incividuals preferring this ad tend to be reserved, concrete thinkers, docile, trusting, easily pleased, placid, cautious, prefer to work and make decisions with other people, and are unfrustrated. Comparable analysis of Dallas Mutual Company oriented recruitment ad appears in the following section.

Dallas Mutual Life's Company Oriented Ad. Based upon the analysis of mean scale values it appears that individuals characterized as being docile, compromising, and joiners viewed this stimulus most auspiciously.

Semantic differential averages on the company oriented advertising copy of Dallas Mutual Iife by personality factors are shom in Table E.VII of Appendix E. An inspection of the table indicates that the mean scalevalues ranged from a low of 1.8 scale units to a high of 4.8 scale units, a range of 3.0 scale units. Of the 576 mean scale-values presented in Table E.VII, approximately 13 per cent were in the neutral position. It 
is interesting to note that this neutral judgment appeared on the excitable-calm and complex-simple semantic rating scales. This result is similar to the finding noted in the preceding analysis.

In general, all of the mean scale scores were positive; that is, they were all toward the favorable side of the semantic rating scales. This uniformity indicates that personality groups agreed on the propitious connotation of the concept. Although the observed results from the semantic differential averages are interesting, further analyses are needed to confirm the first hypothesis. In view of the precedent established in the preceding sections, the following analysis will concentrate on D statistics to help confirm the hypothesis that personality traits inherent in individuals will cause them to react differently to written mass communication.

The D Matrix for Dallas Mutual Life's company oriented recruitment advertisement appears in Table XX. As can be seen from this table, 40 D's significantly differentiated the 16 persoriality factors from one another. That is, 40 obtained $D$ values indicated a shift of more than one-half of a unit. Therefore, it can be said that personality groups differed specifically in their perception of the experimental stimulus. Moreover, since nearly 83 per cent of the personality variables demonstrated this perceptual disparity, the conclusion, therefore, may be drawn that personality traits inherent in individuals do, in fact, cause them to react differently to recruitment advertisements. This result provides the necessary support to confirm the first hypothesis. In view of this finding and the positive findings for the other three ads, the first hypothesis is fully confirmed on the basis of the $D$ statistic. 
TABLE XX

D MATRTX FOR DATIAAS MUTUAL LIFE'S COMPANY ORIENTIED ADVERTISEMEIT

\begin{tabular}{|c|c|c|c|}
\hline \multirow{2}{*}{$\begin{array}{c}\text { Personality } \\
\text { Factors }\end{array}$} & \multicolumn{3}{|c|}{ Personality Groups } \\
\hline & High/Average & High/Low & Average/Low \\
\hline A & .52 & .62 & .63 \\
\hline$B$ & .71 & .86 & .50 \\
\hline $\mathrm{C}$ & .52 & .58 & .50 \\
\hline $\mathrm{E}$ & .28 & 1.26 & 1.13 \\
\hline$F$ & .86 & .71 & .63 \\
\hline G & .77 & .66 & .84 \\
\hline $\mathrm{H}$ & .65 & .61 & .68 \\
\hline$I$ & .45 & .37 & .32 \\
\hline I & .60 & .72 & .73 \\
\hline$M$ & .64 & .85 & .83 \\
\hline $\mathbb{N}$ & .61 & .59 & .77 \\
\hline 0 & .83 & .79 & .33 \\
\hline Q1 & .49 & .77 & .77 \\
\hline$Q_{2}$ & .80 & 1.13 & .69 \\
\hline$Q_{3}$ & .59 & .67 & .54 \\
\hline$Q 4$ & .43 & .43 & .59 \\
\hline
\end{tabular}

Source: Table E.VII

It is interesting to note the largest $\mathrm{D}$ values shown in Table XX are associated with Factor $\mathrm{E}$ (humble-assertive scale) and Factor $\mathrm{Q}_{2}$ (selfsufficient-group-dependent scale). This result is noteworthy since these two factors were noted above as being the ones which reacted most favorably to the advertisement. Another interesting observation is the similarity of the Factor E (assertive-average scale); Factor I (all scale comparisons); Factor O (average-self-assured scale); Factor $Q_{1}$ (experimenting-average scale); and Factor $Q_{4}$ (tense-average scale and tense-relaxed scale) responses. To say it differently, these personality variables viewed the experimental stimulus alike. Despite this small percentage of perceptual similarity, the above analysis clearly demonstrated that individuals 
possessing various personality traits are sensitive to advertising writins style. Further validation of the sensitivity of personality traits to advertising copy is presented in subsequent discussion.

Tests of personality traits on each semantic rating scale show significant differences. In fact, it may be seen from Table E.VIII (see Appendix $\$$ ) that 165 " $t$ " values met the criterion of the " $t$ " test for the company oriented advertising appeal of Dallas Mutual Iife. This represents the largest total number of significant " $t$ " values for any of the previous tests of significant differences. In addition, fewer personality variables showed a lack of statistically significant difference in the perception of this concept than any of the recruitment advertisements.

When high, average, and low groupings on each of the 16 personality factors are compared, significant differences were observed in each comparison, with the exception of Factors E, G, I, and 0 . Specifically, no significant differences were obtained for the assertive-average scales of Factor $E$. This result is consistent with the finding noted in the above D statistic analysis.

When Factor $\mathrm{G}^{\mathrm{t}} \mathrm{S}$ conscientious group was compared with its average group, the pattern of responses did not approach statistically significant differences at the .05 level. Also, no significant pattern of response differences emerged between the conscientious and expedient group of Factor $G$. It is somewhat surprising that these groups did not respond significantly differently to the ad, because expedient individuals, according to Cattell, tend to be unsteady in purpose, whereas conscientious individuals tend to be exacting in character and dominated by a sense of duty. ${ }^{2}$ 
The pattern of semantic responses of average and low grouping of Factor I showed no statistically significant difference in their perception of the concept. This result corresponds to the finding observed in the analysis of the D statistic. "Further congruency with the D statistic was observed for the average and low grouping of Factor 0 , which is the average-apprehensive scale.

Taken together, those groupings wich indicated no statistically significant difference in response to the experimental stimulus might be described as being more stubborn (Iactor $E$ ), less conscientious and more responsible (Factor G), more self-reliant (Factor $I$ ), and more apprehensive (Factor 0 ) than those groups that viewed the concept as being significantly different.

An examination of the significant items listed in Table E.VIII further reveals the personality trait groups that responded most favorably to the experimentally tested company oriented recruiting message of Dallas Mutual Life. The general personality description appears to include less intelligent, emotional maturity, submissive, shy, self-reliant, trusting, practical, sentimental, serene, conservative, and group dependent.

The specific personality factors incluaed in the above description are given in Figure 5.6 along with their high and low scale characterizations.

Factor $A$ and $F$ were excluded from Figure 5.6 because none of the groupings for these factors had more accumulative " $t$ " values than the other.

A summary of the personality profiles for the Dallas Mutual Iife recruitment advertisements is presented in Figure 5.7. A glance at the figure shows that the personality traits of those preferring the reader oriented ad differed from those preferring the company oriented ad. 
B

C

$\mathrm{E}$

G

$\mathrm{HI}$

I

I

M

$\mathrm{N}$

0

$Q_{1}$

$Q_{2}$

$Q_{3}$
Low

High

Low

Average

Low -

High

Low

Low

Low

Low

Low

Low

Average

Average
Less Intel.Iigent Emotionally Stable

Humble

Average

Shy

Tender-Minded

Trusting

Practical

Forthright

Self-Assured

Conservative

Group-Dependent

Average

Average .

FIGURE 5.6: Personality Traits Which Demonstrated the Most Pavorable Responses to Dallas Mutual Life's Company Oxiented Ad

Source: Table E.VIII

FACTORS
A
$\mathrm{B}$
$\mathrm{C}$
$\mathrm{F}$
$F^{\prime}$
G
$\mathrm{H}$
I
L
$\mathrm{M}$
N
$\mathrm{O}$
Q1
Q
Q

READFR ORTENTED PROFILE

Reserved

Less Intelligent

Average

Humble

Average

Average

-.-

Trusting

Average

Forthright

s f-Assured

Conservative

Group-Dependent

Relaxed
COMPANY ORIENTED PROFTLF

Less Intelligent
Emotionally Stable
Humble
Average
Shy
Tender-Minded
Trusting
Practical
Forthright
Self-Assured
Conservative
Group-Dependent
Average
Average

FIGURE 5.7: Combined Personality Profiles of Dallas Mutual Recruitment Ads

Source: Figures 5.5 and 5.6 
In view of this disparity between personality profiles, it is appaxent that there are personality differences between individuals that favor reader viewpoint recruitnent ads and those that prefer company oriented ads. Significant differences appeaxed or eight of the 16 personality factors, thus proving the second hypothesis that there are personality differences botween favorable responses to reader and company oriented recruitment advertisenents.

Commositie View of Personality Profiles

rine foregoing analyses clearly established that personality traits as:ociated with reader vievooint advertising differed from those associated with company oriented advertising copy. However, a comparison of personality traits between the two reader oxiented and between the two company oriented ads also rovealed differences.

For exmple, the personelity traits associated with reader viewpoint advertisements differed on 10 of the 16 personalj.ty factors, whereas personality dimensions related to company oriented recruitment advertisements differed on eight of the 16 personaljty factors. (See Figure 5.8). These differences suggest that personality traits do, in fact, affect the perception of written mass communication. Moreover, preference for advertising rriting style appears to be a function of personality.

The six personality variables that consistently favored reader oriented advertisements included Factor C (average), F'actor E (humble), Factod: G (sverage), Factor L (trusting), Factor O (self-assured), and Factor $Q_{4}$ (relared). When the personality profiles of company oriented ads are comparea, the following personality factors $\mathrm{E}$ (humble, $\mathrm{C}$ (arcrere), H (shy), I (trusting), M (practics]), N (rorthright), 


\begin{tabular}{|c|c|c|c|c|}
\hline Factors & Massey's & Dallas Mutual Life & Massey's & Dallas Mutual Iife \\
\hline A & Outgoing & Reserved & Reserved & -- \\
\hline $\mathrm{B}$ & Nore Intelligent & Less Intelligent & Average & Less Intelligent \\
\hline $\mathrm{C}$ & Average & Average & Average & Fmotionally Stable \\
\hline$E$ & Humble & Humble & Humble & Humble \\
\hline $\mathrm{F}$ & Sober & Average & Sober & -- \\
\hline $\mathrm{G}$ & Average & Average & Average & Average \\
\hline $\mathrm{H}$ & Venturesome & $-\infty$ & Shy & Shy \\
\hline$I$ & Tough-Minded & -- & Tough-Minded & Tender-Minded \\
\hline I & Trusting & Trusting & Trusting & Trusting \\
\hline$M_{1}$ & Inaginative & Average & Practical & Practical \\
\hline$N$ & - n & Forthright & Forthright & Forthright \\
\hline 0 & Self-Assured & Self-Assured & Self-Assured & Self-Assured \\
\hline Q1 & Experimenting & Conservative & Conservative & Conservative \\
\hline$Q 2$ & Self-Sufficient & Group-Dependent & Self-Sufficient & Group-Dependent \\
\hline Q3 & $\begin{array}{l}\text { Undisciplined Self- } \\
\text { Conflict }\end{array}$ & -- & $\begin{array}{l}\text { Undisciplined Self- } \\
\text { Conflict }\end{array}$ & Average \\
\hline Q44 & Relaxed & Relaxed & $-\infty$ & Average \\
\hline
\end{tabular}

Figure 5.8: Composite Personality Profiles for the Four Experimental Advertisements Sources: Figures 5.4 and 5.6 
$O(s e l f-a s c u r e d)$, and $Q_{1}$ (conservative) were consistintily associated with this form of advertising writing style.

Interesting also is that personality traits described as hurible (Factor $\mathrm{E}$ ), self-assured (Factor 0 ), and a balanced blend of conscientiousness and casualness (Factor G) responded most favorably to all four of the experimental variables. By implication, therefore, this finding seems to suggest that personality traits characterized as humble, selfassured, and a ballanced mixture of conscientiousness and casualness are more responsive to written mass communication. However, this finding cannot be generalized statistically to recruitment advertisements other than those tested in this study, because much more research is needed. For instance, differences in the degree of reader and company viewpoint utilization may lead humble, self-assured, and conscientious-casual individuals to respond differently to recruitment advertisements. It is believed, however, that this test of advertising writing style, relative to personality traits, does provide some indication that, in part, responses to recruitment advertisements are a function of personality. Further ramifications of personality and advertising writing style are discussed in the subsequent section. Specifically, the responses of extraverted and introverted individidals to the four experimental advertisements are analyzed.

\section{Second-Order Factors and Experimental Fiesults}

Apart from the 16 basic personality factors, the 16 P.F. also measures what Cattell calls second-order factors. Specifically, four broad second-order factors can be deterinined from sten scores on the primary personality factors. These second-order factors include: 
I. 3 Adjustment vs Anxiety

II. Introversion vs Extraversion

III. Tenderminded vs Fmotionality vs Alter Poise

IV. Subduedness vs Independence

The present section, however is concerned with the IntroversionExtraversion factor, relative to the experimental investigation. The primary factors of $\mathrm{A}, \mathrm{E}, \mathrm{F}, \mathrm{H}$, and $\mathrm{Q}_{2}$ are components of the IntroversionExtraversion factor. The sten scores for these five primary factors were combined with statistical weights in order to estimate the secondorder factor. ${ }^{4}$

The average sten score is fixed at 5.5 . In other words, a sten score below 5.5 designated the introversion factor and a sten score above the average indicated the extraversion factor. More specifically, a sten score of one through four represents the introversion personality dimension and a sten score of six through ten designates the extraversion component. A sten score of 5.0 to 5.9 designates "average" individuals; those having a balanced mixture of introversion and extraversion tendencies.

3 Roman numberals are used to distinguish the second-order factors from the primary factors, which are designated by alphabetic letters. See Raymond B. Cattell and Herbert W. Eber, Manual for Forms $A$ and $B$ Sixteen Personality Factor Questionnaire (Champaign, III.: Institute for Personality and Ability Testing, 1962), p. 19 .

4 The following example for estimating the Second-order IntroversionExtraversion Factor was taken from the Handbook for the Sixteen Personality Factor Questionnaire, p. 47.

Primary Factors Person's Score X Weight = Total Contribution

$\begin{array}{llll}\mathrm{A} & 8 & +.17 & +1.36 \\ \mathrm{E} & 6 & +.33 & +1.96 \\ \mathrm{~F} & 6 & +.41 & +2.46 \\ \mathrm{H} & 5 & +.48 & +2.40 \\ \mathrm{Q}_{2} & 3 & -.16 & -.48 \\ & & & -7.72 \\ & & \text { Plus Constant-1.26 }\end{array}$


Generally, introverted persons tend to be shy, self-sufficient, and inhibited in interpersonal contacts. These qualities may be favorable or unfavorable, depending upon the particular task the person is expected to perform. Conversely, extraverted persons tend to be socially outgoing, uninhibited, and good at making and maintaining personal contacts. In certain situations, these qualities may be desirable.

The data generated by the second-order factor and semantic responses are analyzed below, relative to the third hypothesis. The third hypothesis to reiterate, states:

Individual.s with extraverted personality characteristics will respond more favorably to reader oriented recruitment advertisements. Individuals with introverted personality traits, on the other hand, will respond less favorably to reader oriented messages.

Second-Ordex Responses to Massey's Recruitment Ads

The number of subjects in each extraversion, "average," and introversion grouping, respectively, were 164, 105, and 125. Differences in patterns of recruitment advertisement preferences with each of the extraversion (exvia), 5 "average," introversion (invia) 6 comparisons are reported in Table XXI for each of Massey's recruitment adverisisements. It can be seen from the table that these three personality grcups judged both ads as being connotatively "good." It is interesting to note that the exvia, average, and invia personality groupings showed clear-cut agreement on the characterization of the Massey advertisements. That is to say, they viewed both ads as being good, kind, believing, progressive, positive, reputable, masculine, hard, serious, active, excitable, and complex. There is, however, one notable exception; the exvia group felt that the company oriented

5 and 6 Cattel 1 frequently refers to extraversion-introversion factor as exvia-invia factor. 
TABLE XXI

SEMANTIC DIFFERENTAIL MEAN VALUES FOR MASSEY'S RECRUITMENT ADVERTISEMENTS BY SECOND-ORDER INTROVERSION-EXTRAVERSION FACTOR

\begin{tabular}{|c|c|c|c|c|c|c|c|}
\hline \multirow{2}{*}{$\begin{array}{l}\text { Sc. } \\
\text { No. }\end{array}$} & \multirow[b]{2}{*}{ Semantic Rating Scaies } & \multicolumn{3}{|c|}{ Reader Oriented $A d$} & \multicolumn{3}{|c|}{ Company Oriented Ad } \\
\hline & & Extraversion & Average & Introversion & Extraversion & Average & Introversion \\
\hline 1 & GOOD-BAD & 2.8 & 2.7 & 2.8 & 2.7 & 2.6 & 2.8 \\
\hline 2 & KIND-CRUEL & 2.9 & 2.8 & 2.8 & 2.9 & 2.8 & 2.9 \\
\hline 3 & BEIIEVING-SKEPTICAI & 3.4 & 3.2 & 3.4 & 3.0 & 3.1 & $3 \cdot 3$ \\
\hline 4 & PROGRESSIVE-REGRESSIVE & 2.3 & 2.1 & 2.2 & 2.2 & 2.2 & 2.2 \\
\hline 5 & POSITIVL-NEGATIVE & 2.1 & 2.1 & 2.0 & 2.2 & 2.1 & 2.0 \\
\hline 6 & REPUTABLE-DISREPUTABIE & 3.2 & 3.3 & 3.2 & 3.1 & 3.1 & 3.1 \\
\hline 7 & MASCULINE-FENININE & 3.1 & 3.4 & 3.2 & $3 \cdot 3$ & $3 \cdot 3$ & 3.2 \\
\hline 8 & HARD-SOFT & $3 \cdot 3$ & 3.5 & 3.2 & 3.4 & 3.4 & 2.8 \\
\hline 9 & SERIOUS-HUMOROUS & 2.7 & 2.9 & 2.6 & 2.9 & 3.0 & 2.8 \\
\hline 10 & ACTIVE-PASSIVE & 2.2 & 2.1 & 2.0 & 2.2 & 2.4 & 1.8 \\
\hline 11 & EXCITABLE-CAIM & 2.9 & 3.0 & 2.8 & 2.8 & 2.8 & 2.7 \\
\hline 12 & COMPLEX-SIMPLE & 4.8 & 4.6 & 4.7 & 5.0 & 4.4 & 4.7 \\
\hline
\end{tabular}

Source: Primary 
ad was simple rather than complex. (The mean scale score for the bipolar adjective complex-simple was five.) The above observations are based upon the direction in the polar continuum.

To test the significance of differences in the meaning of the concepts between any two personality groups for each of the semantic rating scales, " $t$ " tests were employed. Table XXII presents the " $t$ " values of those tests of significant differences. An analysis of the "t" tests indicates that extraverted, "average," introverted grouping perceived the ads significantly differently at the .05 level of significance.

A comparatively few significant differentiations were made apropos to the reader viewpoint advertising appeal of Massey's. This is particuIarly noted in the comparison of exvia-"average" and exvia-invia where only one significant difference was obtained. Signif'icant differences, on the other hand, were observed on three semantic rating scales between "average" and introverted individuals. Further analysis based upon the cumulative number of significant " $t$ " values for the second-order personality grouping revealed that introverted individuals viered the reader oriented concept more auspiciously than extraverted individuals. The lack of significant numbers of popular responses by extraverted individuals on the semantic rating scales does not disaffirm the third hypothesis. This lack of confirmation is presently limited to the reader viewpoint advertising of Massey's. The finding suggests that introverted persons are more responsive to reader oriented advertising copy than either extraverted or "average" second-order personality groups.

Turning to the company oriented ad of Massey's, the results of the "t" tests show that 10 of the 36 " $t$ " values were significantly different. 
TABIE XXII

"U" VALUES ${ }^{1}$ OF THE DIFFERENCES BETWEEN SECOND-ORDER FACTOR PAIRS FOR EACH OF MASSEY RECRUITMEIUT ADS AND EACH SEMAIPIC RATING SCALE

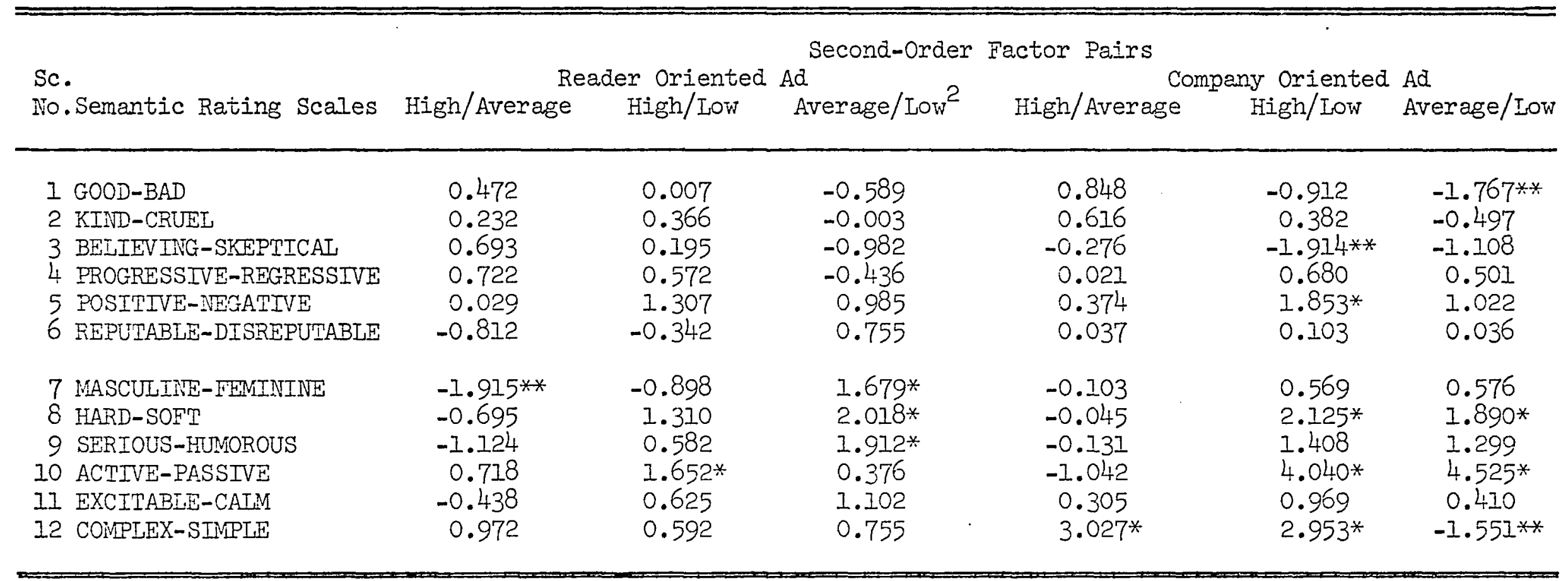

Groups compared: High-Average, High-Low, and Average-Low

Degrees of freedom: $167 \quad 287 \quad 230$

Critical "t" value single tailed test: 1.645

Ionly those values significant at the .05 level are shown with asterisks.

2 High--represents extraversion

Average--indicates a normal mixture of Extraversion-Introversion Tendency

Low--represents Introversion

* +1.645 indicates that average perceived the ads more favorably than high, low more favorably than high, and low more favorably than average.

**-1.645 indicates that high perceived the ads more favorably than average, high more favorably than low, and average more favorably than low.

Source: Table XXI 
A statistically significant response pattern was found for each secondorder personality grouping when compared with one another. The most interesting finding is the preference for company oriented writing by introverted individuals over other second-order groups. The "average" group, however, perceived the company oriented concept as being more desirable than second order extraversion groups.

The fact that introverted people responded more favorably than either extraverted or "average" individuals on both ads would seem to suggest that recruitment advertisement, regardless of writing style, is more effective on shy, self-sufficient, inhibited individuals than extraverted persons or those individuals having a balanced mixture of extraversion and introversion tendencies. Additional analysis, relevant to the third hypothesis, is presented below.

Dallas Mutual Life's Exvia-Invia Second-Order Responses

The specific objectives of this section are similar to those in the previous section, but they are presented here in the form of three questions of varying generalities: (a) What are the differing connotations of Dallas Mutual Life's recruitment advertisements, and are there any overa.l differences in connotation between exvia, "average," and invia individuals? (b) Do the connotations of the ads vary with personality types? (c) What personality type perceived the reader viewpoint advertisement of Dallas Mutual Iife most favorably?

Table XXIII gives the mean scale scores of the 164 extraverted individuals, 105 "average" persons, and 125 introverted people on each semantic rating scale for each stimulus. For the present, only gross differences are pointed out; however, individual " $t$ " tests were computed among the mean scores for each personality type. Both ads, as in all previous 
TABLE XXIII

SEMANTIC DIFFERENTIAI MEAN VALUES FOR DALLAS MUTUAL LIFE'S RECRUITMENT ADVERTISEMENTS BY SECOND-ORDER INTROVERSION-EXTRAVERSION FACTOR

\begin{tabular}{|c|c|c|c|c|c|c|c|}
\hline \multirow{2}{*}{$\begin{array}{l}\text { Sc. } \\
\text { No. }\end{array}$} & \multirow[b]{2}{*}{ Semantic Rating Scales } & \multicolumn{3}{|c|}{ Reader Oriented Ad } & \multicolumn{3}{|c|}{ Company Oriented Ad } \\
\hline & & Extraversion & Average & Introversion & Extraversion & Average & Introversion \\
\hline 1 & GOOD-BAD & 2.3 & 2.0 & 2.4 & 2.2 & 2.1 & 2.4 \\
\hline 2 & KIND-CRUSL & 2.8 & 2.6 & 2.8 & 2.7 & 2.8 & 3.0 \\
\hline 3 & BELIEVING-SKEPTICAL & 2.7 & 2.7 & 2.8 & 2.4 & 2.5 & 2.7 \\
\hline 4 & PROGRESSTVE-REGRESSIVE & 2.4 & 2.3 & 2.3 & 2.3 & 2.4 & 2.2 \\
\hline 5 & POSITIVE-NEGATIVE & 2.2 & 2.1 & 2.1 & 2.1 & 2.3 & 2.2 \\
\hline 6 & REPUTABLE-DISREPUTABAE & 2.9 & 2.7 & 2.9 & 2.6 & 2.7 & 2.7 \\
\hline 7 & MASCULINE-FEMININE & $3 \cdot 3$ & 3.2 & 3.1 & 3.5 & 3.5 & 3.4 \\
\hline 8 & HARD-SOFT & 3.4 & 3.3 & 3.2 & 3.9 & 3.5 & 3.4 \\
\hline 9 & SERIOUS-HUMOROUS & 2.0 & 2.2 & 1.8 & 2.1 & 2.6 & 2.0 \\
\hline 10 & ACTIVE-PASSIVE & 2.6 & 2.5 & 2.3 & 2.8 & 2.9 & 2.7 \\
\hline 11 & EXCITABLE-CAIM & 4.2 & 4.2 & 3.9 & 4.4 & 4.1 & $4 \cdot 3$ \\
\hline 12 & CONPLEX-SIMPLE & 4.1 & 4.2 & 4.4 & 4.1 & 3.9 & 3.9 \\
\hline
\end{tabular}

Source: Primary 
analyses (in this Chapter and Chapter IV), received positive connotation. Extraverted, "average," and introverted personality groups agreed on the neutral connotation of the bipolar adjective excitable-calm and complex-simple. This agreement was observed for both the reader and company oriented concepts. It seems as though introverted individuals had the most positive connotation of both concepts. The reader oriented advertising appeal appears to have received the greatest degree of favorable connotation from the "average" group. On the other hand, "average" and extraverted individuals perceived the company oriented ad very similarly. It is interesting to note, however, that introverted people, again, appeared to have the most positive connotation of this concept.

The first part of the first question, as to whether Dallas Mutual Life's stimuli had differing connotations from the three personality groups, seems easily answered in the affirmative. The differences, however, are primarily in the degree of connotative favorableness. The second part, concerned with allover differences between personality types, apparently differed in the degree of auspicious connotation. The qualifying phrase "apparently" should be stressed since the observations were based upon gross magnitude rather than any test of significant differences.

In order to answer the second question, regarding personality differences in the connotation of the experimental stimuli, "t" tests were conducted. Table XXIV presents the results of these parametric tests. Examining Table XXIV, it will be noted that there were significant differences among personality types. Specifically, when the responses of extraverted, "average," and introverted individuals to the reader oriented 
TABIE XXIV

"t" VALUES ${ }^{I}$ OF THE DIFFERENCES BETWEEN SECOND-ORDER FACTOR PAIRS FOR EACH OF DALIAS MUTIUAL LIFE ADS AND EACH SEMANTIC RAIING SCALE

\begin{tabular}{|c|c|c|c|c|c|c|c|}
\hline \multirow{2}{*}{$\begin{array}{l}\text { Sc. } \\
\text { No. }\end{array}$} & \multirow[b]{2}{*}{ Semantic Rating Scales } & \multicolumn{6}{|c|}{ Second-Order Factor Pairs } \\
\hline & & High/Average & $\mathrm{High} /$ Low & Average/Low ${ }^{2}$ & High/Average & High/Low & Average/Low \\
\hline 1 & GOOD-BAD & $1.693 *$ & -0.696 & $-2.895 * *$ & 0.617 & -1.561 & $-2.027^{* *}$ \\
\hline 2 & KIND-CRUPL & 1.450 & -0.220 & $-2.125 * *$ & -0.395 & $-2.858 * *$ & $-1.707^{* *}$ \\
\hline 3 & BEIIEVING-SKEPTICAI & 0.102 & -0.536 & -0.539 & -0.955 & $-2.272 * *$ & -0.925 \\
\hline 4 & PROGRESSIVE-REGRESSIVE & 1.053 & 1.138 & -0.453 & -0.557 & 1.216 & $1.725 *$ \\
\hline 5 & PCSITIVE-NEGATIVE & 0.644 & 0.548 & -0.461 & -1.336 & -1.015 & 0.908 \\
\hline 6 & REFUTAELD-DISREPUTABLE & 1.066 & 0.003 & -1.296 & -0.474 & -0.522 & 0.196 \\
\hline 7 & MASCULINE-FEMININE & 0.057 & 1.300 & 0.968 & 0.005 & $2.190 *$ & $1.651 *$ \\
\hline 8 & HARD-SOFT & -0.360 & $1.762 *$ & $1.982 *$ & $1.987 *$ & $3.465 *$ & 0.107 \\
\hline 9 & SERIOUS-IUUMOROUS & -1.326 & $1.918 *$ & $3.270 *$ & $-2.967 * *$ & $1.747 *$ & $5.448 *$ \\
\hline 10 & ACIIVE-PASSIVE & 0.404 & $2.804 *$ & $1.831 *$ & 0.340 & 1.562 & $1.775 *$ \\
\hline 11 & EXCITABLE-CAIM & -0.290 & $1.660 *$ & $1.796 *$ & 1.394 & 0.953 & -1.054 \\
\hline 12 & COMPLEX-SIMPLE & -0.315 & 0.321 & 0.689 & 0.935 & 1.472 & -0.047 \\
\hline
\end{tabular}

Groups compared: High-Average, High-Low, and Average-Iow

Degrees of freedom: $167 \quad 187 \quad 230$

Critical "t" value single tail test: 1.645

${ }^{I}$ only those values significant at the .05 level are show with asterisks

2High--represents Extraversion

Average--a normal mixture of Extraversion-Introversion Tendency

Low--represents Introversion

* +1.645 indicates that average perceived the ads more favorably than high, low more favorably than high, and low more favorably than average.

**-1.645 indicates that high perceived the ads more favorably than average, high more favorably than Iow, and average more favorably than low.

Source: Table XXIII 
stimulus are compared, significant differences are observed in each comparison. This comparison reveals that only one statistically significant difference was obtained between exvia and "average" individuals, four significant patterns of responses emerged between exvia and invia persons, and "average" and invia people differed significantly on six of the 12 semantic rating scales. In view of these results, it may be concluded that personality differences are present in the connotation of the reader viewpoint concept.

Since the single tailed "t" test was utilized, the following observations were noted for the reader oriented ad. First of all, "average" people perceived the ad moxe favorably than extraverted individuals. Secondly, introverted persons demonstrated a greater preference for the concept than extraverted people. Finally, introverted individuals viewed the ad connotatively better than "average" persons. Interesting, also, is that extraverted persons had the least positive connotation of the concept. These results would seem to suggest that the connotative meaning of recruitment advertisements vary with personality types.

In pursuing the same line of analysis for the company oriented concept, significant differences in the pattern of responses emerged between extraverted and "average" individuals. Introverted people were found to have perceived this stimulus more favorably than extraverted persons. The pattern of response differences between "average" and introverted persons was significant and indicated that introverted individuals held the ad in higher esteem than "average" persons. These results further suggest that connotative meaning relative to writing style in recruitment ads varies with personality groups.

The last question, the personality type that perceived the reader 
viewpoint ad most favorably, was approached by summing the number of significant "t" values relative to each personality type. This summation revealed that introverted individuals perceived the reader oriented concept more propitiously than either extraverted or "average" persons. This result further disapproves the third hypothesis that extraverted individuals respond more favorably to reader viewpoint recruitment advertisements than introverted persons. Interesting, also, is that introverted individuals also viewed the company oriented concept more auspiciously than either of the other personal.ity groups. This finding and the findings relative to Massey's recruitment advertisements suggest that perhaps introverted individuals, because of their "make-up", are more susceptible to advertising, at least to recruitment advertisement, than either "average" or extraverted individuals. Discussion of the experimental results are presented in the subsequent section.

\section{Discussion and Implication of Findings}

The most significant implication of this investigation seems to the author to be the following: There is significant evidence to indicate that a relationship exists between personality traits, personality types (extraversion-introversion) and the perception of written mass communication.

Experinental results demonstrated that personality traits favoring reader viewpoint witing differed from those preferring company oriented advertising messages. This empirical evidence indicated with a high degree of consistency that there is a relationship existing between the 
traits humble, conscientious (delicately balanced with casualness), trusting, self-assured, relaxed (to a lesser degree than other traits noted in the P.F.), and reader viewpoint recruitment advertisements. The traits referred to as humble, conscientious (balanced with casualness), shy, trusting, practical, forthright, self-assured, and conservative bear a very important relation to company oriented recruiting messages. of all the personality traits studied, those which are related to reader and company oriented advertising seem to be sufficiently important to influence the perception of recruitment advertisement. What is important here is that there is a definite indication that personality differences do, in fact, influence the perception of written mass communication, or at least the recruitment advertisements utilized in the present experimental investigation. It seems reasonable to suggest, then, that advertisers in their attempt to attract prospective employees should try to develop advertising copy with interpersonal appeal. That is to say, they should develop advertising messages which appeal to personality traits or personality types that are regarded as being desirable by the employer. It would seem that copywriters are capable of offering advertising messages compatible with personality traits or personality types. Research similar to the one delineated in this study may be helpful in clearing the way for future investigation dealing with personality and its effects on the perception of written mass communication. Differences in advertising writing style may be of more overriding importance than differences inl company imagery; the results of this investigation seem to bear out this generalization, since the names of the advertisers in the experimental ads were fictitious. Moreover, differences in writing styles may be especially important when companies use rather 
similar advertising appeals such as those used in recruitment advertisement which stress promotion opportunities, bonuses, challenging work, and so on. In such cases, the writing style may minimize differences in prospective employees' predj.sposition toward the company.

Generally, advertising copies are not pure types seeking to cater to certain personality characteristics. For example, recruitment advertisements generally attract more thas one type of individual. Therefore, it seems that written recruiting messages which psychologically employ personal pronouns, such as "you," "your," or "we," "our," "us," woild provide some sort of emotional involvement, and thus, the advertising message may be generally attractive to certain personality types. The results of the present investigation seem to support such a notion. For example, this research indicated that humble, conscientious, trusting, self-assured, relaxed individuals preferred reader oriented recruiting messages. Conversely, persons possessing traits described as shy, practical, forthright, and conservative, favored the company oriented advertising appeals.

Experimental results also demonstrated that personality types (extraverts-introverts) are definitely an influencing factor in the perception of written mass comnunication. Introverts were more sensitive to recruiting messages than either extraverts or "average" individuals. Because of this, there are communication implications for both advertisers and copywriters. It would seem likely that there may be analogous situations in other forms of advertising writing style as well, although the experiment report was confined to only reader and company oriented writing styles.

Personality traits and personality types may well be a meaningful 
variable in communication and persuasion processes. Therefore, written mass communication may be segmented along the lines of personality factors delineated by Cattell. Much more research, however, is needed in this and other related areas. Advertising writing style seeking specific personality traits or personality types might benefit from compatible intexpersonal appeals. Differential preferences for receiving interpersonal influence may cause individuals possessing certain personality characteristics to prefer one advertising writing style over another and ultimately, one company over another.

\section{Capsule Presentation of Experimental Results}

The findings presented in the present Chapter reinforce the idea that personality characteristics affect the perception of written mass communications. The experiment did indicate that persons possessing certain personality traits responded differently to reader and company oriented recruitment advertisements. The findings also showed that personality traits inherent in individuals caused them to react differently to the experimental variables, thereby confirming the first hypothesis.

The data further indicated that there were personality differences between favorable responses to reader and company oriented advertising appeals. In fact, exposure to reader viewpoint advertising copy demonstrated that six personality factors of the 16 P.F. were consistentIy related to this form of advertising writing style. Specifically, the factors included were: C (average), E (humble), G (average), I (trusting), 0 (self-assured), and $Q_{4}$ (relaxed).

Factors $\mathrm{I}$ (humble), G (average), H (shy), I (trusting), M (practical), $N$ (fortluight), $O$ (self-assured), and $Q_{1}$ (conservative) were consistently 
related to company oriented recruitment advertisements. Throughout the experiment, four personality variables described as humble (Factor $\mathrm{E}$ ), conscientiousness balanced with casualness (F'actor G), trusing (Factor I), and self-assured (Factor 0), favored both reader and company oriented advertisements.

Itwas also found that personality types which included extraverted, "average," and introverted individuals differed in their preferences for advertising writing styles. Introverted people responded more favorably to reader viewpoint recruiting messages than either "average," or extraverted individuals. Extraverted persons, on the other hand, held the least positive view of reader viewpoint advertising than either of the other personaiity types. This result did not support the third hypothesis: Which vredicted that extraverted persons would respond nore propitious?y to alvexising copy presented from the reader's point of view than introvexted people. It was further observed that introverted indiviaualis al_o viewed the company oriented messages more favorably than "average" or extraverted persons.

These results confirmed the first and second hypotheses, but rejected the third hypothesis. In spite of the rejection of the third hypothesis, the results of this investigation may be interpreted as further empirical evidence for the notion that personality traits and personality types are meaningful variables in communication and persuasion processes. 
CHAPTER VI

SUMMARY AND CONCLUSIONS

The major purposes of this experimental research have been (1) to discover the extent to which demographic factors influence the perception of written mass communication and (2) to ascertain the effects of personality characteristics on the perception of reader and company oriented. recruitment advertisements. Specifically, the investigation focused upon (a) the relationship between demographic factors and responses to advertising writing style (company or reader oriented) and (b) the relationship between personality traits and responses to company and reader oriented advertising copy.

To the author's knowledge, no previous research has been directly associated with personality traits or demographic characteristics as factors affecting the perception of written mass communication. This lack of research prompted this investigator to formulate five hypotheses. They are:

1. There are certain personality traits inherent in individuals which will cause them to react differently to written mass communication.

2. There are personality differences, as measured by the Cattell Sixteen Personality Factor Questionnaire, between favorable perception of reader oriented advertisements and favorable responses to advertisements which are company oriented.

3. Individuals with extraverted personality characteristics will respond more favorably to reader oriented recruitment advertisements. Individuals with introverted personality traits, on the other hand, will respond less favorably to reader oriented messages. 
4. Written recruitment advertisements presented as reader oriented messages will induce more Pavorable responses than company orientied messages, regardless of personality characteristics.

5. Demographic factors such as sex, aze, and college classification are influential in generating more favorable responses for reader oriented recruitment advertisements than for company oriented recruitment advertisements.

Results relative to the above hypotheses are briefly summarized in the subsequent sections.

\section{Experimental Results Relative to Evpotheses IV and V}

Since students of communications generally believe that reader viewpoint writing elicits more favorable responses than company oriented writing, the purpose of the fourth hypothesis was to empirically determine whether or not this assertion was correct.

The intent of the fifth hypothesis was to extend the scope of the fourth hypothesis by ascertaining whether demographic factors were responsible for inducing favorable responses to recruiting ads structured with reader viewpoint writing.

Major Findings--Fourth Hypothesis

The mean values and semantic profiles clearly demonstrated that all four experimental ads had favorable appeal. It was speculated, especially for the Massey's ads, that the difference in writing styles was too subtle for respondents to make sharp distinctions in evaluating the ads on the semantic differential. A test of significant difference had to be employed in order to determine which writing style was most favorably perceived. The differences, then, were merely a matter of degree and not direction. 
The test of significant difference at the .05 level revealed that respondents favored the company oriented advertising appeal of Massey ${ }^{2} \mathrm{~S}$ over its reader oriented ad. Dallas Mutual Life's reader oriented ad, on the other hand, was viewed significantly better than its company oriented advertising copy. The findings, of course, partially affirm and partially disaffirm the fourth hypothesis. However, the results did, in part, substantiate the generalized belief that readex oriented writing will receive a more favorable reaction. Perhaps, additional research where differences in writing styles are not subtle would completely support the fourth hypothesis and the views of students of conmunications.

Findings--Demographic Hypothesis

The information produced by the semantic differential was analyzed according to sex, age, and college classification to ascertain whether demographic factors were related to semantic responses. After analyzing the semantic profiles of both men and women, it was found that the sexes responded favorably to all four experimental stimuli. In no instance were there any apparent differences for men and women in the opposite direction. They never crossed each other on the negative end of the polar continuum.

However, the "t's" comparing the mean values for males and females met the value normally required for the one-tailed test of significant difference at the .05 Iuvel. Closer examination of these "t" values disclosed that significant differences between males and females existed for every concept, and that men viewed both reader and company oriented advertising copy more praiseworthy than women. Men also indicated a greater preference for reader viewpoint advertising messages than for company 
oxiented recruitment advertisements. This finding partially supported the fifth hypothesis (at least as far as sex is concerned).

On the basis of the evidence produced by the test of significant differences, the perception of advertising writing style appeared to be a function of age. This tenable conclusion was based upon the fact that as age increased, the number of significant "t" values decreased. overall, the "t" test results for age groups indicated that the company oriented advertising copy of Massey's was more desirable than its sister recruitment ad. In contrast, the arge groups favored the reader oriented advertisement of Dallas Mutual Life over its company oriented advertising appeal. It was interesting to note that individuals between 17 and 19 years of age appeared to be very sensitive in their reaction toward the experimental concepts. The older and more mature (27 to 44 Years of are) subjects, however, indicated they were the least responsive of all groups to the recruitment advertisements.

Since the various age groups demonstrated that they preferred the company oriented ad in one instance and in another instance they preferred the reader viewpoint advertising copy, the demographic hypothesis was only given partial credence.

As a group, the college classification categories perceived the company oriented ad of Massey's connotatively better than its reader viewpoint advertising copy. Conversely, this "group" judged the reader oriented writing of Dallas Mutual Life more desirable than its twin recruiting ad. Once again, this overall pattern of responses provided only partial validation for the fifth hypothesis.

It was found that the greater the difference in college classification, the greater the number of significant " $t$ " values, thereby indicating, perhaps, that the perception of recruitment advertisements was a 
function of college classification. College Freshmen and Sophomores appeared to be more impressionable in their assessment of recruitment ads. Special Indergraduate students, on the other hand, judged the ads less positively than any other classification group.

The findings generated by the demographic data clearly indicated some support for the fifth hypothesis. Throughout this investigation, respondents consistently demonstrated they preferred Dallas Mutual Life's reader oriented ad over its company oriented ad. And respondents also consistently favored the company oriented message of Massey's over its reader oriented counterpart. This consistency was marked, however, with one exception; male subjects responded more favorably to both reader viewpoint ads, while female subjects did not indicate significant preference for either form of advertising writing style.

The possible reasons advanced for the partial confirmation of the fifth hypothesis included:

1. Dallas Mutual Life's reader oriented ad (with 605 words of which 39 were "you" and "your" pronouns and 17 were "we," "us" and "our" pronouns) was of sufficient length to adequately develop the you attitude depicting employment benefits and opportunities, thus, eliciting more favorable responses than its company oriented twin (with 501 words of which four were "reader oriented" pronouns and 18 were "company oriented" pronouns).

2. Massey's company oriented ad (with 162 words) made more effective use of the "company oriented" pronouns than was originally anticipated. Massey's reader oriented ad, on the other hand, (with 225 words) made very subtle use of the 18 "you" and "your" pronouns. This subtIeness, to speculate, rendered the ad obviously less effective than the company 
oriented ad which made effective use of the "we," "our" and "us" pronouns. It was further speculated that it does not seem to matter how often the "reader oriented" pronouns are used in short advertising copy (1ess than 300 words), since, generally, the length does not permit a detailed description of benefits and employment opportunities.

Influence of Personality Characteristics: An Empirical Analysis

Chapter $V$ dealt with the possible relationship between semantic responses and personality characteristics, as measured by the Cattell 16 P.F. The objective of this chapter was to determine the influence of personality characteristics on the perception of written mass communication. Specifically, three major hypotheses were tested. The purpose of the first hypothesis was to ascertain whether or not personality traits caused individuals to respond differently to recruitment advertisements. While the purpose of hypothesis one was to test the influence of traits on the perception of written mass communication, the second hypothesis attempted to determine which personality traits caused individuals to respond more favorably to reader viewpoint recruitment messages and which ones caused them to respond more favorably toward company oriented recruitment advertisements. Finally, the third hypothesis was formulated to test whether extraverted or introverted individuals reacted more propitiously to reader viewpoint advertising copy.

Personality Traits and Hypotheses I and II

Experimental results showed that semantic responses were related to individual differences. It was found that personality traits inherent in persons caused them to react differentiy to recruitment advertisements. 
An analysis of the semantic responses to Massey's reader oriented recruitment ad revealed that individuals possessing certain personality traits perceived the ad differently. The test of significant differences further showed that the individuals with personality traits described as outgoing, more intelligent, humble, sober, venturesome, tough-minded, trusting, imaginative, self-assured, experimenting, self-sufficient, undisciplined self-conflict, and relaxed responded more favorably to Massey's reader oriented advertising appeal.

- Responses to the company oriented message of Massey's also demonstrated that the majority of the subjects having certain personality traits perceived the stimulus connotatively differently. Individuals characterized as reserved, humble, sober, shy, tough-minded, trusting, practical, forthright, self-assured, conservative, self-sufficient, and undisciplined self-conflict had the most favorable attitude towards Massey's company viewpoint advertising copy. In contrasting the personality profile which favored the company orjented message of Massey's, it was found that these profiles differed on nearly 50 per cent of the personality factors.

Similar findings were noted in the analysis of the data generated by the Dallas Mutual Life recruitment ads. For example, the D statistic showed that a very small percentage (about 10 per cent) of the personality variables viewed the reader viewpoint message of Dallas Mutual Life alike. In contrast, 83 per cent of the personality variables demonstrated perceptual disparity for Dallas Mutual Life's company oriented advertising copy. The study also showed that the personality profiles of those who favored the reader oriented. message differed from those who preferred the company oriented ad. 
Those who were favorably inclined toward the reader viewpoint advertising writing style tended to be reserved, concrete thinkers, docile, trusting, easily pleased, placid, cautious, joiners, and unfrustrated; whereas, those who favored the conpany oriented message were characterized as concrete thinkers, emotionally stable, humble, timid, self-reliant, trusting, practical, sentimental, serene, conservative, and joiners. A comparison of profiles showed that differences occurred on eight of the 16 personality factors.

The above findings generated support for the first and second hypotheses. Personality traits inherent in individuals did cause them to react differently to the experimental stimuli. Moreover, the results clearly showed that individuals who preferred reader viewpoint witing possessed certain personality traits, whereas those who favored company oriented writing possessed certain other identifiable personality traits.

\section{Second-Order Factor and Hypothesis III}

An investigation of second-order factor and semantic responses revealed that the personality dimension of extraversion and introversion was sensitive to recruitment advertisements. Specific results indicated that introverted individuals responded more favorably to the Massey's recruitment ads than either "average" or extraverted persons. Similar findings were noted of the Dallas Mutual Life advertisements. Introverted individuals found both ads more desirable than any of the other secondorder personality groups. The study also showed that extraverted persons were less responsive than "average" individuals to recruitment advertisements.

Since introverted individuals responded more favorably to reader oriented advertising appeals than extraverted people, the third hypothesis 
was rejected. The overriding observation from this investigation indicates that a relationship does, in fact, exist between personality characteristics and the perception of written mass conmunication.

\section{Conclusions of the Study}

On the basis of the evidence presented in this study, the following conclusions seem tenable:

1. That individuals, regardless of their personality characteristics, did not consistently respond favorably to reader oriented writing.

2. That the demographic factors, age and college classification, had some effect upon the reaction to reader oriented advertisement. As groups, age and college classification, in one instance, favored the reader oriented ad of Dallas Mutual. Iife, and in another instance, they viewed the company oriented ad of Massey's more desirable.

3. That men perceived reader oriented recruiting messages more auspiciously than women.

4. That the perception of recruitment ads is a function of age and college classification.

5. That Freshmen and Sophomores are more sensitive to recruiting advertising than either Juniors, Seniors, or Special Undergraduate students.

6. That persons between the ages of 17 and 19 are more responsive to written advertisements than individuals between the ages of 20 and 44 .

7. That certain personality traits, as measured by the 16 P.F. were associated with favorable reactions to reader viewpoint writing, while other identifiable personality traits were related to favorable responses to company oriented writing. 
8. That introverted individuals, as selected and measured by the instrument used jn this study, were more receptive to recruitment advertisement than either "average" or extraverted individuals.

This study provides both a methodology for determining the relationship between demographic factors, personality characteristics and responses to written mass communication and a means for evaluating advertising writing style. Moreover, the research methodology does offer a promising source of information to advertisers appealing to certain personality characteristics of prospective employees. 
SELECTED BIBI.IOGRAPHY 
SELECTPD BIBLIOGRAPHY

\section{A. BOOKS}

Allport, Gorcion w. Personality: A Psychological Interpretation. New York: Henry Holt and Company, 1937. 588 pp.

Bartley, S. Howard. Principles of Perception. New York: Harper \& Brothers, 1958. $482 \mathrm{pp}$.

Blake, Robert R., and G. V. Ramsey. Perception: An Approach To Personality. Wew York: Ronald Press, 1951. T42 pp.

Boyd, William P., and Raymond V. Lesikar. Productive Business Writing. Englewool. Cliff, N.J.: Prentice-Hall, Inc., 1959. 513 pp.

Buros, Oscar Krisen. The Sixth Mental Measurements Yearbook. Highland Park, N.J.: The Gryphon Press, 1965. 520 pp.

Catte11, Raymond B. An Introduction to Personality Study. New York: Hutcinson's University Library, 1950. $235 \mathrm{pp}$.

- Personality: A Systematic Theoretical and Factual Study. New York: MeGraw-Hïli Book Company, Inc., 1950.689 pp.

, and Herbert $w$. Eber. Handbook for the Sixteen Personality Factor Questionnaire. Champaign, Illinois: Institute for Personality and Ability Testing, 1957. 54 pp.

- Handbook Supplement for Form $\mathrm{C}$ of the Sixteen Personality Factor Questionnaire. Second edition. Champaign, Illinois: Institute for Persoanlity and Ability Testing, 1962. 27 pp.

- The Scientific Analysis of Personality. Baltinore: Penquin Books, Inc., 1967. 399 pp.

Damerst, William A. Resourceful Business Communication. New York: Harcourt, Brace \& Norld, Inc., 1966. $527 \mathrm{pp}$.

Engel, James F., Hugh G. Wales, and Martin Warshaw. Promotional Strategy. Homewood, Illinois: Richard D. Irwin, 1967. 665 pp.

Engle, T. I. Psychology: The Principle and Applications. New York; World Book Company, 1957. 657 pp.

English, Horace B. A Student's Dictionary of Psychological Terms. Yellow Springs, ohio: The Antioch Press, 1928. 60 pp. 
Hasen, Harry L. Marketing: Text, Cases, and Readings. Homewood, Illinois: Richard D. Irwin, 1961. 940 pp.

Hovland, Carl I., and Irving I. Janis (editors). Personality and. Persuasibility. Volume II. New Haven: Yale University Press, 1959. $333 \mathrm{pp}$.

Jung, Carl G. Psychological Types. New York: Harcourt, Brace \& World, Inc., 1946. $357 \mathrm{pp}$.

Kerlinger, Fred N. Foundations of Behavioral Research. New York: Holt, Rinehart and Winston, Inc., 1964. $739 \mathrm{pp}$.

Lesikar, Raymond V. Business Communication: Theory and Application. Homewood, IIIino is: Richard D. Irwin, $1968.547 \mathrm{pp}$.

Lindquist, E. F. Design and Analysis of Experiments In Psychology and Education. Boston: Houghton Miffilin Company, $\overline{1953.425}$ pp.

Osgood, Charles E., George J. Suci, and Percy H. Tannenbaum. The Measurement of Meaning. Urbana, Illinois: University of Illinois Press, 1957. $342 \mathrm{pp}$.

Rokeach, Milton. The Open and Closed Mind. New York: Basi: Books, Inc., 1960. $4+7$ pp.

Schroder, Harold M., Michael J. Driver, and Siegfried Streufert. Human Informatjon Processing. New York: Holt, Rinehart and Winston, Inc., 1967. $224 \mathrm{pp}$.

\section{B. PERIODICALS}

Allport, Floyd H., Lynette E. Walker, and Eleanor Lathers. "Written Composition and Characteristies of Personality, "Archives of Psychology, XXVI, No. 173 (December, 1934), pp. 1-82.

Allport, Gordon W. "What Is A Trait of Personality?" Journal of Abnormal and Social Psychology, XXV, No. 4 (January-March, I930), pp. $308-3 \overline{72}$.

, and H. Cantril. "Judging Personality From Voice," Journal of Sucial Psychology, V, No. I (February, 1934): pp. 37-55.

- "Traits Revisited," American Psychologist, XXI, No. I (January, 1966), pp. 1-11. 
Anderson, A. W. "Personality Traits In Reading Ability of Western Australian University Freshmen," Journal of Edueational Research, IIV, No. 6 (February, 1961), pp. $\overline{234-237}$.

Barban, Arnold M., and Edward W. Cundiff. "Negro and White Response to Advertising Stimuli," Journal of Marketing Research, I, No. 4 (November, 1964), pp. 53-56.

Barrett, Gerald V., and Jay I. Otis. "The Semantic Differential As A Measure of Changes In Meaning In Educational and Vocational. Counseljing," Psychological Reports, XX, No. 4 (February, 1967) pp. 335-338.

Bennett, George K., and H. Phoebe Gordon. "Personality Test Scores and Success in the Field of Nursing," Journal of Applied Psychology, XXVIII, No. 3 (June, 1944), pp. 267-278.

Blocher, Donald H. "Relationships Among Self-descriptions, Occupational Stereotypes, and Vocational Preferences," Journal of Counseling Psychology, VIII, No. 2 (Winter, 1961), pp. 314-317.

Bogard, Howard M. "Union and Management Trainee--A Comparative Study of Personality and Occupational Choice," Journal of Applied Psychology, XIIV, No. I (February, 1960), pp. 56-63.

Brehm, Jack W., and David Lipsher. "Communicator-Communicatee Discrepancy and Perceived Communicator Trustworthiness," Journal of Personality, XXIII, No. 3 (September, 1959), pp. 352-36I.

Carrigan, Patricia M. "Extraversion-Introversion as Dimension of Personality: A Reappraisal," Psychological Bulletin, I, No. 5 (September, 1960), pp. 329-359.

Carroll, John B. "The Measurement of Meaning. By Charles E. Osgood, George J. Suci, and Percy H. Tannenbaum: Reviewed," Language, XXXV, No. I (January-March, 1959), pp. 57-58.

Cattell, Raymond B. "A Shortened 'Basic English' Version (Form C) of the 16 P.F. Questionnaire," The Journal of Social Psychology, XLIV, No. 2 (November, 1956), pp. 257-278.

, and John H. Marony. "The Use of the 16 P.F. In Distinguishing Homosexuals, Normals, and General Criminals," Journal of Consultins Psychology, XXVI, No. 6 (December 1962), pp. 531-540.

, and Samuel King. "Personality Factor Profile Peculiar to the Student Smoker," Journal of Counseling Psychology, XIV, No. 2 (March, 1967), pp. 116-12I. 
Cohen, Joel B. "An Interpersonal. Orientation to the Study of Consumer Behavior," Journal of Marketing Research, IV, No. 3 (August, 1967), pp. 270-278.

Comrey, Andrew L. "A Study of Thirty-Five Eersonality Dimensions," Educational and Psychological Measurement, XXII, No. 3 (Autumn, 1962), pp. 543-55I.

Diphoye, W. J., and W. F. Anderson. "Occupational Stereotype and Manifest Needs of High School Students," Journal of Counseling Psychology, VIII, No. 4 (Winter, 1961), pp. 296-304.

Dow, Clyde W. "The Personality Traits of Eifective Public Speakers," Speech Monographs, XXVII, No. 4 (Decerver, 1941), pp. 525-532.

Duncan, Melba H. "An Experimental Study of Some of the Relationships Between Voice and Personality Among Students of Speech," Speech Monograpis, XII (Research Annual, 1945), pp. 47-60.

Dunnettee, Marvin D., and Wayne K. Kirchner. "Psychological Test Differences Between Industrial Salesmen and Retail Salesmen," Journal Applied Psychology, XIIV, No. 2 (April, 1960), pp. 121-125.

Endler, Norman S. "Changes in Meaning During Psychotherapy as Measured by the Semantic Differential," Journal of Counseling Psychology, VIII, No. 2 (Summer, 1961), pp. 105-111.

Forehand, Garlie A. "Relationships Among Response Sets and Cognitive Behaviors," Educational and Psychological Measurement, XXII, No. 2 (Fall, 1960), pp. 287-302.

Frandsen, Kenneth D., James R. Rockey, and Yarion Kleinau. "Changes in the Factorial Composition of a Semantic Differential as Function of Differences in Readers Theatre Productions," Speech Monographs, XXXII, No. 2 (June, 1965), pp.112-118.

Garner, W. R. "To Perceive Is To Know," American Psychologist, XXI, No. I (January, 1966), pp. 11-19.

Golden, Alfred L. "Peijonality Traits of Drama School students," Quarterly Journal of Speech, XXVI, No. 4 (December, 1940), pp. 564-575.

Gonyea, George G. "Dimensions of Job Perceptions," Journal of Counseling Psychology, VIII, No. 4 (Winter, 1961), pp. 305-313.

Hanawalt, Nelson G., and Helen M. Richardson. "Leadership as Related to the Bernreuter Personality Measure: Ir. An Item Analysis of Responses of Adult Leaders and Non-Ieaders," Journal of Applied Psychology, XXVIII, No. 5 (October, 1944), pp. 397-410. 
Holland, John L. "The Relation of the Vocational Preference Inventory to the Sixteen Personality Factor Questionnaire," Journal of Applied PsychoIogy, XIIV, INo. 3 (August, 1960), pp. 291-296.

Holler, A: 0., and Carole E. Wolff. "Personality Orientations of Farm, Village, and Uxban Boys," Rural Sociology, IXVII, No. 3 (September, 1962), pp. 275-293.

Hood, Albert B. "A study of the Relationship Between Physique and Personality Variables Measured by the MMPI," Journal of Personality, XXXI, No. 2 (March, 1963), pp. 97-107.

Husek, T. R. "Acquiescence as a Response Set and as a Personality Characteristic," Educational and Psychological Measurement, XXI; No. 2 (Fall, 1961), pp. 295-307.

Izard, Carroll E. "Personality Characteristics of Engineers as Measured by the Edwards Personal Preference Schedule," Journal Applied Psychology, XIIV, No. 5 (October, 1968), pp. $3 \overline{32-335 .}$

Janis, Irving L., and Seynour Feshbach. "Effects of Fear-Arousing Communications," The Journal of Abnormal and Social. Psychology, XLVIII, No. 1 (Jamuary, 1953), pp. 78-83.

Jenkins, James J., and Wallace A. Russell. "An Atlas of Semantic Profiles for 360 Words," The American Journal of Psychology, IXXI, No. 4 (December, 1958), pp. 688-699.

Jurgensen, Clifford E. "Report on the 'Classification Inventory,' a Personality Test for Industrial Use," Journal of Applied Psychology, XXVIII, No. 6 (December, 1944), pp. 445-460.

Kassarjian, Harold H. "Social Character and Differential Preference for Mass Communication," Journal of Marketing Research, II, No. 2 (May, 1965), pp. 146-153.

Kelly, Jane A., and Leon H. Levy. "The Discriminability of Concepts Differentiated by Means of the Semantic Differential, "Educational and Psychological Measurement. XXI, No. I (Spring, 1961), pp. 53-57.

Kempler, Bernhard and Morton Wiener. "Personality-Perception Characteristic Response to Available Part-Cues," Journal of Personality, XXXII, No. 2 (March, 1964), pp. 57-74.

Kjeldergaara, Paul M. "Attitudes Towards Newscasters as Measured by the Semantic Differential," Journal of Applied Psychology, XIV, No. I (February, 1961), pp. 35-40. 
Korman, Maurice. "Implicit Personality Theories of Clinician as Defined by Semantic Structures," Journal of Consulting Psychology, XXIV, No. 2 (April, 1960), pp. 180-186.

LaForge, Rolfe. "A Correlational study of. Two Personality Tests: The MMPI and Catte11 16P.F.," Journal of Consulting Psychology, XXVI, No. 5 (October, 1962), pp. 402-411.

Lambert, Wallace E., and Leon A. Jakobovits. "Verbal Satiation and Changes In the Intensity of Meaning," Journal of Experimental Psychology, Lix, No. 6 (December, 1960), pp. 376-303.

Ievonian, Edward. "A Statistical Analysis of the 16 Personality Factor Questionnaire," Educational and Psychological Measurement, XXI, No. 3 (Autumn, 1961), pp. 589-596.

- "Personality Measurement With Items Selected From the 16 P.F. Questionnaire," Educational and Psychological Measurement, XXI, No. 4 (Wintex, 1961), pp. 937-946.

Iittle, Kenneth B. "Connotations of the Rorschach Inkblots," Journal of Personali.ty, XXVII, No. 3 (September, 1959), pp. 397-400.

Iuria, Zella. "A Semantic Analysis of a Normal and a Neurotic Therapy Group," Journal of Abnormal and Social Psychology, LVIII, No. 2 (March, 1959), pp. $\overline{216-220 .}$

Maltz, Howard E. "Ontagenetic Change In the Meaning of Concepts as Measured by the Semantic Differential," Child Development, XXXIV, No. 3 (September, 1963), pp. 667-674.

Manis, Melvin. "Assessing Communication With the Semantic Differential," Journal of American Psychology, LXXII, No. 2 (March, 1959), pp. 111-113.

Margolis, Charles and Charles R. Porter. "The Relationship of Message Unity ('Full') to the Recipient's Response Potential," Journal of Applied Psychology, XI, No. 6 (Decembex, 1959), pp. 361-368.

McDavid, John W., and Frank Sistrunk. "Personality Correlates of Two Kinds of Conforming Behavior," Journal of Personality, XXXII, No. 3 (Septcmber, 1964), pp. $420-434$.

Messick, Samuel. "Response Style and Content Measures from Personality Inventories," Fiducational and Psychological Measurement, XXII, No. I (Spring, 1962), pp. 4.1-55.

Miller, Gerald R., and Murray A. Hewgill. "Some Recent Research on FearArousing Message Appeals," Speech Monographs, XXXIII, No. 4 (November, 1966), pp. 377-391. 
Mindak, William A. "Fitting the Semantic Differential to the Marketing Problem," Journal of Marketing, XXV, No. 2 (April, 1961), pp. 28-33.

Moss, C. Scott. "Current and Projected Status of Semantic Differential Research," The Psychological Record, X, No. I (January, 1960), pp. $47-54$.

Murray, Elwood. "Personality Studies In Speech," Speech Monographs, II, No. 1 (October, 1935), pp. 51-52.

Nunnally, Jim C., and Ronald. L. Flaugher. "Correlates of Semantic Habits," Journal. of Personality, XXXI, No. 2 (June, 1963), pp. 192-201.

Osgood, Charles E., and George J. Suci. "A Measure of Relation Determined by Both Mean Differences and Profile Information," Psychological Bulletin, XIIX, No. I (January, 1952), 251-262.

- "The Nature and Measurement of Meaning," Psychological Bulletin, XIIX, No. 3 (May, 1952), pp. 192-237.

, and Zella Iuria. "A Bline Analysis of a Case of Multiple Personality Using the Semantic Differential," Journal of Abnormal and Social Psychology, XIIX, No. 4 (October, 1954), pp. 579-591.

, and Percy H. Tannenbaum. "The Principle of Congruity in the Prediction of Attitude Change," Psychological Review, LXII, No. 1 (January, 1965), pp. 42-55.

- "Studies on the Generality of Affective Meaning Systems," American Psychologist, XVII, No. I (January, 1962), pp. 10-28.

Osmon, William R. "The Personality Patterns of Failing Freshmen, Indiana State College, 1961-1962," The Teachers College Journal, XXXV, No. 2 (November, 1963), pp. $61-65$.

Rabin, A. I. "A Contribution to the 'Meaning' of Rorschacks's Inkblots Via the Semantic Differential," Journal of Consulting Psychology, XXIII, No. 4 (August, 1959), pp. $\overline{368-374}$.

Richardson, Helen M. and Nelson G. Hanawalt. "Leadership as Related to the Bernreuter Personality Measure: III. Leadership Among Adult Men in Vocational and Social Activities," Journal of Applied Psychology, XXVIII, No. 4 (August, 1944), pp. 308-317.

Sanford, Fillmore H. "Speech and Personality," Psychological Bulletin, XXXIX, No. I (December, 1942), pp. 811-845.

Secord, Paul F., and Ellen Saumex Berscheid. "Stereotyping and the Generality of Implicit Personality Theory," Journal of Personality, XXXI, No. I (March, 1963), pp. 65-77. 
Segal, Stanley J. "A Psychoanalytic Analysis of Personality Factors in Vocational Choice," Journal of Counseling Psychology, VIII, No. 3 (F'all, 1961), pp. 202-209.

Shepherd, John R., and Thomas M. Scheidel. "A Study of the Personality Configuration of Effective Oral Feeders," Speech Monographs, XXIII, No. 4 (November, 1956), pp. 298-304.

Smith, Raymond G. "Development of s Semantic Differential For Use with Speech Related Concepts," Speech Uonographs, XXVI, No. 4 (November, 1959), pp. 263-272.

- "A Semantic Differential For Theatre Concepts," Speech Monographs, XXVIII, No. 1 (March, 196.l), pp. 1-8.

Spilka, Bernard, T. D. Hanley, and M. D. Steer. "Personality Traits and Speaking Intelligibility," The Journel of Abnormal and Social Psychology, XLVIII, No. I (Februemy, 1953), pp. 330-333.

Suhr, Virtus W. "Personality and Driving Efficiency," Perceptual and Motor Skills, XII, No. I (February, 1961), p. 34.

Triandis, Harry C. "Differential Perception of Certain Jobs and People by Managers, Clerks, and Workers in Industry," Journal Applied Psychology, XIIII, No. 4 (August, 2959), pp. 22I-225.

- "A Comparative Factorial Analysis of" Job Semantic Structures of Managers and Workers," Journal of Applied Psychology, XIIV, No. 5 (October, 1960), pp. 297-302.

Tucker, W. T. "How Much of the Corporate Image Is Stereotype?" Journal of Marketing, XXV, No. 3 (January, 196I), pp. 6I-65.

Weaver, Carl H. "The Quantification of the Frame of Reference in Iabor Management Communication," Journal of Applied Psychology, XIII, No. 1 (February, 1958), pp. 1-8.

Wilding, John and Raymond A. Bauer. "Consumer Goals and Reactions to a Communication Source," Journal of Marketing Research, V, No. I (February, 1968), pp. 73-77.

Wyer, Robert S. Jr. "Assessment and Correlates of Cognitive Differentiation and Integration," Journal of Personality, XXXII, No. 3

(September, 1964), pp. 495-509. 


\section{UNPUBLISHED MATERIALS}

Duncan, Walter Jackson. "On The Epistemology and Methadology of Management and Organizations: A General Semantics Approach with an Analysis of Academic Opinion." Unpublished Doctorial dissertation, Louisiana State University, Baton Rouge, 1969.

Pettit, John Douglas, Jr. "An Analysis of the Effects of Various Message Presentations on Communicatee Responses." Unpublished Doctorial dissertation, Louisiana State University, Baton Rouge, 1969.

\section{MISCELIAANEOUS}

College Placement Annual 1.969. Bethelhem, Pa.: The College Placement Council, Inc., 1968. $695 \mathrm{pp}$. 
A P P EN DICES 


\section{-}

Appendix A: Experimental Recruitment Advertisements 
RETAILING'S GOT THE ACTION!

MASSEY'S IS RETAILING!

As you may know, retailing is America's biggest industry!

It may interest you to know that retailing is anticipating. Innovating. Influencing. You'11 find that retailing is change. And Massey needs you to continue to change with it. You can help us to continue a growth rate that ritnessed the opening of 190 new stores over the last 10 years. You' 11 also note that during the past decade Massey has established the widely acclaimed Merchandise Research and Development Testing Laboratory. Introduced new concepts in catalog merchandising. Instituted centralized control buying. And laid dynamic new plans for expansion that calls for an average of: 25 store openings a year.

This is the kind of growth that can make your advancement opportunities move fast--in virtually every professional category. You'Il find that Massey has a lot to offer you. Your opportunities include annual performance appraisals, liberal bonuses that range up to $200 \%$ of your base salary, a modern benefit program designed especially for you to build on, and much more. If you're a person who wants to move up fast, there's no better place to turn your potential loose than right here. At the changing lassey. Is your future in retailing? This booklet, describing your many career opportunities at Massey, may provide the answer. For more facts on what your future can be at Massey send for your free copy today.

D. C. Borbas, College Relations Coordinator Administrative office \& Corporate Headquarters

619 W. Chicago Avenue/Chicago, Illinois 60607

An Equal Opportunity Employer 
AN UNUSUAL OPPORTUNITY FOR COLLEGE GRADUATES

WHY THIS PROGRAM?

You'll find that the rapid growth of Tre Dallas Mutual Life in recent years and aggressive plans for continued expansion intensify our need for young men and women. If you possess initiative and leadership ability, it's very likely your abilities and our outlook are made for each other. Sales training is designed to develop you for management responsibilities as soon as your capabilities permit. Cur Sales and Sales Management Training Program has been established $\doteqdot$ help you to develop to your full potential and advance you into a position of increasing responsibility.

WHAT IS OUR OBJECIIVE?

It may interest you to know that The Iallas Mutual Life conducts its sales and service activities through 100 general agency offices throughout the United States. You'II find thet the men and women who head these offices represent the Company in all insurance matters. They are men and women of broad executive ability, resnected in their communities. Operating for all practical purposes as independent businessmen, they enjoy excellent incomes and have freedom of ection. The Sales and sales Management Training Program is designes primarily to prepare you for future general agency openings and for other sales management opportunities in the Field and Home Office.

HOW MANY MEN AND WOMEN DO WE' NEED?

It shouldn't surprise you that we have no absolute minimum or maximum quota. As a nation-wide organization there are always more opportunities than there are good men and women available. You'Il find that we will not sacrifice quality for quantity.

\section{CAN YOU QUALIFY?}

If your background and college experience have led you to think independently, to be resourceful and to exercise sound judgment you can qualify for this program. If you're a person mo can demonstrate evidence of leadership, initiative and ambition tnis.program is designed especially for you. It may interest you to knov that we also want young men and women who appreciate that financial incependence and security are much more likely to result from a career ofiering full opportunity for development of personal skills than from one where progress is limited by factors beyond personal capacity and performance. If you are such a person we have some truly unusual opportunities for you. 
You'Il find all the training you need. The program has several phases in which you receive intensive training at the Home office. It is designed primarily to develop your initiative, your sales ability, your executive judgment and your self-confidence. You are invited to send for the brochure, "Sales and Sales Management Training Program," which gives you a step by step detail of the program.

ABOUT THE DALLAS MUTUAL LIFE

As you may know, Dallas Mutual Life was founded in 1846, and it is respected as one of the finest life insurance companies in the world. With over two billion dollars of assets, you'll find it ranks among America's major financial institutions. You'll also note that its management is aggressive, and views the future as a challenge to continue the growth of the past century.

ACTUARIAI, OPPORTUNITIES

A limited number of Home office positions are available to you in Dallas Mutual Life's Actuarial Training Program. If you have an outstanding overall college record with particular strength in mathematics you should investigate the excellent opportunities available to you in the actuarial profession.

HOW TO APPLY

To learn more about a Dallas Mutual. Iife career write to: James $W$. Shaner, Department P, The Dallas Mutual Life Insurance Company, Hartford, Connecticut 06115. You will be sent an application blank and a brochure giving you further details. A personal interview may then be arranged for you. 


\section{RETAIIING'S GOT THE ACTION!}

MASSEY'S IS RETAILING!

Retailing is America's biggest industry!

Retailing is anticipating. Innovating. Influencing. Retailing is change. And Massey continues to change with it. In the past decade, Massey has opened 190 new stores. Installed the industry's largest Data Control Center. Established the widely acclaimed Massey's Merchandise Research and Development Testing Laboratory. Introduced new concepts in catalog merchandising. Instituted centralized control buying. And laid dynamic plans for expansion that call for an average of 25 store openings a year.

This is the kind of growth that means fast-moving advancemement opportunities--in virtually every professional category. Opportunities that include annual performance appraisals, liberal bonuses that range up to $200 \%$ of base salary, a modern benefit program, and much more. If you're a person who wants to move up fast, there's no better place to turn your potential loose than right here. At the changing Massey. Is your future in retailing? This booklet, describing the many career opportunities at Massey, may provide the answer. Send for your free copy today.

D. C. Borbas, College Relations Coordinator Administrative Office \& Corporate Headquarters 619 W. Chicago Avenue/Chicago, Illinois 60607 
AN UNUSUAL OPPORTUNITY FOR COLIEGE GRADUATES

\section{WHY THIS PROGRAM?}

The rapid growth of The Dallas Mutual Life in recent years and assressive plans for continued expansion intensify our need for men and women with initiative and leadership ability. Sales training is one of the best methods of developing young men and women who are able to take advantage of management opportunities. Our Sales and Sales Management Training Program has been established to accomplish this training and develop such talent.

\section{WHAT IS OUR OBJECTIVE?}

The Dallas Mutual. Iife conducts its sales and service activities through 100 general agency offices throughout the United States. The men and women who head these offices represent the company in all insurance matters. They are men and women of broad executive ability, respected in their communities. Operating for all practical purposes as independent businessmen, they enjoy excellent income and have great freedom or action. The Sales and Sales Management Training Program is designed primarily to develop young men and women for future general agency openings and for other sales management opportunities in the Field and Home Office.

\section{HOW MANY MEN AND WOMEN DO WE NEED?}

We have no absolute minimum or maximum quota. As a nation-wide orsanization there are always more opportunities than there are good men and. women available. But we will not sacrifice quality for quantity.

\section{CAN YOU QUALIFY?}

For this program we are seeking men and women whose background and college experience have led them to think independently, to be resourceful and to exercise sound judgment. We look for evidence of leadership, initiative and ambition. We want men and women who appreciate that financial independence and security are much more likely to result from a career offering full opportunity for development of personal skills than from one where progress is limited by factors beyond personal capacity and performance. For such men and women we have some truly unusual opportunities.

\section{WHAT WILL YOU DO WHIIE TRAINING?}

The program has several phases, including intensive training at the Home Office, designed to develop initiative, sales ability, executive judgment and self-confidence. For details of the program, step by step, you are invited to send for the brochure, "Sales and Sales Management Training Program." 
Founded in 1846, The Dallas Mutual Iife is respected as one of the finest life insurance companies in the vorld. With over two billion doliars of assets, it ranks among America's major financial institutions. Its manarrement is aggressive, and views the future as a challenge to continue the growth of the past century.

ACTUARIAL' OPPORTUNITIES

The Dallas Mutual Iife has a limited nuber of Home Office positions in our Actuarial Training Program. Men $\equiv x d$ women who have an outstanding overall college record with particular strength in mathematics should investigate the excellent opportunities availabie in the actuarial profession.

HOW TO APPLY

Write to James $W$. Shaner, Department 三, The Dallas Mutual Life Insurance Company, Hartford, Connecticut 06115. An application blank will be sent to you with a brochure giving further betails. A personal interview may then be arranged. 
Appendix B: Sixteen Personality Factor Test Profile 
16 P.F. TEST PROFILE

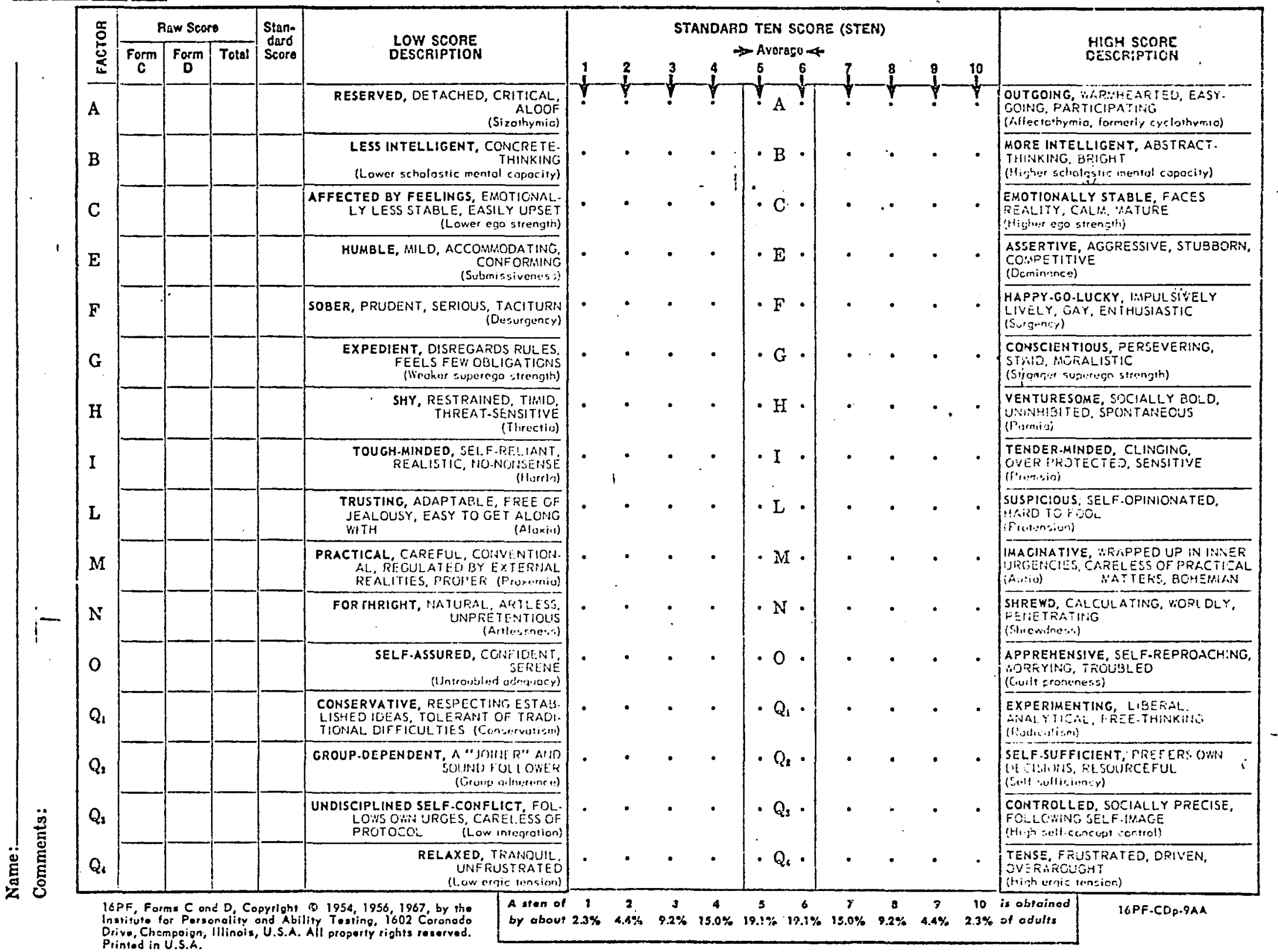


Appendix C: Semantic Difierential Questionnaires 
CLASSIFICATION DATA

NAMST

SEX AGE $M$ or $F$

1. Are you presently enrolled in Management 71-72? Yes No

2. Have you had Management 71? Yes No

3. Check the appropriate blank to indicate your MAJOR FIELD OF STUDY. Accounting Marketing General Business

Finance
Management Secretarial Administration Economics Statistics

General Business
other $\frac{\text { Secretarial Administration }}{\text { write in }}$

4. Check the appropriate blank to indicate your CLASSIFICATION.

Freshman
Sophomore
write in

5. What type of employment will you seek when you complete your college education? 
The purpose of this study is to measure your impression of recruitment advertisement copy. In order to accomplish this objective you are asked to judge these ads against a series of descriptive scales.

It is important that you mark the scales on the basis of your reaction to the writing style. On each page you will find a different ad to evaluate and behind it a set of scales. The scales should be marked as follows:

If you think the concept at the top of the descriptive scale page is very closely related to one end of the scale place your mark in the following manner:

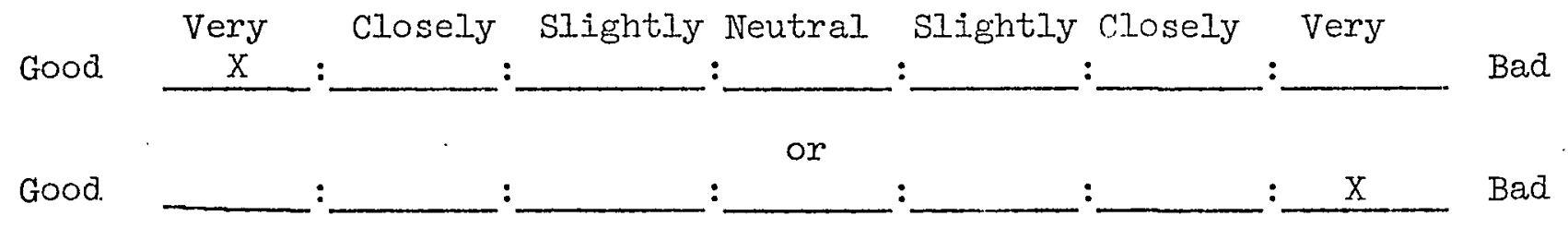

If you think the concept is quite closely related to one end of the scale (but not extremely), mark it as follows:

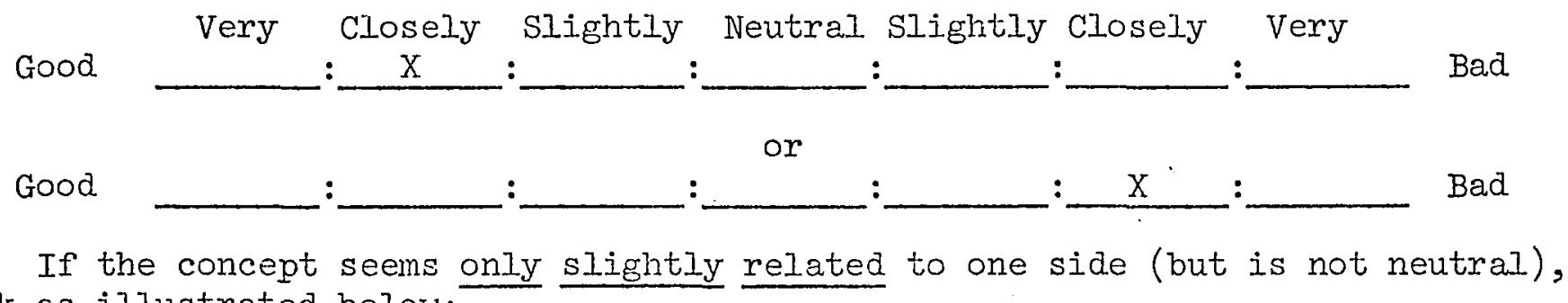
mark as illustrated below:

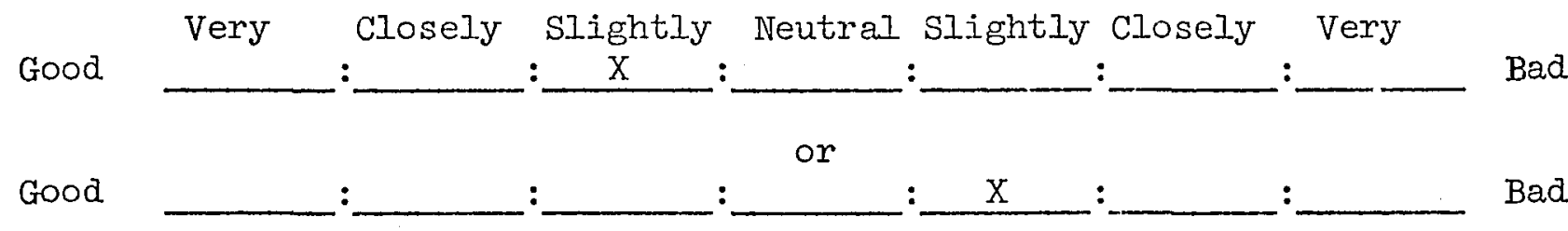

The extreme toward which you mark depends upon which extreme seems the most characteristic of the adverisement being judged. If you think the concept is neutral with respect to a particular scale or that a given scale is completely irrelevant, place your mark in the middle space.

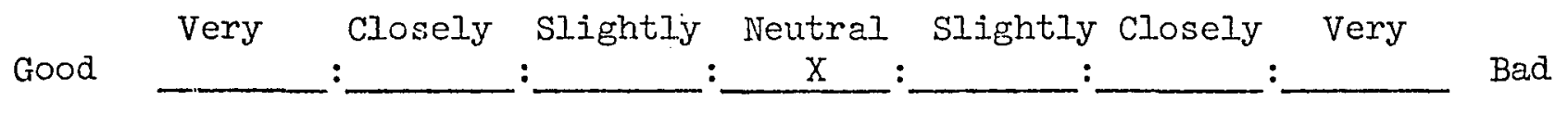


IMPORTANT:

(1) Please mark in the center of the space

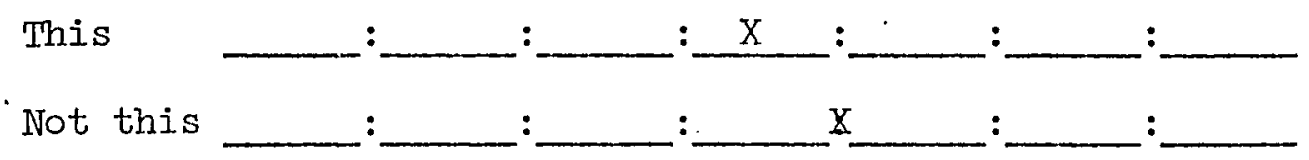

(2) Please mark every scale for every concept--do not omit any.

(3) Never put more than one mark on a single scale.

None of the concepts will be repeated so please do not look back and forth through the items and do not try to remember how you marked associated items earlier in the questionnaire. Make each item a separate and independent judgment.

You are encouraged to work at a fairly high rate of speed. Do not be puzzled over individual items; it is your first impression that is important. On the other hand, please work carefully so that the true impressions may be revealed. 


\section{RETAIJING'S GOT THE ACTION!}

\section{MASSEY'S IS RETAILING!}

\section{As you may know, retailing is America's biggest industry!}

It may interest you to know that retailing is anticipating. Innovating. Influencing. You'll find that retailing is change. And Massey needs you to contime to change with it. You can help us to continue a growth rate that witnessed the opening of 190 new stores over the last 10 years. You'll also note that during the past decade Massey has established the widely acclaimed Merchandise Research and Development Testing Laboratory. Introduced new concepts in catalog rerchandising. Instituted centralized control buying. And laid dynamic new plans for expansion that calls for an average of 25 store openings a year.

This is the kind of growth that can make your advancement opportunitjes move fast--in virtually every professional category. You'll find that Massey has a lot to offer you. Your opportunities include annual performance appraisals, liberal bonuses that range up to $200 \%$ of your base salary, a modern benefit program designed especially for you to build on, and much more. If you're a person who wants to move up fast, there's no better place to turn your potential loose than right here. At the changing Massey. Is your future in retailing? This booklet, describing your many career opportunities at Massey, may provide the answer. For more facts on what your future can be at Massey send for your free copy today.

D. C. Borbas, College Relations Coordinator Administrative Office \& Corporate Headquarters

619 W. Chicago Avenue/Chicago, Illinois 60607 


\section{MASSEY' 'S}

In the space below, you are to rate your impression of this ad on each of these scales.

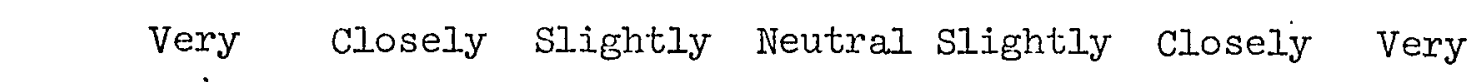

GOOD

: : :

KIND

:

$:$

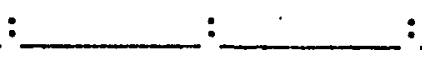

CRUEL

BELIEVING

:

:

:

:

: SKEPTICAL

PROGRESSTVE :

: $-$

:

: REGRESSIVF

POSITIVE : : : : : $-$ NEGATIVE

DISREPUIABLE FEMININE

HARD

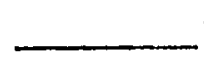
: $:$ : $: \quad:$ SOFT

HUMOROUS : : : : : : SERIOUS ACTIVE : : : : PASSIVE CAIM : : : $-$ : EXCITABIJE : $:$ : COMPLEX 
AN UNUSUAL OPPORTUNITY FOR COLLEGE GRADUATES

\section{WHY THIS PROGRAM?}

You'll find that the rapid growth of The Dallas Mutual Life in recent years and aggressive plans for continued expansion intensify our need for young men and women. If you possess initiative and Jeadership ability, it's very likely your abilities and our outlook are made for each other. Sales training is designed to develop you for management responsibilities as soon as your capabilities permit. Our Sales and Sales Management Training Program has been established to help you to develop to your full potential and advance you into a position of increasing responsibility.

\section{WHAT IS OUR OB-JECTIVE?}

It may interest you to know that The Dallas Mutual Life conducts its sales and service activities through 100 general agency offices throughout the United States. You'll find that the men and women who head these offices represent the Company in all. insurance matters. They are men and women of broad executive ability, respected in their communities. Operating for all practical purposes as independent businessmen, they enjoy excellent incomes and have freedom of action. The Sales and Sales Management Training Program is designed primarily to prepare you for future general agency openings and for other sales management opportunities in the Field and Home office.

HOW MANY MEN AND WOMEN DO WE NEED?

It shouldn't surprise you that we have no absolute minimum or maximum quota. As a nation-wide organization there are always more opportunities than there are good men and women available. You'll find that we will not sacrifice quality for quantity.

\section{CAN YOU QUALIFY?}

If your background and college experience have led you to think independentiy, to be resourceful and to exercise sound judgment you can qualify for this program. If you're a person who can demonstrate evidence of leadership, initiative and ambition this program is designed especially for you. It may interest you to know that we also want young men and women who appreciate that financial independence and security are much more likely to result from a career offering full opportunity for development of personal slilils than from one where progress is limited by factors beyond personal capacity and performance. If you are such a person we have some truly unusual opportunities for you.

\section{WHAT WILL YOU DO WHILE TRAINING?}

You'll find all the training you need. The program has several phases in which you receive intensive training at the Home office. It is designed primarily to develop your initiative, your sales ability, your executive judgment and your 
self-confidence. You are invited to send for the brochure, "Sales and Sales Management Training Program," which gives you a step by step detail of the program.

ABOUT THE DALLAS MUIUAT, LIFE

As you may know, Dallas Mutual Life was founded in 1846, and it is respected as one of the finest life insurance companies in the world. With over two billion dollars of assets, you'Il find it ranks amone America's major financial institutions. You'll also note that its management is aggressive, and views the future as a challenge to continue the growth of the past century:

ACTUARIAT, OPPORTUNTTIES

A limited number of Home office positions are available to you in Dallas Mutual Iife's Actuarial Training Program. If you have an outstanding overall college record with particular strength in mathematics you should investigate the excellent opportunities available to you in the actuarial profession.

HOW TO APPLY

To learn more about a Dallas Mutual Life career write to: James W. Shaner, Department $\mathrm{P}$, The Dallas Mutual Iif'e Insurance Company, Hartford, Connecticut 06115. You will be sent an application blank and a brochure giving you further details. A personal interview may then be arranged for you. 
DALLAS MUTUAL LIFE

In the space below, you are to rate your impression of this ad on each of these scales.

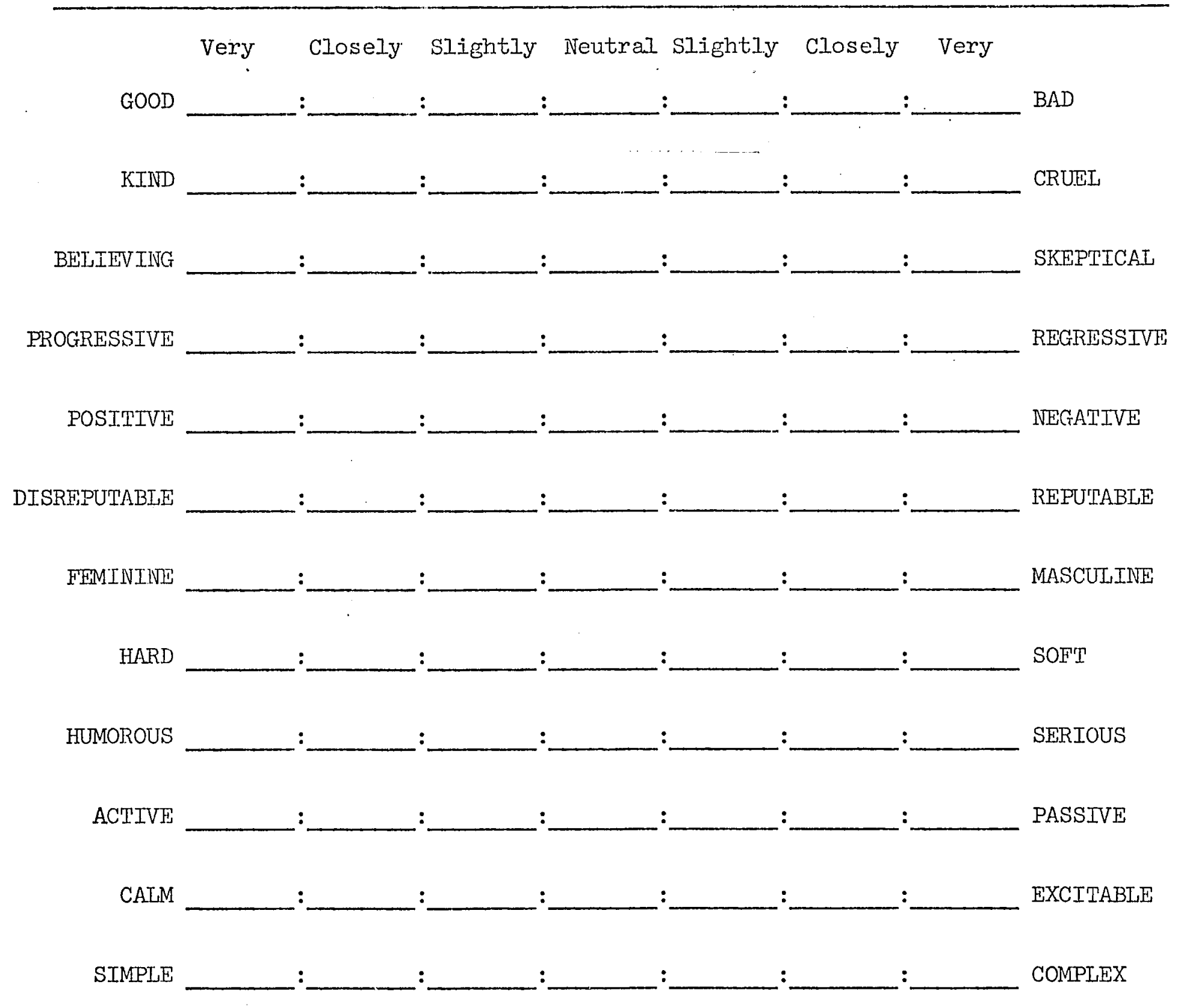




\section{INSTRUCTIONS}

The purpose of this study is to measure your impression of recruitment advertisement copy. In order to accomplish this objective you are asked to judge these ads against a series of descriptive scales.

It is important that you mark the scales on the basis of your reaction to the writing style. On each page you will find a different ad to evaluate and behind it a set of scales. The scales should be marked as follows:

If you think the concept at the top of the descriptive scale page is very closely related to one end of the scale place your mark in the following manner:

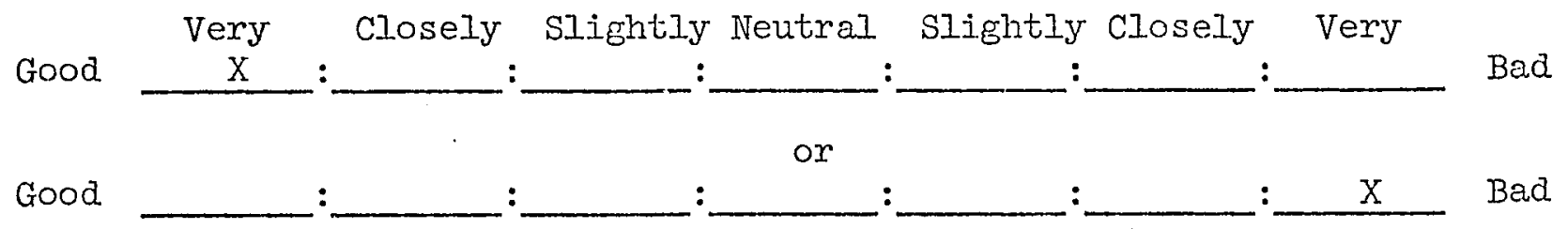

If you think. the concept is quite closely related to one end of the scale (but not extremely), mark it as follows:

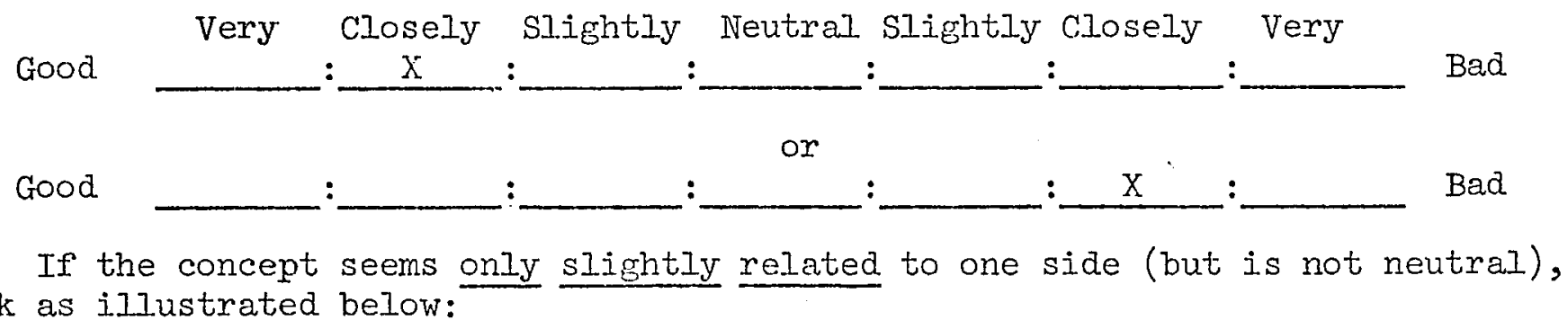
mark as illustrated below:

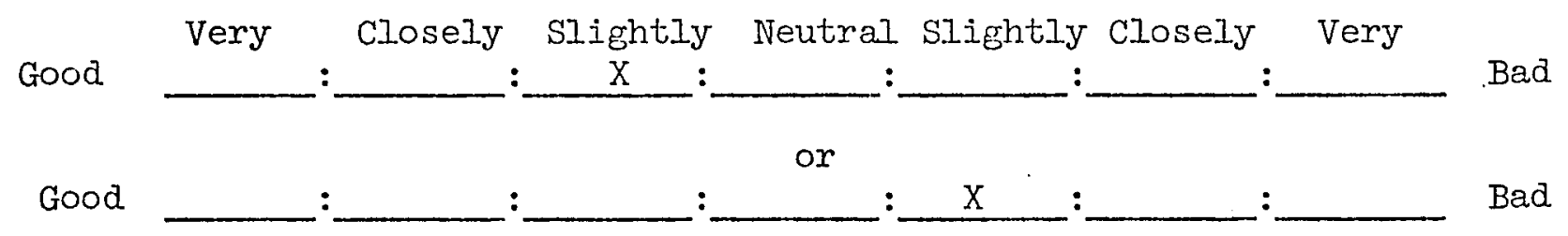

The extreme toward which you mark depends upon which extreme seems the most characteristic of the advertisement being judged. If you think the concept is neutrail with respect to a particular scale or that a given scale is completely irrelevant, place your mark in the middle space.

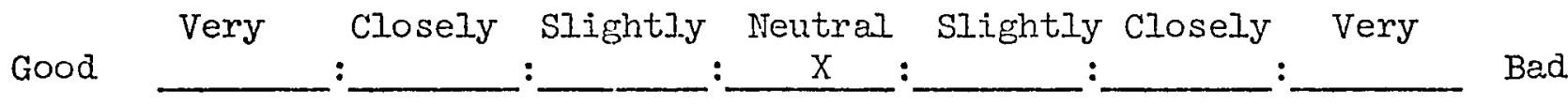


IMPORTANT:

(1) Please mark in the center of the space

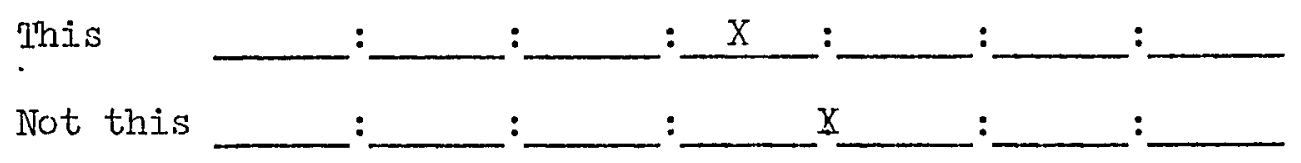

(2) Please mark every scale for every concept-- do not omit any.

(3) Never put more than one mark on a single scale.

None of the concepts will be repeated so please do not look back and forth through the items and do not try to remember how you marked associated items earlier in the questionnaire. Make each item a separate and independent judgment.

You are encouraged to work at a fairly high rate of speed. Do not be puzzled over individual items; it is your first impression that is important. On the other hand, please work carefully so that the true impressions may be revealed. 
RETAILING'S GOT IYHE ACTION!

MASSEY'S IS RETAILING!

\section{Retailing is America's biggest industry!}

Retailing is anticipating. Innovating. Influencing. Retailing is change. And Massey continues to change with it. In the past decade, Massey has opened 190 new stores. Installed the industry's largest Data Control Center. Established the widely acclaimed Massey's Merchandise Research and Development Testing Iaboratory. Introduced new concepts in catalog merchandising. Instituted centralized control buying. And laid dynamic plans for expansion that call for an average of 25 store openings a year.

This is the kind of growth that means fast-moving advancement opportunities-in virtually every professional category. Opportunities that include annual performance appraisals, liberal bonuses that range up to $200 \%$ of base salary, a modern benefit program, and much more. If you're a person who wants to move up f'ast, there's no better place to turn your potential loose than right here. At the changing Massey. Is your future in retailing? This booklet, describing the many career opportunities at Massey, may provide the answer. Send for your free copy today.

D. C. Borbas, College Relations Coordinator Administrative Office \& Corporate Headquarters 619 W. Chicago Avenue/Chicago, Illinois 60607

An Equal Opportunity Employer 


\section{MASSEY'S}

In the space below, you are to rate your impression of this ad on each of these scales.

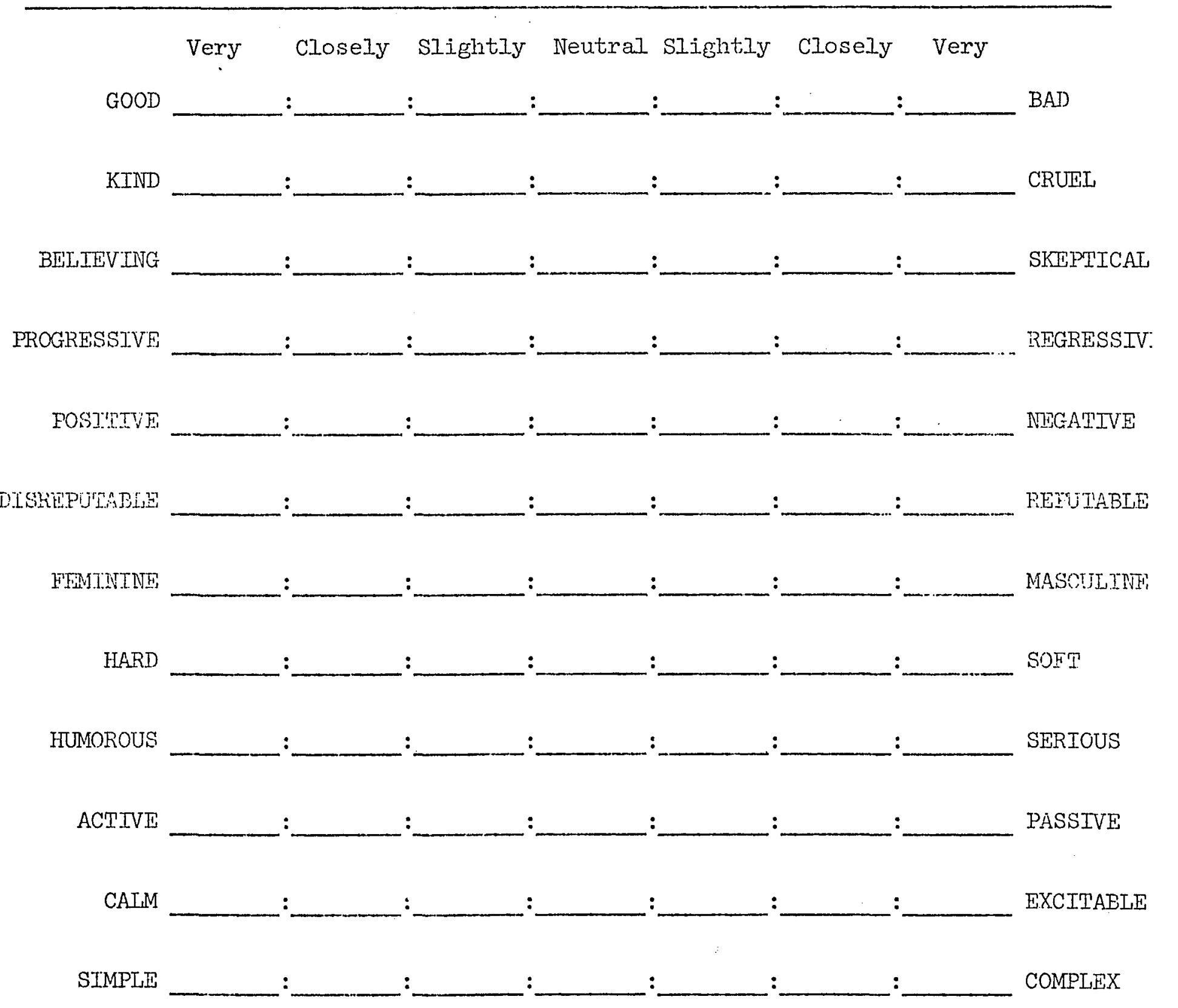




\section{AN UNUSUAT OPPORTUNITY FOR COLLEGE GRADUATES}

\section{WHY THIS PROGRAM?}

The rapid growth of The Dallas Mutual Life in recent years and aggressive plans for continued expansion intensify our need for men and women with initiative and leadership ability. Sales training is one of the best methods of developing young men and women who are able to take advantage of management opportunities. our Sales and Sales Management Training Program has been established to accomplish this training and develop such talent.

WHAT IS OUR OBJECTIVE?

The Dallas Mutual Life conducts its sales and service activities through 100 general agency offices throughout the United States. The men and women who head these offices represent the Company in all insurance matters. They are men and women of broad executive ability, respected in their communities. Operating for all practical purposes as independent businessmen, they enjoy excellent income and have great freedom of action. The Sales and Sales Management Training Program is designed primarily to develop young men and women for future general agency openings and for other sales management opportunities in the Field and Home office.

HOW MANY MEN AND WOMEN DO WE INEED?

We have no absolute minimum or maximum quota. As a nation-wide organizatiori there are always more opportunities than there are good men and women available. But we will not sacrifice quality for quantity.

\section{CAN YOU QUALIFY?}

For this program we are seeking men and women whose background and college experience have led them to think independently, to be resourceful and to exercise sound judgment. We look for evidence of leadership, initiative and ambition. We want men and women who appreciate that financial independence and security are much more likely to result from a career offering full opportunity for development of personal skills than from one where progress is limited by factors beyond personal capacity and performance. For such men and women we have some truly unusual opportunities.

WHAT WILL YOU DO WHILE TRAINING?

The program has several phases, including intensive training at the Home office, designed to develop initiative, sales ability, executive judgment and selfconfidence. For details of the program, step by step, you are invited to send for the brochure, "Sales and Sales Management Iraining Program."

\section{ABOUT THE DALLAS MUIUAI, LIFE}

Founded in 1846 , The Dallas Mutual Life is respected as one of the finest life insurance companies in the world. With over two billion dollars of assets, it 
ranks among America's major finarcial institutions. Its management is aggressive, and views the future as a challenge to continue the growth of the past century.

\section{ACTUARIAT OPPORTUNITIES}

The Dallas Mutual Life has a limited number of Home Office positions in our Actuarial Training Program. Men and women who have an outstanding overall college record with particular strength in mathematics should investigate the excellent opportunities available in the actuarial profession.

HOW TO APPLY

Write to James W. Shaner, Department P, The Dallas Mutual Iife Insurance Company, Hartford, Connecticut 06115. An application blank will be sent to you with a brochure giving further details. A personal interview may then be arranged. 
DALIAS MTTUAI LIFE

In the space below, you are to rate your impression of this ad on each of these scales.

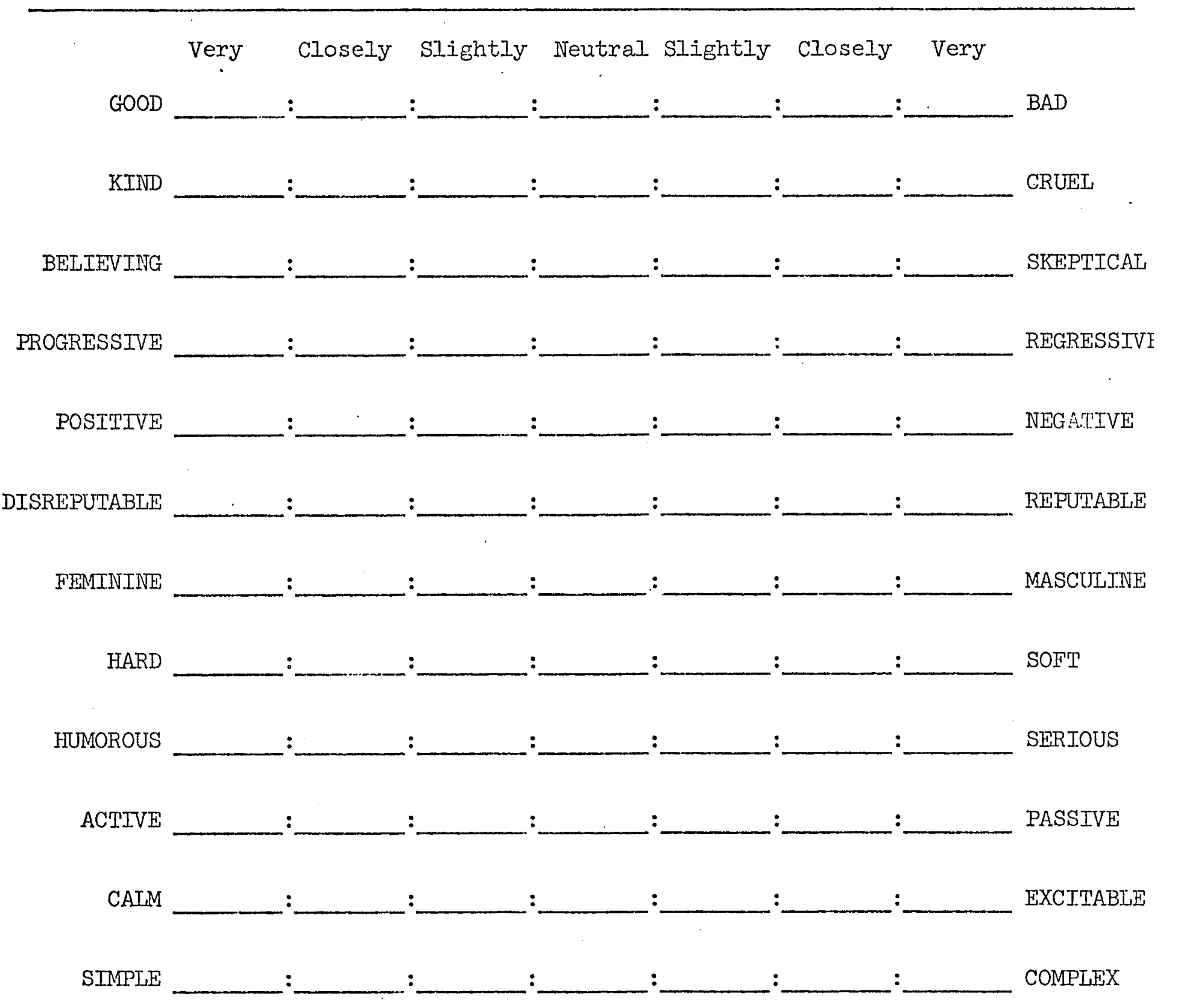


Appendix D: Visual Semantic Profiles Relative to Hypotheses Four and Five 


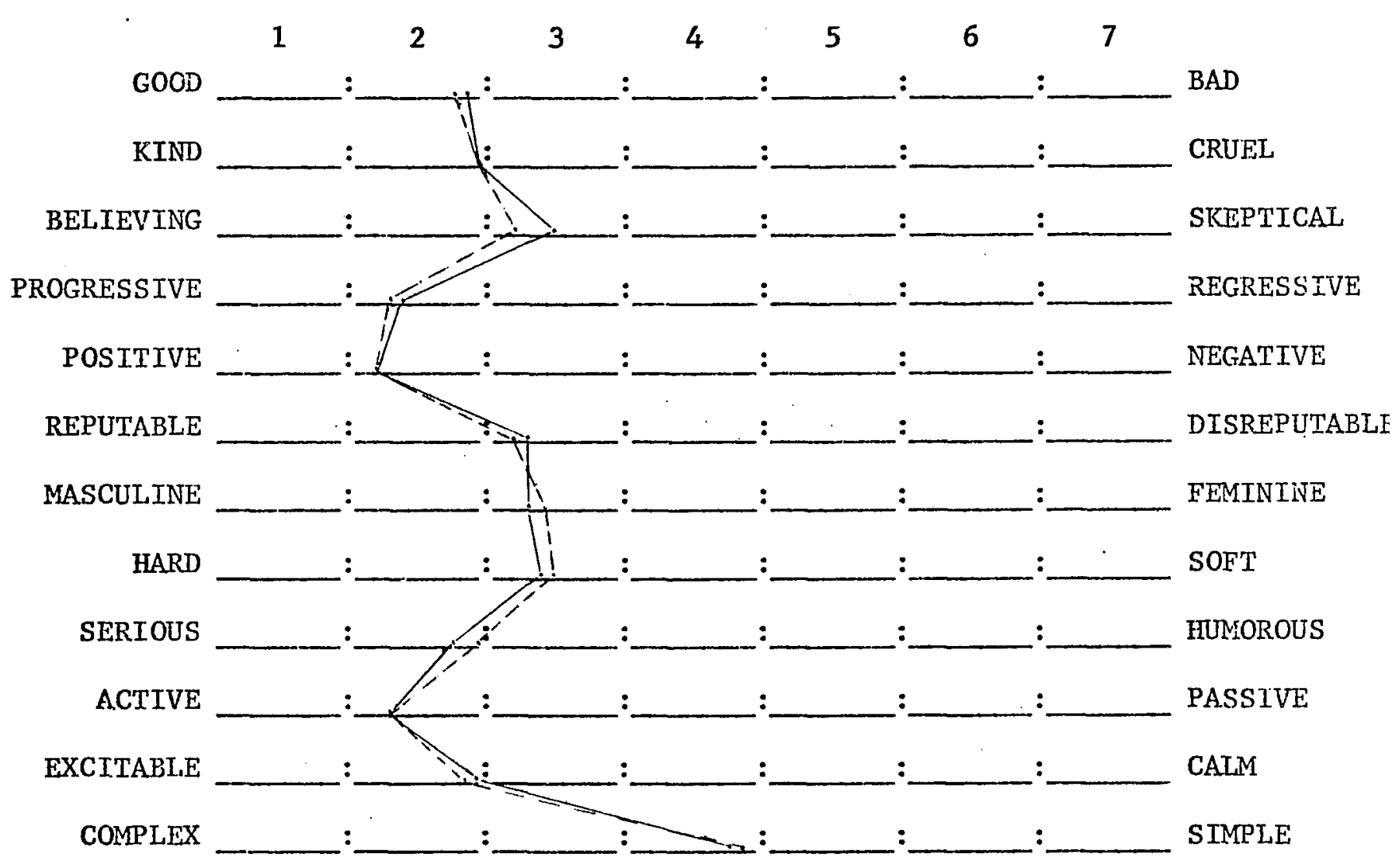

Figure D.I: Comparison of Massey's Reader and Company Oriented Recruitment Advertisements

The scales have been reorganized so that the adjectives on the left are the favorable adjectives.

- - Broken Iine denotes company oriented ad Solid line denotes reader oriented ad 


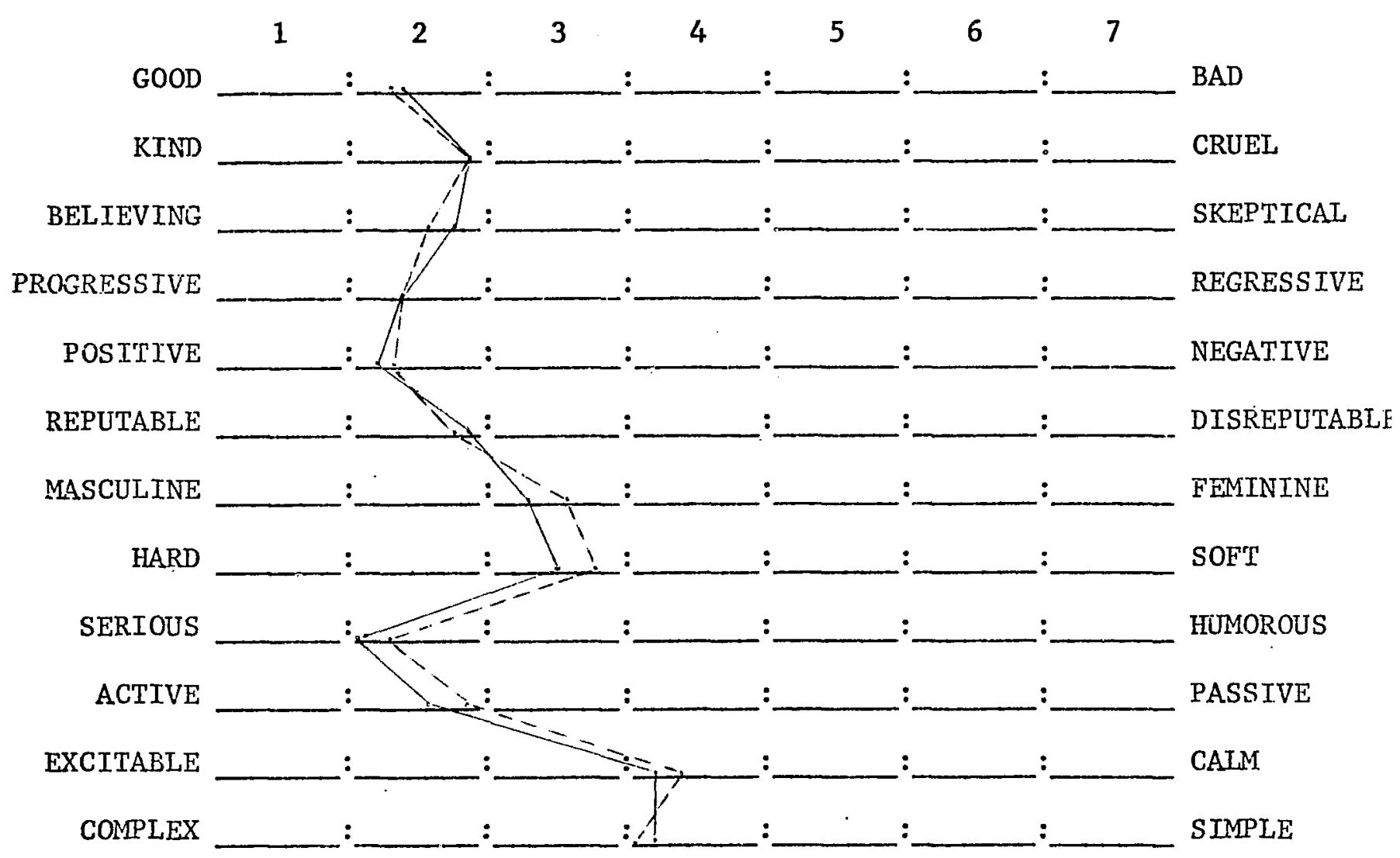

Figure D.2: Comparison of Dallas Mutual Iife's Reader and Company Oriented Recruitment Advertisements

The scales have been reorganized so that the favorable side is on the left and the unfavorable side appears on the right.

- - Broken line denotes company oriented message Solid line denotes reader oriented message 


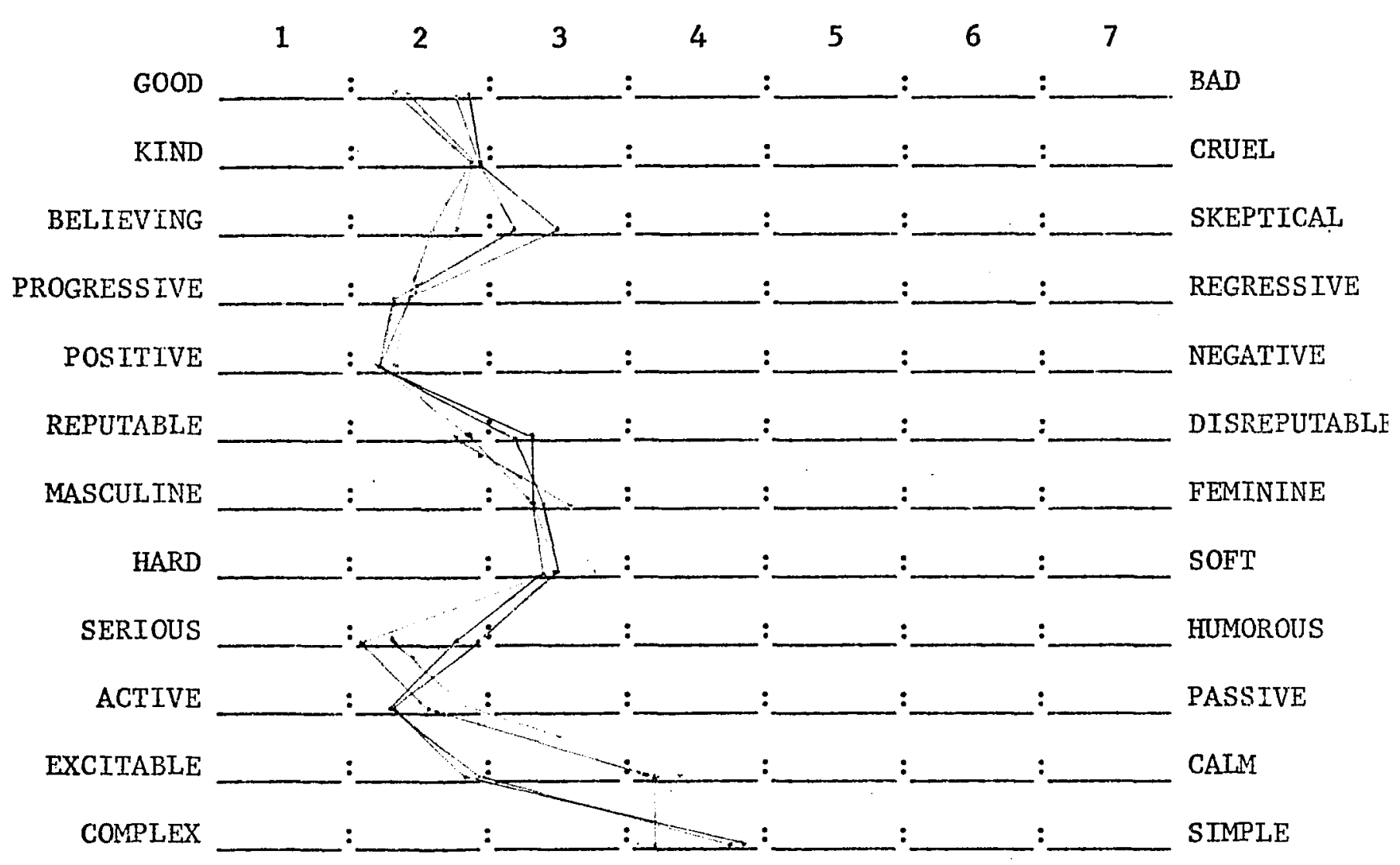

Figure D.3: Composite Reader and Company Oriented Recruitment Advertisement

The above scales have been rotated so that favorable polar adjectives are on the left and the unfavorable ones are on the right.

Reader Oriented Massey's Ad Company Oriented Massey's Ad

Reader Oriented Dallas Mutual Iife

Company Oriented Dallas Mutual Life 


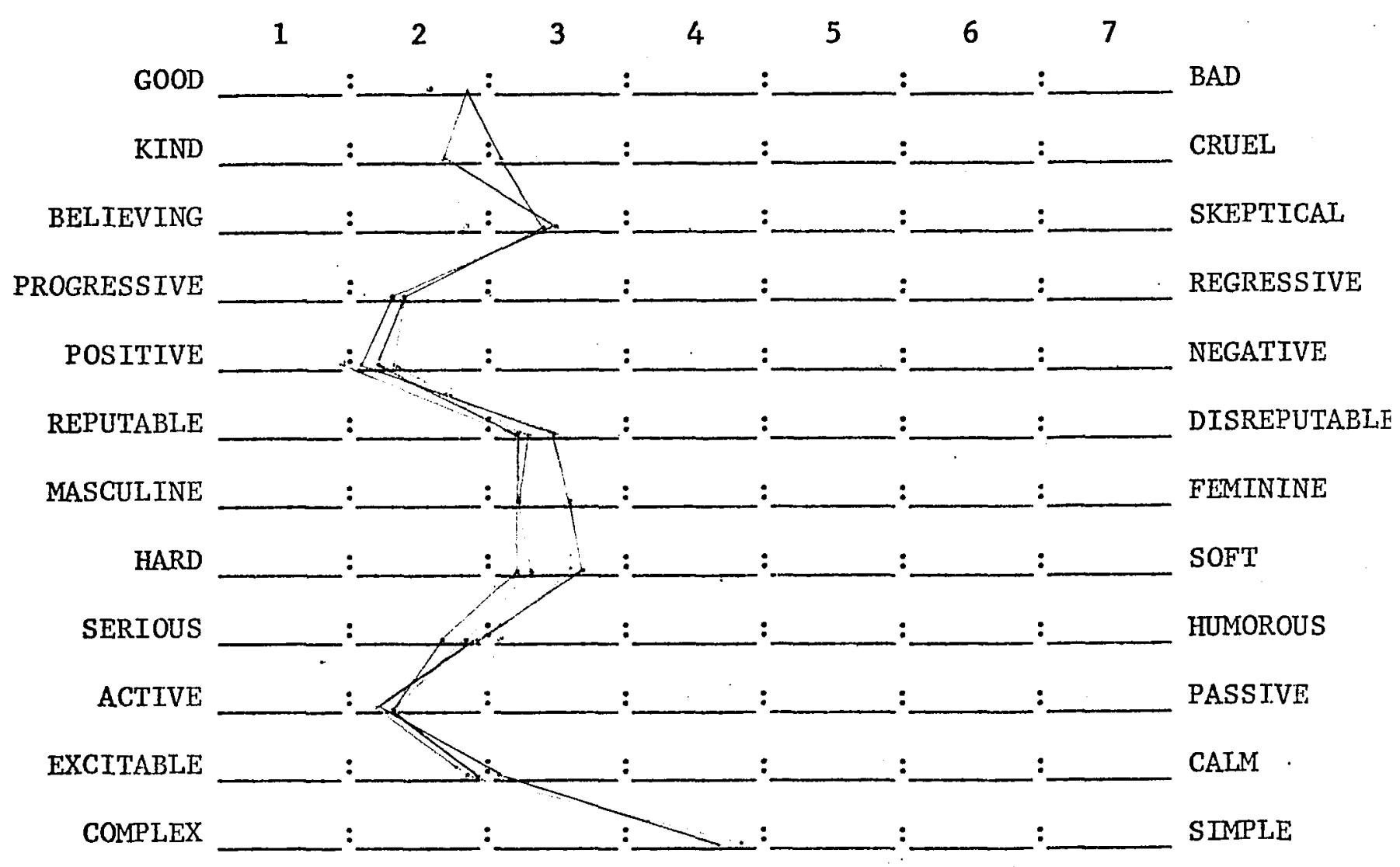

Figure D.4: Male and Female Semantic Profile for Massey's Reader and Company Oriented Recruitment Ads

Male-Reader oriented. Female-Reader Oriented Male-Company Oriented Female-Company Oriented 


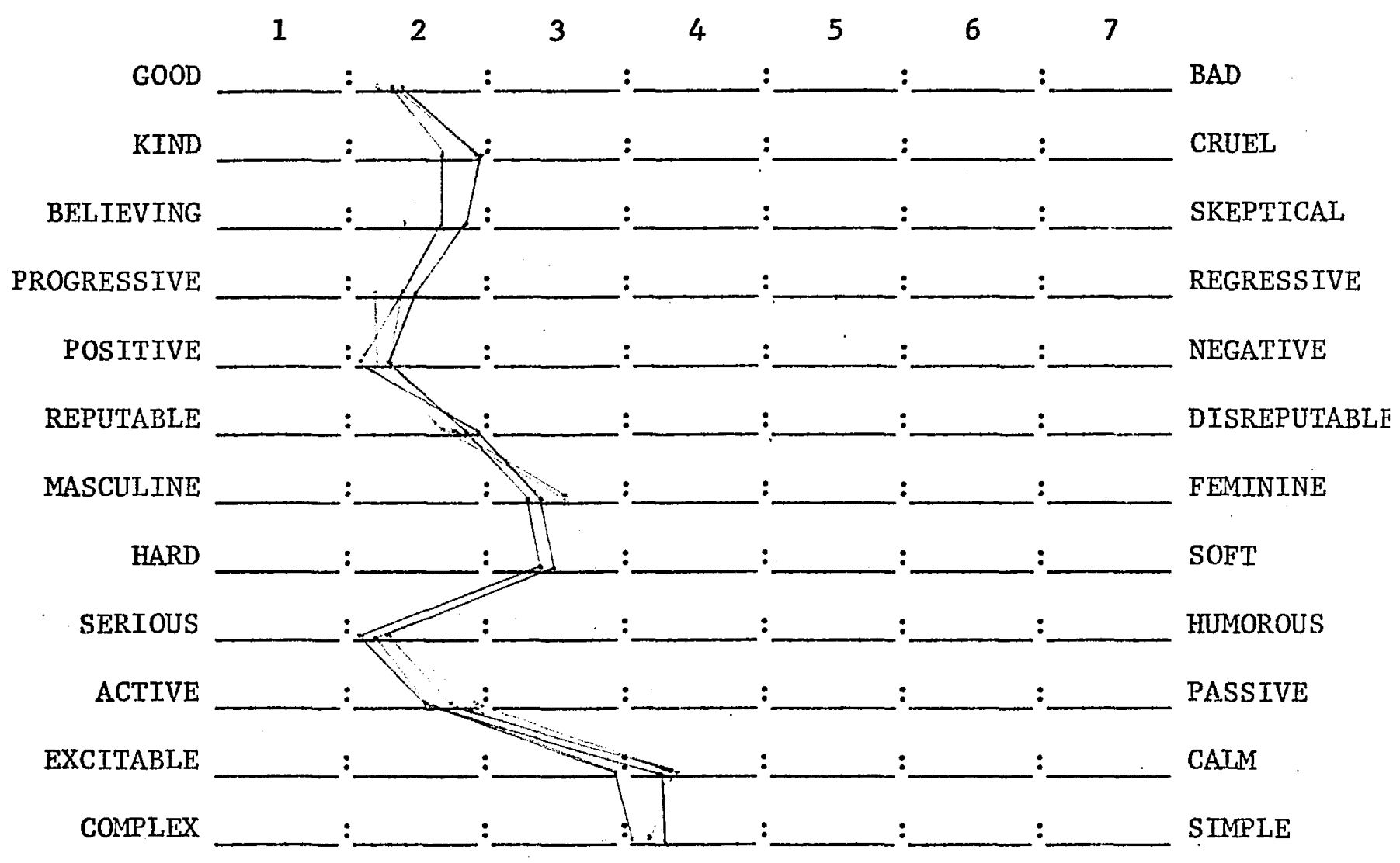

Figure D.5: Male and Female Semantic Profiles for Both Reader and Company Oriented Advertisement for Dallas Mutual Life

Male-Reader Oriented Female-Reader Oriented Male-Company Oriented Female-Company Oriented 


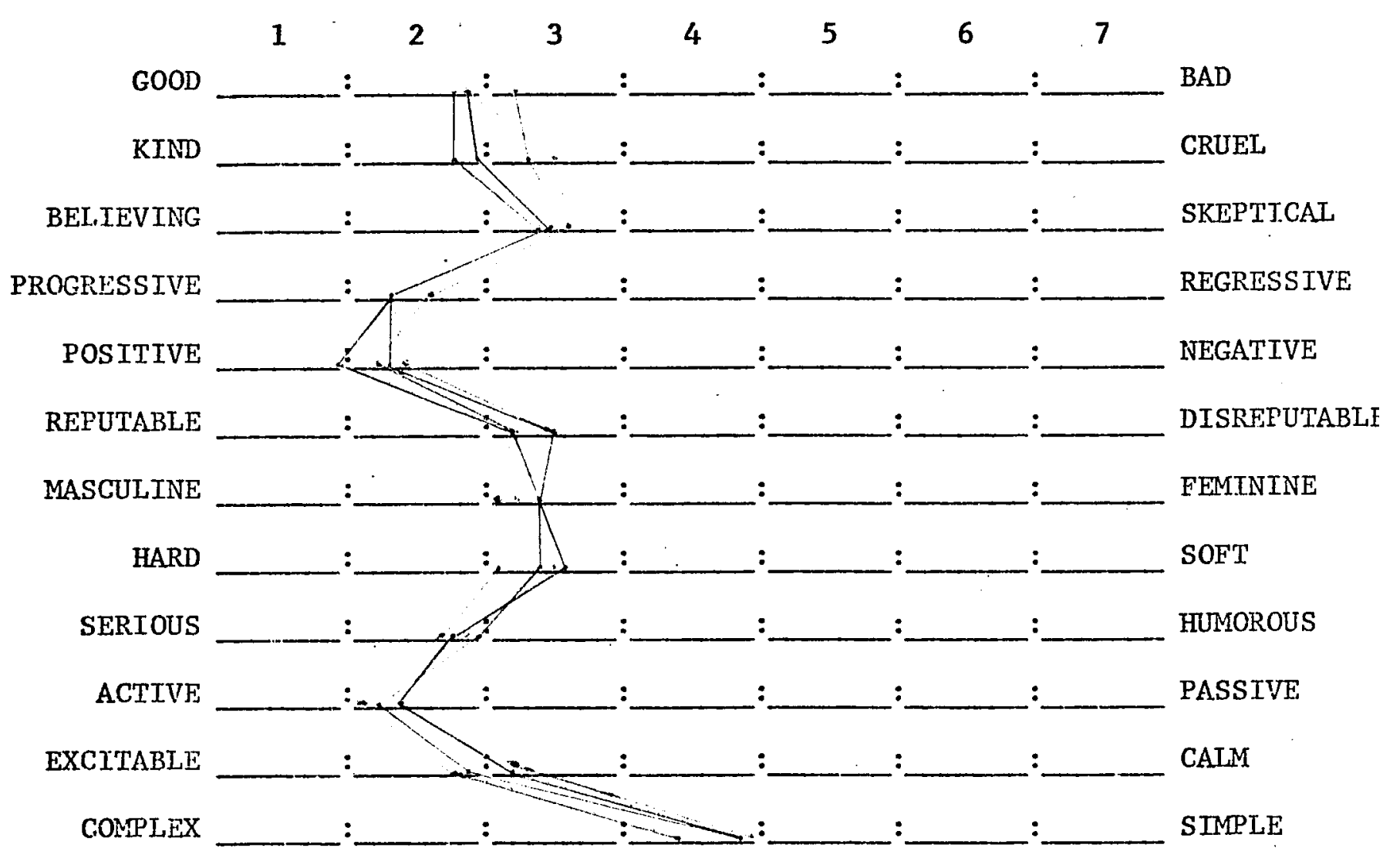

Figure D.6: Comparison of Age Groups I - IV for Massey's Reader Oriented Advertisement

Age Group I
Age Group II
Age Group III
Age Group IV




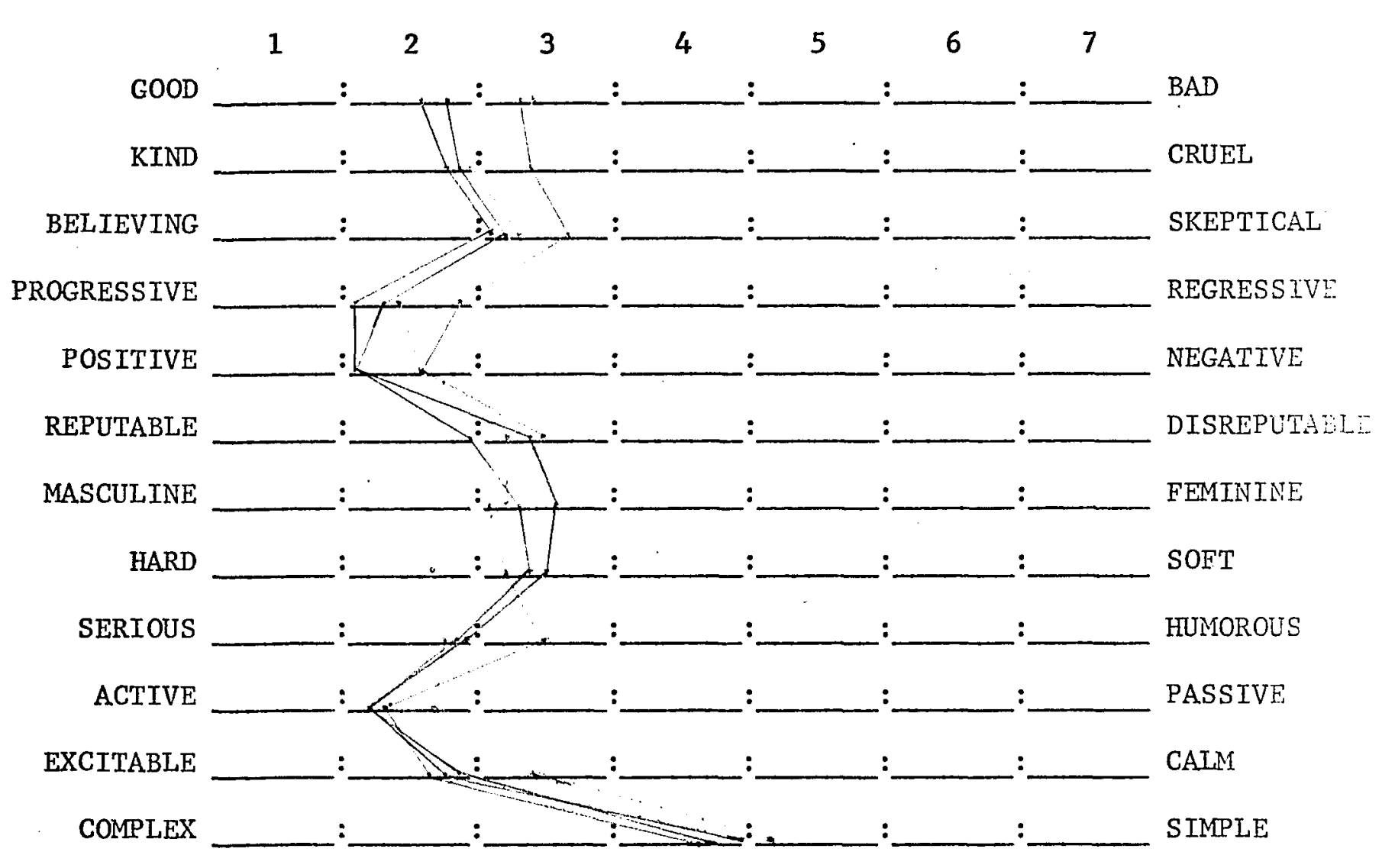

Figure D.7: Comparison of Age Groups I - IV for Massey's Company oriented Advertisement

Age Group I

Age Group II

Age Group III

Age Group IV 


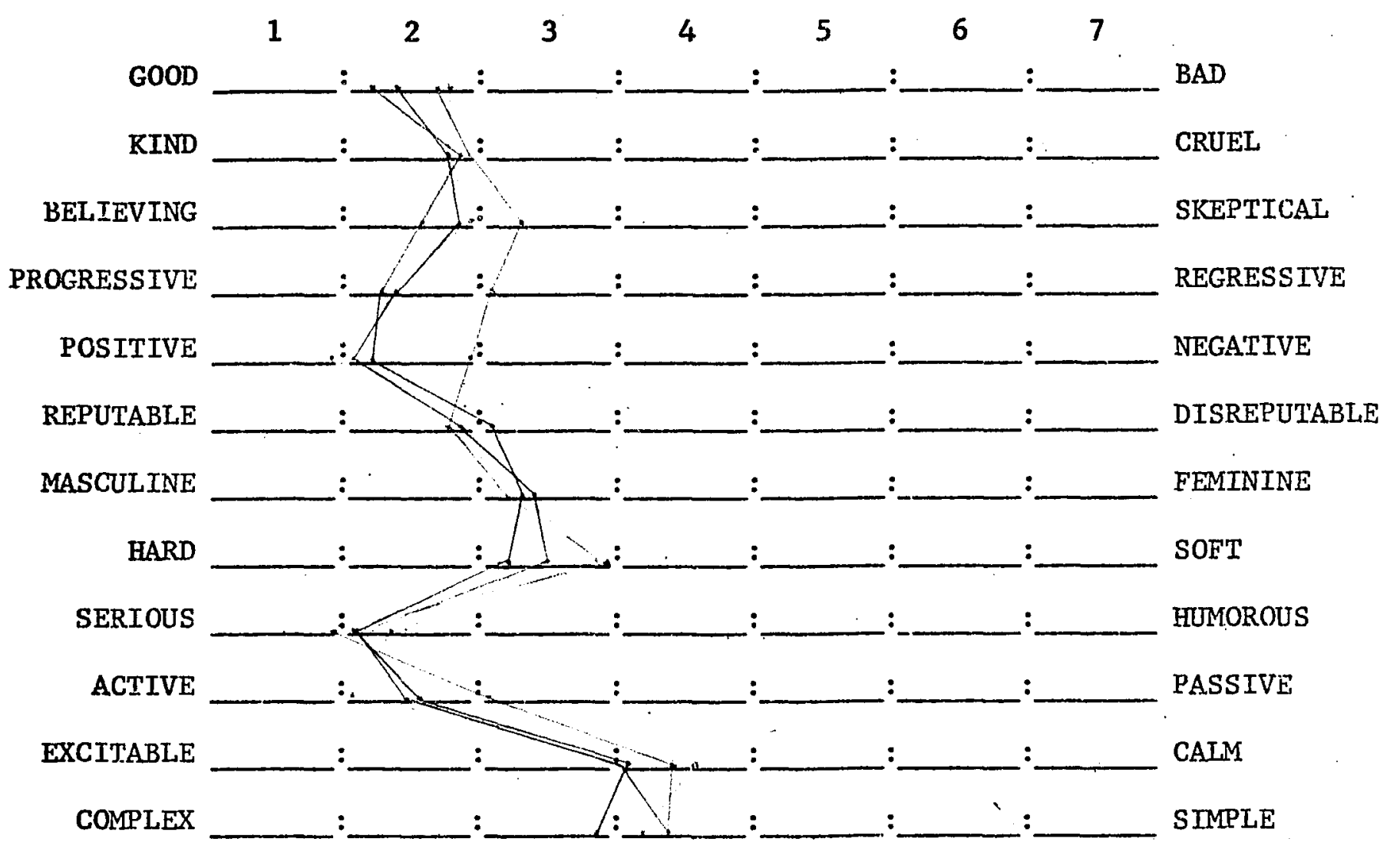

Figure D.8: Comparison of Age Groups I - IV for Dallas Mutual Life's Reader Oriented Advertisement

Age Group I Age Group II Age Group III Age Group IV 


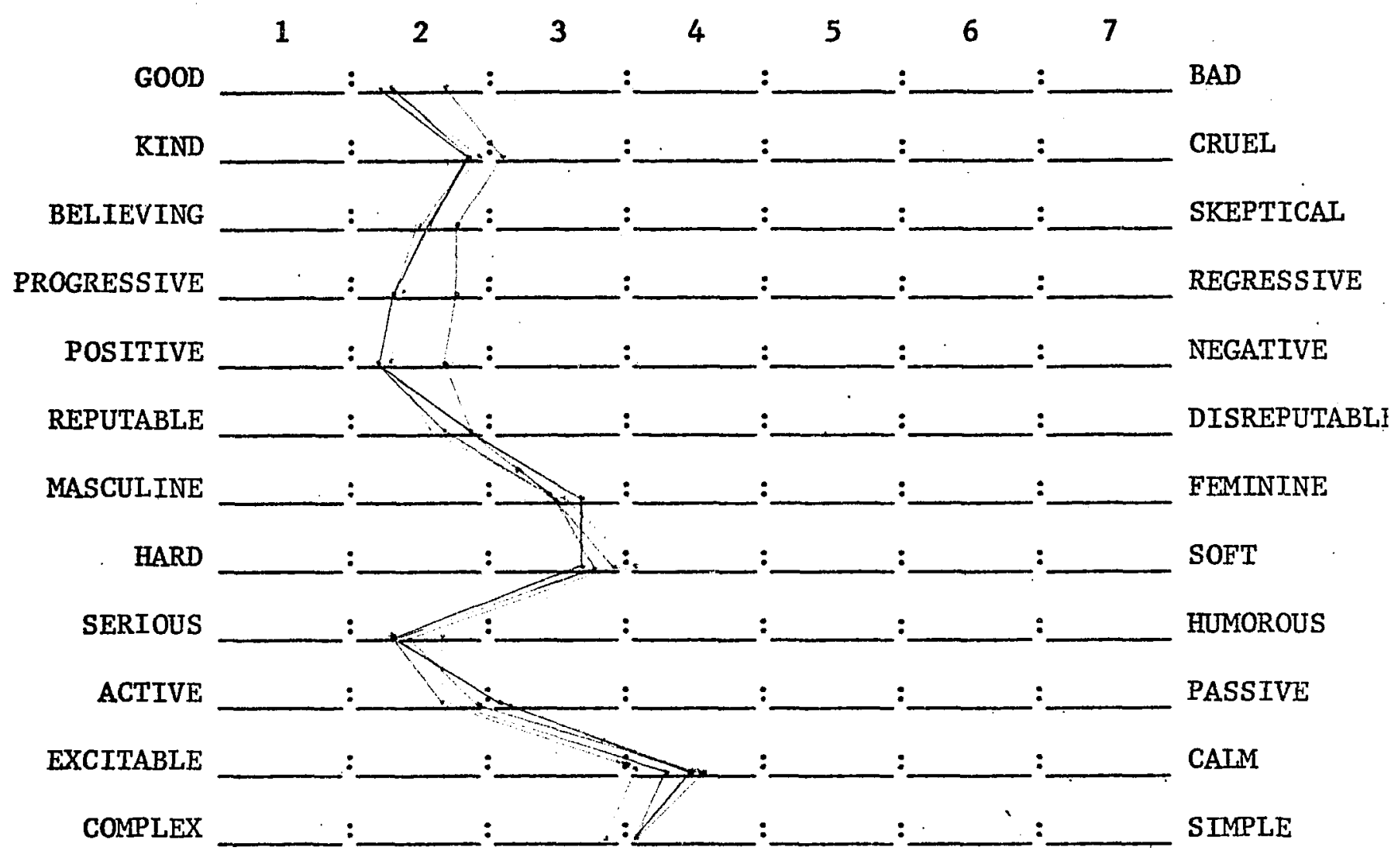

Figure D.9: Comparison of Age Groups I - IV for Dallas Mutual

Life's Company Oriented Advertisement

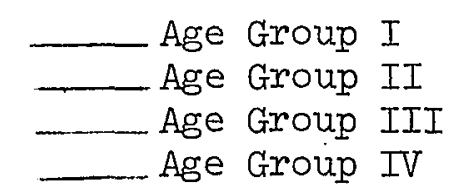




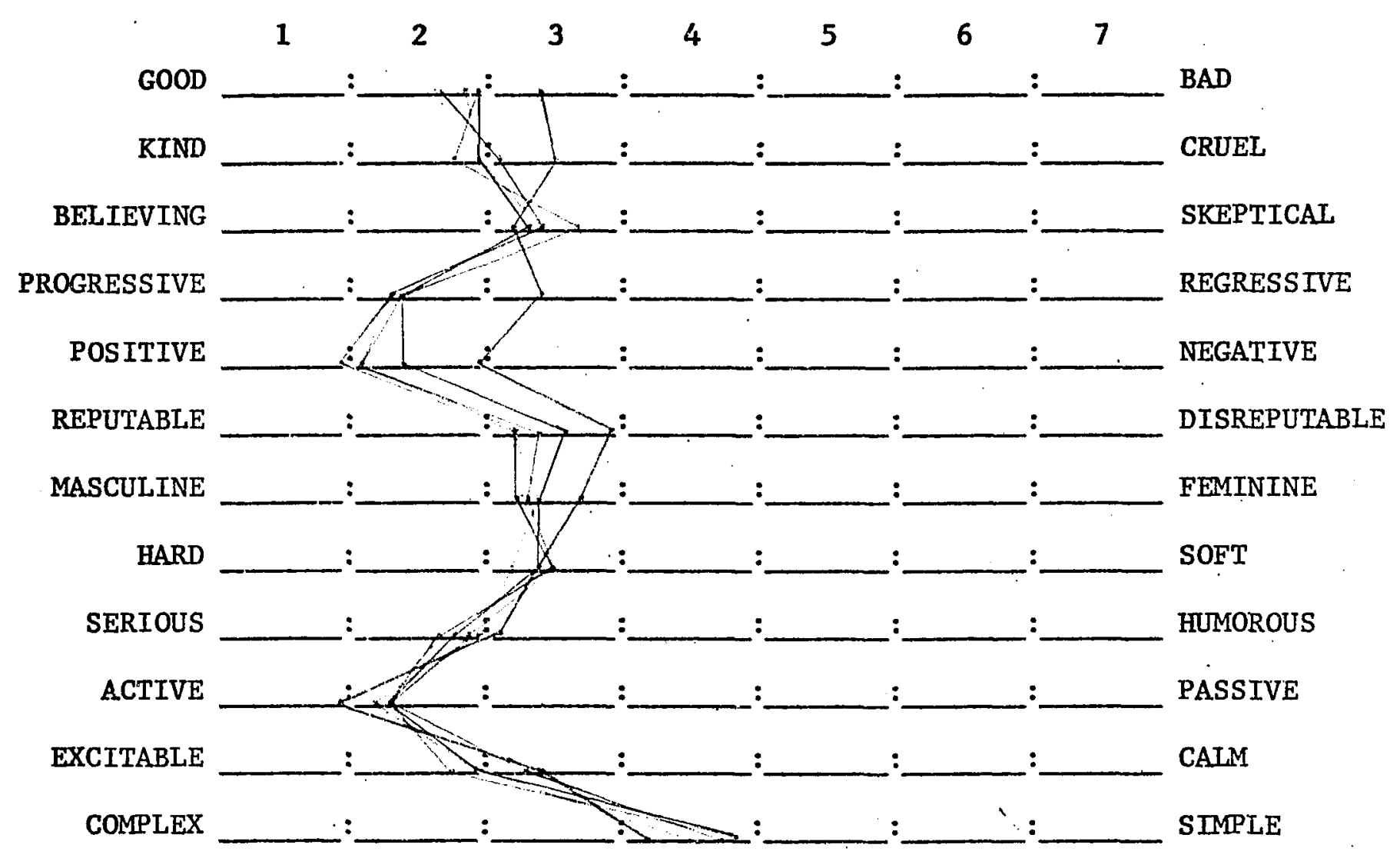

Figure D.10: Comparison of Classification Groups to Massey's Reader Oriented Advertisement

Freshmen

Sophomores

Juniors

Seniors

Special Undergraduates 


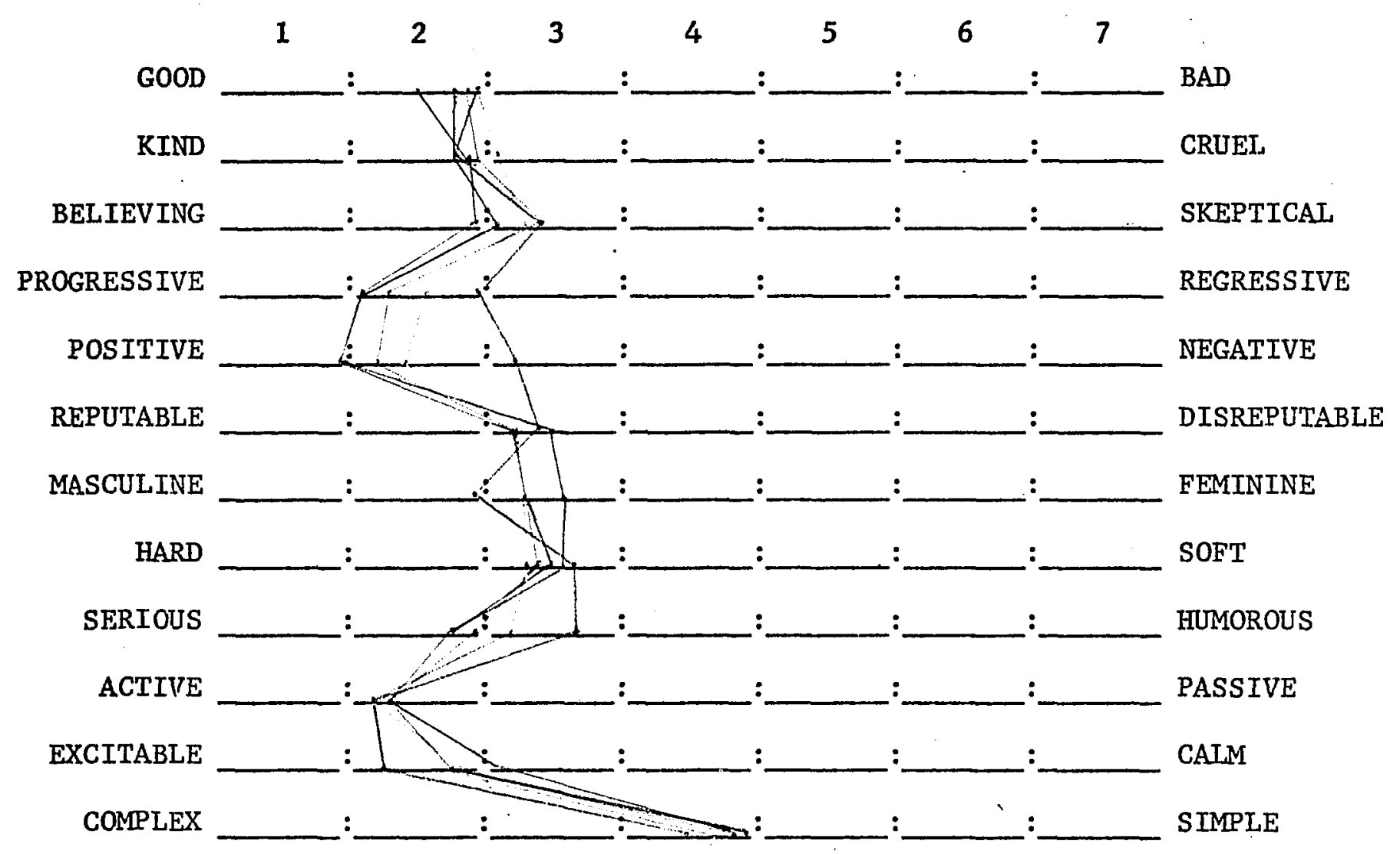

Figure D.11: Comparison of All Classifications to Massey's Company Oriented Recruiting Message

Freshmen

Sophomores

Juniors

Seniors

Special Undergraduates 


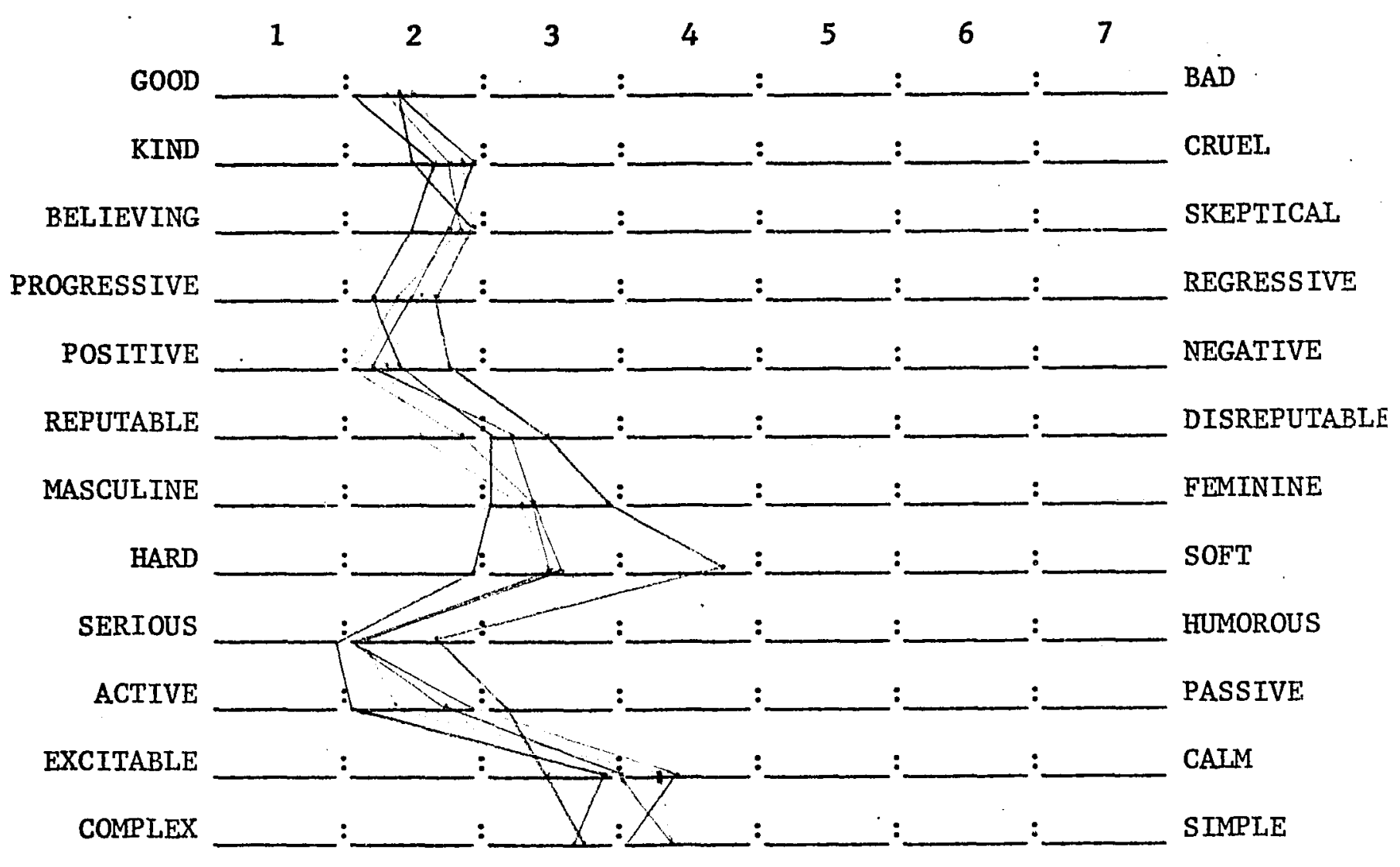

Figure D.12: Comparison of All Classifications to Dallas Mutual Life's Reader Oriented Advertisement

Freshmen
Sophomores
Juniors
Seniors
Special Undergraduates




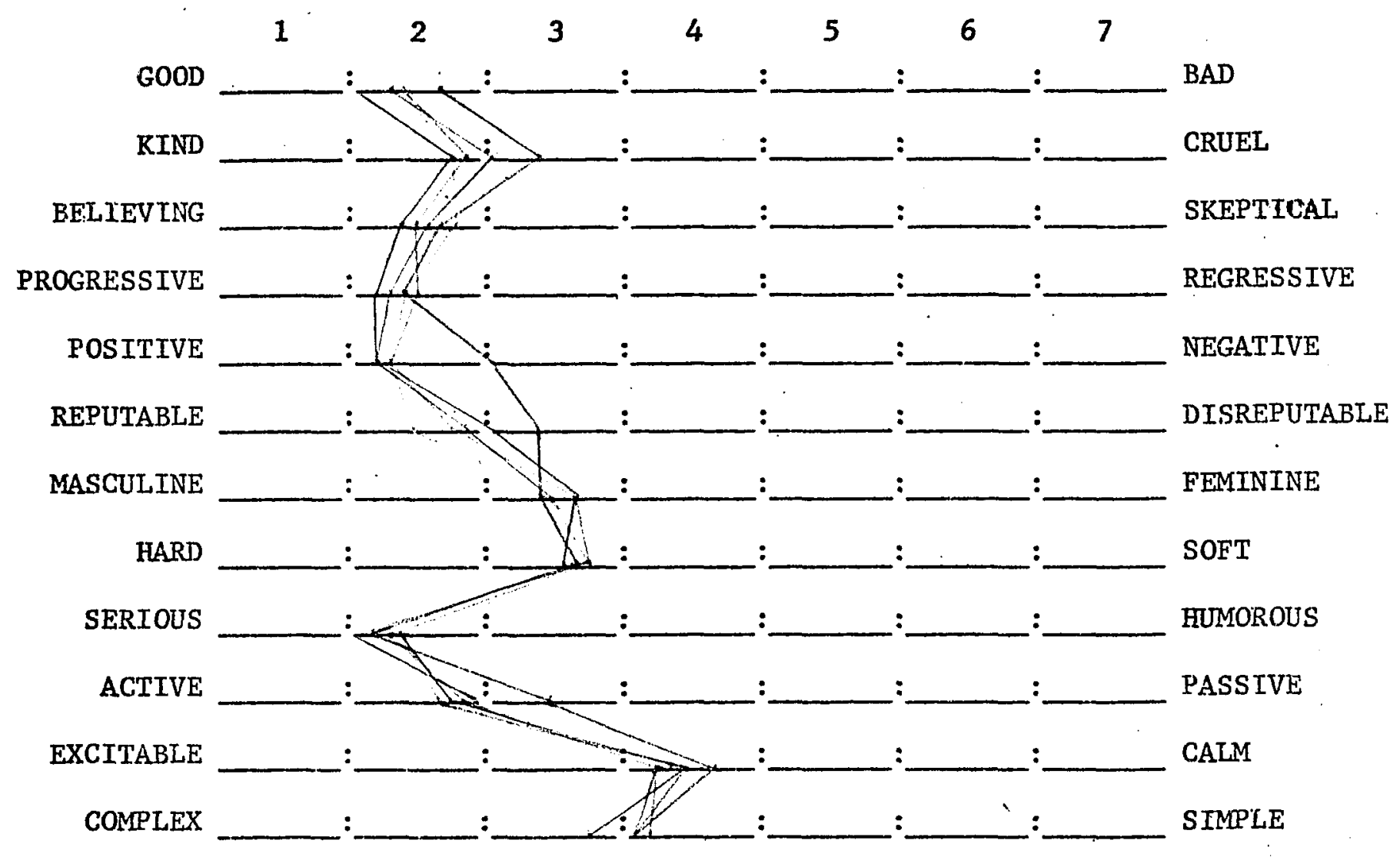

Figure D.13: Comparison of All Classifications to Dallas Mutual Life's Company Oriented Recruitment Advertisement

Freshmen

Sophomores

Juniors

Seniors

Special Undergraduates 


\section{Appendix E: Semantic Differential Scale Means and " $t$ "Values of the Difference Between Personality Traits For Each Recruitment Advertisement}


TABLE E.I

SEMANTIC DIFFERENTIAI SCALE MEANS FOR MASSEY'S READER ORIENTED ADVERTISEMENT BY PERSOIVAIITY FACTORS

\begin{tabular}{|c|c|c|c|c|c|c|c|c|c|c|c|c|}
\hline Personality Factors & 1 & 2 & 3 & 4 & $\begin{array}{c}\text { Seman } \\
5\end{array}$ & ${ }_{6}^{\text {ic } R a}$ & ing 5 & $\begin{array}{c}\text { Ies } \\
8\end{array}$ & 9. & 10 & 17 & $12^{*}$ \\
\hline \multicolumn{13}{|l|}{ Factor A } \\
\hline outgoing & 2.6 & 2.9 & 3.1 & 2.1 & 2.0 & 3.1 & 3.3 & 3.3 & 2.8 & 2.1 & 2.7 & 4.7 \\
\hline Average & 3.0 & 2.9 & 3.4 & 2.3 & 2.1 & $3 \cdot 3$ & 3.2 & 3.3 & 2.7 & 2.2 & 3.1 & 4.8 \\
\hline Reserved & 2.8 & 2.8 & 3.5 & 2.4 & 2.1 & 3.2 & 3.2 & $3 \cdot 3$ & 2.7 & 2.2 & 2.9 & 4.7 \\
\hline \multicolumn{13}{|l|}{ Factor B } \\
\hline More Intelligent & 2.9 & 2.9 & 3.3 & 2.3 & 2.1 & 2.9 & 3.1 & 2.9 & 2.5 & 2.0 & 2.5 & 4.6 \\
\hline Average & 2.8 & 2.9 & 3.4 & 2.2 & 2.0 & 3.3 & 3.2 & 3.2 & 2.8 & 2.1 & 3.0 & 4.7 \\
\hline Iess Intelligent & 2.6 & 2.8 & 3.3 & 2.4 & 2.2 & $3 \cdot 3$ & 3.4 & 3.9 & 2.8 & 2.3 & 3.1 & 4.8 \\
\hline \multicolumn{13}{|l|}{ Factor C } \\
\hline Frotionally Stable & 2.3 & 2.6 & 3.0 & 2.0 & 1.7 & 3.2 & $3 \cdot 3$ & 3.4 & 2.8 & 2.2 & 3.1 & 4.9 \\
\hline Average & 2.5 & 2.8 & 2.9 & 2.0 & 1.9 & 3.1 & 3.1 & 3.3 & 2.7 & 1.9 & 2.7 & 4.7 \\
\hline Affected by Feelings & 3.1 & 3.0 & 3.8 & 2.5 & 2.3 & 3.3 & $3 \cdot 3$ & $3 \cdot 3$ & 2.8 & 2.3 & 3.0 & 4.7 \\
\hline \multicolumn{13}{|l|}{ Factor E } \\
\hline Assertive & 2.9 & 2.9 & 3.4 & 2.4 & 2.1 & 3.1 & 3.2 & $3 \cdot 3$ & 2.8 & 2.2 & 2.9 & 4.8 \\
\hline Average & 2.6 & 2.9 & 3.3 & 2.1 & 2.0 & 3.4 & $3 \cdot 3$ & $3 \cdot 3$ & 2.8 & 2.1 & 2.9 & 4.6 \\
\hline Hunble & 2.8 & 2.7 & 3.5 & 2.2 & 2.1 & 3.6 & 3.5 & 3.5 & 2.6 & 2.0 & 2.9 & 4.7 \\
\hline \multicolumn{13}{|l|}{ Factor F } \\
\hline Happy-go-Iucky & 2.9 & 2.8 & $3 \cdot 3$ & 2.3 & 2.1 & 3.2 & 3.2 & 3.4 & 2.6 & 2.3 & 3.1 & 4.7 \\
\hline Average & 2.7 & 3.0 & 3.4 & 2.2 & 2.2 & $3 \cdot 3$ & 3.2 & 3.4 & 2.9 & 2.0 & 2.8 & 4.7 \\
\hline SoDer & 2.8 & 2.8 & 3.4 & 2.3 & 1.9 & 3.2 & $3 \cdot 3$ & 3.1 & 2.7 & 2.1 & 2.9 & 4.7 \\
\hline
\end{tabular}


TABLE E.I (Continued)

\begin{tabular}{|c|c|c|c|c|c|c|c|c|c|c|c|c|}
\hline Fersonality Factors & \multicolumn{12}{|c|}{ Semantic Rating Scales } \\
\hline \multicolumn{13}{|l|}{ Factor G } \\
\hline Conscientious & 2.6 & 2.5 & 3.5 & 1.9 & 1.8 & 2.9 & 3.1 & 3.6 & 2.9 & 2.1 & 3.2 & 4.8 \\
\hline Average & 2.8 & 2.9 & 3.2 & 2.2 & 2.1 & 3.3 & 3.2 & 3.4 & 2.7 & 2.2 & 2.8 & 4.5 \\
\hline Expedient & 2.9 & 2.9 & 3.5 & 2.4 & 2.1 & 3.2 & 3.3 & 3.2 & 2.7 & 2.2 & 3.0 & 4.9 \\
\hline \multicolumn{13}{|l|}{ Factor $\mathrm{H}$} \\
\hline Venturesome & 2.8 & 2.8 & 3.3 & 2.2 & 1.9 & 3.0 & 3.2 & 3.4 & 2.7 & 2.1 & 3.0 & 4.8 \\
\hline Average & 2.8 & 2.9 & 3.5 & 2.2 & 2.1 & 3.3 & 3.2 & 3.4 & 2.7 & 2.2 & 2.8 & 4.7 \\
\hline Shy & 2.8 & 2.9 & 3.3 & 2.4 & 2.2 & 3.3 & 3.3 & 3.2 & 2.8 & 2.2 & 3.0 & 4.7 \\
\hline \multicolumn{13}{|l|}{ Factor I } \\
\hline Tender-Minded & 2.8 & 2.8 & 3.4 & 2.3 & 2.0 & 3.2 & 3.4 & 3.5 & 2.9 & 2.1 & $2: 9$ & 4.7 \\
\hline Average & 2.9 & 3.0 & $3 \cdot 3$ & 2.2 & 2.1 & 3.4 & 3.3 & 3.3 & 2.6 & 2.1 & 3.1 & 4.9 \\
\hline 'Jouch-Minded & 2.7 & 2.9 & 3.5 & 2.2 & 2.0 & 3.0 & 3.0 & 3.0 & 2.7 & 2.2 & 2.9 & $1+.5$ \\
\hline \multicolumn{13}{|l|}{ Factor I } \\
\hline Suspicious & 2.8 & 2.9 & 3.5 & 2.3 & 2.0 & 3.4 & 3.2 & 3.2 & 2.8 & 2.1 & 2.8 & 4.8 \\
\hline Average & 2.9 & 2.9 & 3.3 & 2.4 & 2.3 & 3.0 & 3.4 & 3.5 & 2.7 & 2.3 & 3.1 & 4.8 \\
\hline Trusting & 2.7 & 2.7 & 3.2 & 2.1 & 1.9 & 3.1 & 3.1 & 3.4 & 2.7 & 2.1 & 3.0 & 4.3 \\
\hline \multicolumn{13}{|l|}{ Factor M } \\
\hline Imaginative & 2.8 & 2.9 & 3.3 & 2.3 & 2.1 & 3.2 & 3.3 & 3.2 & 2.7 & 2.1 & 3.0 & 4.9 \\
\hline Average & 2.9 & 2.8 & 3.4 & 2.2 & 2.1 & 3.3 & 3.1 & 3.3 & 2.8 & 2.2 & 2.9 & 4.5 \\
\hline Practical & 2.8 & 2.8 & 3.4 & 2.2 & 1.9 & 3.2 & 3.3 & 3.5 & 2.7 & 2.3 & 2.8 & 4.4 \\
\hline \multicolumn{13}{|l|}{ Factor $\mathrm{N}$} \\
\hline Shrewd & 2.9 & 3.0 & 3.4 & 2.4 & 2.1 & 3.1 & 3.3 & 3.4 & 2.8 & 2.1 & 2.9 & 4.8 \\
\hline Average & 2.7 & 2.9 & 3.3 & 2.2 & 2.1 & 3.3 & 3.2 & 3.3 & 2.7 & 2.1 & 2.9 & 4.7 \\
\hline Forthright & 2.7 & 2.7 & 3.4 & 2.2 & 2.0 & 3.4 & 3.2 & 3.2 & 2.7 & 2.3 & 3.1 & 4.6 \\
\hline
\end{tabular}


TABIE R.: (Continued)

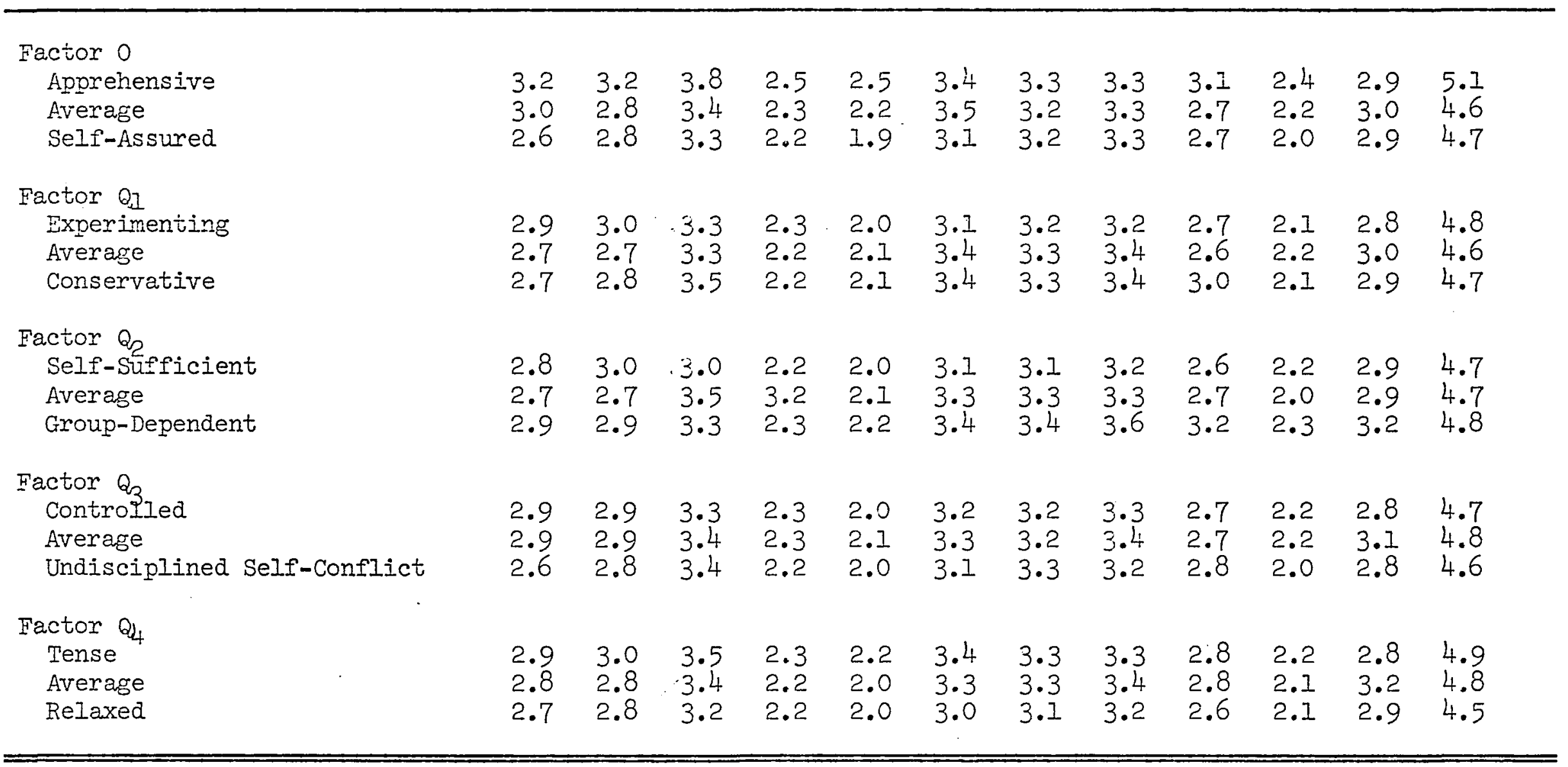

*The semantic rating scales numbers correspond to the scale description in Table E.II.

Source: Primary 
TABLE E.II

"t"VALUES ${ }^{I}$ OF THE DIFHERENCES BETWEEN PERSONAITTY TRAITS FOR MASSEY'S READER ORIENTTED ADVERTISEMENT

\begin{tabular}{|c|c|c|c|c|c|c|c|}
\hline \multirow{2}{*}{$\begin{array}{l}\text { Scale } \\
\text { Number }\end{array}$} & \multirow[b]{2}{*}{ Semantic Rating Scales } & \multicolumn{3}{|c|}{ Factor $A^{2}$} & \multicolumn{3}{|c|}{ Factor B } \\
\hline & & $\mathrm{Hi} / \mathrm{AV}$ & $\mathrm{Hi} / \mathrm{LO}$ & $\mathrm{Av} / \mathrm{LO}$ & $\mathrm{Hi} / \mathrm{Av}$ & $\mathrm{Hi} / \mathrm{Io}$ & Av/Lo \\
\hline 1 & GOOD-BAD & $-1.736 * *$ & $-1.697 * *$ & & & $-4.145 * *$ & $1.881 *$ \\
\hline 2 & KIND-CRUEI & & & & & & \\
\hline 3 & BELIEVING-SKEPTICAL & & $-2.359 * *$ & & & & \\
\hline 4 & FROGRESSIVE-REGRESSIVE & & $-2.206 * *$ & & & & $-2.198 * *$ \\
\hline 5 & POSITIVE-NEGATIVE & & & & & & $-2.074 * *$ \\
\hline 6 & REPUTABLE-DISREPUTABIE & & & & $-1.937^{* *}$ & $-2.536 * *$ & \\
\hline 7 & MASCULINE-FEMININE & & & & & & $-2 \cdot 382 * *$ \\
\hline 8 & HARD-SOFT & & & & $-1.957^{* *}$ & $-6.240 * *$ & $-6.715 * *$ \\
\hline 9 & SERIOUS-HUMOROUS & & & & & & \\
\hline 10 & ACTIVE-PASSIVE & & & & & & \\
\hline 11 & EXCITABLE-CAIM & & & & $-2.203^{* *}$ & $-2.844 * *$ & \\
\hline \multirow[t]{2}{*}{12} & COMPLEX-SIMPLE & & & & & & \\
\hline & & & Factor $\mathrm{C}$ & & & Factor $\mathrm{E}$ & \\
\hline 1 & GOOD-BAD & & $-4.145 * *$ & $-4.385 * *$ & & & \\
\hline 2 & KIIND-CRUEL & & $-2.283 * *$ & & & $2.504 *$ & $1.920 *$ \\
\hline 3 & BELTEVING-SKEPTICAL & & $-3.736 * *$ & $-5.245 * *$ & & & \\
\hline 4 & PROARESSIVE-REGRESSIVE & & $-3.083 * *$ & $-3.868 * *$ & $1.915 *$ & $1.790 *$ & \\
\hline 5 & POSITIVE-NEGATIVE & & $-3.499 * *$ & $-2.765 * *$ & & & \\
\hline 6 & REPUTABLE-DISREPUTABLE & & & $-1.692 * *$ & & $-4.607 * *$ & \\
\hline 7 & MASCULINE-FEMININE & $\therefore$ & & & & $-3.374 * *$ & \\
\hline 8 & HARD-SOFT & & & & & $-2.495 * *$ & $-1.836 * *$ \\
\hline 9 & SERIOUS-HUMOROUS & & & & & & \\
\hline 10 & ACTIVE-PASSIVE & & & $-2.644 * *$ & & & $2.862 *$ \\
\hline 11 & EXCITABLE-CALM & & & $-1.786 * *$ & & & \\
\hline 12 & COMPIEX-SIMPLE & & & & & & \\
\hline
\end{tabular}


TABLE E.II (Continued)

\begin{tabular}{|c|c|c|c|c|c|c|c|}
\hline \multirow{2}{*}{$\begin{array}{l}\text { Scale } \\
\text { Number }\end{array}$} & \multirow[b]{2}{*}{ Semantic Rating Scales } & \multicolumn{3}{|c|}{ Factor $F$} & \multicolumn{3}{|c|}{ Factor G } \\
\hline & & $\mathrm{Hi} / \mathrm{AV}$ & $\mathrm{Hi} / \mathrm{LO}$ & $\mathrm{AV} / \mathrm{IO}$ & $\mathrm{Hi} / \mathrm{Av}$ & $\mathrm{Hi} / \mathrm{LO}$ & $\mathrm{Av} / \mathrm{IO}$ \\
\hline 1 & GOOD-BAD & & & & & & \\
\hline 2 & KIND-CRUEI & & & & $-1.696 * *$ & $-1.758 * *$ & \\
\hline 3 & BELIEVING-SKEPTICAL & & & & & & $-1.920 * *$ \\
\hline 5 & PROGRESSIVE-REGRESSIVE & & & & & $-2.060 * *$ & $-2.204 * *$ \\
\hline 5 & POSITIVE-NEGATIVE & & $1.997 *$ & $2.501 *$ & & & \\
\hline 6 & REPUTABLE-DISREPUTABLE & & & & & & \\
\hline 7 & MASCULINE-FEMININE & & & & & & \\
\hline 8 & HARD-SOFT & & $2.634 *$ & $2.831 *$ & & & \\
\hline 9 & SERIOUS-HUMOROUS & & & & & & \\
\hline 10 & ACTTVE-PASSIVE & & $2.054 *$ & & & & \\
\hline 11 & EXCITABLE-CALM & & & & & , & \\
\hline 12 & COMPLEX-SIMPLE & & & & & & -1.715 \\
\hline & . & & Factor $\mathrm{H}$ & & & Factor I & \\
\hline 1 & GOOD-BAD & & & & & & \\
\hline 2 & KIND-CRUEL & & & & & & \\
\hline 3 & BELIEVING-SKEPTICAL & & & & & & \\
\hline 4 & PIROGRESSIVE-REGRESSIVE & & & $-1.896 * * *$ & & & \\
\hline 5 & POSITIVE-NEGATIVE & & $-2.539 * *$ & & & & \\
\hline 6 & REPUTABLE-DISREPUTABLE & $-1.749 * *$ & $-2.334 * *$ & & & & $2.569 *$ \\
\hline 7 & MASCULINE-FEMININE & & & & & $4.549 *$ & $2.572 *$ \\
\hline 8 & HARD-SOFT &. & & & & $3.704 *$ & $2.394 *$ \\
\hline 9 & SERIOUS-HUMOROUS & & & & $1.831 *$ & & \\
\hline 10 & ACTIVE-PASSIVE & & & & & & \\
\hline 11 & EXCITABLE-CAIM & & & & & & \\
\hline 12 & COMPLEX-SIMPLE & & & & & & $2.184 *$ \\
\hline
\end{tabular}


TABLE E.II (Continued)

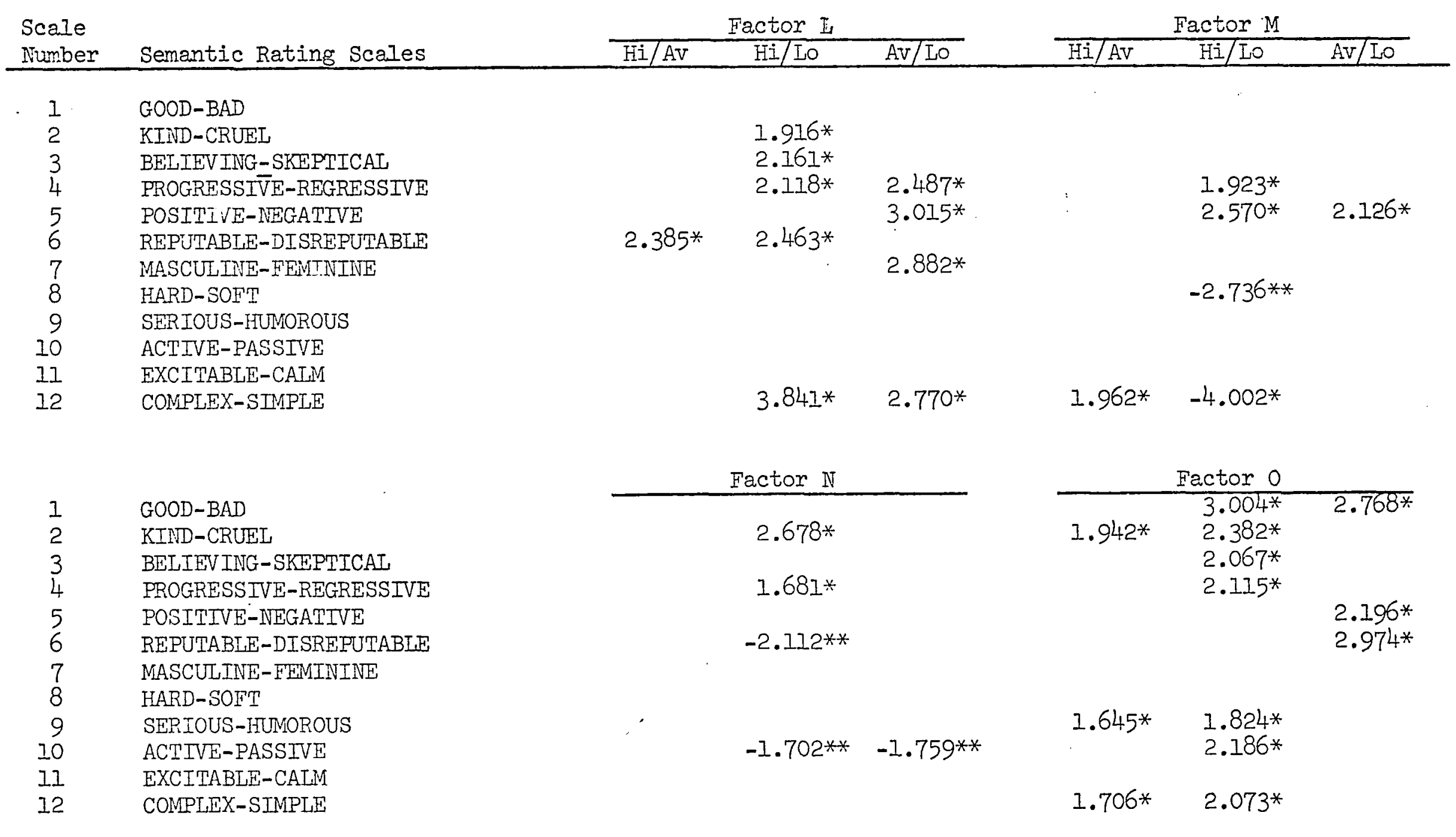


TABLE E.III

SEMANTIC DIFFERENTIAI SCALE MEANS FOR MASSEY'S COMPANY ORIENTED ADVERTISEMENT BY PERSONAIITY FACTORS

\begin{tabular}{|c|c|c|c|c|c|c|c|c|c|c|c|c|}
\hline Personality Factors & 1 & 2 & 3 & 4 & $\begin{array}{c}\text { Seman } \\
5\end{array}$ & ${ }_{6}^{\text {ic }} \mathrm{Ra}$ & ing $\mathrm{S}$ & $\begin{array}{c}\text { ales } \\
8\end{array}$ & 9 & 10 & $I I$ & $12 \%$ \\
\hline $\begin{array}{l}\text { Factor A } \\
\text { Outgoing } \\
\text { Average } \\
\text { Reserved }\end{array}$ & $\begin{array}{l}2.7 \\
2.7 \\
2.7 \\
2.7\end{array}$ & $\begin{array}{l}2.8 \\
2.8 \\
2.9 \\
2.9\end{array}$ & $\begin{array}{l}3.1 \\
3.1 \\
3.1 \\
3.2\end{array}$ & $\begin{array}{l}2.3 \\
2.3 \\
2.1 \\
2.2\end{array}$ & $\begin{array}{l}2.1 \\
2.1 \\
2.1 \\
2.1\end{array}$ & $\begin{array}{l}3.2 \\
3.2 \\
3.1 \\
3.0\end{array}$ & $\begin{array}{l}3.2 \\
3.2 \\
3.3 \\
3.3\end{array}$ & $\begin{array}{l}3.4 \\
3.4 \\
3.4 \\
3.3\end{array}$ & $\begin{array}{l}2.9 \\
2.9 \\
3.0 \\
2.8\end{array}$ & $\begin{array}{l}2.3 \\
2.3 \\
2.2 \\
2.0\end{array}$ & $\begin{array}{l}2.8 \\
2.8 \\
2.8 \\
2.8\end{array}$ & $\begin{array}{l}5.0 \\
5.0 \\
4.7 \\
4.7\end{array}$ \\
\hline $\begin{array}{l}\text { Factor B } \\
\text { More Intelligent } \\
\text { Average } \\
\text { Less Intelligent }\end{array}$ & $\begin{array}{l}2.6 \\
2.8 \\
2.5\end{array}$ & $\begin{array}{l}3.1 \\
2.8 \\
2.7\end{array}$ & $\begin{array}{l}3.0 \\
3.2 \\
3.1\end{array}$ & $\begin{array}{l}2.3 \\
2.2 \\
2.2\end{array}$ & $\begin{array}{l}2.2 \\
2.0 \\
2.1\end{array}$ & $\begin{array}{l}3.1 \\
3.2 \\
3.0\end{array}$ & $\begin{array}{l}3.1 \\
3.3 \\
3.4\end{array}$ & $\begin{array}{l}3.0 \\
3.4 \\
2.6\end{array}$ & $\begin{array}{l}2.9 \\
2.9 \\
2.8\end{array}$ & $\begin{array}{l}2.2 \\
2.2 \\
2.2\end{array}$ & $\begin{array}{l}2.7 \\
2.8 \\
2.9\end{array}$ & $\begin{array}{l}5.0 \\
4.6 \\
4.9\end{array}$ \\
\hline $\begin{array}{l}\text { Factor C } \\
\text { Emotionally Stable } \\
\text { Average } \\
\text { Affected by Feeling }\end{array}$ & $\begin{array}{l}2.4 \\
2.6 \\
2.8\end{array}$ & $\begin{array}{l}2.8 \\
2.9 \\
2.9\end{array}$ & $\begin{array}{l}3.0 \\
2.9 \\
3.3\end{array}$ & $\begin{array}{l}2.1 \\
2.2 \\
2.3\end{array}$ & $\begin{array}{l}2.1 \\
1.9 \\
2.2\end{array}$ & $\begin{array}{l}3.3 \\
3.0 \\
3.1\end{array}$ & $\begin{array}{l}3.3 \\
3.2 \\
3.3\end{array}$ & $\begin{array}{l}3 \cdot 5 \\
3 \cdot 3 \\
3 \cdot 3\end{array}$ & $\begin{array}{l}2.9 \\
2.9 \\
2.9\end{array}$ & $\begin{array}{l}1.9 \\
2.1 \\
2.3\end{array}$ & $\begin{array}{l}2.6 \\
2.5 \\
3 \cdot 3\end{array}$ & $\begin{array}{l}4.7 \\
4.8 \\
4.8\end{array}$ \\
\hline $\begin{array}{l}\text { Factor } \mathrm{E} \\
\text { Assertive } \\
\text { Average } \\
\text { Humble }\end{array}$ & $\begin{array}{l}2.7 \\
2.6 \\
2.6\end{array}$ & $\begin{array}{l}2.9 \\
2.9 \\
2.5\end{array}$ & $\begin{array}{r}3.1 \\
3.3 \\
2.8\end{array}$ & $\begin{array}{l}2.3 \\
2.2 \\
2.0\end{array}$ & $\begin{array}{l}2.2 \\
2.1 \\
1.8\end{array}$ & $\begin{array}{l}3.1 \\
3.3 \\
3.1\end{array}$ & $\begin{array}{l}3.2 \\
3.2 \\
3.6\end{array}$ & $\begin{array}{l}3.4 \\
3.1 \\
3.6\end{array}$ & $\begin{array}{l}2.8 \\
3.1 \\
2.8\end{array}$ & $\begin{array}{l}2.3 \\
2.0 \\
1.9\end{array}$ & $\begin{array}{l}2.9 \\
2.5 \\
2.7\end{array}$ & $\begin{array}{l}4.9 \\
4.5 \\
4.8\end{array}$ \\
\hline $\begin{array}{l}\text { Factor F } \\
\text { Happy-Go-Iucky } \\
\text { Average } \\
\text { Sober }\end{array}$ & $\begin{array}{l}2.7 \\
2.8 \\
2.7\end{array}$ & $\begin{array}{l}2.9 \\
2.8 \\
2.9\end{array}$ & $\begin{array}{l}3.1 \\
3.1 \\
3.2\end{array}$ & $\begin{array}{l}2.2 \\
2.3 \\
2.1\end{array}$ & $\begin{array}{l}2.1 \\
2.2 \\
2.0\end{array}$ & $\begin{array}{l}3.1 \\
3.2 \\
3.2\end{array}$ & $\begin{array}{l}3 \cdot 3 \\
3 \cdot 2 \\
3 \cdot 3\end{array}$ & $\begin{array}{l}3.4 \vdots \\
3.5 \\
3.2\end{array}$ & $\begin{array}{l}2.9 \\
2.9 \\
2.9\end{array}$ & $\begin{array}{l}2.2 \\
2.3 \\
2.0\end{array}$ & $\begin{array}{l}2.7 \\
2.8 \\
2.8\end{array}$ & $\begin{array}{l}4.8 \\
4.7 \\
4.7\end{array}$ \\
\hline
\end{tabular}


TABLE E.III (Continued)

\begin{tabular}{|c|c|c|c|c|c|c|c|c|c|c|c|c|}
\hline Personality Factors & 1 & 2 & 3 & 4 & $\begin{array}{c}\text { Semant } \\
5\end{array}$ & c Rat & $\begin{array}{c}n g \\
7\end{array}$ & $\begin{array}{r}\text { Les } \\
8\end{array}$ & 9 & 10 & 11 & 12 \\
\hline \multicolumn{13}{|l|}{ Factor G } \\
\hline Conscientious & 2.4 & 2.5 & 2.8 & 2.2 & 1.8 & 2.8 & 3.2 & 3.7 & 2.9 & 1.9 & 2.6 & 5.4 \\
\hline Average & 2.7 & 2.8 & 3.0 & 2.1 & 2.1 & 3.1 & 3.3 & 3.4 & 2.9 & 2.2 & 2.8 & 4.5 \\
\hline Expedient & 2.7 & 3.0 & $3 \cdot 3$ & 2.3 & 2.1 & 3.2 & 3.2 & 3.2 & 2.8 & 2.2 & 2.8 & 4.9 \\
\hline \multicolumn{13}{|l|}{ Factor $\mathrm{H}$} \\
\hline Venturesome & 2.7 & 2.9 & 3.0 & 2.2 & 2.2 & 3.0 & $3 \cdot 3$ & 3.4 & 2.8 & 2.1 & 2.7 & 4.9 \\
\hline Average & 2.6 & 2.8 & 3.0 & 2.2 & 2.0 & 3.2 & 3.3 & 3.4 & 2.9 & 2.3 & 2.9 & 4.9 \\
\hline Shy & 2.8 & 2.9 & 3.3 & 2.3 & 2.1 & 3.2 & $3 \cdot 3$ & 3.2 & 2.9 & 2.1 & 2.8 & 4.5 \\
\hline \multicolumn{13}{|l|}{ Factor I } \\
\hline Tender-Minded & 2.6 & 2.7 & 3.0 & 2.1 & 2.0 & 3.1 & 3.5 & 3.4 & 3.0 & 2.1 & 2.7 & 4.9 \\
\hline Average & 2.8 & 3.0 & 3.1 & 2.4 & 2.1 & 3.3 & 3.2 & 3.4 & 2.9 & 2.2 & 2.7 & 4.8 \\
\hline Tough-Minded & 2.7 & 2.9 & $3 \cdot 3$ & 2.2 & 2.2 & 3.1 & 3.0 & 3.2 & 2.7 & 2.2 & 2.9 & 4.6 \\
\hline \multicolumn{13}{|l|}{ Factor I } \\
\hline Suspicious & 2.7 & 2.9 & 3.2 & 2.1 & 2.1 & 3.2 & 3.2 & $3 \cdot 3$ & 2.9 & 2.2 & 2.9 & 4.8 \\
\hline Average & 2.6 & 2.7 & 2.9 & 2.2 & 2.0 & 3.0 & 3.5 & 3.5 & 2.8 & 2.2 & 2.7 & 4.8 \\
\hline Trusting & 2.9 & 3.1 & 3.2 & 2.4 & 2.2 & 3.3 & 3.2 & $3 \cdot 3$ & 3.2 & 2.0 & 2.6 & 4.6 \\
\hline \multicolumn{13}{|l|}{ Factor M } \\
\hline Imaginative & 2.6 & 3.0 & 3.1 & 2.2 & 2.0 & 3.0 & 3.3 & 3.3 & 2.9 & 2.1 & 2.7 & 4.8 \\
\hline Average & 2.6 & 2.8 & 3.1 & 2.3 & 2.2 & $3 \cdot 3$ & 3.2 & 3.4 & 2.9 & 2.3 & 3.0 & 4.7 \\
\hline Practical & 2.9 & 2.6 & 3.1 & 2.0 & 2.0 & 3.1 & 3.4 & 3.4 & 2.8 & 2.1 & 2.7 & 4.7 \\
\hline \multicolumn{13}{|l|}{ Factor N } \\
\hline Shrewd & 2.8 & 2.9 & 3.2 & 2.2 & 2.1 & 3.2 & 3.2 & 3.3 & 2.8 & 2.1 & 3.0 & 4.8 \\
\hline Average & 2.6 & 2.9 & 3.0 & 2.1 & 2.0 & 3.0 & 3.4 & 3.5 & 3.0 & 2.1 & 2.6 & 4.8 \\
\hline Forthright & 2.7 & 2.7 & 3.1 & 2.3 & 2.2 & 3.2 & 3.1 & $3 \cdot 3$ & 2.8 & 2.3 & 2.8 & 4.7 \\
\hline
\end{tabular}


TABLE E.III (Continued)

\begin{tabular}{|c|c|c|c|c|c|c|c|c|c|c|c|c|}
\hline \multirow[b]{2}{*}{ Personality Factors } & \multicolumn{12}{|c|}{ Semantic Rating Scales } \\
\hline & 1 & 2 & 3 & 4 & 5 & & & 8 & 9 & 10 & 11 & 12 \\
\hline \multicolumn{13}{|l|}{ Factor 0} \\
\hline Apprehensive & 2.8 & 2.8 & 3.0 & 2.2 & 2.0 & $3 \cdot 3$ & 3.5 & 3.4 & 3.3 & 2.3 & 2.8 & 5.1 \\
\hline Average & 2.7 & 2.8 & 3.0 & 2.2 & 2.0 & 3.2 & 3.2 & 3.4 & 2.9 & 2.1 & 2.9 & 4.8 \\
\hline Self-Assured & 2.7 & 2.9 & 3.2 & 2.2 & 2.1 & 3.1 & 3.2 & 3.3 & 2.8 & 2.1 & 2.7 & 4.7 \\
\hline \multicolumn{13}{|l|}{ Factor $Q_{1}$} \\
\hline Experimenting & 2.9 & 3.0 & 3.3 & 2.3 & 2.2 & 3.0 & 3.2 & 3.2 & 2.9 & 2.1 & 2.8 & 4.8 \\
\hline Average & 2.5 & 2.7 & 2.9 & 2.1 & 2.0 & 3.2 & 3.4 & 3.5 & 2.0 & 2.1 & 2.8 & 4.7 \\
\hline Conservative & 2.6 & 2.8 & 3.0 & 2.1 & 2.0 & $3 \cdot 3$ & 3.2 & 3.4 & 2.8 & 2.3 & 2.8 & 4.8 \\
\hline \multicolumn{13}{|l|}{ Factor $Q_{2}$} \\
\hline Self-Sufficient & 2.7 & 2.7 & 3.2 & 2.2 & 2.1 & 3.3 & 3.2 & 3.2 & 2.9 & 2.1 & 2.6 & 4.7 \\
\hline Average & 2.7 & 2.8 & 3.0 & 2.2 & 2.1 & 3.1 & 3.4 & 3.4 & 2.8 & 2.2 & 2.9 & $4 \cdot 9$ \\
\hline Group-Dependent & 2.6 & 2.9 & 3.0 & 2.1 & 2.0 & 2.9 & 3.3 & 3.6 & 3.1 & 2.5 & 3.1 & 4.8 \\
\hline \multicolumn{13}{|l|}{ Factor $Q_{3}$} \\
\hline Controlied & 2.7 & 2.9 & $3 \cdot 3$ & 2.3 & 2.1 & 3.1 & 3.2 & $3 \cdot 3$ & 2.9 & 2.0 & 2.8 & 4.9 \\
\hline Average & 2.7 & 2.8 & 3.1 & 2.2 & 2.0 & 3.1 & $3 \cdot 3$ & 3.5 & 2.8 & 2.2 & 2.8 & 4.8 \\
\hline Undisciplined Self-Conflict & 2.7 & 2.9 & 3.0 & 2.1 & 2.1 & 3.2 & $3 \cdot 3$ & 3.2 & 3.0 & 2.3 & 2.8 & 4.6 \\
\hline \multicolumn{13}{|l|}{ Factor $Q_{4}$} \\
\hline Tense & 2.7 & 2.9 & 3.1 & 2.2 & 2.0 & 3.2 & 3.2 & $3 \cdot 3$ & 2.9 & 2.2 & 2.8 & 4.6 \\
\hline Average & 2.7 & 2.8 & 3.0 & 2.0 & 2.0 & 3.2 & 3.4 & 3.4 & 2.9 & 2.1 & 2.8 & 5.0 \\
\hline Relaxed & 2.8 & 2.8 & 3.2 & 2.3 & 2.2 & 3.0 & 3.2 & 3.4 & 3.0 & 2.1 & 2.8 & 4.8 \\
\hline
\end{tabular}

*The semantic rating scale numbers correspond to the scale description in Table E.II.

Source: Primary 
TABLE E.IV

" $t "$ VALUES ${ }^{1}$ OF THE DIFFERENCES BETWEEN PERSONALITY TRAITS FOR MASSEY'S COMPANY ORIENTED ADVERTISEMIENT

\begin{tabular}{|c|c|c|c|c|c|c|c|}
\hline \multirow{2}{*}{$\begin{array}{l}\text { Scale } \\
\text { Number }\end{array}$} & \multirow[b]{2}{*}{ Semantic Rating Scales } & \multicolumn{3}{|c|}{ Factor $A^{2}$} & \multicolumn{3}{|c|}{ Factor B } \\
\hline & & $\mathrm{Hi} / \mathrm{Av}$ & $\mathrm{Hi} / \mathrm{LO}$ & $\mathrm{Av} / \mathrm{Lo}$ & $\mathrm{Hi} / \mathrm{Av}$ & $\mathrm{Hi} / \mathrm{IO}$ & $\mathrm{Av} / \mathrm{LO}$ \\
\hline$I$ & GOOD-BAD & & & & & & $2.511 *$ \\
\hline 2 & KIND-LRUEL & & & & $2.179 *$ & $3.478 *$ & $1.752 *$ \\
\hline 3 & BEIIEVING-SKEPTICAI & & & & & & \\
\hline 4 & PROGRESSIVE-PEGRESSIVE & & $1.878 *$ & & & & \\
\hline 5 & POSITIVE-NEGATIVE & & & & & & \\
\hline 6 & REPUTABLE-DISREPUTABLE & & & & & & $2.805 *$ \\
\hline 7 & MASCULINE-TEMININE & & & & & $-2.351 * *$ & $-1.864 * *$ \\
\hline 8 & HARD-SOFT & & & & $-2.012 * *$ & $-3.781 * *$ & $-2.311 * *$ \\
\hline 9 & SERIOUS-HUMOROUS & & & & & & \\
\hline 10 & ACTIVE-PASSIVE & - & $3.733^{*}$ & $2.088 *$ & & & \\
\hline 11 & EXCITNBIE-CAIM & & & & & & \\
\hline 12 & COMPLEX-STMPLE & $1.696 *$ & $2.522 *$ & & $1.952 *$ & & $-2.189 * *$ \\
\hline & & & Factor $\mathrm{C}$ & & & Factor $\mathrm{E}$ & \\
\hline 1 & GOOD-BAD & & $-2.486 * *$ & $-2.224 * *$ & & $1.881 *$ & \\
\hline 2 & KIND-CRUEL & & & & & $5.431 *$ & $2.932 *$ \\
\hline 3 & BELIEVING-SKEPTICAL & & $-1.760 * *$ & $-3.120 * *$ & & $3.415 *$ & $2.638 *$ \\
\hline 4 & PROGRESSIVE-REGRESSIVE & & & & & $3.320 *$ & $1.854 *$ \\
\hline 5 & POSITIVE-NEGATIVE & & & $-2.883 * *$ & & $4.097^{*}$ & $1.883^{*}$ \\
\hline 6 & REPUTABLE-DISREPUTABLE & & & & & & \\
\hline 7 & MASCUIINE-FEMININE & , & & & & $-4.510 * *$ & $-3.405 * *$ \\
\hline 8 & HARD-SOFT & & & & & $-2.413 * *$ & $-3.541 * *$ \\
\hline 9 & SERIOUS-HUMOROUS & & & & $-1.904 * *$ & & $2.504 *$ \\
\hline 10 & ACTIVE-PASSIVE & & $-2.754 * *$ & $-1.793 * *$ & $1.970 *$ & $4.217 *$ & \\
\hline 11 & EXCITABLE-CALM & & $-2.206 * *$ & $-4.007 * *$ & $2.605 *$ & $2.531 *$ & \\
\hline 12 & COMPLEX-SIMPLE & & & & $1.949 *$ & & $-1.690 * *$ \\
\hline
\end{tabular}


TABLE E.IV (Continued)

\begin{tabular}{|c|c|c|c|c|c|c|c|}
\hline \multirow{2}{*}{$\begin{array}{l}\text { Scale } \\
\text { Number }\end{array}$} & \multirow[b]{2}{*}{ Semantic Rating Scales } & \multicolumn{3}{|c|}{ Factor $F$} & \multicolumn{3}{|c|}{ Factor $\mathrm{G}$} \\
\hline & & $\mathrm{Hi} / \mathrm{Av}$ & $\mathrm{Hi} / \mathrm{LO}$ & $\mathrm{Av} / \mathrm{IO}$ & $\mathrm{Hi} / \mathrm{Av}$ & $\mathrm{Hi} / \mathrm{LO}$ & $\mathrm{Av} / \mathrm{Lo}$ \\
\hline 1 & GOOD-BAD & & & & & & \\
\hline 2 & KIND-CRUEL & & & & & $-2.313 * *$ & \\
\hline 3 & BELIEVING-SKEPTICAL & & & & & $-1.787^{* *}$ & $-1.880 * *$ \\
\hline 5 & PROGRESSIVE-REGRESSIVE & & & & & & $-1.831 * *$ \\
\hline 5 & POSITIVE-NEGATIVE & & & & & & \\
\hline 6 & REPUTABLE-DISREPUTABLE & & & & & & \\
\hline 7 & MASCULINE-FEMININE & & & & & & \\
\hline 8 & HARD-SOFT & & & $2.614 *$ & & $1.772^{*}$ & $2.055 *$ \\
\hline 9 & SERIOUS-HUMOROUS & & & & & & \\
\hline 10 & ACTIVE-PASSIVE & & & $2.006 *$ & & & \\
\hline 11 & EXCITABLE-CAIM & & & & & & \\
\hline 12 & COMPLEX-SIMPLE & & & & $3.030 *$ & & $-3.412 * *$ \\
\hline & & & Factor $\mathrm{H}$ & & & Factor I & \\
\hline 1 & GOOD-BAD & & & $-2.229 * *$ & & & \\
\hline 2 & KIND-CRUEL & & & & $-2.458 * *$ & $-2.765 * *$ & \\
\hline 3 & BEIIEVING-SKEPTICAL & & $-1.881 * *$ & $-1.901 * *$ & & $-2.530 * *$ & \\
\hline 4 & PROGRESSIVE-REGRESSIVE & & & & $-1.839 * *$ & & \\
\hline 5 & POSITIVE-NEGATIVE & & & & & & \\
\hline 6 & REFUTABLE-DISREPUTABIE & & & & & & $1.666 *$ \\
\hline 7 & MASCÜLINE-FEMININE & & & & $1.704 *$ & $4.866 *$ & $2.185 *$ \\
\hline 8 & HARD-SOFT & & $1.743 *$ & & & & \\
\hline 9 & SERIOUS-HUMOROUS & , & & & & $3.219 *$ & $2.189 *$ \\
\hline 10 & ACTIVE-PASSIVE & & & $2.113^{*}$ & & & \\
\hline 11 & EXCITABLE-CALM & & & & & & \\
\hline 12 & COMPLEX-SIMPLE & & $2.700 *$ & $2.331 *$ & & $2.422 *$ & \\
\hline
\end{tabular}


TABLE E.IV (Continued)

\begin{tabular}{|c|c|c|c|c|c|c|c|}
\hline \multirow{2}{*}{$\begin{array}{l}\text { Scale } \\
\text { Number }\end{array}$} & \multirow[b]{2}{*}{ Semantic Rating Scales } & \multicolumn{3}{|c|}{ Factor I } & \multicolumn{3}{|c|}{ Factor M } \\
\hline & & $\mathrm{Hi} / \mathrm{AV}$ & $\mathrm{Hi} / \mathrm{LO}$ & Av/Lo & $\mathrm{Hi} / \mathrm{Av}$ & $\mathrm{Hi} / \mathrm{LO}$ & $\mathrm{Av} / \mathrm{IO}$ \\
\hline $\begin{array}{r}1 \\
2 \\
3 \\
4 \\
5 \\
6 \\
7 \\
8 \\
9 \\
10 \\
11 \\
12\end{array}$ & $\begin{array}{l}\text { GOOD-BAD } \\
\text { KIND-CRUEL } \\
\text { BELIEVING-SKEPTICAI } \\
\text { PROGRESSIVE-REGRESSIVE } \\
\text { POSITIVE-NEGAIIVE } \\
\text { REPUTABLF-DISREPUTABLE } \\
\text { MASCULINE-FEMININE } \\
\text { HARD-SOFT } \\
\text { SERIOUS-HUMOROUS } \\
\text { ACTIVE-PASSIVE } \\
\text { EXCITABLE-CALM } \\
\text { COMPLEX-SIMPLE }\end{array}$ & $-1.974 * *$ & $\begin{array}{l}-1.763 * * \\
-2.724 * * \\
-3.522 * *\end{array}$ & $\begin{array}{l}-2.297 * * \\
-4.303^{*} \\
-2.057 * * \\
-2.284^{*} \\
-1.940 * * \\
2.691 * \\
1.810 * \\
-3.338 * * \\
1.707 *\end{array}$ & $1.651 *$ & $\begin{array}{c}-2.980 * * \\
4.778 * \\
2.328 *\end{array}$ & $\begin{array}{c}-2.380 * * \\
1.658 * \\
1.914 *\end{array}$ \\
\hline & & & Factor N & & & Factor 0 & \\
\hline 1 & GOOD-BAD & & & & & & \\
\hline 2 & KIND-CRUEL & & $2.862 *$ & $2.857^{*}$ & & & \\
\hline $\begin{array}{l}3 \\
4\end{array}$ & $\begin{array}{l}\text { BELIEVING-SKEPTICAL } \\
\text { PROGRESSIVE-REGRESSIVE }\end{array}$ & & & & & & \\
\hline $\begin{array}{l}5 \\
6\end{array}$ & $\begin{array}{l}\text { POSITIVE-NEGATIVE } \\
\text { REFiJTABLE-DISREPUTABLE }\end{array}$ & & & $1.742^{* *}$ & & & \\
\hline $\begin{array}{l}7 \\
8\end{array}$ & $\begin{array}{l}\text { MASCULINE-FEVININE } \\
\text { HARD-SOFT }\end{array}$ & & & $\begin{array}{l}3.294^{*} \\
1.919^{*}\end{array}$ & & $2.059 *$ & \\
\hline 9 & SERIOUS-HUMOROUS & - & & $1.658 *$ & $1.781 *$ & $2.303^{*}$ & \\
\hline 10 & ACTIVE-PASSIVE & & $-1.877^{* *}$ & $-2.134 * *$ & & & \\
\hline 11 & EXCITABIE-CATM & $1.984^{*}$ & & $-2.163^{* *}$ & & & \\
\hline 12 & COMPLEX-STMPLE & & & & & $1.897 *$ & \\
\hline
\end{tabular}


TABLE E.IV (Continied)

\begin{tabular}{|c|c|c|c|c|c|c|c|}
\hline \multirow{2}{*}{$\begin{array}{l}\text { Scale } \\
\text { Number }\end{array}$} & \multirow[b]{2}{*}{ Semantic Rating Scales } & \multicolumn{3}{|c|}{ Fector $Q_{1}$} & \multicolumn{3}{|c|}{ Factor $Q_{2}$} \\
\hline & & $\mathrm{Hi} / \mathrm{Av}$ & $\mathrm{HI} / \mathrm{IO}$ & $\mathrm{Av} / \mathrm{Io}$ & $\mathrm{Hi} / \mathrm{AV}$ & $\mathrm{Hi} / \mathrm{LO}$ & $\mathrm{Av} / \mathrm{IO}$ \\
\hline 1 & GOOD-BAD & $2.008 *$ & $2.939 \div$ & & & & \\
\hline 2 & KIND-CRUEI & $1.923 *$ & & & & & \\
\hline 3 & BEIIEVING-SKEPTICAI & $2.199 *$ & $2.642 *$ & & & & \\
\hline 4 & FROGRESSIVE-REGRESSIVE & $1.732 *$ & $2.162 *$ & & & $1.809 *$ & \\
\hline 5 & POSIRIVE-NEGATIVE & & & & & & \\
\hline 6 & REPUIABLE-DISREPUTABLE & & $-1.939 * *$ & & & $3.715^{*}$ & $1.703^{*}$ \\
\hline 7 & MASCULINE-FEMININE & & & $1.868 *$ & $-2.173 * *$ & $-2.159 * *$ & \\
\hline 8 & HARD-iNOFT & & $-1.673 * *$ & & & $-3.368 * *$ & \\
\hline 9 & SERIOUS-HUMOROUS & & & - & & $-2.169 * *$ & $-1.970 * *$ \\
\hline 10 & ACTIVE-PASSIVT & & & & & $-4.886 * *$ & $-2.946 * *$ \\
\hline 11 & EXCITABLE-CALM & & & & & $-4.559 * *$ & $-2.008 * *$ \\
\hline \multirow[t]{2}{*}{12} & COMPLEX-SIMPLE & & & & & & \\
\hline & & \multicolumn{3}{|c|}{ Factor Q3 } & \multicolumn{3}{|c|}{ Factor $Q_{4}$} \\
\hline 1 & GOOD-BAD & & & & & & \\
\hline 2 & KIND-CRUEL & & & & & & \\
\hline 3 & BELIEV ING-SKEPTICAI & & & & & & \\
\hline 4 & PROGRESSIVE-REGRESSIVE & & & & & & $-2.746 * *$ \\
\hline 5 & POSITIVE-NEGATIVE & & & & & & \\
\hline 6 & REPUTABLE-DISREPUTABLE & & & & & & \\
\hline 7 & MASCULINA-FMMTNINE & & & & & & $2.245 \%$ \\
\hline 8 & HAIRD- 'SOL"I! & & & $2.414 *$ & & & \\
\hline 9 & SERIOUS-HUMOROUS & & & $-1.841 * *$ & & & \\
\hline 10 & ACTIVE-PASSTVE & & $1.710 * *$ & & & & \\
\hline 11 & EXCITABLE-CAIM & & & & & & \\
\hline 12 & COMPLEX-SIMPLE & & $1.954 *$ & $1.717^{*}$ & $-1.691 * *$ & & \\
\hline
\end{tabular}

Groups compared: High-Average, High-Low, and Average-jow for each of the 16 personality factors. Critical "t" value for single tailed test: 1.645

Ionly those values significant at the .05 level are given.

2 High represents high score description of the personality factor. Average represents average score description of the personality factor. Low indicates raw score description of the personality factor.

* +1.645 -- denotes that average perceived the ad more favorably than high, low better than high, and low better than average.

**-1.645 -- indicates that high perceived the ad more favorably than average, high better than low, and average better than low.

Source: Table T.III 
TABLE E.V

SEMANTIC DIFFERENTIAL SCAIE MEANS FOR DALLAS MUTUAL IIFE'S READER ORIENTED ADVERTISEMENTS BY PERSONALITY FACTORS

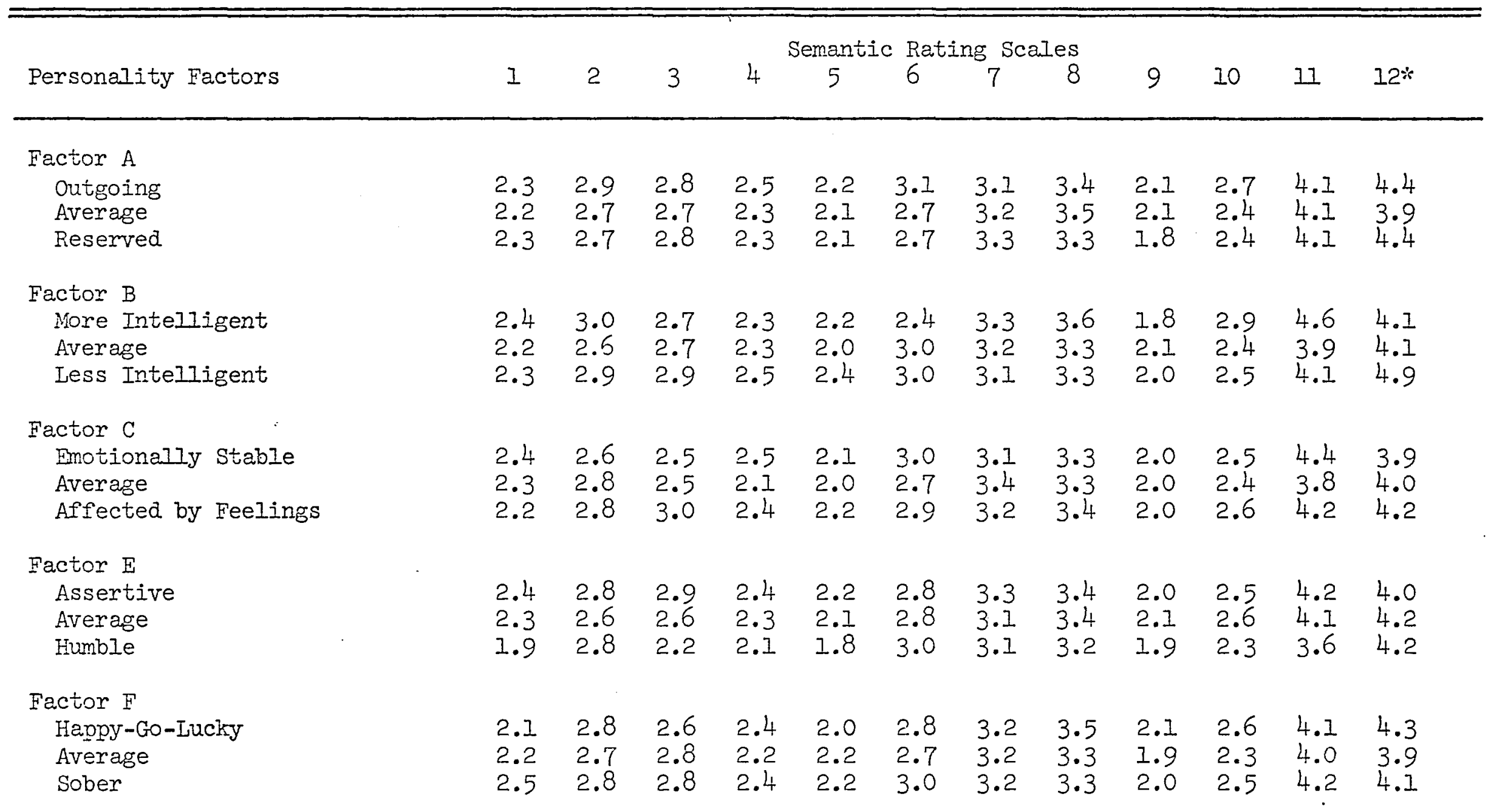


TABIE E.V (Continued)

\begin{tabular}{|c|c|c|c|c|c|c|c|c|c|c|c|c|}
\hline Personality Factors & \multicolumn{12}{|c|}{ Semantic Rating Scales } \\
\hline \multicolumn{13}{|l|}{ Factor G } \\
\hline Conscientious & 2.1 & 2.8 & 2.3 & 2.0 & 2.2 & 2.8 & 3.4 & 3.4 & 2.0 & 2.4 & 3.6 & 3.7 \\
\hline Averaש̃e & 2.1 & 2.5 & 2.5 & 2.3 & 2.1 & 2.6 & 3.2 & 3.5 & 2.1 & 2.6 & 4.1 & 4.1 \\
\hline Expedient & 2.5 & 3.0 & 3.1 & 2.5 & 2.2 & 3.0 & 3.2 & 3.3 & 2.0 & 2.5 & 4.2 & 4.2 \\
\hline \multicolumn{13}{|l|}{ Factor $\mathrm{H}$} \\
\hline Venturesome & 2.4 & 2.7 & 2.7 & 2.5 & 2.2 & 2.8 & 3.3 & 3.3 & 1.9 & 2.6 & 4.1 & 4.2 \\
\hline Average & 2.2 & 2.8 & 2.7 & 2.2 & 2.0 & 2.8 & 3.1 & 3.5 & 2.2 & 2.5 & 4.1 & 4.0 \\
\hline Sny & 2.2 & 2.8 & 2.8 & 2.3 & 2.2 & 2.9 & 3.2 & 3.3 & 1.9 & 2.4 & 4.0 & 4.1 \\
\hline \multicolumn{13}{|l|}{ Factor I } \\
\hline Tender-Minded & 2.4 & 2.7 & 2.8 & 2.4 & 2.2 & 2.8 & 3.2 & 3.4 & 2.1 & 2.5 & $4: 2$ & 4.0 \\
\hline Average & 2.2 & 2.9 & 2.6 & 2.3 & 2.1 & 2.9 & $3 \cdot 3$ & 3.4 & 2.0 & 2.5 & 3.9 & 4.2 \\
\hline Tough-Minded & 2.2 & 2.6 & 2.8 & 2.3 & 2.1 & 2.8 & 3.2 & 3.3 & 1.9 & 2.5 & 4.2 & 4.1 \\
\hline \multicolumn{13}{|l|}{ Factor I } \\
\hline Suspicious & 2.4 & 2.8 & 2.8 & 2.5 & 2.2 & 2.8 & $3 \cdot 3$ & 3.4 & 2.0 & 2.6 & 4.3 & 4.2 \\
\hline Average & 2.2 & 2.7 & 2.7 & 2.2 & 2.1 & 2.9 & 3.1 & 3.4 & 2.1 & 2.4 & 4.0 & 4.0 \\
\hline Trusting & 2.1 & 2.8 & 2.6 & 2.3 & 2.1 & 2.7 & 3.2 & 3.4 & 2.0 & 2.5 & 3.8 & 4.0 \\
\hline \multicolumn{13}{|l|}{ Factor M } \\
\hline Imaginative & 2.4 & 2.9 & 2.8 & 2.5 & 2.2 & 2.8 & 3.2 & 3.4 & 2.1 & 2.5 & 4.2 & 4.1 \\
\hline Average & 2.0 & 2.5 & 2.7 & 2.2 & 2.0 & 2.8 & 3.2 & 3.4 & 2.0 & 2.4 & 4.1 & 4.1 \\
\hline Practical & 2.3 & 2.0 & 2.7 & 2.2 & 2.3 & 3.1 & 3.2 & $3 \cdot 3$ & 1.9 & 2.5 & 3.9 & 4.1 \\
\hline \multicolumn{13}{|l|}{ Factor N } \\
\hline Shrewd & 2.4 & 3.0 & 3.0 & 2.5 & 2.2 & 3.0 & 3.2 & $3 \cdot 3$ & 2.0 & 2.5 & 4.1 & $4 \cdot 3$ \\
\hline Average & 2.2 & 2.8 & 2.6 & 2.3 & 2.2 & 2.8 & 3.2 & 3.4 & 2.0 & 2.5 & 4.1 & 3.8 \\
\hline Forthright & 2.2 & 2.4 & 2.6 & 2.2 & 2.0 & 2.7 & $3 \cdot 3$ & 3.4 & 2.0 & 2.4 & 4.0 & 4.2 \\
\hline
\end{tabular}


TABIE E.V (Continued)

\begin{tabular}{|c|c|c|c|c|c|c|c|c|c|c|c|c|}
\hline Personality Factors & 1 & 2 & 3 & 4 & $\frac{\operatorname{lemant}}{5}$ & $\begin{array}{l}\text { c Rat } \\
6\end{array}$ & $\begin{array}{c}\text { ng Sce } \\
7\end{array}$ & $\begin{array}{r}\text { Les } \\
8\end{array}$ & 9 & 10 & 11 & 12 \\
\hline \multicolumn{13}{|l|}{ Factor 0} \\
\hline Apprenensive & 2.2 & 2.6 & 2.5 & 2.2 & 2.0 & 2.7 & 3.3 & 3.5 & 2.6 & 2.4 & 4.1 & 4.2 \\
\hline Average & 2.1 & 2.7 & 2.7 & 2.3 & 2.1 & 2.9 & 2.2 & 3.3 & 2.0 & 2.7 & 3.9 & 4.0 \\
\hline Self-Assured & 2.4 & 2.8 & 2.8 & 2.4 & 2.2 & 2.8 & 3.2 & 3.4 & 1.9 & 2.5 & 4.2 & 4.1 \\
\hline \multicolumn{13}{|l|}{ Factor Q1 } \\
\hline Experimenting & 2.5 & 2.9 & 3.0 & 2.6 & 2.3 & 2.8 & 3.1 & $3 \cdot 3$ & 2.1 & 2.5 & 4.1 & $4 \cdot 3$ \\
\hline Average & 2.1 & 2.6 & 2.6 & 2.3 & 2.0 & 3.0 & 3.4 & 3.4 & 2.1 & 2.5 & 4.2 & 4.0 \\
\hline Conservative & 2.1 & 2.8 & 2.5 & 2.1 & 2.0 & 2.7 & 3.2 & 3.4 & 1.8 & 2.4 & $3 \cdot 9$ & 3.9 \\
\hline \multicolumn{13}{|l|}{ Factor $Q_{2}$} \\
\hline Self-Süficient & 2.5 & 2.9 & 2.9 & 2.5 & 2.2 & 2.8 & 3.2 & 3.3 & 2.0 & 2.5 & 4.1 & 4.0 \\
\hline Average & 2.0 & 2.6 & 2.5 & 2.2 & 2.0 & 2.9 & 3.4 & 3.4 & 1.9 & 2.5 & 4.0 & 4.4 \\
\hline Group-Dependent & 2.3 & 2.8 & 2.7 & 2.2 & 2.1 & 2.7 & 3.0 & 3.4 & 2.3 & 2.4 & 3.9 & 3.7 \\
\hline \multicolumn{13}{|l|}{ Factor $Q_{3}$} \\
\hline Controlled & 2.3 & 2.6 & 2.7 & 2.3 & 2.1 & 2.6 & $3 \cdot 3$ & 3.6 & 1.9 & 2.5 & 4.3 & 4.1 \\
\hline Average & 2.2 & 2.8 & 2.7 & 2.3 & 2.1 & 3.1 & 3.2 & $3 \cdot 3$ & 2.0 & 2.6 & 4.1 & 4.0 \\
\hline Undisciplined Self-Conflice & 2.4 & 2.8 & 2.9 & 2.4 & 2.2 & 2.7 & 3.2 & $3 \cdot 3$ & 2.0 & 2.4 & 3.9 & 4.1 \\
\hline \multicolumn{13}{|l|}{ Factor $Q_{4}$} \\
\hline Tense ${ }^{4}$ & 2.2 & 2.8 & 2.8 & 2.3 & 2.1 & 2.9 & 3.2 & 3.2 & 2.0 & 2.5 & 4.0 & 4.0 \\
\hline Average & 2.4 & 2.7 & 2.7 & 2.4 & 2.1 & 2.7 & 3.2 & 2.2 & 1.9 & 2.5 & 4.2 & 4.3 \\
\hline Relaxed & 2.2 & 2.7 & 2.8 & 2.4 & 2.2 & 2.9 & 3.3 & 3.6 & 2.1 & 2.5 & 4.1 & 4.0 \\
\hline
\end{tabular}

Source: Primary 


\section{TABLE E.VI}

" $t$ " VALUES ${ }^{l}$ OF THE SIGNIFICANT DIFFERENCE BETWEEN PERSONALITY TRAITS FOR DALLAS MUTUAL LIEE'S READER ORIENTED ADVERTISEMENT

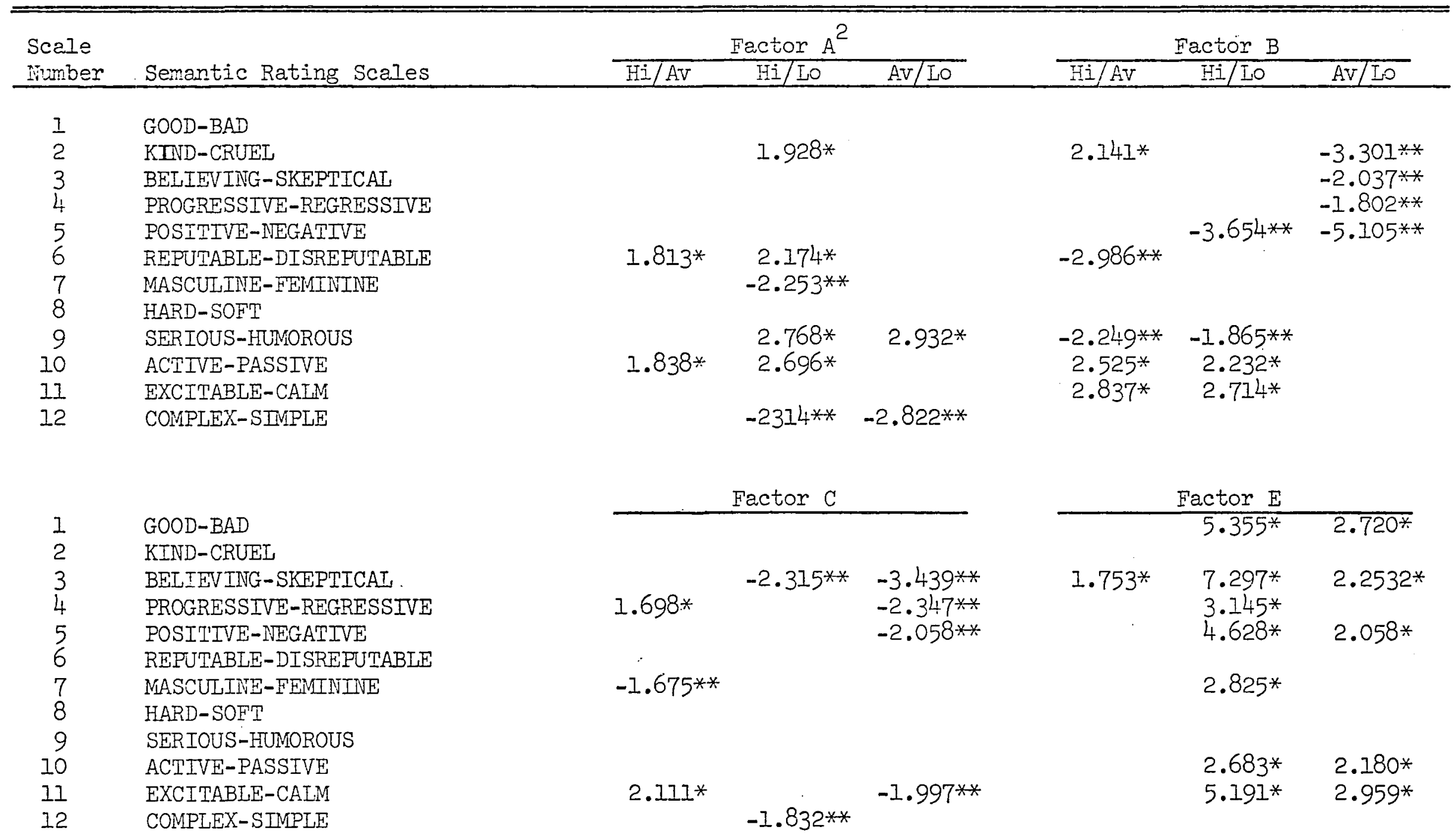


TABLE E.VI (Continued)

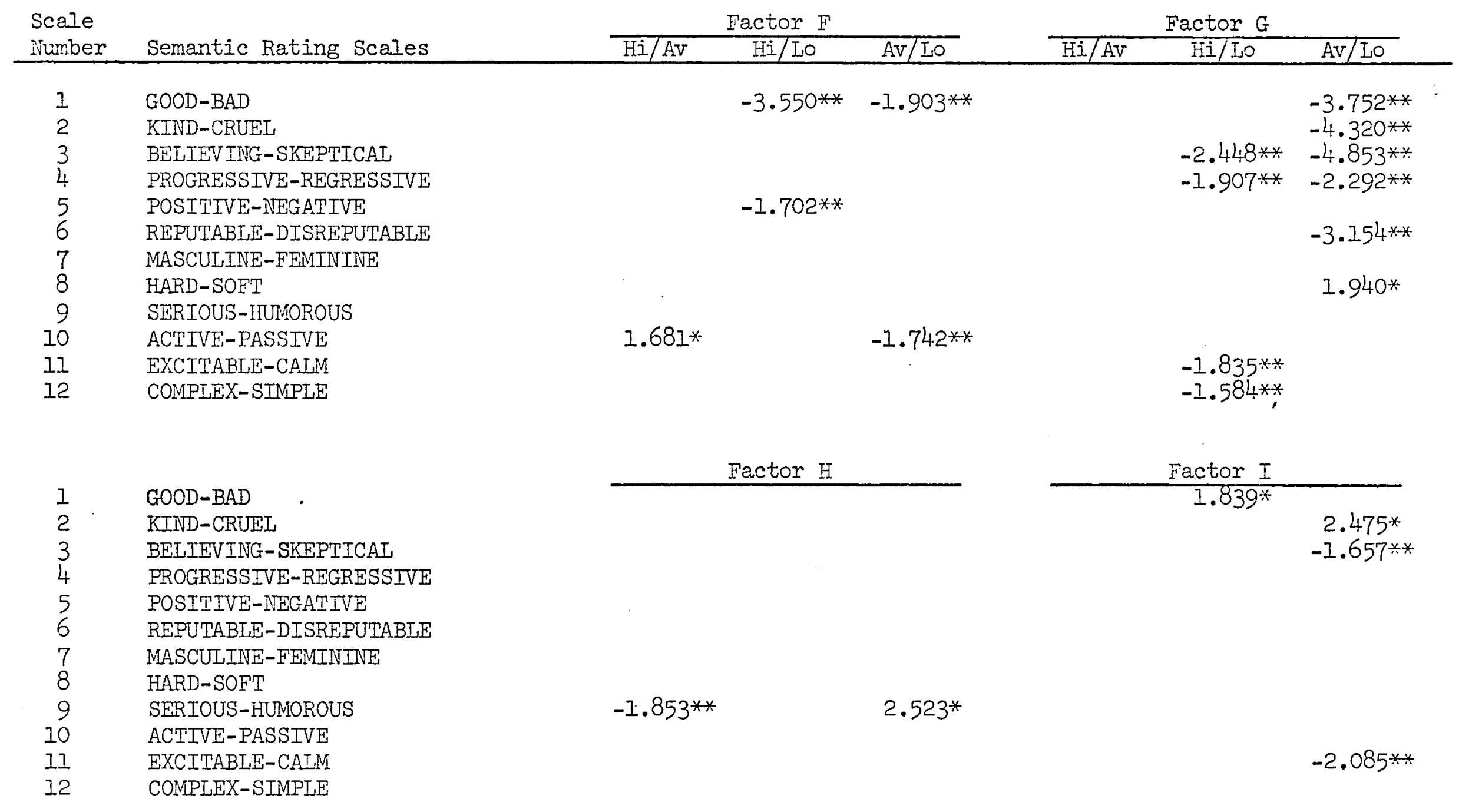


TABLE E.VI (Continued)

\begin{tabular}{|c|c|c|c|c|c|c|c|}
\hline \multirow{2}{*}{$\begin{array}{l}\text { Scale } \\
\text { Number }\end{array}$} & \multirow[b]{2}{*}{ Semantic Rating Scales } & \multicolumn{3}{|c|}{ Factor I } & \multicolumn{3}{|c|}{ Factor M } \\
\hline & & $\mathrm{Hi} / \mathrm{AV}$ & $\mathrm{Hi}$ i/LO & $\mathrm{Av} / \mathrm{LO}$ & $\mathrm{Hi} / \mathrm{Av}$ & $\mathrm{Hi} / \mathrm{LO}$ & $\mathrm{Av} / \mathrm{LO}$ \\
\hline 1 & GOOD-BAD & & $3.661 *$ & & $2.852 *$ & & $-3.011 * *$ \\
\hline 2 & KIND-CRUEI & & & & $2.701 *$ & & $-3.624 * *$ \\
\hline 3 & BELIEVING-SKEPTICAL & & $2.368 *$ & & & & \\
\hline 4 & PROGRESSIVE-REGRESSIVE & & & & & $2.354 *$ & \\
\hline 5 & FOSTTIVE-IVEGATIVE & & & & & & $-2.835^{* *}$ \\
\hline 6 & REFUTABLE-DISREPUTABLE & & & $1.682 *$ & & $-2.533^{* *}$ & \\
\hline 7 & MASCULINE-FEMININE & & & & & & \\
\hline 8 & HARD-SOFT & & & & & $1.767^{*}$ & \\
\hline 9 & SERIOUS-HUNOROUS & & & & & & \\
\hline 10 & ACTIVE-PASSIVE & & & & & & \\
\hline 11 & EXCITABLE-CAIM & & $3.545 *$ & & & $2.656 *$ & \\
\hline 12 & COMPLEX-SIMPLE & & & & & . & \\
\hline & & & $\operatorname{ctor} \mathbb{N}$ & & & actor 0 & \\
\hline 1 & GOOD-BAD & & $2.185 \%$ & & & & $-1.949^{*} *$ \\
\hline 2 & KIND-CRUEL & & $5.324 *$ & $4.265 *$ & & & \\
\hline 3 & BELIEVING-SKEPTICAL & $2.142 *$ & $3.328 \%$ & & & & \\
\hline 4 & PROGRESSIVE-REGRESSIVE & $1.830 *$ & $3.038 *$ & & & & \\
\hline 5 & POSITIVE-NEGATIVE & & & & & & \\
\hline 6 & REPUTABIE-DISREPUTIABLE & & $2.479 *$ & & & & \\
\hline 7 & MASCULINE-FEMINIIVE & & & & & & \\
\hline 8 & HARD-SOFT & & & & & & \\
\hline 9 & SERIOUS-HUMOROUS & $\therefore$ & & & $2.707^{*}$ & $4.105 *$ & \\
\hline 10 & ACTIVE-PASSIVE & & & & & & \\
\hline 11 & EXCITABILE-CALM & & . & & & & \\
\hline 12 & COMPLEX-SIMPLE & $2.200 *$ & & $-2.629 * *$ & & & \\
\hline
\end{tabular}


MABIE E.VI (Continued)

\begin{tabular}{|c|c|c|c|c|c|c|c|}
\hline \multirow{2}{*}{$\begin{array}{l}\text { Scale } \\
\text { inumber }\end{array}$} & \multirow[b]{2}{*}{ Semantic Rating Scales } & \multicolumn{3}{|c|}{ Factor $Q_{1}$} & \multicolumn{3}{|c|}{ Factor Q 2} \\
\hline & & $\mathrm{Hi} / \mathrm{Av}$ & $\mathrm{Hi} / \mathrm{IO}$ & $\mathrm{Av} / \mathrm{LO}$ & $\mathrm{Hi} / \mathrm{Av}$ & $\mathrm{Hi} / \mathrm{IO}$ & $\mathrm{Av} / \mathrm{IrO}$ \\
\hline 1 & COOD-BAD & $2.662 *$ & 3.6717 & & $3.125 *$ & $2.028 *$ & $-2.727^{* *}$ \\
\hline$\underline{2}$ & MIND-CRUEI & $2.393 *$ & $2.673 *$ & & $1.768 \div$ & & \\
\hline 3 & BEIIEVIKG-SKEPTICAI & $2.044 \%$ & $3.520 *$ & & $2.569 \%$ & $1.669 *$ & $-1.993 \% *$ \\
\hline 4 & FROGRESSIVE-REGRESSIVE & $1.849 *$ & $5.023 *$ & $1.888 *$ & & $2.355 *$ & \\
\hline 5 & POSITIVE-NEGATIVT & & $2.821 *$ & & & $1.827 *$ & \\
\hline 6 & PEPUTABLE-DISREFUTABLE & & & & & & \\
\hline 7 & MASCUIINE-FEMININE & $-1.865^{* *}$ & & & & $1.765 *$ & $3.507 *$ \\
\hline 8 & HARD-SOFT & & & & & & \\
\hline 9 & SERIOUS-HUMOROUS & & $2.824 *$ & $2.468 *$ & & $-4.424 * *$ & $-3.465 * *$ \\
\hline 10 & ACIIVE-PASSIVE & & & & & & \\
\hline 11 & EXCITABLE-CALM & & & $2.034 *$ & & $1.741 *$ & \\
\hline \multirow[t]{2}{*}{12} & COMPLEX-SIMPLE & & $3.217^{*}$ & & $-1.972^{* *}$ & $2.242 *$ & $4.444 *$ \\
\hline & & \multicolumn{3}{|c|}{ Factor $Q, 3$} & \multicolumn{3}{|c|}{ Factor Q 4} \\
\hline 1 & GOOD-BAD & & & $-1.947^{*} *$ & & & \\
\hline 2 & KIIVD-CRUEL & & & & & & \\
\hline 3 & BELIEVING-SKEPTICAI & & & & & & \\
\hline 4 & PROGRESSIVE-REGRESSIVE & & & & & & \\
\hline 5 & POSITTVE-NEGATIVE & & & & & & \\
\hline 6 & REPUTABLE-DISREPUTABLE & $-2.253 * *$ & & $2.642 *$ & & & \\
\hline 7 & MASCUIINE-FEMININE & & & & & & \\
\hline 8 & FARD-SOFT & $1.796 *$ & & & & $3.034 *$ & $-1.739 * *$ \\
\hline 9 & SERIOUS-HUMOROUS & & & & & $2.016 *$ & $-1.897^{* *}$ \\
\hline 10 & ACTIVE-PASSIVE & & & & & & \\
\hline 11 & EXCITABIE-CAIM & & $2.116 *$ & & & & \\
\hline 12 & COMPLEX-SIMPLE & & & & . & & $1.875 *$ \\
\hline
\end{tabular}

Groups compared: High-Average, High-Low, and Average-Low for each of the 16 personality factors. Critical "t" value for single tailed test: 1.645

Ionly those values significant at the .05 level are given.

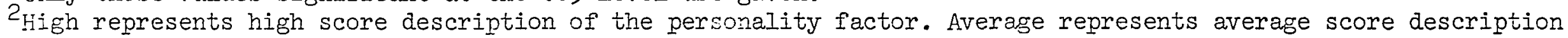
of the personality factor. Low indicates raw score description of the personality factor.

$*+1.645$-- denotes that average perceived the ad more favorably than high, Iow better than high, and low better than average.

**-1.645 -- indicates that high perceived the ad nore favorably than average, high better than low, and

Source: Table $\mathrm{I} . \mathrm{V}$ average better than low. 


\section{TABLE E.VII}

SEMAIVTIC DIFFERENTIAL SCALE IVANS FOR DALLAS MUTUAT IIF''S COMPANY ORIENTED ADVERTISEMENT BY PERSONALITY FACTORS

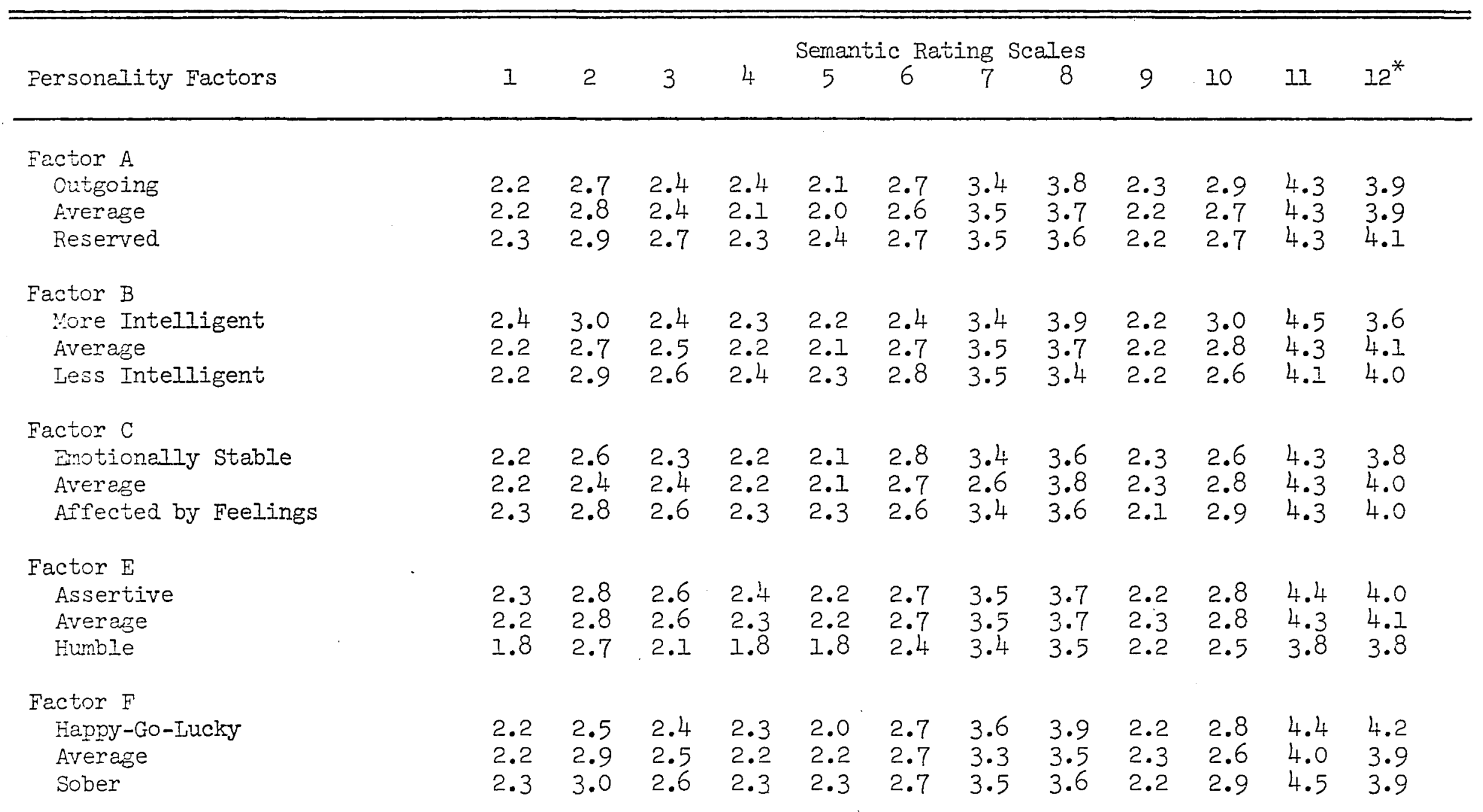


TABLE E.VII (Continued)

\begin{tabular}{|c|c|c|c|c|c|c|c|c|c|c|c|c|}
\hline \multirow{2}{*}{ Personality Factors } & \multicolumn{12}{|c|}{ Semantic Rating Scales } \\
\hline & 1 & 2 & 3 & 4 & 5 & 6 & 7 & 8 & 9 & 10 & 11 & 12 \\
\hline \multicolumn{13}{|l|}{ Factor G } \\
\hline Conscientious & 2.3 & 2.7 & 2.6 & 2.2 & 2.2 & 2.6 & 3.4 & 3.6 & 2.3 & 2.8 & 3.9 & 4.2 \\
\hline Average & 2.0 & 2.5 & 2.3 & 2.2 & 2.1 & 2.6 & 3.5 & 3.8 & 2.3 & 2.9 & 4.4 & 3.9 \\
\hline Expedient & 2.4 & 3.0 & 2.6 & 2.3 & 2.2 & 2.8 & 3.4 & 3.6 & 2.2 & 2.7 & 4.3 & 4.0 \\
\hline \multicolumn{13}{|l|}{ Factor $\mathrm{H}$} \\
\hline Venturesome & 2.3 & 2.8 & 2.3 & 2.3 & 2.1 & 2.6 & 3.5 & 3.8 & 2.1 & 2.7 & $4 \cdot 3$ & 4.2 \\
\hline Average & 2.1 & 2.7 & 2.4 & 2.2 & 2.1 & 2.8 & 3.5 & 3.7 & 2.5 & 3.0 & 4.3 & 3.9 \\
\hline Shy & 2.3 & 2.9 & 2.7 & 2.2 & 2.3 & 2.7 & 3.5 & 3.5 & 2.1 & 2.7 & 4.3 & 3.9 \\
\hline \multicolumn{13}{|l|}{ Factor I } \\
\hline Tender-Minded & 2.2 & 2.7 & 2.5 & 2.2 & 2.2 & 2.6 & 3.5 & 3.7 & 2.3 & 2.8 & 4.3 & $3 \cdot 9$ \\
\hline Average & 2.2 & 2.9 & 2.5 & 2.3 & 2.1 & 2.7 & 3.4 & 3.7 & 2.2 & 2.7 & 4.3 & 4.2 \\
\hline Tough-Minded & 2.3 & 2.8 & 2.6 & 2.3 & 2.3 & 2.8 & 3.5 & 3.7 & 2.1 & 2.8 & 4.3 & 4.0 \\
\hline \multicolumn{13}{|l|}{ Factor I } \\
\hline Suspicious & 2.4 & 2.9 & 2.6 & 2.3 & 2.2 & 2.7 & 3.4 & 3.7 & 2.1 & 2.9 & 4.5 & 4.0 \\
\hline Average & 2.2 & 2.7 & 2.6 & 2.3 & 2.2 & 2.8 & 3.5 & 3.6 & 2.3 & 2.7 & 4.0 & 4.0 \\
\hline Trusting & 2.0 & 2.8 & 2.2 & 2.1 & 2.0 & 2.5 & 3.6 & 3.8 & 3.2 & 2.8 & 4.3 & 3.9 \\
\hline \multicolumn{13}{|l|}{ Factor M } \\
\hline Imaginative & 2.3 & 2.9 & 2.5 & 2.4 & 2.2 & 2.7 & 3.5 & 3.8 & 2.2 & 2.9 & 4.4 & 4.1 \\
\hline Average & 2.0 & 2.6 & 2.4 & 2.1 & 2.1 & 2.6 & 3.4 & 3.6 & 2.3 & 2.8 & 4.4 & 3.9 \\
\hline Practical & 2.3 & 2.8 & 2.6 & 2.2 & 2.1 & 2.9 & 3.4 & 3.5 & 2.1 & 2.5 & 3.8 & 3.9 \\
\hline \multicolumn{13}{|l|}{ Factor IN } \\
\hline Snrewd & 2.3 & 2.9 & 2.6 & 2.3 & 2.2 & 2.6 & 3.4 & 3.8 & 2.2 & 2.8 & 4.2 & 4.2 \\
\hline Average & 2.2 & 2.9 & 2.4 & 2.3 & 2.2 & 2.8 & 3.6 & 3.6 & 2.3 & 2.9 & 4.4 & 3.7 \\
\hline Forthright & 2.1 & 2.5 & 2.5 & 2.1 & 2.0 & 2.6 & 3.4 & 3.7 & 2.1 & 2.7 & 4.3 & 4.1 \\
\hline
\end{tabular}




\section{TABLE E.VII (Continued)}

\begin{tabular}{|c|c|c|c|c|c|c|c|c|c|c|c|c|}
\hline & & & & & emant & Rat & ${ }^{2 g} \mathrm{Sc}$ & & & & & \\
\hline Personality Factors & 1 & 2 & 3 & 4 & 5 & 6 & 7 & 8 & 9 & 10 & 11 & 12 \\
\hline Factor 0 & & & & & & & & & & & & \\
\hline Apprehensive & 2.2 & 2.8 & 2.6 & 2.3 & 2.2 & 2.9 & 3.6 & 3.5 & 2.2 & 3.1 & 4.8 & 4.2 \\
\hline Average & 2.3 & 2.9 & 2.5 & 2.3 & 2.3 & 2.7 & 3.5 & 3.7 & 2.2 & 2.8 & 4.1 & 4.0 \\
\hline Self-Assured & 2.2 & 2.8 & 2.5 & 2.2 & 2.1 & 2.7 & 3.4 & 3.7 & 2.2 & 2.7 & $4 \cdot 3$ & 4.0 \\
\hline Factor $Q_{1}$ & & & & & & & & & & & & \\
\hline Experimenting & 2.3 & 2.9 & 2.7 & 2.4 & 2.2 & 2.7 & 3.5 & 3.8 & 2.3 & 2.8 & 4.3 & 4.1 \\
\hline Average & 2.2 & 2.6 & 2.4 & 2.2 & 2.2 & 2.6 & 3.5 & 3.7 & 2.3 & 2.9 & 4.5 & 4.1 \\
\hline Conservative & 2.1 & 2.9 & 2.4 & 2.2 & 2.1 & 2.8 & 3.4 & 3.4 & 2.0 & 2.7 & 4.2 & 3.7 \\
\hline Factor $Q_{2}$ & & & & & & & & & & & & \\
\hline Self Sufficient & 2.4 & 3.0 & 2.7 & 2.4 & 2.3 & 2.8 & 3.5 & 3.6 & 2.3 & 2.9 & 4.4 & 4.0 \\
\hline Averarre & 2.1 & 2.6 & 2.4 & 2.1 & 2.0 & 2.7 & 3.4 & 3.7 & 2.1 & 2.6 & 4.2 & 4.1 \\
\hline Group-Dependent & 1.9 & 2.5 & 2.2 & 2.2 & 1.9 & 2.4 & 3.5 & 3.8 & 2.3 & 2.7 & 4.4 & 3.7 \\
\hline Factor $Q_{3}$ & & & & & & & & & & & & \\
\hline Controlled & 2.2 & 2.6 & 2.5 & 2.2 & 2.2 & 2.5 & 3.6 & 3.9 & 2.3 & 2.7 & 4.4 & 4.1 \\
\hline Averaije & 2.1 & 2.9 & 2.4 & 2.2 & 2.0 & 2.7 & 3.5 & 3.6 & 2.1 & 2.8 & 1.2 & 4.0 \\
\hline Undisciplined Self-Conflict & 2.4 & 2.8 & 2.6 & 2.3 & 2.3 & 2.8 & 3.5 & 3.6 & 2.3 & 2.8 & $4 \cdot 3$ & 3.8 \\
\hline Factor $Q_{4}$ & & & & & & & & & & & & \\
\hline Tense & 2.2 & 2.8 & 2.6 & 2.2 & 2.2 & 2.8 & 3.5 & 3.7 & 2.2 & 2.8 & $4 \cdot 3$ & 4.0 \\
\hline Average & 2.2 & 2.8 & 2.3 & 2.2 & 2.0 & 2.8 & $3 \cdot 5$ & 3.7 & 2.1 & 2.7 & $4 \cdot 3$ & 4.0 \\
\hline Relaxed & 2.2 & 2.7 & 2.6 & 2.4 & 2.2 & 2.5 & 3.4 & 3.6 & 2.3 & 2.9 & 4.3 & 3.9 \\
\hline
\end{tabular}

*The semantic rating scale numbers correspond to the scale description in Table E.VI. Source: Primary 
TABLE E.VIII

"t" VALUES ${ }^{l}$ OF THE SIGNIFICANT DIFFERENCES BETWEEN PERSONALITY TRAITS FOR DALIAS MUTUAL LIFE'S COMPANY ORIENTED ADVERTISEMENT

\begin{tabular}{|c|c|c|c|c|c|c|c|}
\hline \multirow{2}{*}{$\begin{array}{l}\text { Scale } \\
\text { Number }\end{array}$} & \multirow[b]{2}{*}{ Semantic Rating Scales } & \multicolumn{3}{|c|}{ Factor $\mathrm{A}^{2}$} & \multicolumn{3}{|c|}{ Factor B } \\
\hline & & $\mathrm{Hi} / \mathrm{AV}$ & $\mathrm{Hi} / \mathrm{IO}$ & AV/LO & $\mathrm{Hi} / \mathrm{AV}$ & $\mathrm{Hi} / \mathrm{LO}$ & $\mathrm{Av} / \mathrm{IO}$ \\
\hline 1 & GOOD-BAD & & & & & & \\
\hline 2 & KIND-CRUEL & & $-2.086 * *$ & $-2.366 * *$ & $1.686 *$ & & $-2.506 * *$ \\
\hline 3 & BEIIEVING-SKEPTICAL & & $-2.269 * *$ & $-2.357 * *$ & & & \\
\hline 5 & PROGRESSIVE-PTGRESSIVE & $2.711 *$ & & $-3.674 * *$ & & & $-3.014 * *$ \\
\hline 5 & POSITIVE-INEGATIVE & & $-2.332^{* *}$ & & & & $-1.760 * *$ \\
\hline 6 & REPUTABLE-DISREPUIABLE & & & & & $-1.882 * *$ & \\
\hline 7 & MASCULINE-FWININE & & & & & & \\
\hline 8 & HARD-SOFT & & $1.727^{*}$ & & & $2.915 *$ & $2.856 *$ \\
\hline 9 & SERIOUS-HUMOROUS & & & & & & \\
\hline 10 & ACTIVE-PASSIVE & & & & & $2.405 *$ & $1.651 *$ \\
\hline 11 & EXCITABLE-CAIM & & & & & $2.009 *$ & \\
\hline \multirow[t]{2}{*}{12} & COMPLEX-SIMPLE & & $-1.947^{* *}$ & & & & \\
\hline & & \multicolumn{3}{|c|}{ Factor C } & & Factor $\mathrm{E}$ & \\
\hline 1 & GOOD-BAD & & & & & $6.531 *$ & $3.543^{*}$ \\
\hline 2 & KIND-CRUEL & $-1.661 * *$ & & & & $2.205^{*}$ & \\
\hline 3 & BELIEVING-SKEPTICAL & & $-1.726 * *$ & $-1.827 * *$ & & $5.443 *$ & $2.994 *$ \\
\hline 5 & PROGRESSIVE-REGRESSIVE & & & & & $8.566 *$ & $5.188 *$ \\
\hline 5 & POSITIVE-NEGATIVE & & & & & $6.074 *$ & $3.873^{*}$ \\
\hline 6 & REPJPABLE-DISREPUTAELE & & & & & $2.863^{*}$ & $1.749 *$ \\
\hline 7 & MASCULINE-FEMININE & $-1.845^{* * *}$ & & $2.529 *$ & & & \\
\hline 8 & HARD-SOPT & & & & & & $1.705 *$ \\
\hline 9 & SERIOUS-HUMOROUS & & & & & & \\
\hline 10 & ACTIVE-PASSIVE & & & & & $3.276 *$ & $2.045 *$ \\
\hline 11 & EXCITABLE-CALM & & & & & $5.036 *$ & $2.735 *$ \\
\hline 12 & COMPLEX-SIMPLE & & & & & & \\
\hline
\end{tabular}


TABLE E.VIII (Continued)

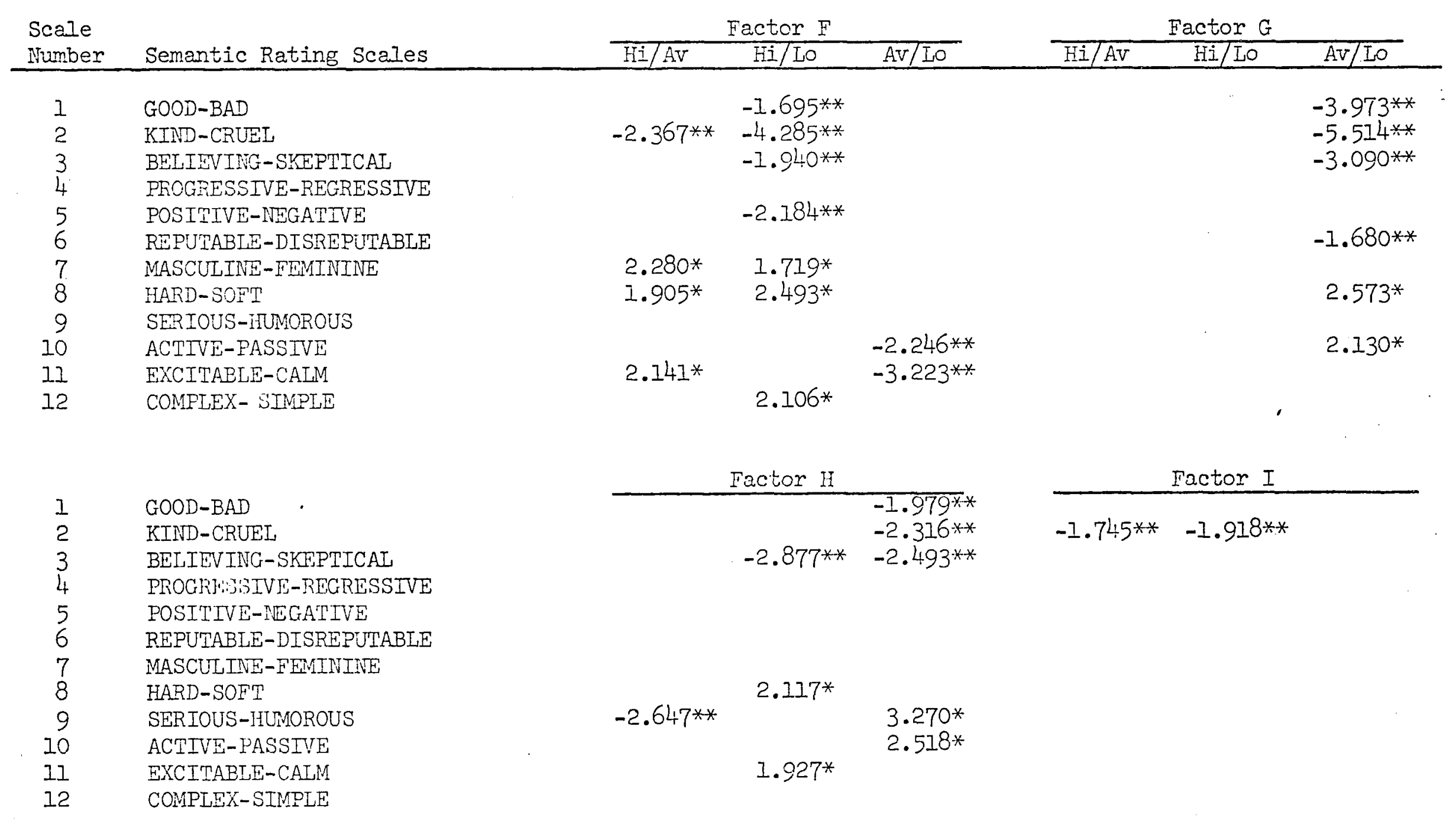


TABLE E.VIII (Continued)

\begin{tabular}{|c|c|c|c|c|c|c|c|}
\hline \multirow{2}{*}{$\begin{array}{l}\text { Scale } \\
\text { Irumber }\end{array}$} & \multirow[b]{2}{*}{ Semantic Rating Scales } & \multicolumn{3}{|c|}{ Factor L } & \multicolumn{3}{|c|}{ Factor M } \\
\hline & & $\mathrm{Hi} / \mathrm{Av}$ & $\mathrm{Hi} / \mathrm{IO}$ & $\mathrm{Av} / \mathrm{LO}$ & $\mathrm{Hi} / \mathrm{Av}$ & $\mathrm{Hi} / \mathrm{LO}$ & Av/Lo \\
\hline 1 & GOOD-BAD & & $4.732 *$ & $2.536 *$ & $2.052 *$ & & $-1.980 * *$ \\
\hline 2 & KIND-CRUEL & & & & $2.285 *$ & $1.930 *$ & \\
\hline 3 & BELIEVING-SKEPTICAL & & $3.410 *$ & $2.816 *$ & & & \\
\hline 4 & PROGRESSIVE-REGRESSIVE & & $2.217 *$ & $2.479 *$ & $2.263^{*}$ & $2.006 *$ & \\
\hline 5 & POSITIVE-NEGATIVE & & $2.468 *$ & $2.380 *$ & & $1.882 *$ & \\
\hline 6 & REPUTABIE-DISREPUTABIT & & & & & $-2.100 * *$ & $-2.096 * *$ \\
\hline 7 & MASCULINE-FEMININE & & $-2.747 * *$ & & & $1.848 *$ & \\
\hline 8 & HARD-SOFT & & & $-1.914 * *$ & & $3.224 *$ & \\
\hline 9 & SERIOUS-HUMOROUS & & $-1.726 * *$ & & & & \\
\hline 10 & ACTIVE-PASSTVE & & & & & $3.880 *$ & $2.030 *$ \\
\hline 11 & EXCITABLE-CAIM & $2.340 *$ & & $-2.075 * *$ & & $4.720 *$ & $4.161 *$ \\
\hline 12 & COMPLEX-SIMPLE & & & & & 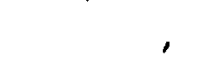 & \\
\hline & & & actor $\mathrm{N}$ & & & Factor 0 & \\
\hline 1 & GOOD-BAD & & $2.501 *$ & & & & \\
\hline 2 & KIND-CRUEL & & $4.284 *$ & $4.573 *$ & & & \\
\hline 3 & BELIEVIIIG-SKEPTICAL & & & & & & \\
\hline 4 & PROGRESSIVE-REGRESSIVE & & $2.261 *$ & & & & \\
\hline 5 & POSITIVE-NEGATIVE & & & $2.056 *$ & & & \\
\hline 6 & REPUTABLE-DISREPUTABIE & & & & & & \\
\hline 7 & MASCULINE-FEMIININE & & & $3.044 *$ & & & \\
\hline 8 & HARD-SOFT & & & & & & \\
\hline 9 & SERIOUS-HUMOROUS & & & & & & \\
\hline 10 & ACTIVE-PASSIVE & & & $1.701 *$ & & $1.805^{*}$ & \\
\hline 11 & EXCITABLE-CAIM & & & & $2.472 *$ & $2.302 *$ & \\
\hline 12 & COMPLEX-SIMPLE & $2.217^{*}$ & & $-2.707 * *$ & & & \\
\hline
\end{tabular}


TABLE E.VIII (Continued)

\begin{tabular}{|c|c|c|c|c|c|c|c|}
\hline \multirow{2}{*}{$\begin{array}{l}\text { Scale } \\
\text { Number }\end{array}$} & \multirow[b]{2}{*}{ Semantic Rating Scales } & \multicolumn{3}{|c|}{ Factor QI } & \multicolumn{3}{|c|}{ Factor Q2 } \\
\hline & & $\mathrm{Hi} / \mathrm{Av}$ & $\mathrm{Hi} / \mathrm{LO}$ & $\mathrm{AV} / \mathrm{IO}$ & $\mathrm{Hi} / \mathrm{Av}$ & $\mathrm{Hi} / \mathrm{LO}$ & $\overline{\mathrm{Av}} / \mathrm{LO}$ \\
\hline 1 & $\overline{G O O D-B A D}$ & & $3.231 \div$ & & $2.009 *$ & $5.614 *$ & $1.870 *$ \\
\hline 2 & KIND-CRUEL & $1.828 *$ & & $-2.155 * *$ & $2.458 *$ & $5.229 *$ & \\
\hline 3 & BEIIEVING-SKEPTICAI & $1.657^{*}$ & $2.946 \%$ & & $1.977 * 1$ & $5.281 *$ & $1.730^{*}$ \\
\hline 4 & PROGRESSIVE-REGRESSIVE & & $2.117 \div$ & & $2.314 *$ & $2.387 \%$ & \\
\hline 5 & POSITIVE-IEGAIIVE & & & & $2.169 *$ & $5.768 *$ & $1.929 *$ \\
\hline 6 & REPUTABIE-DISREPUTABIE & & & & & $3.758 *$ & $2.211 *$ \\
\hline 7 & MASCULIIYE-FEMININE & & $2.147 \div$ & & & & \\
\hline 8 & HARD-SOFT & & $3.434 *$ & $2.756 *$ & & $-1.936 * *$ & \\
\hline 9 & SERIOUS-IIUMOROUS & & $3.059 *$ & $2.965 *$ & & $-2.083 * *$ & \\
\hline 10 & ACTIVE-PASSIVE & & & & $2.092 *$ & $2.312 *$ & \\
\hline 11 & EXCITABIE-CAIM & & & & & & \\
\hline \multirow[t]{2}{*}{12} & COMPLEX-SIMPLE & & $3.428 *$ & $3.069 *$ & & $2.964 *$ & $2.731 *$ \\
\hline & & \multicolumn{3}{|c|}{ Factor $Q_{3}$} & \multicolumn{3}{|c|}{ Eactor $Q_{4}$} \\
\hline 1 & GOOD-BAD & & $-1.828 * *$ & $-2.623^{* *}$ & & & \\
\hline 2 & KIIND-CRUEL & $-1.652 * *$ & & & & & \\
\hline 3 & BELIEVING-SKEPTICAI & & & $-1.779 * *$ & $2.129 *$ & & $-2.457 * *$ \\
\hline 4 & PROGRESSIVI-REGRESSIVE & & & & & $-2.027 * *$ & $-2.109 * *$ \\
\hline 5 & POSITIVE-NEGATIVE & & & $-2.452 * *$ & & & $-1.657 * * *$ \\
\hline 6 & REPUTABIE-DISREFUTABLE & & $-2.055 * *$ & & & $2.463 *$ & $2.084 *$ \\
\hline 7 & MASCULINE-FEMININE & & $2.258 *$ & $1.784 *$ & & & $1.715 *$ \\
\hline 8 & HARD-SOFT & $2.223^{*}$ & $2.332 \%$ & & & & \\
\hline 9 & SERIOUS-HUMOROUS & & & $-1.762 * *$ & & & $-1.196 * *$ \\
\hline 10 & ACIIVE-PASSIVE & & & & & & \\
\hline 11 & EXCITABLE-CALM & & & & & & \\
\hline 12. & COMPLEX-SINELS & & $1.743^{*}$ & & & & \\
\hline
\end{tabular}

Groups compared: High-Average, High-Icr, and Average-Low for each of the 16 personality factors. Critical "t" value for single tailed test: 1.645

Ionly those values significant at the .05 level are given.

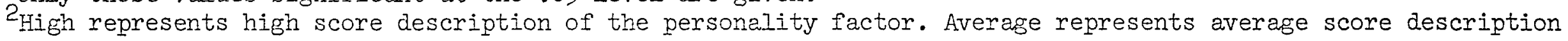
of the personality factor. Low inaicates raw score description of the personality factor.

* +1.645 - - denotes that average perceived the ad more favorably than high, low better than high, and low better than average.

**-1.645 -- indicates that high perceived the ad more favorably than average, high better than low, and Source: Table I.VII average better than low. 
VITA

Sam J. Bruno, the son of Mr. and Mrs. Joe R. Brumo, was born in Port Arthur, Texas, on September 6, 1929. He was graduated from Thomas Jefferson Senior High School of Port Arthur, Texas, in June, 1948 .

After nine years of data processing work at Gulf Oil Corporation, Port Arthur Refinery, he entered Lamar state College of Technology at Beaunont, T'exas, in September of 1958. In June, 1962, he completed the requirements for the degree of Bachelor of Business Administration in accounting.

Tn September, 1962, he entered the Graduate School of Louisiana State Unjversity and earned a Master of science degree in marketing in August, 1965. During the 1963-1964 acadinic year, he taught at Redemptorist Junior High School in Baton Rouge, Louisiana. He was an instructor in the Eusiness Administration Department at Southeastern Louisiana College, Hammond, Louisiana, during the 1964-1965 academic year. After resigning his position at Southeastern Louisiana College in June, 1965 , he returned to Louisiana State University to continue his graduate studies with the aid of a Research Assistantship in the Bureau of Business Research. From 1966-1969, he served as a Graduate Teaching Assistant in the Department of Management and Marketing.

Inring the 1969-1970 academic year, he joined the faculty at Wichita State University, Wichita, Kansas, and is at the present time a candidate for the degree of Doctor of Plillosophy.

He is married to the former Joan Elizabeth Dowty of New Orleans, Louisiana, and they have one child, Chad Joseph. 
Candidate: Sam J. Bruno

Major Field: Management

Title of Thesis: The Effects of Personality Traits on the Perception of Written Mass Communication

Approved:

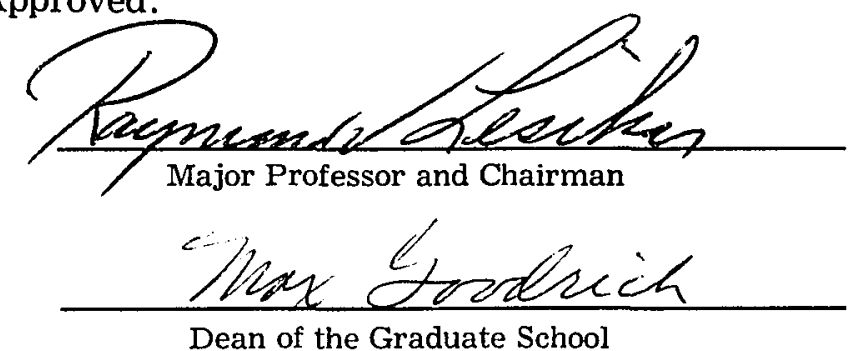

EXAMINING COMMITTEE:
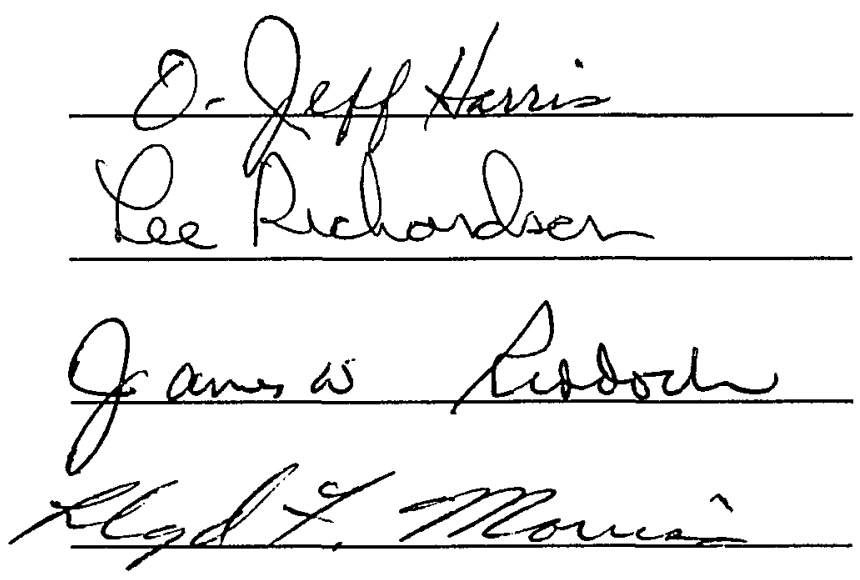

Date of Examination:

March 17, 1971 